NIST Technical Note 1969

\title{
Investigation of Residential Cooking Fire Suppression Technologies
}

\author{
Anthony Hamins \\ Sung Chan Kim \\ Daniel Madrzykowski \\ Jonathan Kent
}




\title{
NIST Technical Note 1969
}

\section{Investigation of Residential Cooking Fire Suppression Technologies}

\author{
Anthony Hamins \\ Fire Research Division \\ Engineering Laboratory \\ National Institute of Standards and Technology \\ Gaithersburg, MD 20899-8663 \\ Sung Chan Kim \\ Department of Fire Safety, Kyungil University, Gyeongbuk, Republic of Korea \\ Daniel Madrzykowski \\ Underwriter's Laboratory, Northbrook, IL \\ Jonathan Kent \\ Consumer Product Safety Commission, Rockville, MD
}

This publication is available free of charge from: https://doi.org/10.6028/NIST.TN.1969

February 2018

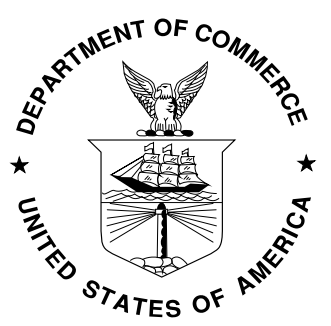

U.S. Department of Commerce Wilbur L. Ross, Jr., Secretary

National Institute of Standards and Technology Walter Copan, NIST Director and Undersecretary of Commerce for Standards and Technology 
Certain commercial entities, equipment, or materials may be identified in this document in order to describe an experimental procedure or concept adequately. Such identification is not intended to imply recommendation or endorsement by the National Institute of Standards and Technology, nor is it intended to imply that the entities, materials, or equipment are necessarily the best available for the purpose.

Regarding Non-Metric Units: The policy of the National Institute of Standards and Technology is to use metric units in all its published materials. To aid the understanding of this report, in most cases, measurements are reported in both metric and U.S. customary units.

National Institute of Standards and Technology Technical Note 1969 Natl. Inst. Stand. Technol. Tech. Note 1969, 107 pages (February 2018) CODEN: NTNOEF

This publication is available free of charge from: https://doi.org/10.6028/NIST.TN.1969 


\section{Abstract}

A series of cooking fire experiments were conducted to examine the effectiveness of residential kitchen fire suppression systems. A series of experiments provided data on the hazard associated with cooking oil fires. Then, a series of real-scale fire suppression experiments followed, using scenarios outlined in the UL 300A draft standard. Various fire suppression systems were tested. Experiments were conducted in a full-scale residential kitchen with dimensions $3.6 \mathrm{~m} \mathrm{x} 3.4 \mathrm{~m} \mathrm{x}$ $2.4 \mathrm{~m}$ high with an open doorway. Both gas and electric ranges were used. Several types of cooking pans were tested.

The suppression systems tested included both automatic and manual suppression technologies. The manual devices included wet and dry chemical type extinguishers. The automatic systems included room-wide and range hood installed systems. The room wide systems included water mist and a residential sprinkler system. The hood installed systems included water mist and wet and dry chemical systems.

Manual extinguishers consistently suppressed the oil fires while maintaining tenable conditions in the mock-up kitchen. One hood-installed wet chemical system tested demonstrated success in extinguishing the oil fires in all experiments, and maintained tenability in the mock up kitchen throughout most of the experiments. The hood-installed dry chemical system tested failed to extinguish the oil fire in all experiments, and introduced tenability hazards not present prior to the system activation. All other system types provided mixed results; they either could not reliably suppress the fire, or they consistently generated tenability hazards in the test kitchen.

The effectiveness of ionization smoke alarms to provide early warning of fire were also tested as part of this study. The results showed that the smoke alarms inside, or just outside, the kitchen fire scenarios considered here generally activated several minutes before auto-ignition occurred, but not for all cases.

The results of the experiments demonstrate the need to develop other approaches to kitchen fire safety such as ignition prevention technologies and reliable, early, and nuisance-free warning of pre-ignition conditions possibly through the development of specialized sensors or sensor combinations. 


\section{Acknowledgements}

The authors are indebted to Matthew Bundy, Lauren DeLauter, G. Ko, and Shivani Mehta for helpful discussions and technical support. 


\section{Table of Contents}

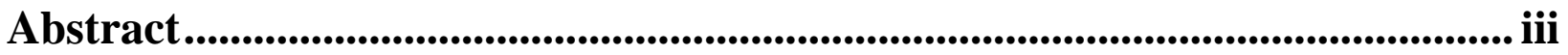

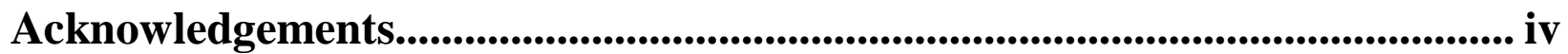

List of Figures........................................................................................................... vii

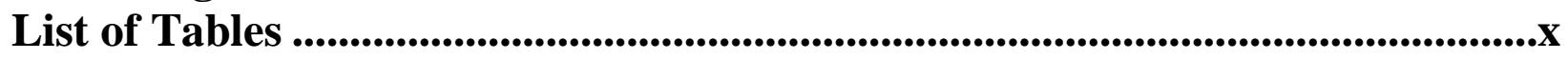

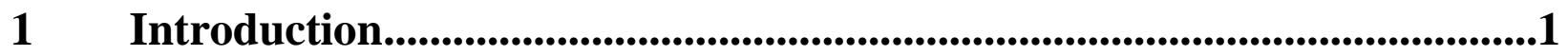

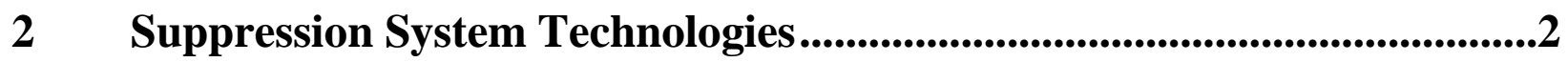

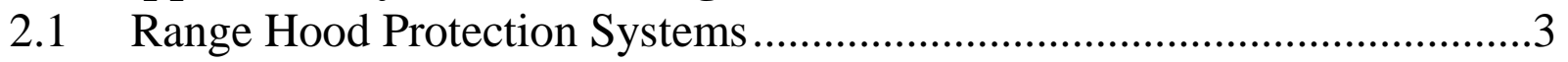

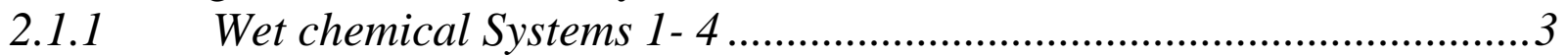

2.1.2 Dry Chemical Systems.......................................................................

2.1.3 Water Mist Systems (Water Mist 2 \& 3)........................................... 8

2.2 Automatic Room Protection.................................................................8

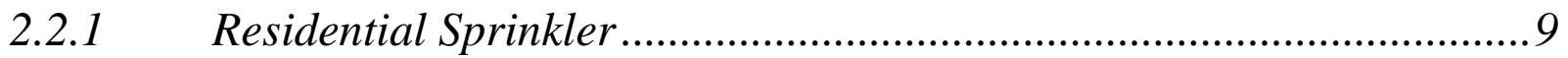

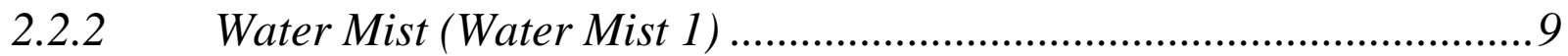

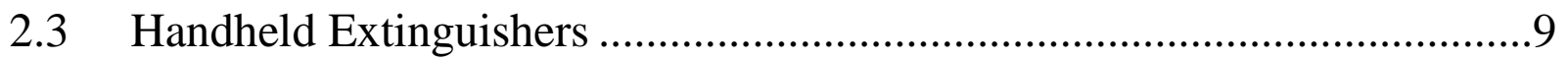

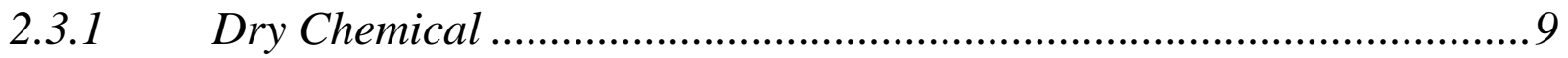

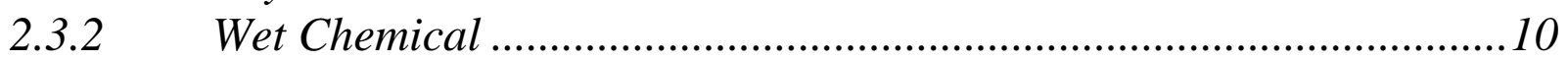

2.4 Suppression System Characterization ......................................................11

3 Cooktop Fire Characterization ...............................................................13

3.1 Experimental Apparatus and Configuration ...........................................13

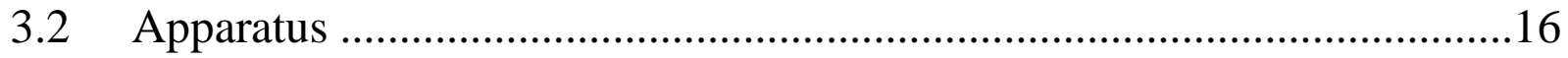

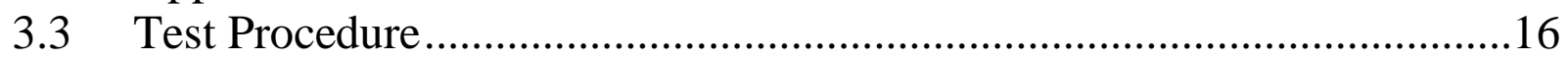

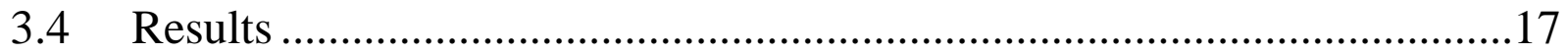

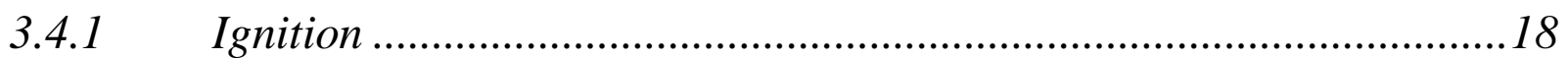

3.4.2 Heat release rate of cooking oil ......................................................19

3.4.3 Ignition surface temperature and fire characteristics .......................22

3.5 Summary of Cooktop Fire Characterization Experiments..........................26

$4 \quad$ Description of Kitchen Fire Suppression Experiments...............................28

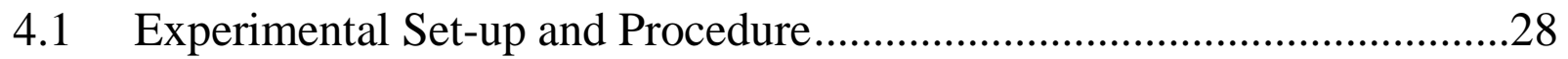

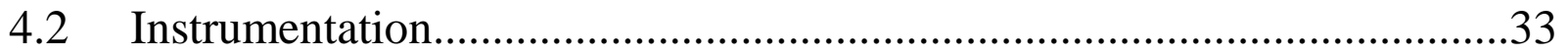

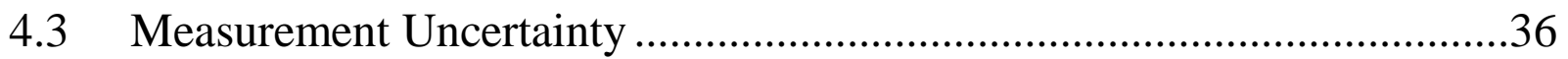

$5 \quad$ Experimental Results...........................................................................36

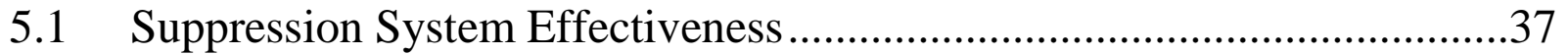

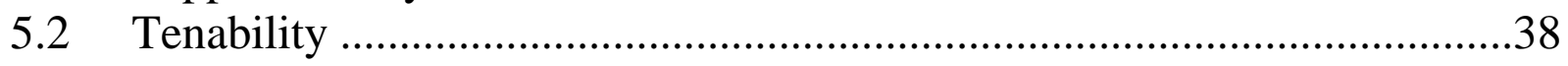

5.3 Spatter, Loss of Containment, and Visibility …........................................42

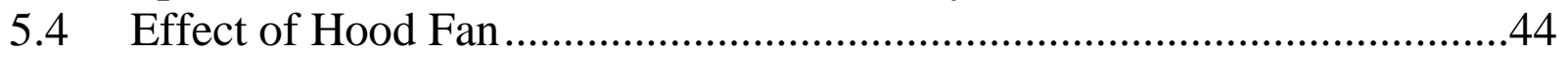

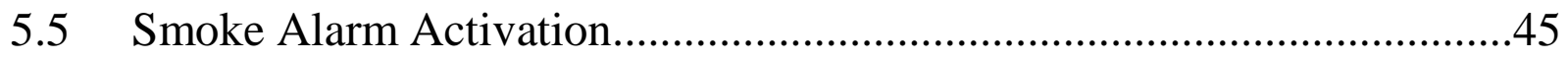




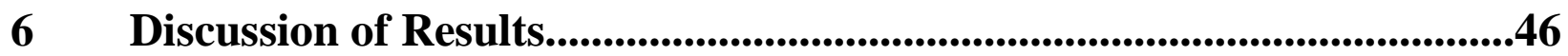

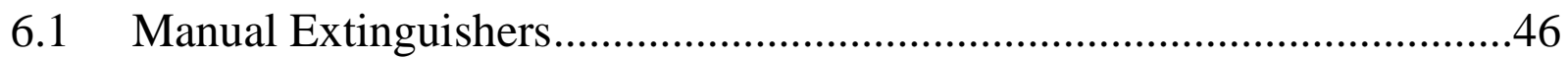

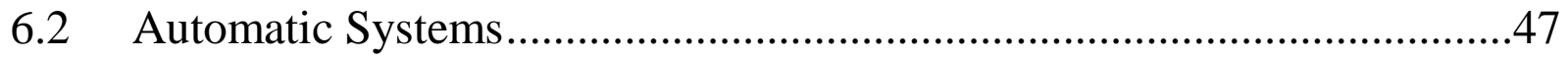

6.2.1 Automatic Wet Chemical Systems ..................................................47

6.2.2 Automatic Dry Chemical System......................................................4

6.2.3 Water Mist Systems (Room and Hood Protection) ...............................47

6.2.4 Sprinkler Room Protection..................................................................48

$7 \quad$ Summary and Conclusions ...................................................................................48

8 References...............................................................................................51

Appendix 1: Experimental Results.........................................................................53

Appendix 2: Experimental Environmental Conditions...........................................96 


\section{List of Figures}

Figure 2-1. Components of an automatic, self-contained, wet chemical system including the automatic gas stovetop shutoff valve, which was not used in these experiments... 4

Figure 2-2. One side of a "typical" wet chemical system; two thermal links and a nozzle are shown, the opposing side was similarly configured. .......................................... 5

Figure 2-3. AWC3 was a single nozzle system that used an electrical thermal trigger................ 5

Figure 2-4. A wall-mounted, wet chemical system with arms containing heat sensitive bulb used to trigger agent deployment. Thermocouples mounted on the arms were not an

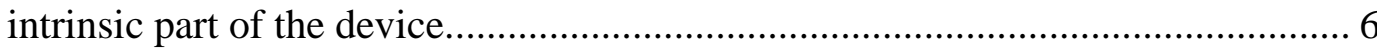

Figure 2-5. Autonomous dry chemical system installed above the stovetop. The thermocouples seen in the image were added and were not an intrinsic part of the device............ 7

Figure 2-6. Plumbing for a water mist system above the range exhaust hood. .......................... 8

Figure 3-1. Schematic diagram of the apparatus used in the cooking oil fire characterization

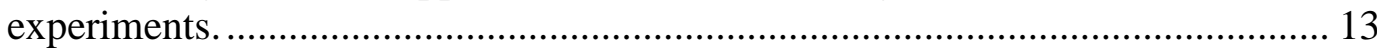

Figure 3-2. Photograph of the experimental configuration and instrumentation during Test 1. . 14 Figure 3-3. Photographs of the electric and the gas cooktops used in the cooking oil fire

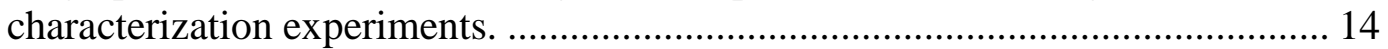

Figure 3-4. Plume of cooking oil vapor above pan before ignition during Test 2..................... 18 Figure 3-5. Comparison of the measured time to ignition as a function of pan and oil type on the electric cooktop......................................................................................... 19

Figure 3-6. Measured heat release rate and mass loss during Test 2 (corn oil in Pan C).......... 21

Figure 3-7. The measured heat release rate and mass burning rate during Test 11 (peanut oil in

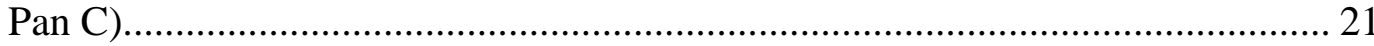

Figure 3-8 The evolving temperatures measured at three locations on the cooking vessel during Test 11 (peanut oil in Pan C). ........................................................................ 22

Figure 3-9. Measured mean temperatures on the cooking pan at the time of peanut oil ignition during Tests 7, 8, 10, and 11............................................................................ 23

Figure 3-10. Measured mean temperatures on the cooking pan at the time of corn oil ignition during Tests $1,2,3,6$, and 9

Figure 3-11. The measured heat flux at three positions near the stove during Test 1 (corn oil in Pan C).

Figure 3-12. The measured $\mathrm{CO}$ and $\mathrm{CO}_{2}$ volume fraction in the exhaust hood as a function of time during Test 1 (corn oil in Pan C).............................................................. 25

Figure 3-13. The measured heat release rate as a function of time during Test 2 (corn oil in Pan C). Photographs of the fire behavior are also shown................................ 27

Figure 3-14. The measured heat release rate as a function of time during Test 3 (corn oil in Pan B). Photographs of the fire behavior are also shown................................. 27

Figure 4-1. View of kitchen and adjoining hallway through doorway (left) and side view of the kitchen under a canopy exhaust hood (right)................................................ 29

Figure 4-2. Elevation view schematic of the mock kitchen looking toward the range............... 32

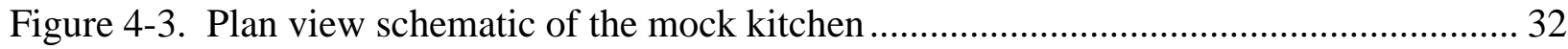

Figure 4-4. Elevation view schematic of the mock kitchen ................................................. 32

Figure 4-5. Elevation view schematic with instrumentation, oriented toward the range ............ 35 
Figure 4-6. Plan view schematic with instrumentation...................................................... 35

Figure 4-7. Elevation view schematic with instrumentation, oriented parallel to the countertop 35 Figure 5-1. Photo of the burning oil just prior to activation of an auto dry chemical system. .... 41

Figure A1-1. Experiment KSE 1 timeline and data .......................................................... 54

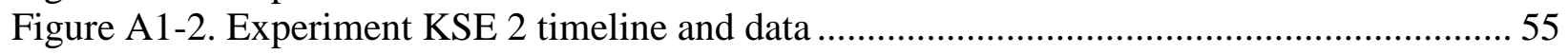

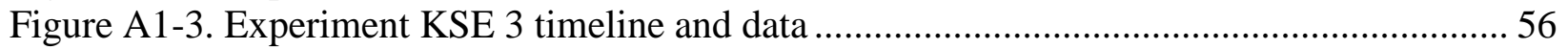

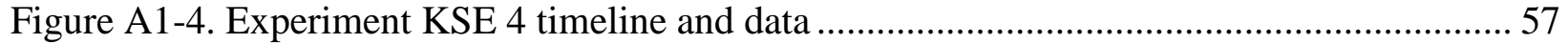

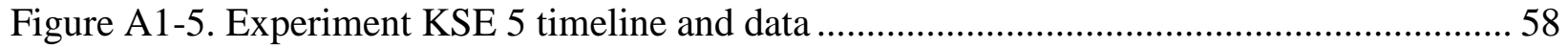

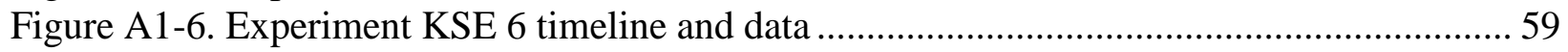

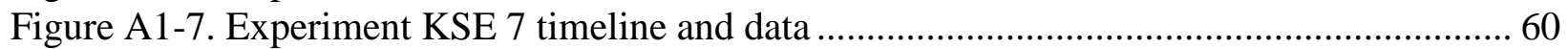

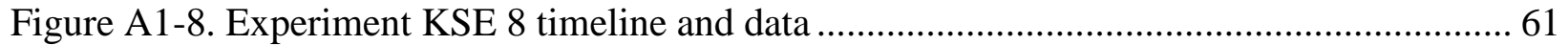

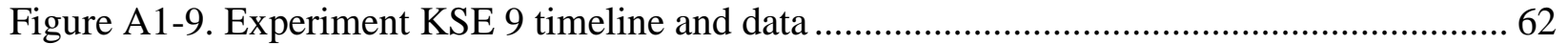

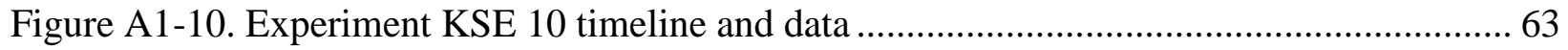

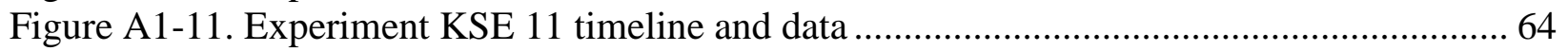

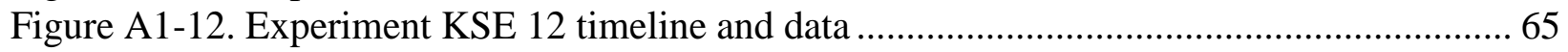

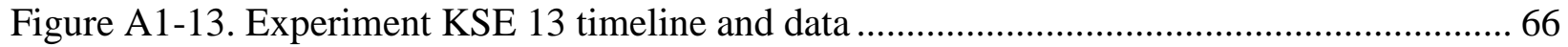

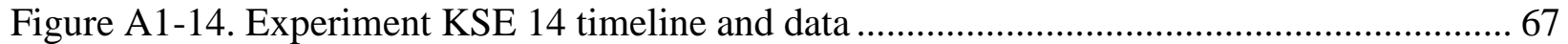

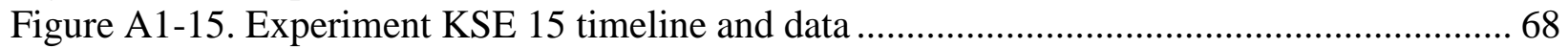

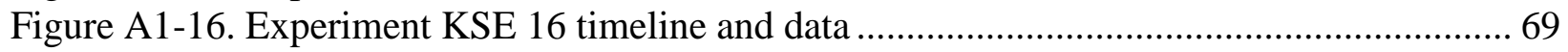

Figure A1-17. Experiment KSE 17 timeline and data ................................................... 70

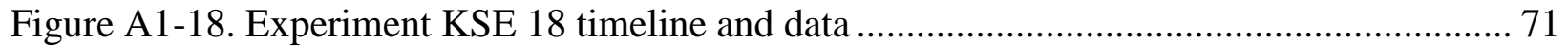

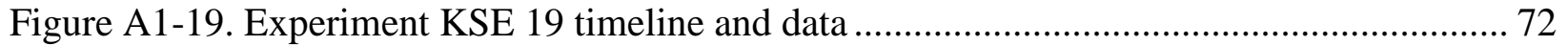

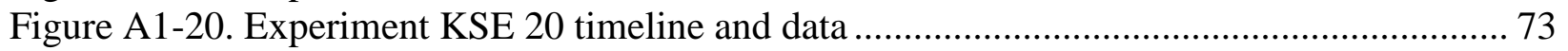

Figure A1-21. Experiment KSE 21 timeline and data .................................................. 74

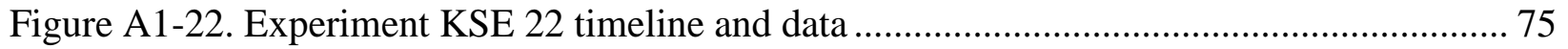

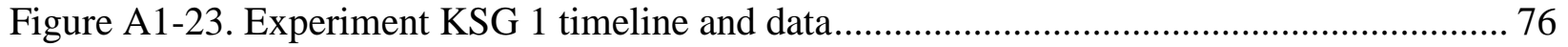

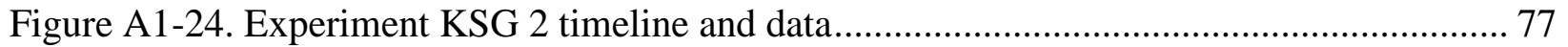

Figure A1-25. Experiment KSG 3 timeline and data......................................................... 78

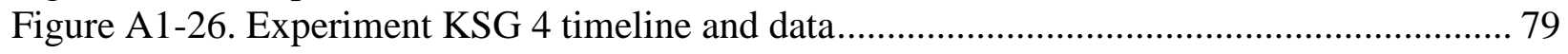

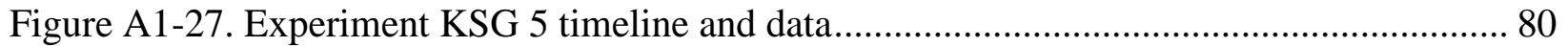

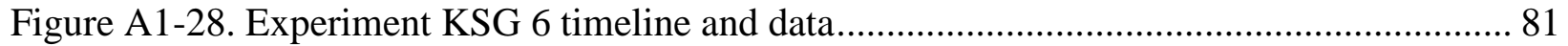

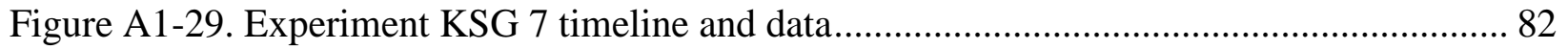

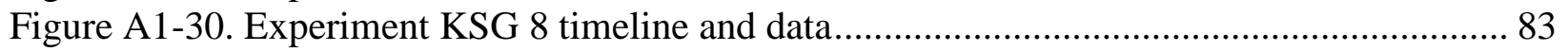

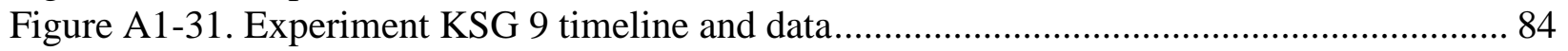

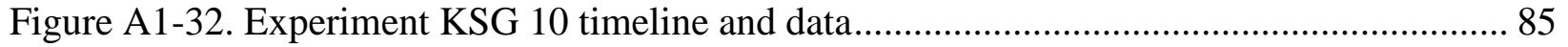

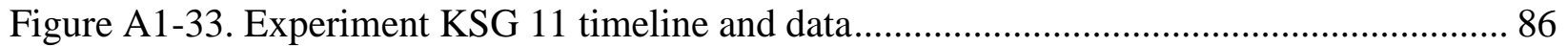

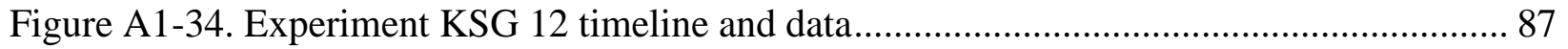

Figure A1-35. Experiment KSG 13 timeline and data........................................................ 88

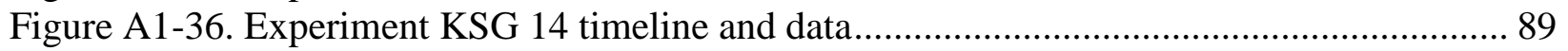

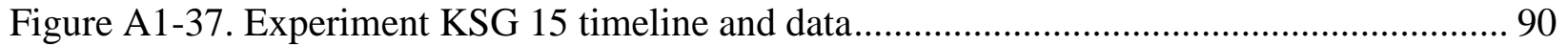

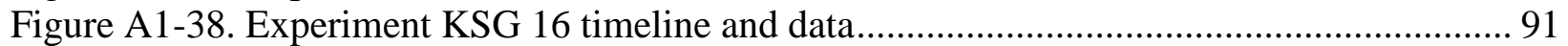

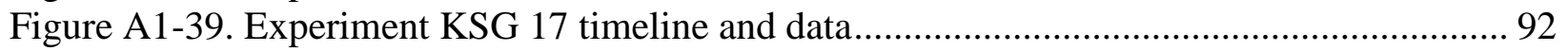

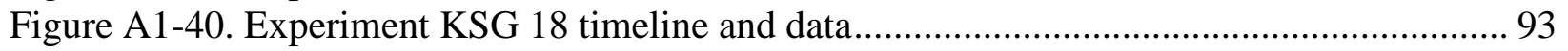

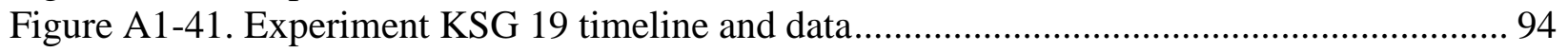


Figure A1-42. Experiment KSG 20 timeline and data..................................................... 95 


\section{List of Tables}

Table 2-1. Activation temperatures for automatic wet chemical system tests............................. 3

Table 2-2. Mass delivery rate, spatial variance and total mass of the suppressants ................... 12

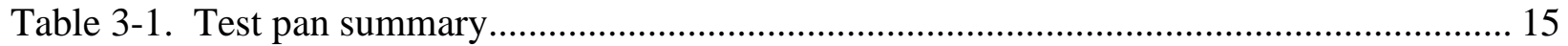

Table 3-2. Thermophysical and combustion properties of oils ............................................ 15

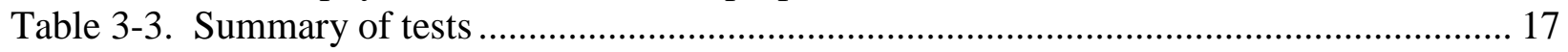

Table 3-4. Pan surface temperatures at the time of ignition. .................................................... 24

Table 4-1. Power output of the electric and gas burners...................................................... 30

Table 4-2. Experimental arrangement including, the burner, pan, and volume of fuel .............. 33

Table 5-1. Time of suppression system deployment after ignition and its outcome .................. 38

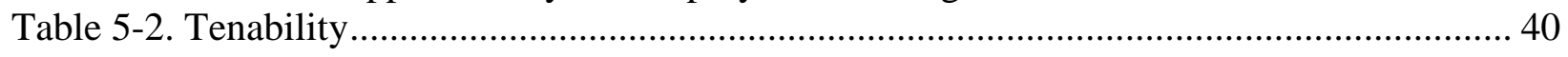

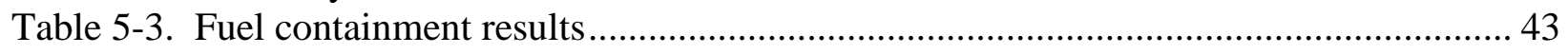

Table 5-4. Activation times and fan status for tests using automatically delivered wet chemicals

Table 5-5. Time difference between activation of smoke alarms (inside and outside of kitchen)

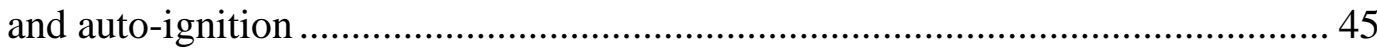

Table 7-1. Summary of Suppression and Tenability Measurements. ..................................... 50 


\section{Introduction}

A 2016 study conducted by the National Fire Protection Association on home fires involving cooking equipment over the five year period from 2010 to 2014 indicates that U.S. fire departments responded to an average of 166,000 structure fires annually associated with cooking [1]. The damage caused by these fires included an annual average of 480 civilian deaths, 5500 civilian injuries, and $\$ 1.1$ billion in direct property damage. Cooking equipment was involved in $46 \%$, that is almost one-half of reported home fires, $19 \%$ of home fire fatalities, and $44 \%$ of reported home fire injuries with U.S. Fire Departments responding to more than 450 home cooking fires per day during this period. While there has been significant progress in reducing home fire fatalities over the last 30 years, there has been relatively little progress in home cooking fire fatalities with home fire fatalities dropping by about half, while cooking fire deaths have been reduced only $4 \%$ over the same period.

Cooktops, or ranges, have been involved in the majority of the cooking fires and associated losses [1]. In reported home fires, involving cooking equipment, ranges or cooktops accounted for $62 \%$ of fires, $88 \%$ of the civilian cooking fire deaths, $79 \%$ of the civilian cooking fire injuries, and $73 \%$ of the direct property damage. Electric ranges are associated with a higher risk of cooking fires, as compared to gas ranges. Whereas about $60 \%$ of households cook with electric cooktops, $80 \%$ of cooktops involved in reported cooking fires were powered by electricity. Using this information, NFPA reports that the rate of reported fires per million households was 2.6 times higher with electric ranges [1]. In addition, the study reports that unattended equipment was a leading cause contributing to the ignition of $34 \%$ of cooking fires. More than half (55 \%) of nonfatal civilian cooking fire injuries occurred when the victims tried to fight the fire themselves.

Cooking fires are a significant problem and are unlikely to go away on their own - without significant educational and/or technological advances. In April 2006, a workshop was held at the National Institute of Standards and Technology (NIST) in Gaithersburg, MD that outlined the kitchen fire problem and worked to identify the factors that limit the use of localized kitchen fire suppression systems [2]. The workshop identified the popularity of kitchen suppression systems and the fire control effectiveness of these devices as key factors that will affect the kitchen fire problem through this technology. The workshop suggested research into the effectiveness of existing systems could improve these factors by educating consumers about potential benefit as well as by helping to improve the cost of kitchen suppression systems by aiding technological development. Education of consumers was identified as an important means to prevent kitchen fires and how research could help characterize the hazard of a cooking fire as a means to educate consumers on kitchen fire prevention [2].

In 2014, an abnormal cooking test to prevent ignition during cooking was added to the UL 858 standard for new electric coil cooktops [3]. At the same time, an ignition-prevention standard for gas ranges is currently not in place. Therefore, significant fire losses associated with stovetop cooking can be expected to continue for the next couple of decades as older electric cooktops are gradually replaced and a standard for gas ranges is developed. This suggests that means other than ignition prevention need to be considered to address these fires, which compose a significant fraction of the U.S. fire loss profile. 
Recently, Johnsson conducted experiments to examine kitchen photoelectric smoke detectors to warn of approaching ignition of food during unattended cooking [4]. An electric range, range hood, and cabinets were installed in a mock-up kitchen. Commercially available photoelectric smoke detectors were found to activate at least $2 \mathrm{~min}$ before ignition. The experiments, however, were conducted for a closed compartment established with non-conventional ventilation conditions.

The acceptance of residential fire suppression systems by industry and the public will require the development of a standard test method. Existing standard suppression test methods designed for residential sprinklers (UL 1626) and commercial systems (UL 300) are not optimized for devices developed specifically for residential cooktop fires [5, 6]. Introduction of suppression systems to the market may be hindered without the development of an accepted standard test method to certify their effectiveness. Although there is currently no accepted standard test method for residential kitchen fire hazards, UL has a "pre-standard" method that it has developed to examine the performance of automatic fire suppression and control systems for kitchen stovetop residential applications [7].

To address these issues, an investigation was conducted to characterize various types of cooking fires and the parameters that might be used to determine successful fire control or suppression. This report describes experiments intended to characterize range fires and examine the performance of suppression systems applied in a full-scale residential kitchen scenario. Based on discussions from the NIST workshop, there was an emphasis on getting a baseline on the suppression performance of existing technologies that were available for retrofit. Cost was also a concern of the group, however given the use of prototype products that are not readily available for sale, direct cost comparisons were difficult to make. This report is broken into several parts that describe the experimental setup, apparatus, instrumentation, experimental procedure, results, and analysis of all experiments. In Section 2, the suppression system technologies considered in this study are described. In Section 3, the nature of cooktop fires is investigated experimentally. In Section 4, the results of full-scale kitchen fire experiments are described. Section 5 provides a summary and conclusions of the study. Appendix 1 presents the detailed results for each of the suppression experiments and Appendix 2 lists the environmental conditions during each of the suppression experiments.

\section{Suppression System Technologies}

A variety of suppression systems were used in these experiments, representing a range of current technologies available to address residential kitchen fires. Two types of suppression strategies were considered. The first approach focused on range hood systems, deploying systems that address the fire at its source - on the cooktop. The range hood technologies tested included wet and dry chemical systems as well as water mist. The second approach considered automatic fire protection for an entire room, addressing not just the stovetop surface but also nearby cabinets and other materials that may be involved in the fire. The room fire protection technologies tested included wet and dry chemical systems, water mist, and a water sprinkler. In all cases, the 
technologies were installed and deployed following manufacturer guidance in accord with applicable standards, if any.

Following the UL 300 A pre-standard, cooking oil fires were the focus of the experiments conducted here. These were challenging scenarios in terms of fire suppression as the temperature of the fuel was extensively preheated, such that the stored energy in the liquid fuel can present a challenge in terms of re-ignition. Thus, both suppression and prevention of re-ignition must be considered when evaluating these systems.

\subsection{Range Hood Protection Systems}

Range hood protection systems were installed specifically to suppress a fire originating from the range surface. They activated automatically based on a thermal triggering mechanism or in one case a multi-sensor triggering mechanism.

\subsubsection{Wet chemical Systems 1- 4}

The automatic, self-contained, wet chemical systems delivered aqueous fire suppressant designed for Class K fires. Three of the systems tested in these experiments were commercially available systems or a system composed of listed components which could be installed with limited modification to an existing cooking range and exhaust hood. The fourth system was a novel prefabricated system that could be installed onto the wall behind a cooking range. The pressure pan in all four systems used Class K suppression agent, which contained a solution of potassium carbonate and water; the exact compositions were proprietary.

Table 2-1. Activation temperatures for automatic wet chemical system tests

\begin{tabular}{|llc|llc|}
\hline Suppressant & Test & $\begin{array}{c}\text { Activation Temp } \\
\left({ }^{\circ} \mathrm{C}\right)\end{array}$ & Suppressant & Test & $\begin{array}{c}\text { Activation Temp } \\
\left({ }^{\circ} \mathrm{C}\right)\end{array}$ \\
\hline & KSE 02 & 100 & & KSE 06 & 182 \\
& KSE 03 & 100 & & KSE 07 & 182 \\
Auto Wet & KSE 04 & 100 & Auto Wet & KSE 08 & 182 \\
Chem 1 & KSG 02 & 182 & Chem 2 & KSE 09 & 182 \\
& KSG 03 & 182 & & KSG 05 & 182 \\
& KSG 04 & 182 & & KSG 06 & 182 \\
& KSG 19 & 182 & & KSG 07 & 182 \\
\hline \multirow{2}{*}{ Auto Wet } & KSE 05 & Not Specified & & KSE 10 & 121 \\
Chem 3 & KSG 08 & Not Specified & Auto Wet & KSE 11 & 121 \\
& KSG 18 & Not Specified & Chem 4 & KSE 21 & 121 \\
& & & & KSE 22 & 121 \\
\hline
\end{tabular}




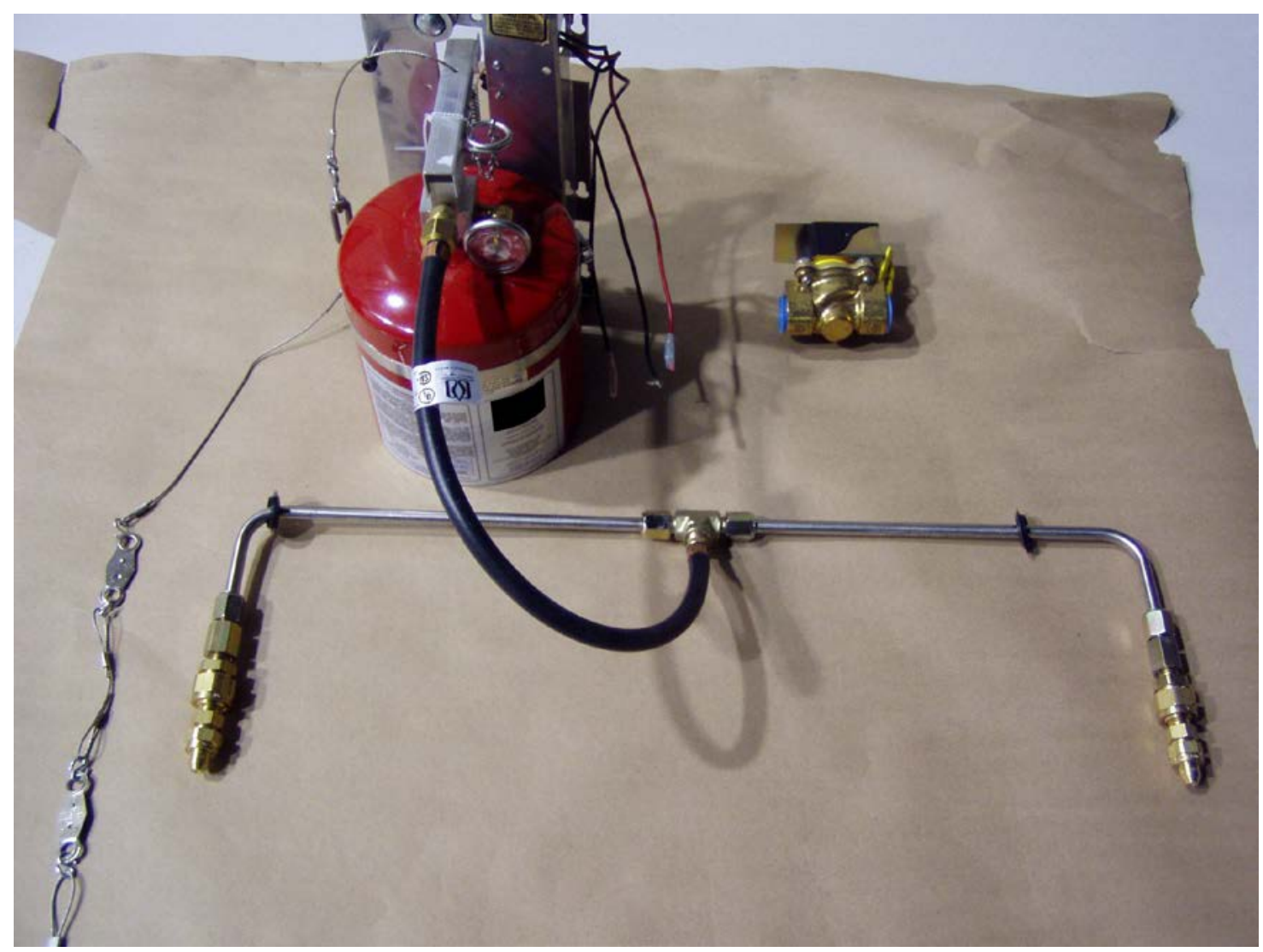

Figure 2-1. Components of an automatic, self-contained, wet chemical system (AWC1) including the automatic gas stovetop shutoff valve, which was not used in these experiments.

The self-contained, wet chemical suppression agent systems were comprised of three basic components related to fire detection, agent storage, and agent delivery. The multi-component systems typically used (1) temperature or heat detector(s) located above the range surface in the exhaust hood, (2) a pressure vessel, which was slightly remote from the range surface in a cabinet or box, and (3) nozzle(s), which was either permanently fixed above the range surface or was mechanically deployed there. These elements can be seen in Figure 2-1 for the AWC1 system. System activation was managed by the system detector; the manufacturer specified activation temperature for each system is given in Table 2-1. The Auto Wet Chem 1 (AWC1) was supplied with two types of eutectic solder links with different activation temperatures $\left(100{ }^{\circ} \mathrm{C}\right.$ and $\left.182{ }^{\circ} \mathrm{C}\right)$. AWC2 exclusively used links that activated at $182^{\circ} \mathrm{C}$. AWC3 was a commercial system commonly used in parts of Asia, which was equipped with a proprietary electronic thermal sensor and a smoke sensing system. AWC4 was a prototype system that used a frangible glass bulb with an activation temperature of $121^{\circ} \mathrm{C}$. The test identifiers all include "KS" for Kitchen Suppression and either an "E” for electric range or a "G” for gas range.

The fire detection systems utilized different technologies. AWC1 and AWC2 utilized a mechanical cable/chain device in concert with two thermal links. The links and the cable were under tension. One thermal link was located above each side of the range surface. The cable 
was attached to a rigid anchor point at one end, while the other end of the cable was attached to the pressure vessel. When the thermal link activated, it released tension on the cable and the pressure vessel valve opened allowing agent to discharge from the pressure vessel and out of the nozzles. As the agent in the vessel was deployed, the discharge rate slowed until it stopped completely. AWC1 and AWC2 both utilized two nozzles that were positioned near the side edges of the hood, directed such that the agent discharge covered the area on the top of the range. A portion of the cable arrangement and one nozzle from AWC2 can be observed in Figure 2-2.

AWC3 utilized a proprietary electronic thermal system to detect the presence of a fire and used an electro-mechanical mechanism to activate the pressure vessel. The electronics simplified the installation of the system. AWC3 utilized a single nozzle that was positioned above the center of the range. The single nozzle is seen in Figure 2-3 positioned near the hood.

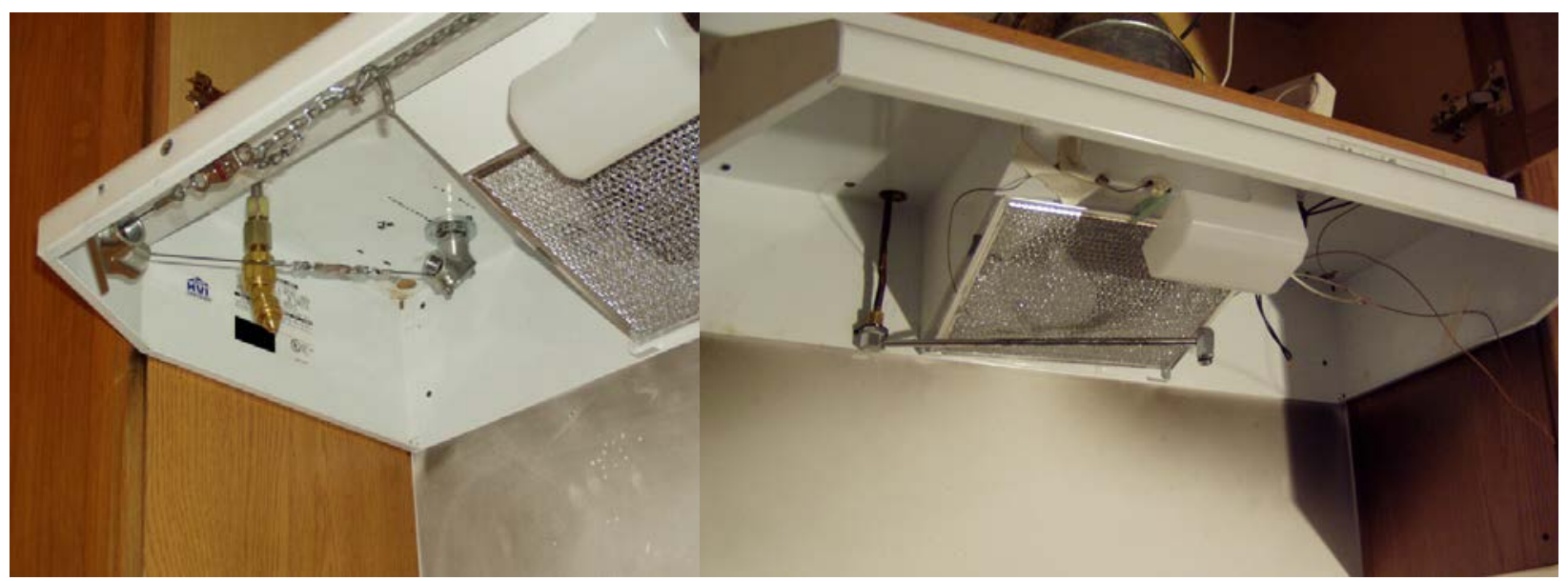

Figure 2-2. One side of a "typical" wet chemical system; two thermal links and a Figure 2-3. AWC3 was a single nozzle system that used an electrical thermal trigger. nozzle are shown, the opposing side was similarly configured.

Three of the systems were mounted with the thermal activation links (or sensors) and agent delivery hardware positioned within the exhaust hood of the range; the fourth system, AWC4 was wall-mounted behind the range. A typical arrangement of the wall mounted system can be seen in Figure 2-4. The pressure vessels for the hood-mounted systems were located in a cabinet above the hood for all experiments. For the wall-mounted system, the pressure vessel was integral to the wall mounted structure. The nozzle hardware for all three hood-mounted systems was permanently fixed above the range with each nozzle directed downward, in contrast to the wall-mounted system, which had a spring-loaded deployment mechanism. The wall-mounted system used two nozzles, but the nozzles were essentially co-located on the end of a single tube in the deployment arm. Each nozzle was directed towards the opposite side of the range surface. When one or both of the thermal links activated, the tension on a cable restraining agent 
deployment was released. As a spring pulled the deployment arm to the discharge position, a valve mounted on one end of the pressure vessel opened and the agent begins to discharge.

All four of the automatic, self-contained, wet chemical suppression systems were designed to incorporate an automatic range disabling switch, which would remove the heat-production functions of the range either by disabling the electrical input, in the case of an electrical range, or by disabling the gas input, in the case of a gas range. In all experiments for which the suppression system being tested included a disabling device, the range was manually deenergized when the system activated. The commercially available systems also had the capability to de-energize the range either by automatically shutting off the gas or by disconnecting the electricity. In these experiments, power shut-off was accomplished manually within $5 \mathrm{~s}$ of the initial activation of the suppression system.

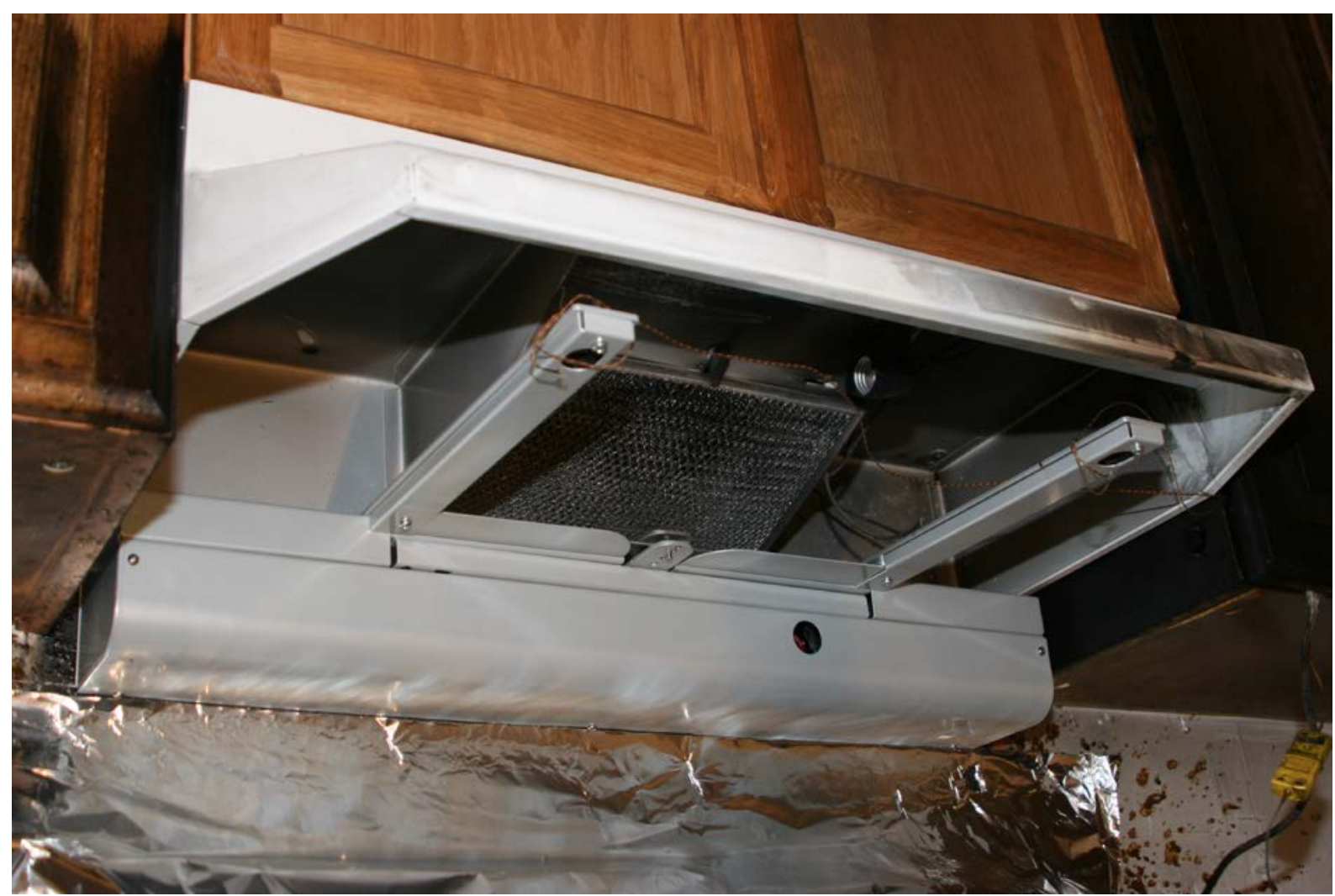

Figure 2-4. A wall-mounted, wet chemical system with arms containing heat sensitive bulb used to trigger agent deployment. Thermocouples mounted on the arms were not an intrinsic part of the device. 


\subsubsection{Dry Chemical Systems}

The automatic, self-contained, dry chemical systems delivered sodium bicarbonate powder to the range surface. The systems used in these experiments could be installed quickly with limited or no modification to an existing range exhaust hood.

The dry chemical system used for these experiments consisted of two or more self-contained suppression devices. Each device incorporated a flame activated fuse trigger, storage for the dry chemical suppressant, and a small pyrotechnic charge for deploying the suppressant to the range surface. Direct flame impingement on the fuse of the device caused activation. Each device consisted of a canister, approximately $89 \mathrm{~mm}$ (3.5 in) in diameter and $86 \mathrm{~mm}$ (3.4 in) in height, containing $282 \mathrm{~g}$ of sodium bicarbonate powder. In these experiments, two devices were used, each positioned to protect about half of the range surface.

The canister systems were installed directly above the cooking surface in the exhaust hood of each range, as specified by the manufacturer. This allowed the dry chemical to directly fall onto the fire that is being suppressed. Unlike the automatic, wet chemical systems, the dry chemical system was capable of partial activation, only discharging one of the two devices. The dry chemical systems are not equipped with a stovetop power disabling device. Thus, the range continued to heat the fuel during and after deployment of the automatic, dry chemical suppression systems. A typical manufacturer-recommended installation of an automatic, dry chemical system in the vent hood is seen in Figure 2-5.

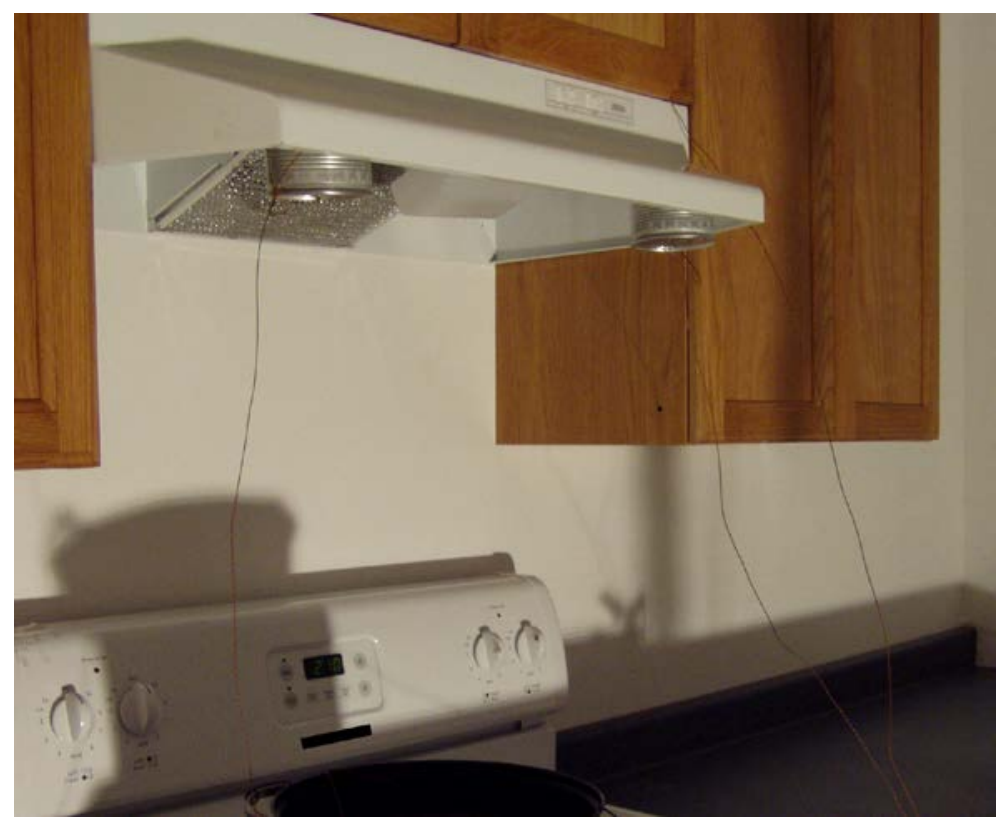

Figure 2-5. Autonomous dry chemical system installed above the stovetop. The thermocouples seen in the image were added and were not an intrinsic part of the device. 


\subsubsection{Water Mist Systems (Water Mist 2 \& 3)}

The automatic water mist systems delivered water at high pressure through a specialized nozzle designed to achieve sub-mm droplet sizes. Following manufacturer guidance, water was supplied using the laboratory supply line with supplementary pressurization provided by a gas cylinder of nitrogen. The system was electronically activated using a thermocouple mounted several inches from the nozzle with an activation temperature set to $250^{\circ} \mathrm{C}\left(482{ }^{\circ} \mathrm{F}\right)$. The supplied gauge gas pressure was maintained at $448 \mathrm{kPa}$ (65 psi) to $483 \mathrm{kPa}$ (70 psi). The single nozzle was installed in the center of the exhaust hood of the range. The water flow rate was mechanically adjustable.

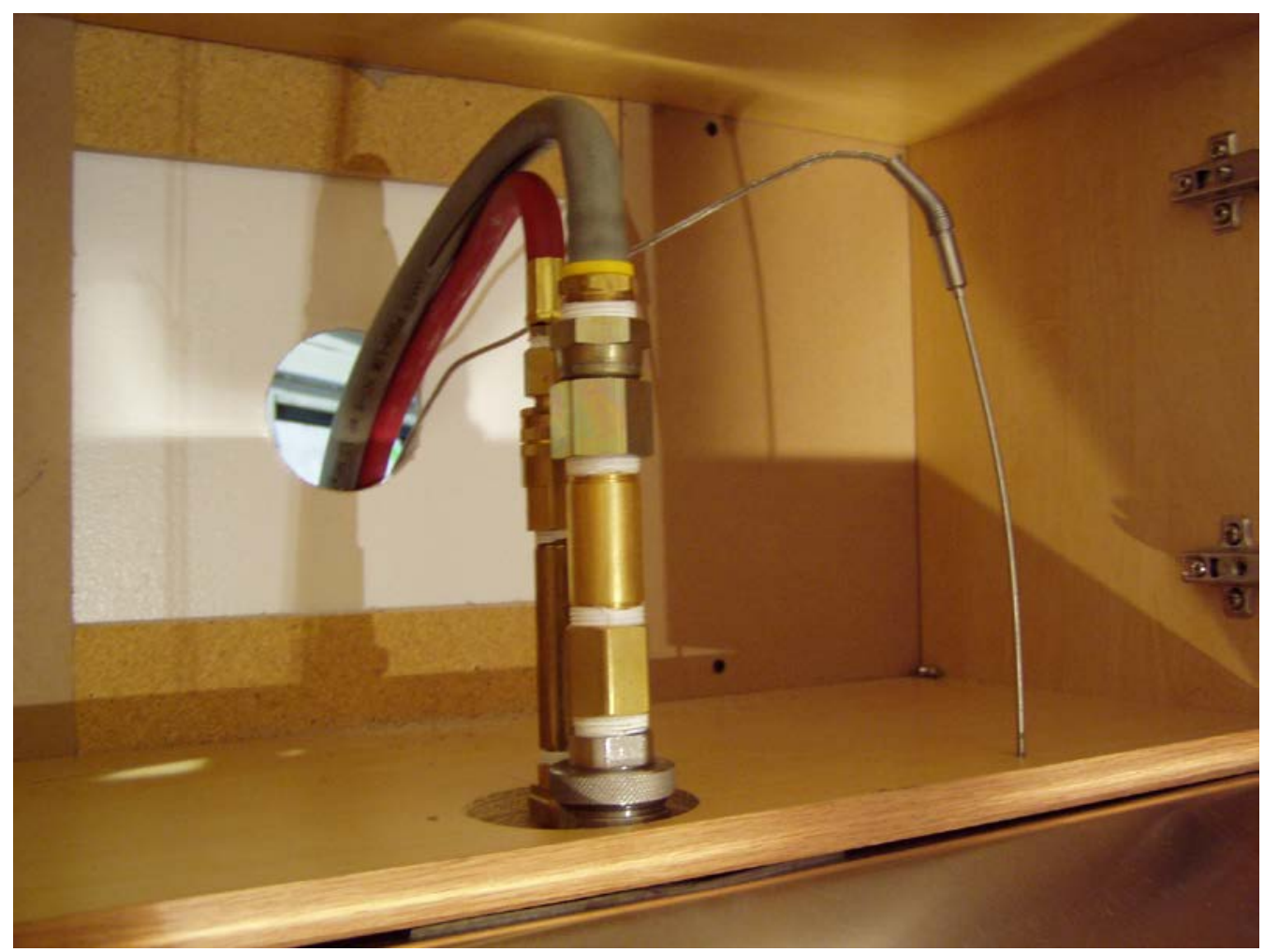

Figure 2-6. Plumbing for a water mist system above the range exhaust hood.

\subsection{Automatic Room Protection}

The automatic suppression systems activated using a thermal triggering mechanism. They were configured so as to protect not only the range surface, but also the kitchen area. Of the two systems used in these experiments, one was a residential sprinkler system installed in accordance with NFPA Standard 13D, whereas the other was a commercially available water mist system for use in industrial and commercial structures. Consideration of its use in residential structures was novel. The water supply for both systems was provided by pressurized water tanks, making both systems independent of the laboratory water supply. 


\subsubsection{Residential Sprinkler}

The single water sprinkler used in this system was installed at the center of the room's ceiling. The water supply provided $0.6 \mathrm{~L} / \mathrm{s}$ ( $9 \mathrm{gpm}$ ) of flow at $0.58 \mathrm{bar}$ ( $8.4 \mathrm{psi}$ ) suitable for a $3.7 \mathrm{~m}$ by $3.7 \mathrm{~m}$ room as per the sprinkler's listing. The sprinkler was a typical commercially available surface mounted pendant sprinkler fashioned with a heat-sensitive bulb as a thermal trigger. The sprinkler had a nominal K-Factor of 3.1 and an activation temperature listed as $68^{\circ} \mathrm{C}\left(155^{\circ} \mathrm{F}\right)$. The sprinkler head used in these experiments is shown in Figure 2-7.

\subsubsection{Water Mist (Water Mist 1)}

This system used a single mist nozzle located at the middle of the ceiling of the experimental structure. The system was supplied with water at $450 \mathrm{kPa}$ (65 psi) to $480 \mathrm{kPa}$ (70 psi) from pressurized tanks. As with the residential sprinkler, a heat sensitive bulb served as a thermal trigger for the nozzle. The nominal activation temperature was $79^{\circ} \mathrm{C}\left(175^{\circ} \mathrm{F}\right)$. The multi-nozzle water mist head used in these experiments is shown in Figure 2-8.

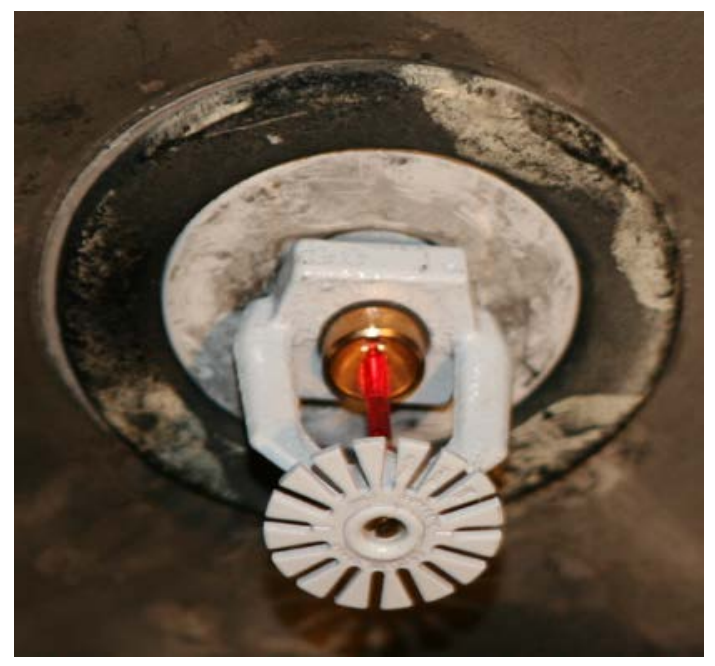

Figure 2-7. Water sprinkler head.

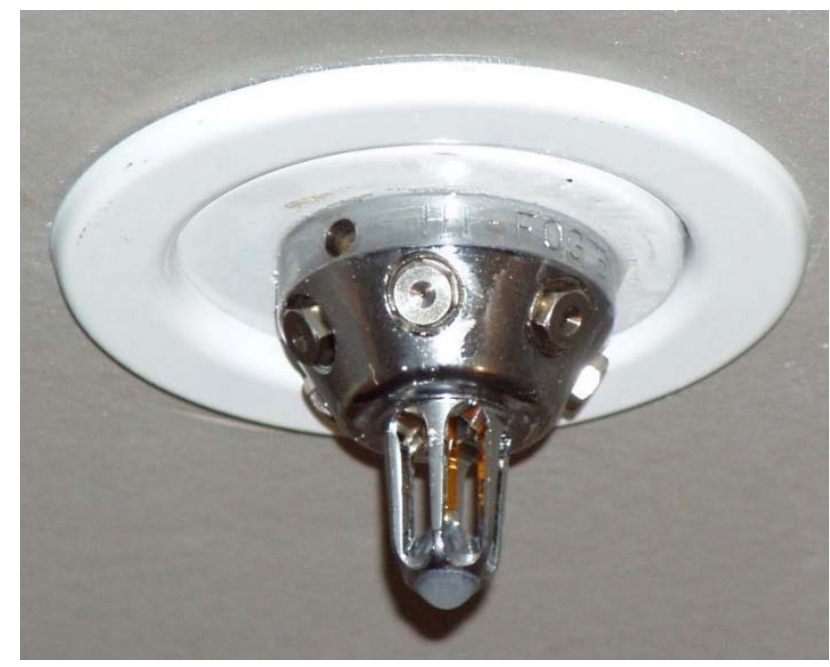

Figure 2-8. Water mist nozzle.

\subsection{Handheld Extinguishers}

Handheld extinguishers suppress a fire when the contents are sufficient in amount and are appropriately directed at the fire. Tests using handheld extinguishers were conducted by staff with extensive experience in handheld fire suppression techniques per manufacturer's instructions and NFPA 10 [8].

\subsubsection{Dry Chemical}

The handheld dry chemical suppression device consisted of a pressurized tank filled with a Class $B$ and Class C powder suppressant and a nozzle to deploy the agent manually. The device could 
be activated by a trigger on the handle and aimed into a kitchen fire where the suppressant will

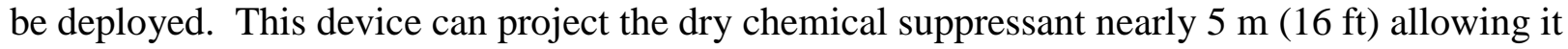
to be deployed from a safe distance. However, because of the high velocity of the suppressant, this type of extinguisher can be dangerous when used on an oil fire at close range because significant agitation of the oil can result, causing spatter and potentially serious injury. The dry chemical suppression device tested here is shown in Figure 2-9.

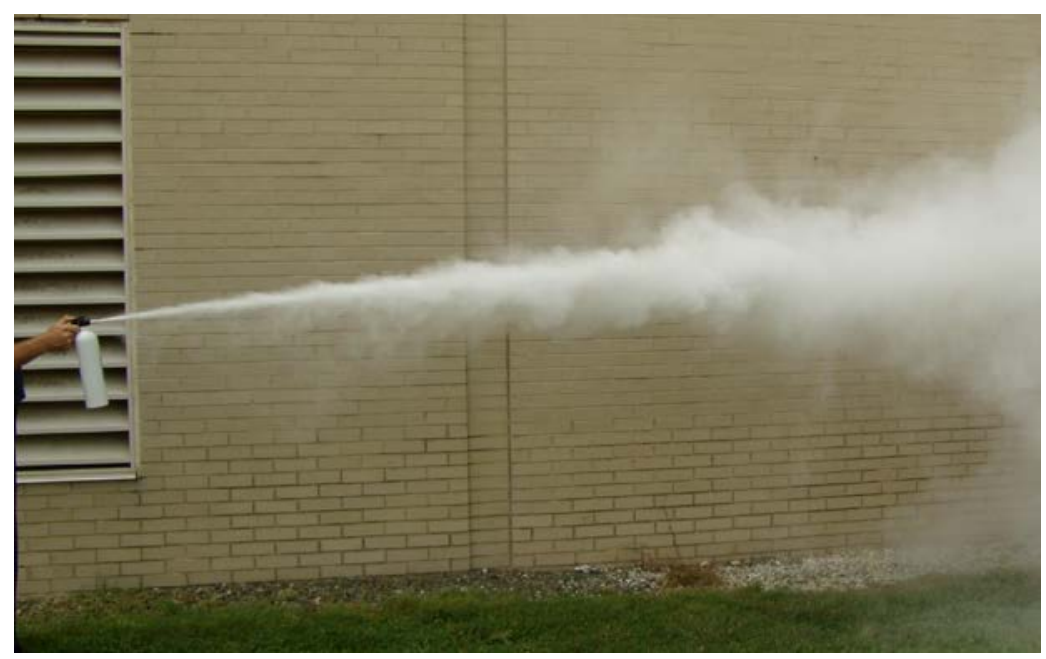

Figure 2-9. Discharge of manual dry chemical extinguisher.

\subsubsection{Wet Chemical}

The handheld wet chemical suppression device consisted of a pressurized tank filled with a Class $\mathrm{K}$ aqueous suppressant and a nozzle to deploy the agent manually. The device could be activated by a trigger on the handle and aimed into a kitchen fire from a safe distance. Although this device could not be deployed from as great a distance as the dry chemical extinguisher, it provided no significant danger of spatter related injury. A typical wet chemical suppression device is shown in Figure 2-10. 


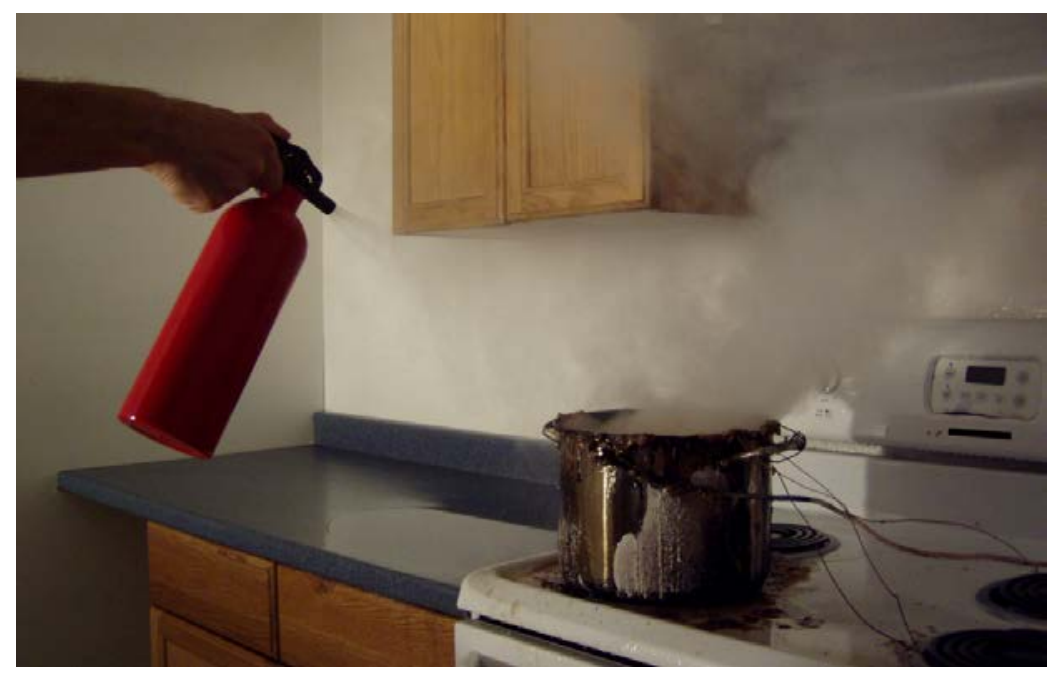

Figure 2-10. Discharge of manual wet chemical extinguisher.

\subsection{Suppression System Characterization}

The suppression systems were characterized in terms of the distribution and rate of agent delivery to the fire source, presumed to be the area defined by the stovetop itself. Measurements were made by deploying the suppression system in the absence of a fire for a given amount of time onto an array of square $(0.15 \mathrm{~m}$ by $0.15 \mathrm{~m})$ containers stationed about the stovetop. The mass flux distribution and delivery rates were determined by weighing the mass of the containers before and after suppressant deployment. Figure 2-11 shows typical measurement results. Here, a normalized gray-scale image of the distribution of water droplets delivered to various sections of a gas stovetop and its surroundings by a water sprinkler. The image is normalized such that pure black represent the maximum local water flux, which was $180 \mathrm{~g} / \mathrm{m}^{2}$-s. The measured average value of the water sprinkler delivery on the surface of the stovetop was $69 \mathrm{~g} / \mathrm{m}^{2}-\mathrm{s}$ and the standard deviation of this spatial average was $\pm 80 \%$. Reporting the average and standard deviation is a reasonable way to characterize the magnitude and uniformity of suppressant application, but it only provides a temporal and spatial average in the absence of a fire. It does not fully define suppressant performance. Optimal suppressant application would be spatially uniform and temporally constant in the presence of the target fire. In addition, the application would need to maximize fuel containment so that splashing of burning fuel beyond the confines of the vessel would not present a hazard.

Table 2-2 shows results for the mass delivery rate distribution of the suppressants. There was large variation in average delivery rate among the various suppressant types and the products within one technology type. The largest and smallest mass fluxes were the dry chemical and the water mist, respectively. The largest variance in the spatial distribution over the stovetop was for the dry chemical, which was a value of almost $200 \%$. Low uniformity of agent delivery can impact suppression system performance. It should be noted that these measurements were 
conducted in the absence of the oil vapor plume or a fire, which may significantly impact the trajectory and ultimate distribution of any agent, particularly for large fire plumes.

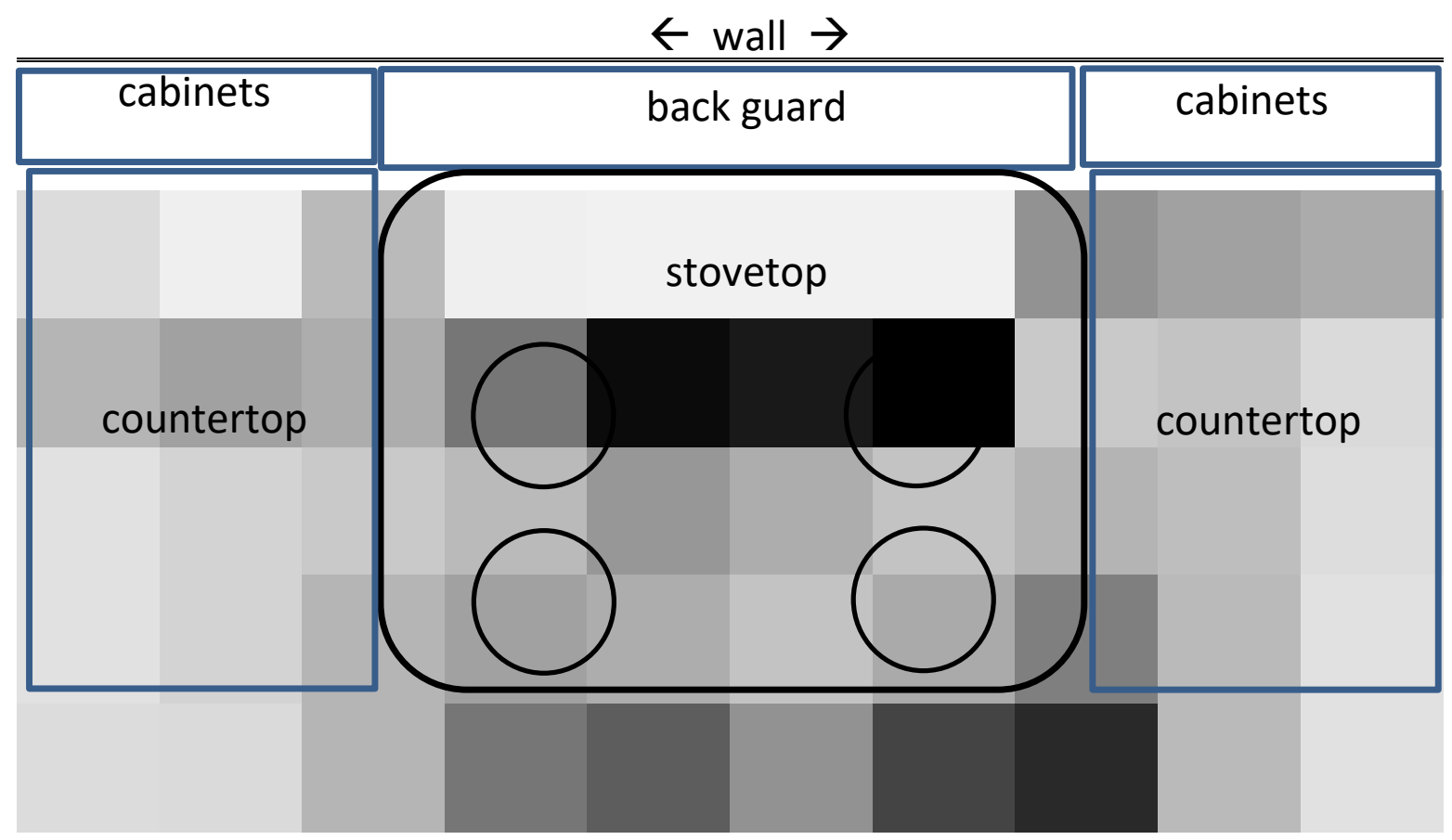

Figure 2-11. Gray-scale map of the measured mass distribution of water delivered by the sprinkler onto the gas stovetop and surroundings normalized by the maximum local water flux $\left(180 \mathrm{~g} / \mathrm{m}^{2}\right.$-s) represented as pure black. Nearby wall, cabinets and countertops are also shown.

Table 2-2. Mass delivery rate, spatial variance and total mass of the suppressants

\begin{tabular}{|l|c|c|c|}
\hline Suppression System & $\begin{array}{c}\text { Average Delivery Rate } \\
\left(\mathrm{g} / \mathrm{m}^{2}-\mathrm{s}\right)\end{array}$ & $\begin{array}{c}\text { Spatial Variance } \\
\text { (Percentage) }\end{array}$ & $\begin{array}{c}\text { Total Mass Available } \\
(\mathrm{kg})\end{array}$ \\
\hline Sprinkler & 69 & 80 & Unlimited \\
\hline Water Mist 1 & 3.7 & 50 & 64 \\
\hline Water Mist 2 & 14 & 170 & 1.2 \\
\hline Water Mist 3 & 210 & 68 & 2.0 \\
\hline Wet Chem 1 & 28 & 94 & 1.1 \\
\hline Wet Chem 2 & 50 & 59 & 0.4 \\
\hline Wet Chem 3 & 5.0 & 210 & 2.0 \\
\hline Wet Chem 4 & 34 & 107 & 0.3 \\
\hline Dry Chem & $145^{* *}$ & 210 & \\
\hline$*$ the spatial variation (see column to the right) is a representation of the uncertainty \\
$* *$ based on a 10 s delivery time (estimated based on observations)
\end{tabular}




\section{Cooktop Fire Characterization}

A series of experiments designed to characterize cooking oil fires on kitchen cooktop burners was conducted. Oil type, oil volume, pan type, and cooktop type were varied to quantify the heat release rate, mass loss rate, heat flux, and time to auto-ignition.

\subsection{Experimental Apparatus and Configuration}

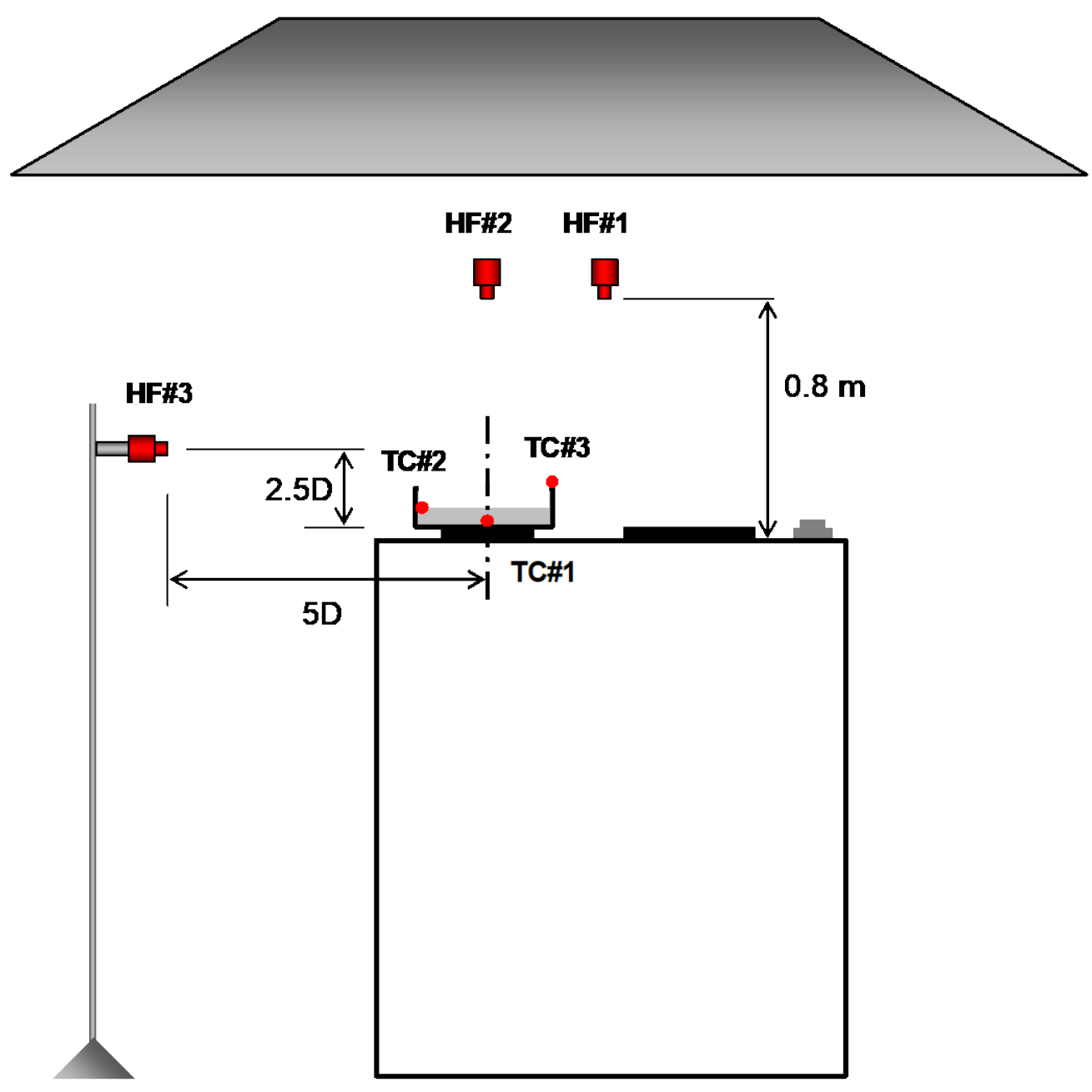

Figure 3-1. Schematic diagram of the apparatus used in the cooking oil fire characterization experiments.

Figure 3-1 shows a schematic diagram of the experimental configuration and a photo of the experimental arrangement is presented in Figure 3-2. A single burner, either electric or gas, was used to provide energy to heat the test pan. The (a) electric and (b) gas stovetops are seen in Figure 3-3. The electric cooktop was furnished with two large (195 mm diameter) and two small (150 mm diameter) coiled heating elements. 


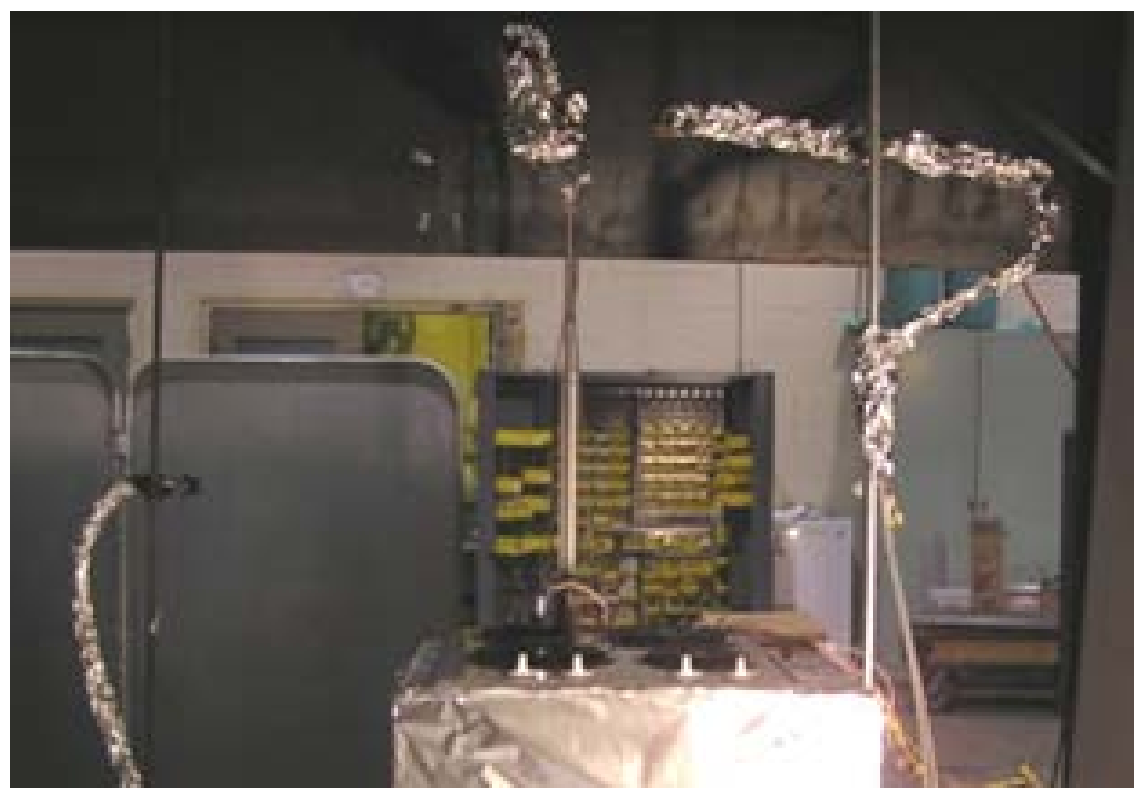

Figure 3-2. Photograph of the experimental configuration and instrumentation during Test 1.

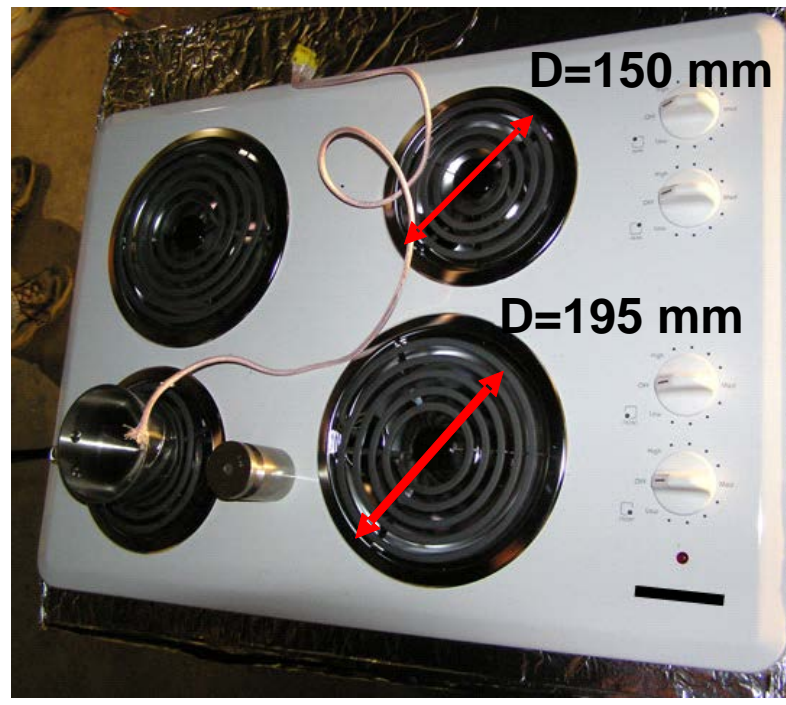

(a) Electric stovetop

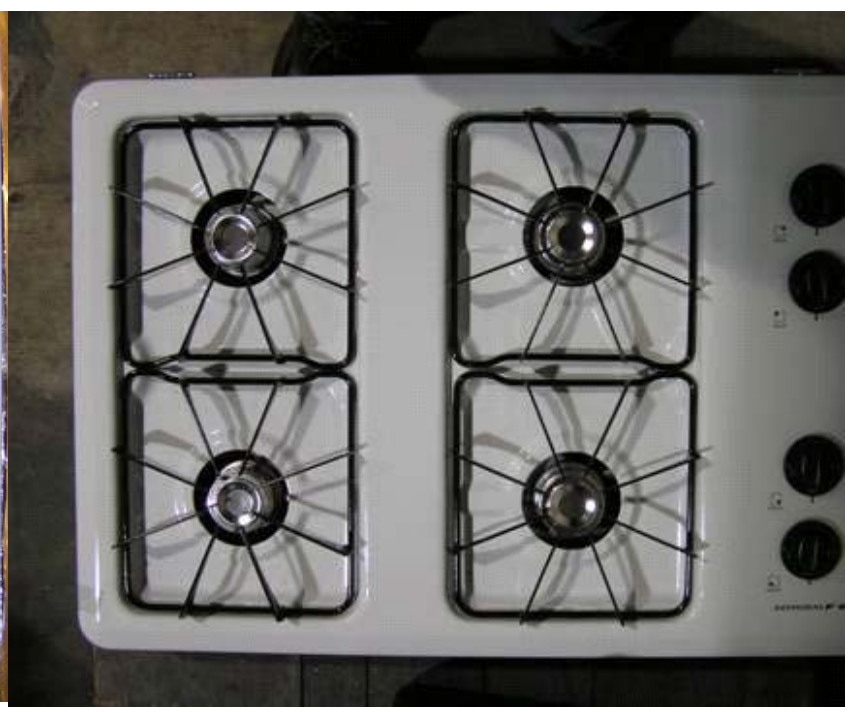

(b) gas stovetop

Figure 3-3. Photographs of the electric and the gas cooktops used in the cooking oil fire characterization experiments.

The experimental set-up included the pan sizes and oil volumes specified by UL300A [7]. Four kinds of pans were tested to examine their effect on the character of fires burning cooking oils. 
The pan sizes and materials were specified in UL300A [7]. The test pans varied in size, shape, and material composition, as shown in Table 3-1. Pans A, B, and C were actual commercial cookware and included a cast iron skillet, a deep pot or "Dutch oven", and a sauce pan, respectively. Pan D was a fabricated $53 \mathrm{~cm}$ by $46 \mathrm{~cm}$ rectangular pan with a $7.6 \mathrm{~cm}$ depth. The pan was designed to cover a large portion of the cooktop surface, representing an oil spill fire.

Pans A, B, and C were placed on the left side of the electric cooktop with Pan C placed on the small front heating element and Pans A and B placed on the large rear heating element. The power delivered to the electric stovetop heating elements was specified by the manufacturer as $2400 \mathrm{~W}$ and $1500 \mathrm{~W}$ for the larger and smaller coiled elements, respectively. The larger heating element was composed of 5 spirals of Inconel rod in a 8 in $(20 \mathrm{~cm})$ diameter round, whereas the smaller heating element was composed of 4 spirals in a 6 in $(15 \mathrm{~cm})$ diameter round. For the gas stovetop, the flow rate of natural gas was measured to estimate the power output. The flow rate was measured as $0.043 \mathrm{~L} / \mathrm{s} \pm 0.002 \mathrm{~L} / \mathrm{s}$, which was equivalent to approximately $1400 \mathrm{~W}$.

Table 3-1. Test pan summary

\begin{tabular}{|l|c|c|c|c|c|c|c|}
\hline Type & Shape & $\begin{array}{c}\text { Width } \\
(\mathrm{cm})\end{array}$ & $\begin{array}{c}\text { Depth } \\
(\mathrm{cm})\end{array}$ & Material & $\begin{array}{c}\text { Pan Mass } \\
(\mathrm{g})\end{array}$ & $\begin{array}{c}\text { Oil depth } \\
(\mathrm{cm})\end{array}$ & $\begin{array}{c}\text { Oil Volume } \\
(\mathrm{ml})\end{array}$ \\
\hline Pan A & round & $33^{*}$ & 5 & Cast iron & $4230 \pm 10$ & $2.5 \pm 0.2$ & $1650 \pm 10$ \\
Pan B & round & $25^{*}$ & 18 & Stainless Steel & $1250 \pm 10$ & $10.0 \pm 0.2$ & $4500 \pm 10$ \\
Pan C & round & $10^{*}$ & 5 & Stainless Steel & $1420 \pm 10$ & $2.5 \pm 0.2$ & $215 \pm 5$ \\
Pan D & rectangular & $53 \times 46$ & 7.6 & Steel & $3000 \pm 800$ & $0.6 \pm 0.1$ & $1600 \pm 20$ \\
\hline * inner diameter at uppermost portion of the rim (or lip) of the pan \\
\hline
\end{tabular}

The cooking oils specified by the UL 300A method were peanut and vegetable oil. Commercial vegetable oil is typically a blend of various types of oils. In this study, fresh commercial $100 \%$ corn oil was substituted for the vegetable oil in an effort to improve repeatability. Table 3-1 lists the volume of oil used in each pan and the resulting oil depth. Table 3-2 lists the thermophysical and combustion properties of the oils including their density, flash point, and auto-ignition temperature. The auto-ignition temperature of corn oil is significantly lower than that of peanut oil [9].

Table 3-2. Thermophysical and combustion properties of oils [9]

\begin{tabular}{|c|c|c|c|}
\hline Oil type & $\begin{array}{c}\text { Density } \\
\left(\mathrm{kg} / \mathrm{m}^{3}\right)\end{array}$ & $\begin{array}{c}\text { Flash point } \\
\left({ }^{\circ} \mathrm{C}\right)\end{array}$ & $\begin{array}{c}\text { Auto ignition temperature } \\
\left({ }^{\circ} \mathrm{C}\right)\end{array}$ \\
\hline Corn & 918 & 254 & 392 \\
\hline Peanut & 920 & 282 & 445 \\
\hline
\end{tabular}




\subsection{Apparatus}

The behavior of the ignition event and subsequent fire were characterized by measuring the ignition time, heat flux, heat release rate, pan temperature, and oil mass loss rate. The entire test was recorded using a digital video camera including the period before ignition that involved oil heating, the moment of ignition, and fire growth. The camera was positioned about $5 \mathrm{~m}$ from the stove. The power for the gas cooktop was measured using a dry test meter and stopwatch, while the power for the electric cooktop was based on manufacturer information.

The open burn tests were performed under the $3 \mathrm{~m} \times 3 \mathrm{~m}$ exhaust hood in the NIST Furniture Calorimeter. The heat release rate was determined using oxygen consumption calorimetry which involved the measurement of many quantities as described in Ref. [10]. The response time of the system is such that it can accurately resolve dynamic heat release rate events of $15 \mathrm{~s}$ or more. The expanded uncertainty was estimated as $\pm 11 \%$ for fire sizes larger than $400 \mathrm{~kW}$ and about $15 \%$ for smaller fires, based on calibration and repeat measurements.

Three thin $(1.6 \mathrm{~mm})$ stainless steel-sheathed type $\mathrm{K}$ thermocouples were spring-loaded such that they made contact at various positions on the pan surface to monitor the temperature (see Figure 3-1). Thermocouples were positioned at the center of the pan bottom, on the inner side wall at the oil-fill level, and on the pan rim. The standard uncertainty of the temperature measurement was $2{ }^{\circ} \mathrm{C}$, as specified by the manufacturer [11]. Unless stated otherwise uncertainties reported here are Type B standard uncertainty [12].

Three calibrated water-cooled Schmidt-Boelter heat flux gauges were used to measure the local time varying heat flux emitted by the fire. The gauges had a wide view angle ( $150^{\circ}$ view angle) and were coated with a high emissivity paint that had a flat spectral response in the infrared. The gauges had a time response of approximately $2 \mathrm{~s}$ [13]. A gauge (HF\#3 in Figure 3-1) was directed towards the fire and positioned a approximately 5 times the pan diameter (D) in the horizontal direction (from the pan center) and 2.5 times the pan diameter above pan rim. Two gauges (HF\#1 and HF\#2 in Figure 3-1) were oriented downward and placed $0.8 \mathrm{~m}$ above the center of the pan and above the center of the cooktop, respectively. The heat flux gauges were calibrated using a secondary standard in a well-characterized radiometer facility and the expanded uncertainty of the measurement was estimated as $8 \%$ [14].

The fuel mass loss rate due to evaporation and burning of the cooking oil was measured using a load cell that was positioned under the stove. Based on repeated calibration measurements, the standard uncertainty in the load cell was about $10 \mathrm{~g}$ with a stove tare weight of about $50 \mathrm{~kg}$.

\subsection{Test Procedure}

The fire tests were performed for different combinations of pan type, oil type and stove type, following the UL300A test guidance [7]. The test procedure involved the following steps. The hood exhaust was opened and the calorimetry system prepared. The instruments were zeroed and the data acquisition system initiated. The volume of oil used in each test was measured using 
a graduated cylinder. The oil was carefully introduced into the pan to avoid spillage. The cooktop element or burner was energized to its highest level and the time was noted.

As the pan heated, a vapor cloud was generated above the liquid oil, which became visible with time. For most of the experiments, the cooktop power was stopped shortly after ignition was observed to prevent thermal damage to the instrumentation. For tests using small amounts of oil (those using Pan C; Tests 1, 2, 4, 11, and 12), the experiments continued until flaming ceased and no oil was observed to remain in the pan. The peak heat release rate was measured in these experiments using oxygen consumption calorimetry. For the other tests, burning was stopped before fuel burnout due to safety concerns. In these cases, the maximum value of the measured heat release rate is listed in Table 3-3.

\subsection{Results}

Twelve full scale fire tests were conducted to investigate ignition and stovetop fire characteristics, such as ignition time, mass loss rate, heat release rate, and heat flux emitted by the fire. Table 3-3 lists the mass of oil tested and the experimental conditions, including the types of cooktop, oil, and pan used. Corn oil was used in 7 tests and peanut oil was used in 5 tests. Pan $\mathrm{C}$ was used in 5 experiments, which was the most, followed by Pans $\mathrm{A}$ and $\mathrm{B}$, which were used 3 times each. Pan D was used once.

Table 3-3. Summary of tests

\begin{tabular}{|c|c|c|c|c|c|c|c|}
\hline $\begin{array}{l}\text { Test } \\
\text { No. }\end{array}$ & $\begin{array}{l}\text { Stove } \\
\text { type }\end{array}$ & $\begin{array}{l}\text { Power } \\
(\mathrm{kW})\end{array}$ & Oil type & $\operatorname{Pan}^{B}$ & $\begin{array}{l}\text { Initial oil } \\
\text { mass (g) }\end{array}$ & $\begin{array}{l}\text { Time to } \\
\text { ignition } \\
\text { (min:s) }\end{array}$ & $\begin{array}{c}\text { Peak HRR } \\
\text { D }(k W)\end{array}$ \\
\hline 1 & Electric & $1.4 \pm 0.3$ & Corn & Pan C & $187 \pm 10$ & $17: 52 \pm 5$ & $73 \pm 20$ \\
\hline $2^{A}$ & Electric & $1.4 \pm 0.3$ & Corn & Pan C & $187 \pm 10$ & $20: 00 \pm 5$ & $101 \pm 20$ \\
\hline 3 & Electric & $2 \pm 0.5$ & Corn & Pan B & $4000 \pm 10$ & $77: 40 \pm 5$ & $472 \pm 20^{\mathrm{E}}$ \\
\hline 4 & Gas & $1.6 \pm 0.2$ & Peanut & Pan C & $185 \pm 10$ & $16: 14 \pm 5$ & $66 \pm 20$ \\
\hline 5 & Gas & $1.6 \pm 0.2$ & Corn & Pan A & $1476 \pm 10$ & $>93^{C}$ & C \\
\hline 6 & Gas & $6.4 \pm 0.8$ & Corn & Pan D & $1432 \pm 10$ & $24: 20 \pm 5$ & $91 \pm 20^{E}$ \\
\hline 7 & Gas & $1.6 \pm 0.2$ & Peanut & Pan B & $4200 \pm 10$ & $145: 30 \pm 5$ & $26 \pm 20^{E}$ \\
\hline 8 & Electric & $2 \pm 0.5$ & Peanut & Pan A & $1454 \pm 10$ & $61: 10 \pm 5$ & $16 \pm 20^{E}$ \\
\hline 9 & Electric & $2 \pm 0.5$ & Corn & Pan A & $1477 \pm 10$ & $57: 24 \pm 5$ & $30 \pm 20^{\mathrm{E}}$ \\
\hline 10 & Electric & $2 \pm 0.5$ & Peanut & Pan B & $4004 \pm 10$ & $79: 35 \pm 5$ & $35 \pm 20^{E}$ \\
\hline 11 & Electric & $1.4 \pm 0.3$ & Peanut & Pan C & $186 \pm 10$ & $19: 10 \pm 5$ & $100 \pm 20$ \\
\hline $12^{\mathrm{A}}$ & Electric & $1.4 \pm 0.3$ & Corn & Pan C & $191 \pm 10$ & $18: 17 \pm 5$ & $115 \pm 20$ \\
\hline \multicolumn{8}{|c|}{$\begin{array}{l}\text { A. repeat of Test } 1 \\
\text { B. see Table } 3-1 \text { for a description of the pans } \\
\text { C. ignition not observed } \\
\text { D. HRR is the heat release rate; here, measured by oxygen consumption calorimetry } \\
\text { E. value of HRR when test was stopped (due to safety concerns) }\end{array}$} \\
\hline
\end{tabular}




\subsubsection{Ignition}

Table 3-3 also lists the time at which ignition was observed. Ignition took a significant amount of time and lots of oil vapor was generated before ignition. Figure 3-4 shows the plume of cooking oil vapor above the pan before ignition during Test 2 . The time to ignition varied from $18 \mathrm{~min}$ to $145 \mathrm{~min}$, depending on test conditions. Generally, the time to ignition was a function of the initial mass of the cooking oil, the mass of the pan, and the cooktop power. The conditions from Test 1 were repeated two additional times (Tests 2 and 12), and the time to ignition was observed to be repeatable with in about $10 \%$ (standard deviation equal to about $10 \%$ ). Test 5 was terminated after $93 \mathrm{~min}$, because ignition was not observed and the temperature of the pan did not significantly increase, according to the thermocouple measurements monitoring the pan temperature.

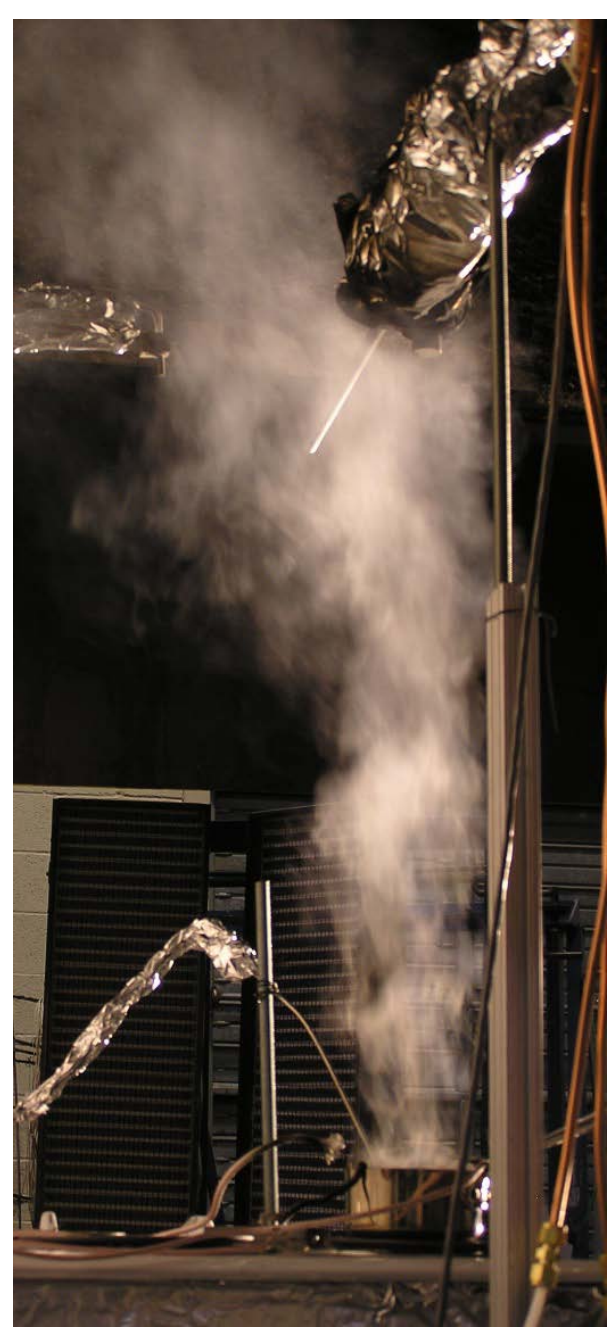

Figure 3-4. Plume of cooking oil vapor above pan before ignition during Test 2 . 


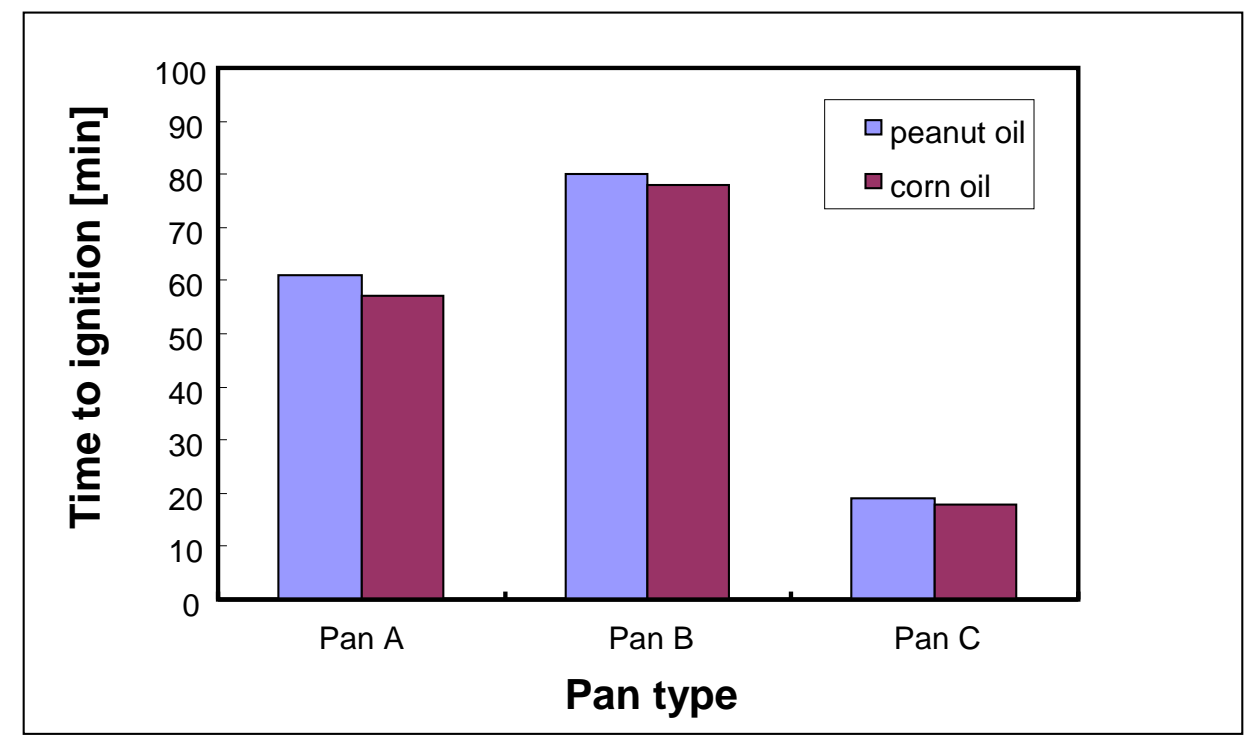

Figure 3-5. Comparison of the measured time to ignition as a function of pan and oil type on the electric cooktop.

Figure 3-5 presents the time to ignition of the corn and peanut oils in the three pans (Pans A, B, C) on the electric cooktop. For each of the pans, the time to ignition of the corn oil was $5 \%$ to $10 \%$ lower than that of the peanut oil consistent with its lower auto-ignition temperature (see Table 3-2).

Ignition took somewhat longer on the electric cooktop for Pan B as compared to the gas cooktop, whereas there was little difference in the time to ignition for Pan C. This is attributed to the lower power output of the gas cooktop used in these experiments but other factors may have played a role. Understanding the details of the heat transfer processes to the pan and the oil was beyond the scope of this study.

\subsubsection{Heat release rate of cooking oil}

Figure 3-6 shows the time varying heat release rate $\dot{Q}(t)$ from the calorimetry and the $20 \mathrm{~s}$ running average of the mass loss rate (or mass burning rate) as a function of time of corn oil during Test 2. As expected, the maxima of the heat release rate and the corn oil mass burning rate occur at about the same time. The average burning rate of cooking oil is calculated as follows: 


$$
\dot{m}_{\text {avg }}=\frac{\Delta m}{\Delta t}
$$

where $\dot{m}_{\text {avg }}$ and $\Delta m$ represent, respectively, the average mass loss rate of the cooking oil and the change in the mass of the oil over that time period, typically taken as the test duration $(\Delta t)$. The average heat release rate $\left(\dot{Q}_{a v g}\right)$ is related to the average mass burning rate ( $\left.\dot{m}_{\text {avg }}\right)$, the heat of combustion $\left(H_{c}\right)$, and the combustion efficiency $\left(\chi_{a}\right)$ :

$$
\dot{Q}_{a v g}=\chi_{a} \cdot H_{C} \cdot \dot{m}_{a v g}
$$

Because Tests 2 and 11 were conducted using an electric stove, no correction was necessary for combustion due to natural gas associated with powering the gas stove. A comprehensive discussion of the measurement uncertainty, using the NIST furniture calorimeter, is given in Ref. [10].

Figure 3-6 and Figure 3-7 present the measured heat release rate and the mass burning rate, $\dot{Q}(t)$ and $\dot{m}(t)$, as a function of time during Tests 2 and 11, respectively. The maximum values of the heat release and mass burning rates during Tests 2 and 11 were roughly $100 \mathrm{~kW}$ and $2 \mathrm{~g} / \mathrm{s}$ in both experiments. Both tests were carried out with Pan C, but with peanut oil for Test 2 and corn oil for Test 11. Previous oxygen bomb calorimetry measurements report a value of about $37 \mathrm{~kJ} / \mathrm{g}$ to $41 \mathrm{~kJ} / \mathrm{g}$ for edible oils [9]. Thus, the similarity in the measured heat release rates is not unexpected. 


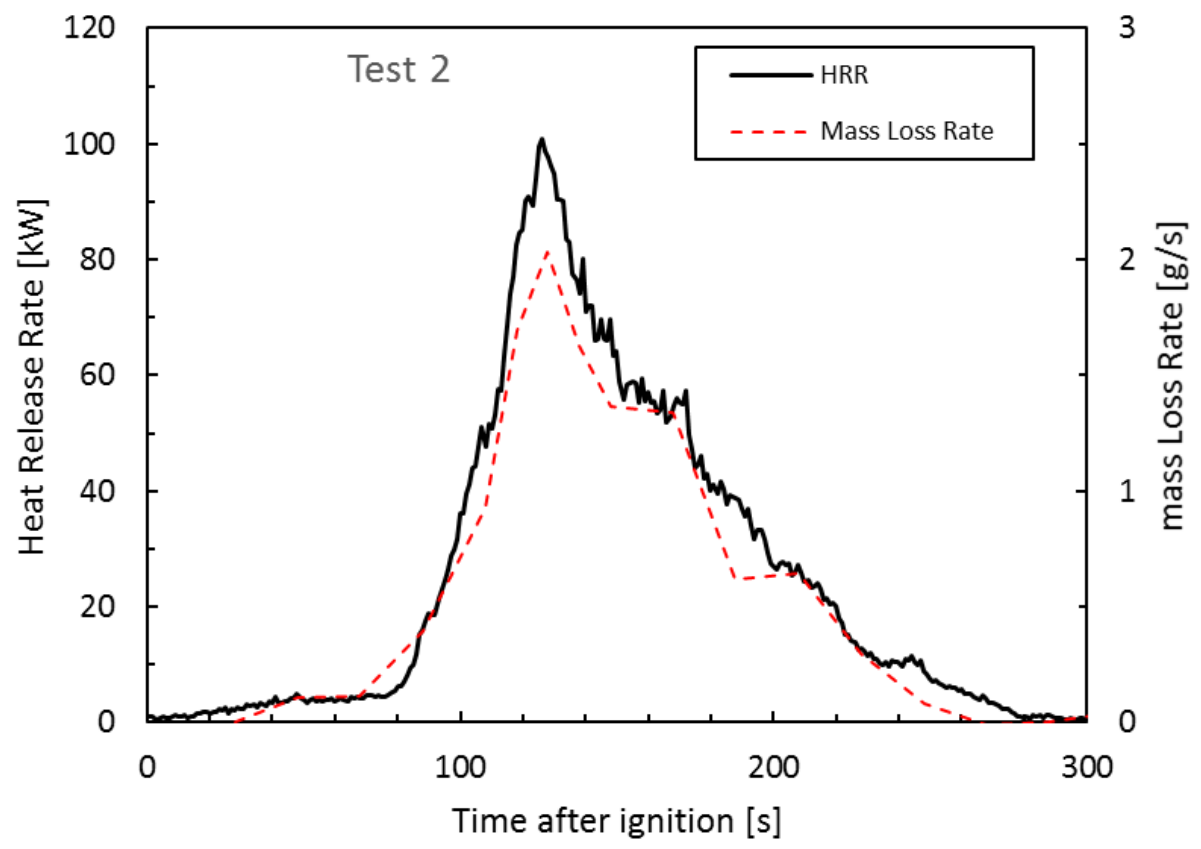

Figure 3-6. Measured heat release rate and mass loss during Test 2 (corn oil in Pan C).

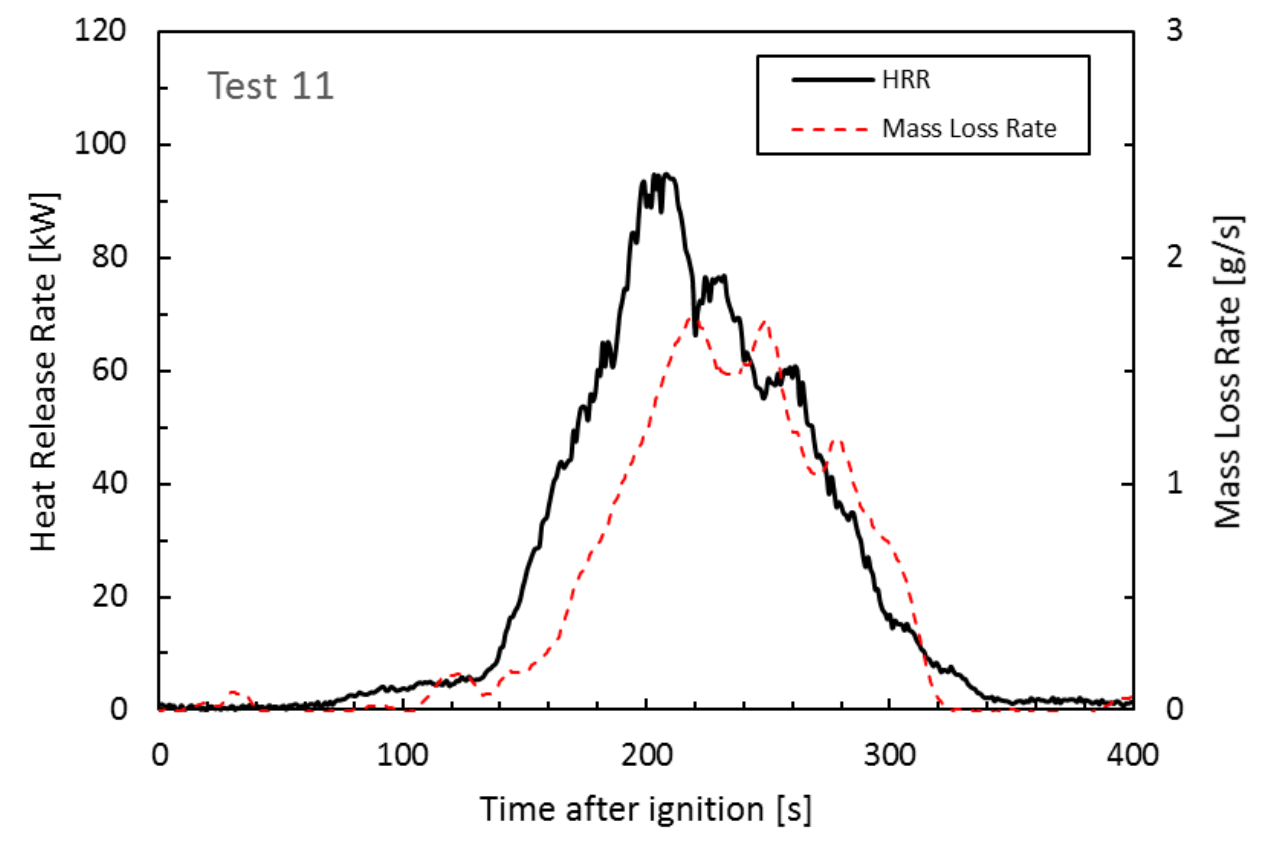

Figure 3-7. The measured heat release rate and mass burning rate during Test 11 (peanut oil in Pan C). 


\subsubsection{Ignition surface temperature and fire characteristics}

The time history of the fuel temperatures during Test 11 (peanut oil) is presented in Figure 3-8 as a function of time after stove start-up. Figure 3-1 shows the locations of thermocouples 1 , 2, and 3 , which were located at the bottom of the pan, on the inner side-wall of the pan halfway between the rim and the pan bottom, and at the top of the rim, respectively. The temperature slowly increased until ignition occurred at about $1150 \mathrm{~s}$. At that time, the oil surface temperature (TC\#3) abruptly increased and the fire was observed to quickly grow. Figure 3-9 and Figure 3-10 show the measured pan temperatures at the time of ignition for each of the tests. This information is also summarized in Table 3-4. Tests 6 and 7 were conducted using the gas stovetop burner, whereas the other tests used the electrically powered stovetop burner. No discernable difference was evident between gas and electric stovetop results. Both figures indicate that the pan temperature at ignition varied as a function of location. For the given temperature measurement locations, ignition generally occurred significantly below $381{ }^{\circ} \mathrm{C}$, a value lower than the reference auto-ignition temperatures (see Table 3-2). This result is attributed to the fact that the temperature was measured at only three positions and apparently not at the exact ignition location where the local temperature was expected to exceed the auto-ignition temperature. The temperature at the pan rim showed the most variation. At the time of ignition, the mean sidewall temperature (TC \#2) was nearly equal to the mean temperature at the pan bottom (TC \#1). The pan bottom temperatures at ignition were somewhat below previously reported results for auto-ignition experiments that used less volumes of oil [15].

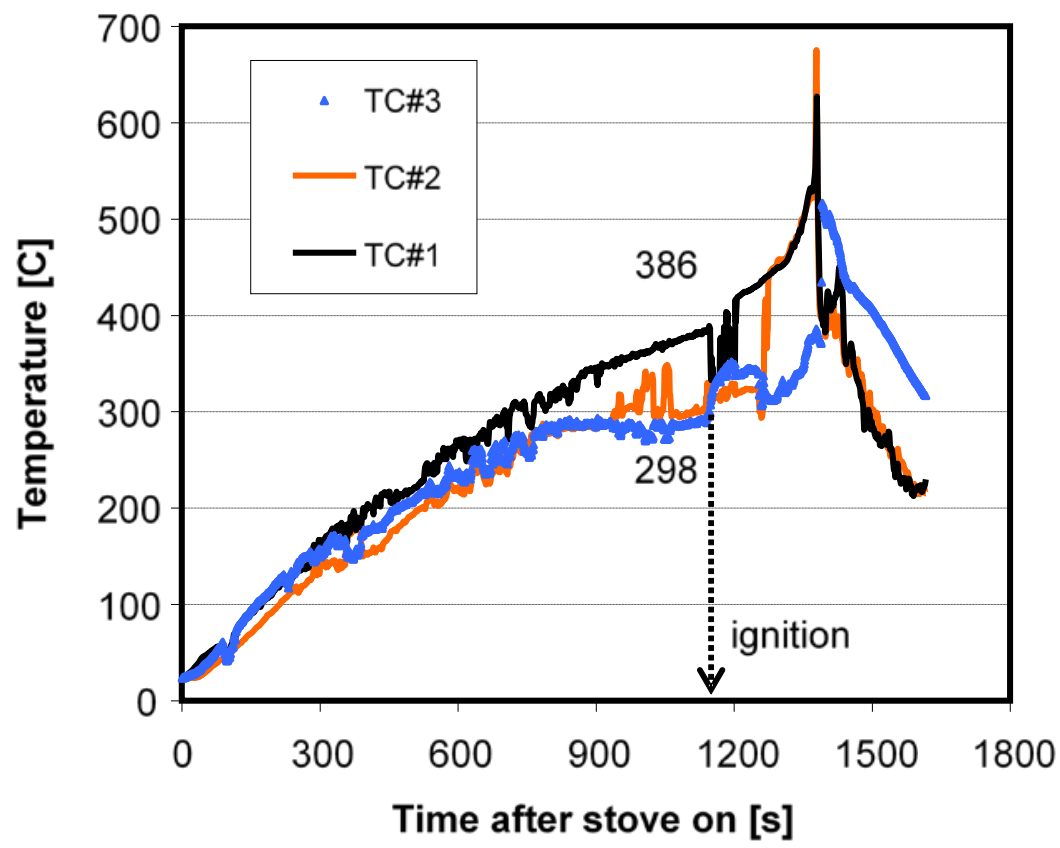

Figure 3-8 The evolving temperatures measured at three locations on the cooking vessel (see Figure 3-1) during Test 11 (peanut oil in Pan C). 


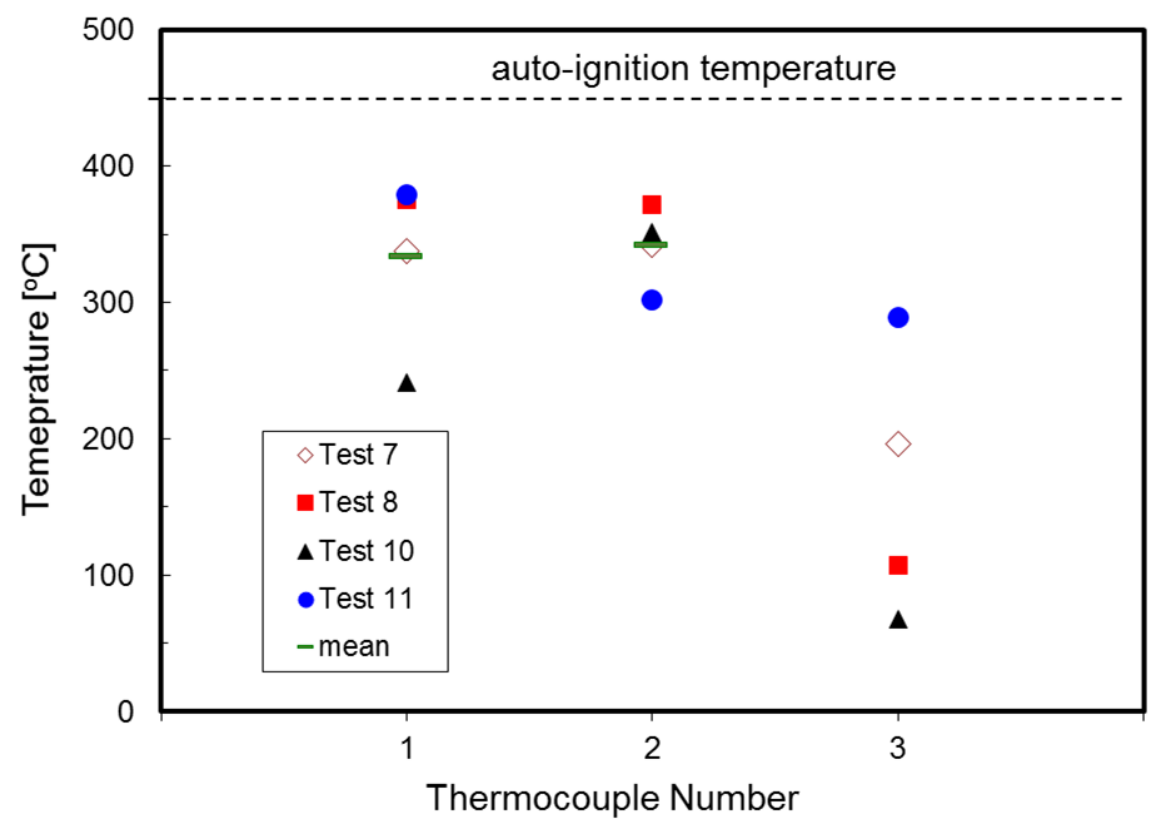

Figure 3-9. Measured mean temperatures on the cooking pan (see Figure 3-1) at the time of peanut oil ignition during Tests $7,8,10$, and 11 .

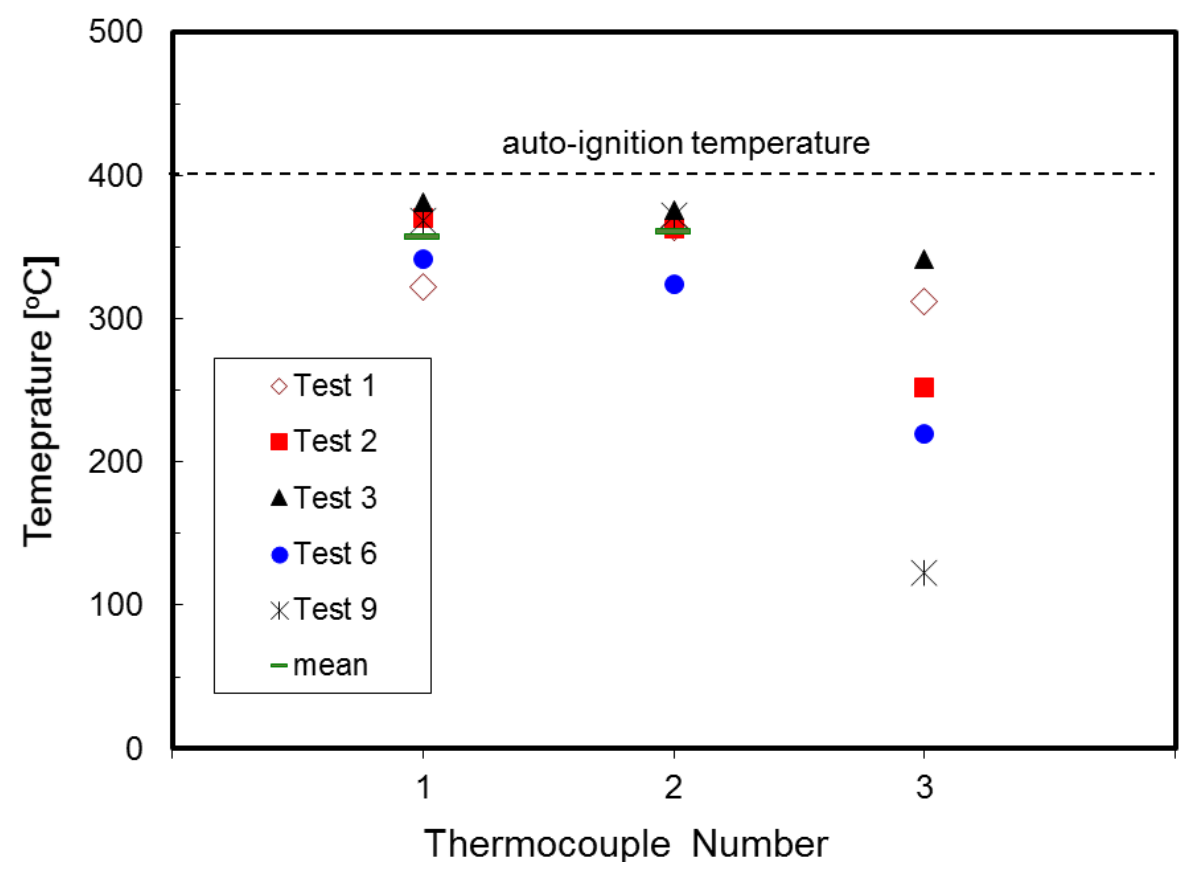

Figure 3-10. Measured mean temperatures on the cooking pan (see Figure 3-1) at the time of corn oil ignition during Tests $1,2,3,6$, and 9 
Table 3-4. Pan surface temperatures at the time of ignition.

\begin{tabular}{|c|c|c|c|c|}
\hline \multirow{2}{*}{ Oil Type } & \multirow{2}{*}{ Test No. } & \multicolumn{3}{|c|}{ Thermocouple Results * } \\
\cline { 2 - 5 } & Test 1 & $\mathrm{T}_{1}\left({ }^{\circ} \mathrm{C}\right)$ & $\mathrm{T}_{2}\left({ }^{\circ} \mathrm{C}\right)$ & $\mathrm{T}_{3}\left({ }^{\circ} \mathrm{C}\right)$ \\
\hline \multirow{4}{*}{ Corn oil } & Test 2 & 322 & 312 & 364 \\
\cline { 2 - 5 } & Test 3 & 370 & 252 & 363 \\
\cline { 2 - 5 } & Test 6 & 381 & 341 & 375 \\
\cline { 2 - 5 } & Test 9 & 342 & 220 & 324 \\
\hline \multirow{4}{*}{ Peanut oil } & Test 7 & 368 & 123 & 372 \\
\cline { 2 - 5 } & Test 8 & 375 & 196 & 342 \\
\cline { 2 - 5 } & Test 10 & 241 & 68 & 371 \\
\cline { 2 - 5 } & Test 11 & 379 & 289 & 302 \\
\hline * the standard uncertainty of the measurement is 2 ${ }^{\circ} \mathrm{C}$ based on manufacturer information. \\
locations of the thermocouples on the pan surface are shown in Figure 3-1. \\
\hline
\end{tabular}

Figure 3-11 shows the measured heat fluxes measured at three locations about the fire. The locations of the gauges are shown in Figure 3-1, which were positioned to the side and above the pan. The maximum heat flux was recorded in the plume directly above the pan, which was larger than $20 \mathrm{~kW} / \mathrm{m}^{2}$. Figure 3-12 shows the concentration of $\mathrm{CO}$ and $\mathrm{CO}_{2}$ measured in the exhaust duct during Test 1 . The $\mathrm{CO}$ volume fraction produced by the burning of the cooking oil was $30 \mu \mathrm{L} / \mathrm{L}$, which occurred during the peak of the heat release rate, whereas the $\mathrm{CO}_{2} \mathrm{~mole}$ fraction reached a value of $3000 \mu \mathrm{L} / \mathrm{L}$. A CO concentration of $30 \mu \mathrm{L} / \mathrm{L}$ is not particularly severe in terms of human physiology with the 8-hour total weight average permissible exposure limit listed as $50 \mu \mathrm{L} / \mathrm{L}$ for $\mathrm{CO}$ [16]. During most of the test, the $\mathrm{CO} / \mathrm{CO}_{2}$ volume fraction ratio was less than $1 \%$ except during the peak heat output period, when a maximum value of $1.4 \%$ was obtained.

Figure 3-13 shows photographs of the evolving corn oil fire in Pan $\mathrm{C}$ as a function of time along with the measured heat release rate during Test 2 . As the cooking oil and the pan were heated, copious amounts of oil vapor was generated above the liquid fuel surface, until ignition was observed. When ignited, the initial flame height was very small and the flame was observed to reside within the pan. With time, the liquid oil temperature increased and the fire grew with the flame height larger than 4 times the pan diameter due to the increased mass-burning rate of the fuel. Finally, the fuel began to visibly boil. Bubbling oil was observed overflowing the pan, falling onto the stovetop. Flames then spread along the stovetop, serving to heat the outside of the pan, further heat the oil and increase the heat release rate. The instantaneous flame height was larger than 10 times the diameter of the pan at the time of the peak heat release rate. As the oil was consumed, the fire size diminished and smoke from the fire appeared very dark. Finally, the fire extinguished due to complete consumption of the fuel. 


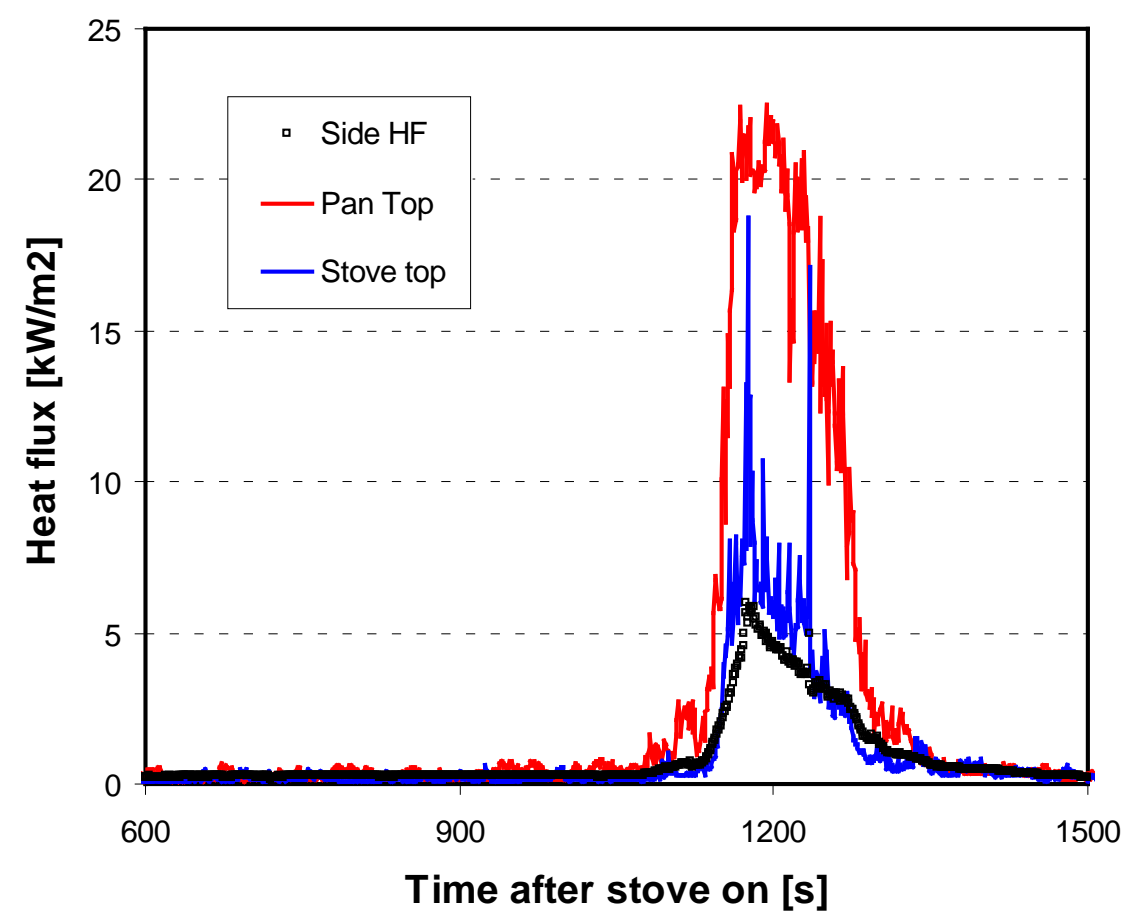

Figure 3-11. The measured heat flux at three positions near the stove (see Figure 3-1) during Test 1 (corn oil in Pan C).

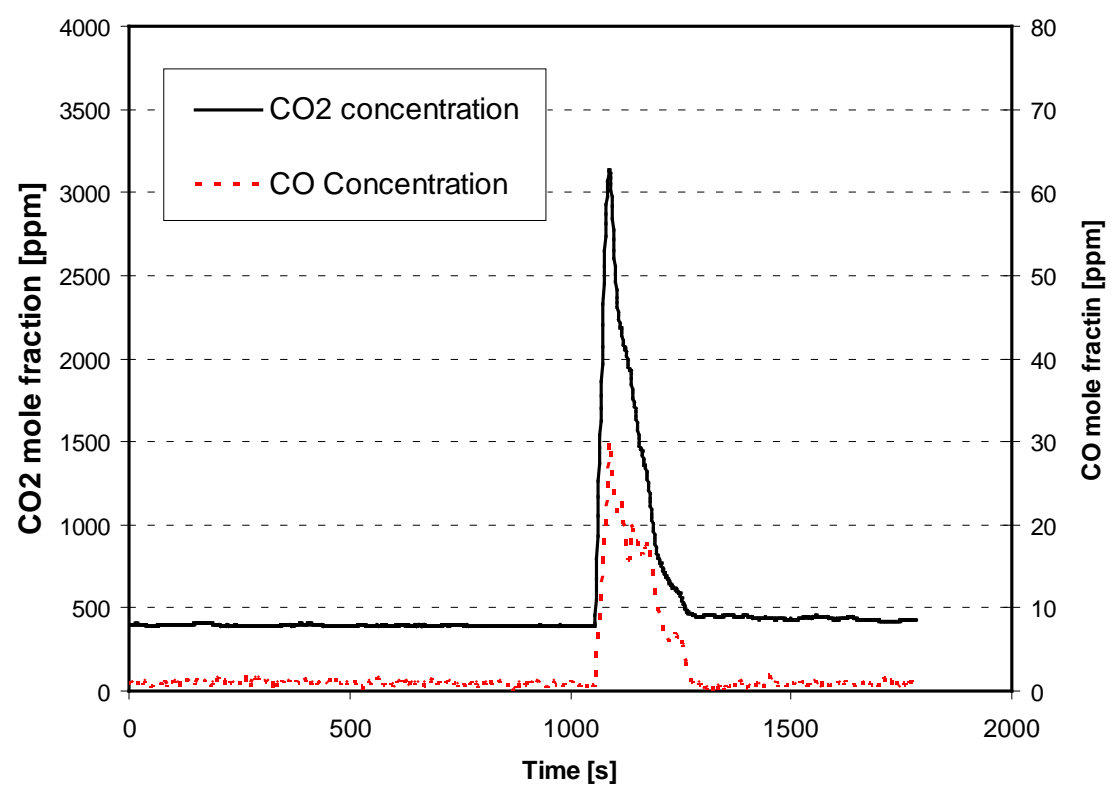

Figure 3-12. The measured $\mathrm{CO}$ and $\mathrm{CO}_{2}$ volume fraction in the exhaust hood as a function of time during Test 1 (corn oil in Pan $\mathrm{C}$ ). 
Figure 3-14 shows photographs of a corn oil fire in Pan B as a function of time along with the measured heat release rate during Test 3. Experimental observations of the ignition and initial fire characteristics were like the results shown in Figure 3-13 for Test 2, except there was a longer pre-heating time associated with the more massive Pan B. After ignition, the fire heat release rate steadily increased until it reached about $50 \mathrm{~kW}$, at which time the heat release rate rapidly increased to about $500 \mathrm{~kW}$ as the corn oil boiled and overflowed the pan. At that time, the fire was manually suppressed.

\subsection{Summary of Cooktop Fire Characterization Experiments}

Experiments were conducted to investigate the ignition and burning characteristics associated with the cooktop fire scenarios defined in UL300A. From a safety perspective, the pan with the smallest amount of oil (Pan C) was the easiest to ignite, because it did not require a long pre-heat time. Once the oil began to boil-over, the pan with the largest amount of oil (Pan B) appeared to be the most hazardous, producing a sudden jump in the heat release rate, flame height, and radiative flux. Although the stove was de-energized and hand-held portable $\mathrm{CO}_{2}$ fire extinguishers were deployed to suppress the fire, suppression efforts were fruitless once boilover occurred. This was a key lesson from this set of experiments.

The large value of the heat release rates and associated flame lengths were unexpected, considering that the steady burning heat release rate for a hydrocarbon (e.g., heptane) pool fire of the same diameter as used in these tests is typically an order of magnitude smaller than that measured here [17]. Using the value of the ratio of the heat of combustion to the latent heat of vaporization for corn oil (=54) [18], and applying the results shown in Fig. 12 in Ref. [17], the expected heat release rate for a steadily burning $0.1 \mathrm{~m}$ diameter corn oil pool fire was about $9 \mathrm{~kW}$, which is a factor of 11 times less than that measured during Test 2 (see Figure 3-13). Thus, a pool fire heated from below represents a significant fire hazard in terms of flame length, heat release rate, the potential to spread to nearby items and to injure people attempting to extinguish such a fire. This will be discussed further in the next section in terms of the full-scale experimental results.

A critical consideration in designing a strategy to mitigate stovetop fires is that suppression must be attempted at an early stage of fire development. An effective fire prevention strategy might consider detection of fuel vapor and de-energization of the stovetop, even before auto-ignition takes place. 


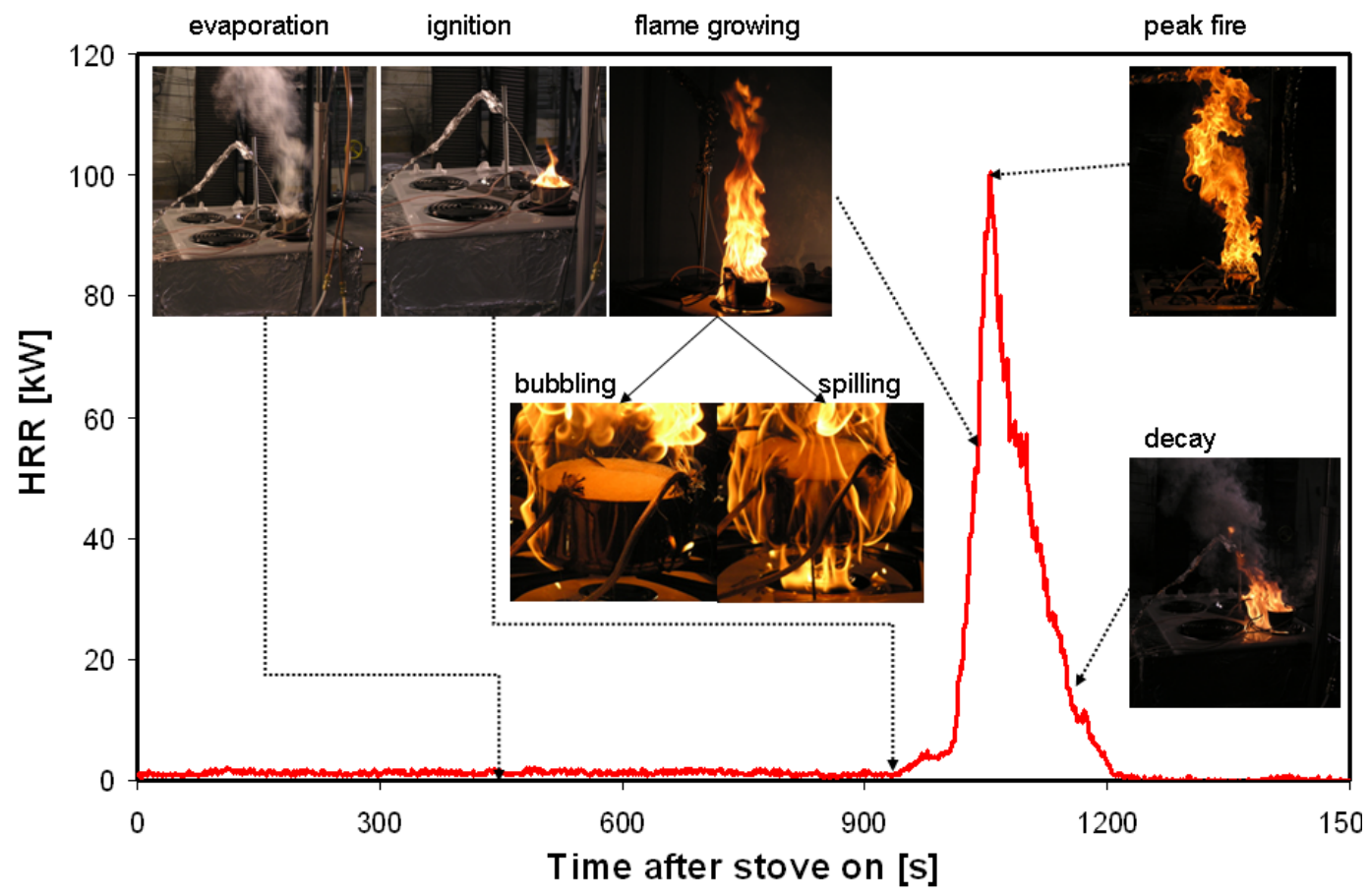

Figure 3-13. The measured heat release rate as a function of time during Test 2 (corn oil in Pan C). Photographs of the fire behavior are also shown.

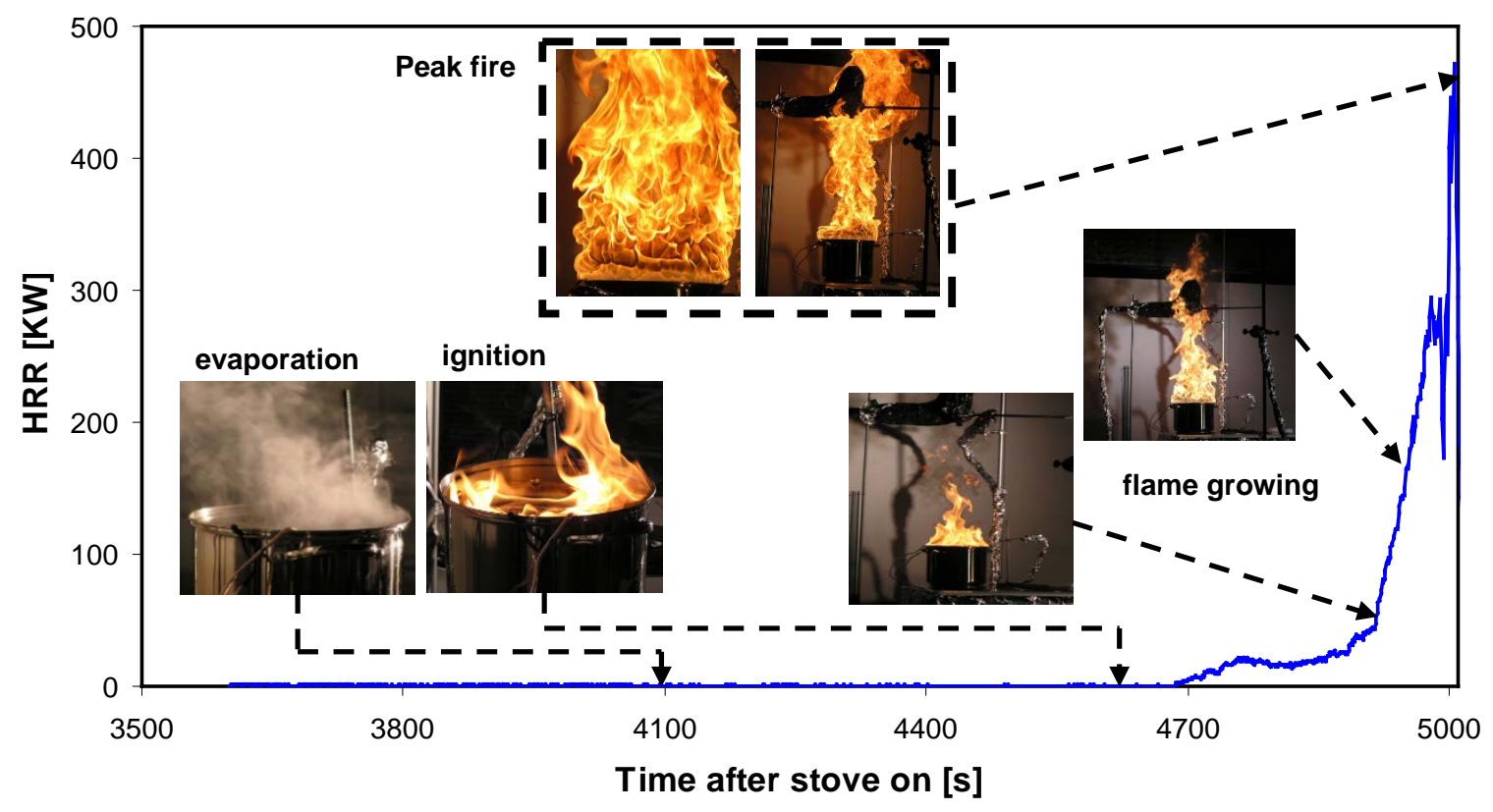

Figure 3-14. The measured heat release rate as a function of time during Test 3 (corn oil in Pan B). Photographs of the fire behavior are also shown. 


\section{Description of Kitchen Fire Suppression Experiments}

A series of laboratory experiments were designed to characterize the effectiveness of a variety of commercially available and prototype suppression systems on range-top cooking oil fires. Corn oil was used, as it was assessed to be an adequate representation of cooking oil used in the home.

The suppression systems tested included automatic and manual suppression technologies. The intent of these experiments was to identify factors which limited the success of suppression technologies in controlling and suppressing stove-top fires and maintaining occupant tenability. The experimental series included 42 tests and 11 different suppression devices. Room size, ventilation, the type and layout of room contents, and other factors can influence fire development and fire suppression. A representative configuration was selected for testing that included an open door, a moderately sized room, and the placement of cellulose-based cabinets adjoining the cooktop.

Heat flux, gas concentration, and temperature measurements were conducted to assess the tenability of the kitchen area before and during suppression. Several additional temperature measurements were made to document the progression of the oil heating and ignition process.

\subsection{Experimental Set-up and Procedure}

The fire suppression experiments were conducted using a full-scale residential kitchen arrangement. The dimensions of the test room were $3.6 \mathrm{~m} \mathrm{x} 3.4 \mathrm{~m} \mathrm{x} 2.4 \mathrm{~m}$ high. A doorway ( $0.90 \mathrm{~m}$ x $2.03 \mathrm{~m})$ provided ventilation and access to a partial "hallway" situated just outside the door (see

Figure 4-1). The entire room was situated under a large exhaust hood. The mock-up kitchen was built using two layers of $12.7 \mathrm{~mm}$ thick gypsum board over steel studs and joists and was furnished using typical materials. The room used vinyl sheet flooring over a nominal $19 \mathrm{~mm}$ plywood sub floor. The cabinets were vinyl covered medium density particle board with wooden doors. The counters were medium density particle board with a plastic laminate coating. A vent was located above the range in all tests. This vent was $0.54 \mathrm{~m}(1.8 \mathrm{ft})$ above the surface of the range and connected to an exhaust hood. In most tests, the fan was off or the duct system was removed to make room for the suppression system. Schematics of the test compartment and the arrangement of the room contents are shown in Figure 4-2 to Figure 4-4. 

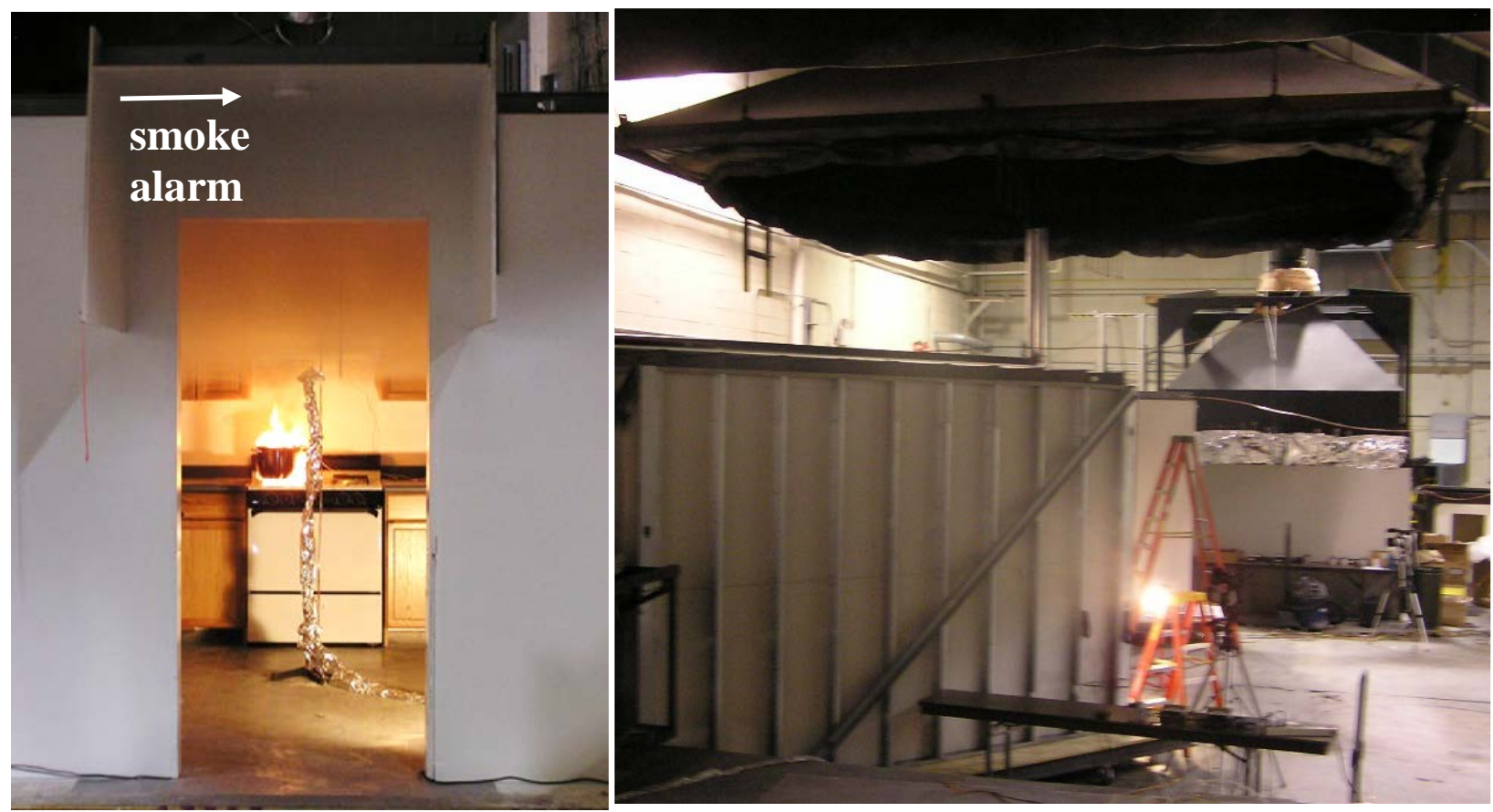

Figure 4-1. View of kitchen and adjoining hallway through doorway (left) and side view of the kitchen under a canopy exhaust hood (right). The burning corn oil on the stovetop and the smoke alarm outside the kitchen are visible in the image on the left.

Both gas and electric ranges were tested. The stoves were commercially available for residential use. Twenty-two of the forty-two tests were conducted using an electric range, which heated food using resistance coils; these tests were labeled with the abbreviation "KSE". The remaining twenty tests were conducted with a cooktop that heated food using natural gas flames; these tests were labeled with the abbreviation "KSG". The model of range used varied between experiments as did the output of the burners on those ranges, as specified in Table 4-1.

Both automatic and manual suppression system technologies were tested, including commercially available systems and systems under development. The manual devices included wet and dry chemical type extinguishers. The automatic systems included room-wide and range hood installed systems. The room wide systems included one water mist suppression system and one residential sprinkler system. The hood installed systems included water mist, wet chemical, and dry chemical suppression types. Many of the automatic suppression systems incorporated a device that disabled the cooktop power upon activation of the suppression system.

For the tests evaluating the automatic suppression systems, once the suppressant delivery system was activated, the scene was observed for several minutes to determine if re-ignition would occur. If it did occur, the fire was manually suppressed. In the 9 tests in which reignition occurred, the fire was allowed to burn for $100 \mathrm{~s}$, then suppressed manually using a handheld extinguisher. 
A skillet or pot containing 100\% corn oil was heated to auto-ignition. Several types of cooking pan were used as specified in UL 300A, holding different amounts of oil as characterized in the cooktop fire experiments reported in Section 3. They included cast iron and stainless steel skillets, and a stainless steel Dutch oven listed in Table 3-1. The results from Section 3 of this report suggest that these fires represent a significant tenability hazard.

Various instruments were used to measure the thermal environment and gas concentrations within the kitchen, enabling an assessment of tenability. Commercially available, single station, battery powered, ionization smoke alarms were installed on the ceiling at the center of the room and on the ceiling $0.3 \mathrm{~m}$ outside the doorway in the mock hallway as indicated in Figure 4-1. The alarm signal was connected to the data acquisition system, indicating the stage of fire development when occupants would be alerted.

Table 4-1. Power output of the electric and gas burners

\begin{tabular}{|c|c|c|c|c|c|}
\hline Suppression Type & Test & $\begin{array}{l}\text { Burner Output } \\
\text { (kW) }\end{array}$ & Suppression Type & Test & $\begin{array}{c}\text { Burner Output } \\
(\mathrm{kW})\end{array}$ \\
\hline \multirow{7}{*}{ Auto Wet Chem 1} & KSE 02 & 2.4 & \multirow{6}{*}{ Auto Dry Chem } & KSE 01 & 2.4 \\
\hline & KSE 03 & 2.4 & & KSE 14 & 1.5 \\
\hline & KSE 04 & 2.4 & & KSG 01 & 1.4 \\
\hline & KSG 02 & 1.4 & & KSG 11 & 1.4 \\
\hline & KSG 03 & 1.4 & & KSG 16 & 1.4 \\
\hline & KSG 04 & 1.4 & & KSG 17 & 1.4 \\
\hline & KSG 19 & 1.4 & \multirow{2}{*}{ Free Burn } & KSG 15 & 1.5 \\
\hline \multirow{7}{*}{ Auto Wet Chem 2} & KSE 06 & 2.4 & & KSG 20 & 1.4 \\
\hline & KSE 07 & 2.4 & \multirow{2}{*}{ Manual Dry Chem } & KSE 15 & 1.5 \\
\hline & KSE 08 & 2.4 & & KSG 12 & 1.4 \\
\hline & KSE 09 & 2.4 & \multirow{4}{*}{ Manual Wet Chem2 } & KSE 12 & 1.5 \\
\hline & KSG 05 & 1.4 & & KSE 13 & 1.5 \\
\hline & KSG 06 & 1.4 & & KSG 09 & 1.4 \\
\hline & KSG 07 & 1.4 & & KSG 10 & 1.4 \\
\hline \multirow{3}{*}{ Auto Wet Chem 3} & KSE 05 & 2.4 & \multirow{2}{*}{ Sprinkler } & KSE 17 & 1.5 \\
\hline & KSG 08 & 1.4 & & KSG 14 & 1.4 \\
\hline & KSG 18 & 1.4 & \multirow{2}{*}{ Water Mist 1} & KSE 16 & 1.5 \\
\hline \multirow{6}{*}{ Auto Wet Chem 4} & KSE 10 & 2.4 & & KSG 13 & 1.4 \\
\hline & KSE 11 & 2.4 & \multirow{2}{*}{ Water Mist 2} & KSE 18 & 1.5 \\
\hline & KSE 21 & 2.4 & & KSE 19 & 1.5 \\
\hline & KSE 22 & 2.4 & Water Mist 3 & KSE 20 & 1.5 \\
\hline & \multicolumn{5}{|c|}{ Electric Range } \\
\hline & \multicolumn{5}{|c|}{ Gas Range } \\
\hline
\end{tabular}


Each cooktop surface had 4 burners, only one of which was used during a single test. Table 4-2 lists the specified maximum power output of the burners, which was $2.6 \mathrm{~kW}$ for the electric stoves and varied from $2.8 \mathrm{~kW}$ to $3.5 \mathrm{~kW}$ for the natural gas stoves. The burner, pan, and volume of oil used in each test are presented in Table 4-2. All tests used corn oil. Three types of cooking pans were used in these experiments. In 33 of the tests, Pan B was used, which was a $25 \mathrm{~cm}$ diameter, $18 \mathrm{~cm}$ deep stainless steel pot that was filled with $4.5 \mathrm{~L}$ of oil. In 9 tests, Pan A was used and Pan C was used once. Pan A was a $30 \mathrm{~cm}$ diameter, $6 \mathrm{~cm}$ deep cast iron skillet filled with $1.62 \mathrm{~L}$ of oil and Pan $\mathrm{C}$ was a $25 \mathrm{~cm}$ diameter, $5 \mathrm{~cm}$ deep filled with $0.5 \mathrm{~L}$ of oil. To shorten the time to achieve auto-ignition, an extra torch was applied to the bottom portion of the cooking pan during the early part of some of the tests. By monitoring the cooking oil temperature, the supplemental heating was removed at least 10 min before auto-ignition was achieved.

Two experiments were "free burns," in which the fire burned unabated. In those experiments, fire spread to the surrounding cabinets and other flammable materials (such as items in the range hood) and flashover occurred.

Since the experiments were conducted over the course of a year, the ambient temperature and relative humidity significantly varied among the tests. These variables were recorded during each of the experiments, as listed in Appendix 2. The ambient temperature and relative humidity were not found to have a significant correlation to any of the experimental results. 


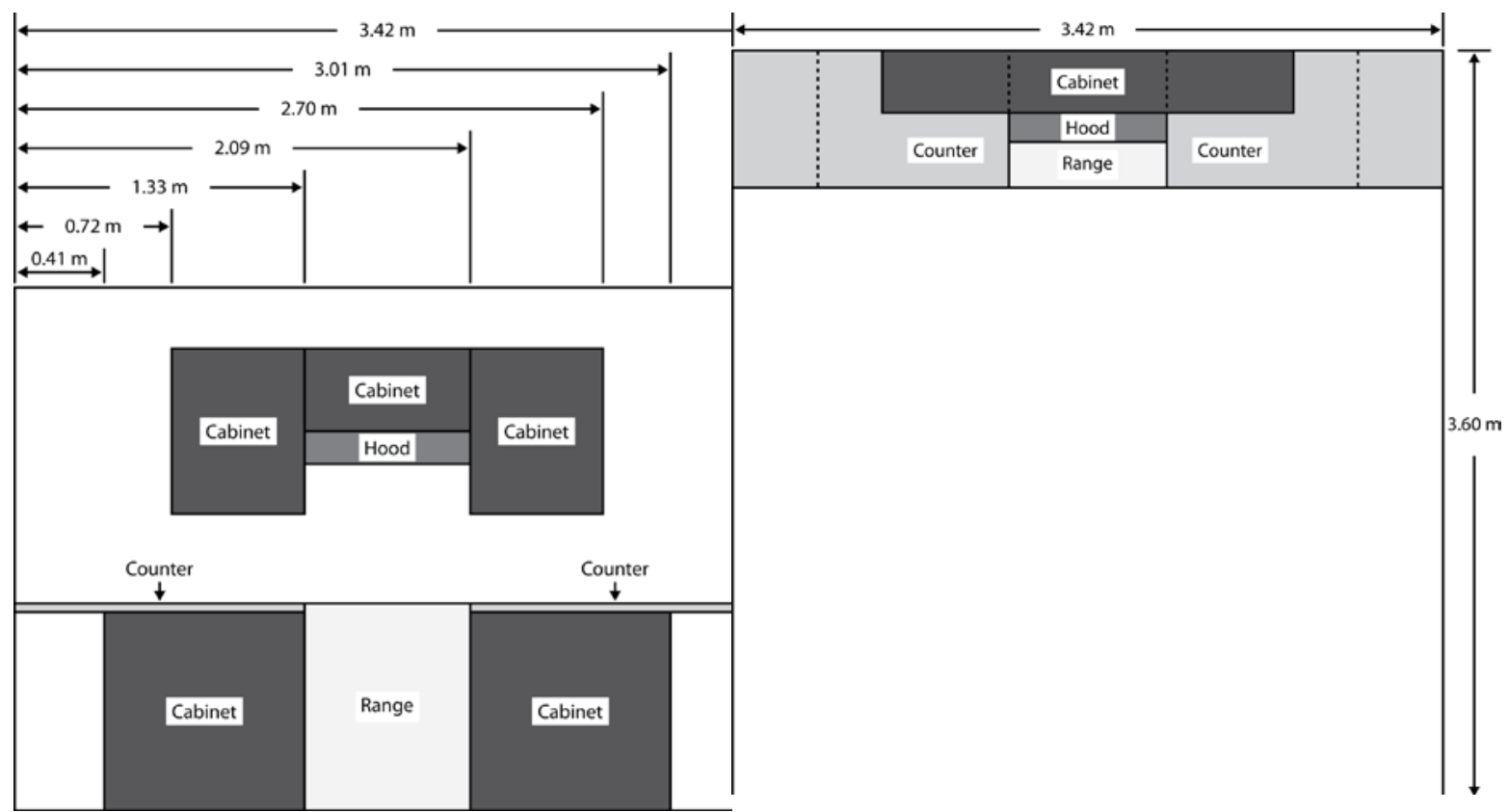

Figure 4-2. Elevation view schematic with dimensions of the mock kitchen looking

Figure 4-3. Plan view schematic with dimensions toward the range

\section{of the mock kitchen}

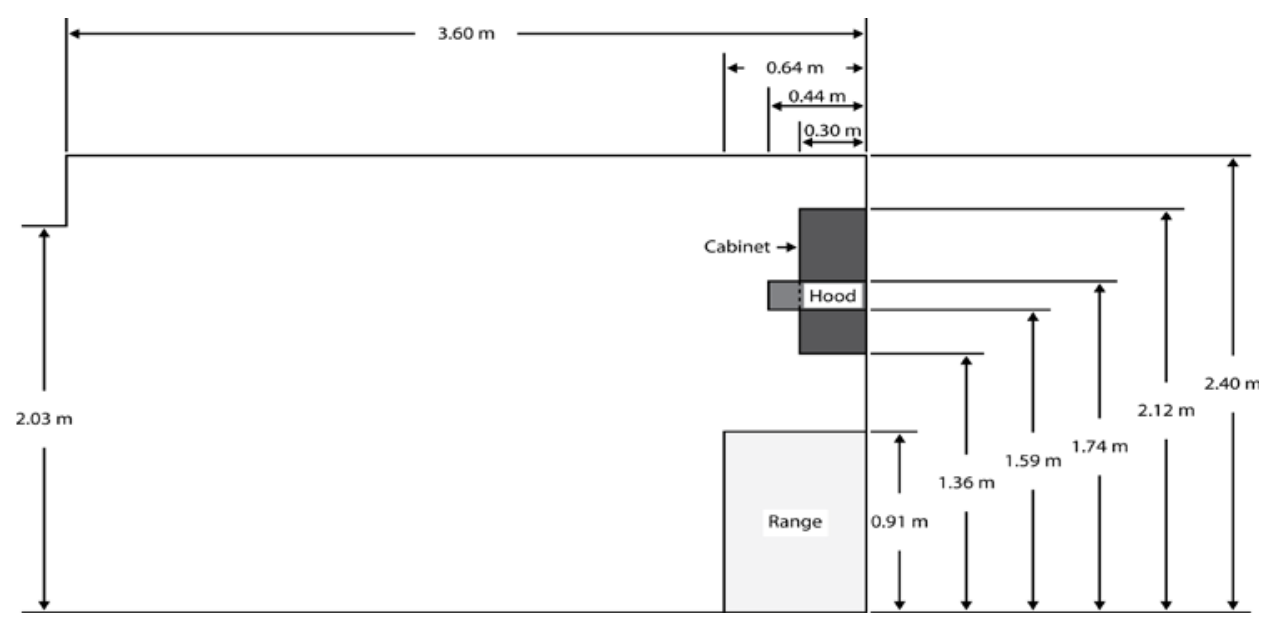

Figure 4-4. Elevation view schematic with dimensions of the mock kitchen oriented parallel to the countertop 
Table 4-2. Experimental arrangement including, the burner, pan, and volume of fuel

\begin{tabular}{|c|c|c|c|c|c|c|c|c|c|}
\hline $\begin{array}{c}\text { Suppressant } \\
\text { Type }\end{array}$ & Test & Burner* & $\mathrm{Pan}^{+}$ & Fuel & $\begin{array}{c}\text { Suppressant } \\
\text { Type }\end{array}$ & Test & Burner* & $\mathrm{Pan}^{+}$ & Fuel \\
\hline \multirow{7}{*}{$\begin{array}{l}\text { Auto Wet } \\
\text { Chem } 1\end{array}$} & KSE 02 & $\mathrm{FL}$ & Pan B & $4.5 \mathrm{~L}$ & \multirow{2}{*}{ Free Burn } & KSG 15 & FR & Pan B & $4.5 \mathrm{~L}$ \\
\hline & KSE 03 & $\mathrm{FL}$ & Pan B & $4.5 \mathrm{~L}$ & & KSG 20 & FR & Pan A & $1.6 \mathrm{~L}$ \\
\hline & KSE 04 & $\mathrm{RR}$ & Pan B & $4.5 \mathrm{~L}$ & \multirow{2}{*}{$\begin{array}{l}\text { Manual Dry } \\
\text { Chem }\end{array}$} & KSE 15 & FR & Pan B & $4.5 \mathrm{~L}$ \\
\hline & KSG 02 & $\mathrm{FL}$ & Pan B & $4.5 \mathrm{~L}$ & & KSG 12 & FR & Pan B & $4.5 \mathrm{~L}$ \\
\hline & KSG 03 & $\mathrm{FL}$ & Pan B & $4.5 \mathrm{~L}$ & \multirow{4}{*}{$\begin{array}{l}\text { Manual Wet } \\
\text { Chem }\end{array}$} & KSE 12 & FR & Pan B & $4.5 \mathrm{~L}$ \\
\hline & KSG 04 & $\mathrm{RL}$ & Pan B & $4.5 \mathrm{~L}$ & & KSE 13 & FR & Pan B & $4.5 \mathrm{~L}$ \\
\hline & KSG 19 & FR & Pan B & $1.6 \mathrm{~L}$ & & KSG 09 & FR & Pan B & $4.5 \mathrm{~L}$ \\
\hline \multirow{7}{*}{$\begin{array}{l}\text { Auto Wet } \\
\text { Chem } 2\end{array}$} & KSE 06 & $\mathrm{FL}$ & Pan B & $4.5 \mathrm{~L}$ & & KSG 10 & FR & Pan B & $4.5 \mathrm{~L}$ \\
\hline & KSE 07 & $\mathrm{FL}$ & Pan B & $4.5 \mathrm{~L}$ & \multirow{2}{*}{ Sprinkler } & KSE 17 & $\mathrm{RL}$ & Pan B & $4.5 \mathrm{~L}$ \\
\hline & KSE 08 & RR & Pan B & $4.5 \mathrm{~L}$ & & KSG 14 & FR & Pan B & $4.5 \mathrm{~L}$ \\
\hline & KSE 09 & $\mathrm{RR}$ & Pan B & $4.5 \mathrm{~L}$ & \multirow{2}{*}{ Water Mist 1} & KSE 16 & $\mathrm{RL}$ & Pan B & $4.5 \mathrm{~L}$ \\
\hline & KSG 05 & $\mathrm{FL}$ & Pan B & $4.5 \mathrm{~L}$ & & KSG 13 & FR & Pan B & $4.5 \mathrm{~L}$ \\
\hline & KSG 06 & $\mathrm{FL}$ & Pan B & $4.5 \mathrm{~L}$ & \multirow{2}{*}{ Water Mist 2} & KSE 18 & FR & Pan A & $1.6 \mathrm{~L}$ \\
\hline & KSG 07 & $\mathrm{RR}$ & Pan B & $4.5 \mathrm{~L}$ & & KSE 19 & FR & Pan A & $1.6 \mathrm{~L}$ \\
\hline \multirow{3}{*}{$\begin{array}{l}\text { Auto Wet } \\
\text { Chem } 3\end{array}$} & KSE 05 & $\mathrm{FL}$ & Pan B & $4.5 \mathrm{~L}$ & Water Mist 3 & KSE 20 & FR & Pan A & $1.6 \mathrm{~L}$ \\
\hline & KSG 08 & $\mathrm{FL}$ & Pan B & $4.5 \mathrm{~L}$ & \multirow{6}{*}{$\begin{array}{l}\text { Auto Dry } \\
\text { Chem }\end{array}$} & KSE 01 & $\mathrm{FL}$ & Pan B & $4.5 \mathrm{~L}$ \\
\hline & KSG 18 & FR & Pan A & $1.6 \mathrm{~L}$ & & KSE 14 & FR & Pan B & $4.5 \mathrm{~L}$ \\
\hline \multirow{4}{*}{$\begin{array}{l}\text { Auto Wet } \\
\text { Chem } 4\end{array}$} & KSE 10 & $\mathrm{FL}$ & Pan B & $4.5 \mathrm{~L}$ & & KSG 01 & $\mathrm{FL}$ & Pan B & $4.5 \mathrm{~L}$ \\
\hline & KSE 11 & $\mathrm{FL}$ & Pan B & $4.5 \mathrm{~L}$ & & KSG 11 & FR & Pan B & $4.5 \mathrm{~L}$ \\
\hline & KSE 21 & $\mathrm{FL}$ & Pan A & $1.6 \mathrm{~L}$ & & KSG 16 & FR & Pan A & $1.6 \mathrm{~L}$ \\
\hline & KSE 22 & $\mathrm{FL}$ & Pan B & $4.5 \mathrm{~L}$ & & KSG 17 & FR & Pan C & $0.5 \mathrm{~L}$ \\
\hline \multicolumn{2}{|c|}{ * Burner Positions: } & $\mathrm{O}$ & $\mathbf{R R}$ & & \multicolumn{5}{|c|}{$\begin{array}{l}\text { + Pan A: Cast Iron } 33 \mathrm{~cm} \mathrm{dia.;} 5 \mathrm{~cm} \text { deep } \\
\text { + Pan B: Stainless Steel } 25 \mathrm{~cm} \text { dia.; } 18 \mathrm{~cm} \text { deep } \\
\text { + Pan C: Stainless Steel } 10 \mathrm{~cm} \text { dia.; } 5 \mathrm{~cm} \text { deep }\end{array}$} \\
\hline
\end{tabular}

\subsection{Instrumentation}

Thermocouples and total heat flux gauges were used to measure the thermal environment within the mock kitchen. The temperature of the cooking oil was measured by a thermocouple suspended within the oil; this thermocouple was similarly placed during every experiment.

The instrumentation locations are schematically shown in Figure 4-5, Figure 4-6, and Figure 4-7. The arrangement was similar for all tests. A linear array of thermocouples stretching from ceiling to floor was used to measure the gas temperature at various heights in the room. The array was located on the centerline of the room, $0.97 \mathrm{~m}$ (3.2 ft) from the range. Type K thermocouples were used with a $0.51 \mathrm{~mm}$ (0.02 in) bare-bead nominal diameter. The thermocouples were 
located $0.025 \mathrm{~m}, 0.305 \mathrm{~m}, 0.610 \mathrm{~m}, 0.920 \mathrm{~m}, 1.22 \mathrm{~m}, 1.52 \mathrm{~m}, 1.83 \mathrm{~m}$, and $2.13 \mathrm{~m}$ (nominally, $1 \mathrm{in}, 1.0 \mathrm{ft}, 2.0 \mathrm{ft}, 3.0 \mathrm{ft}, 4.0 \mathrm{ft}, 5.0 \mathrm{ft}, 6.0 \mathrm{ft}$, and $7.0 \mathrm{ft}$ ) below the ceiling.

Total heat flux measurements were made with water-cooled Schmidt-Boelter gauges. One Schmidt-Boelter total heat flux gauge was installed facing the range on the centerline of the room, $1.19 \mathrm{~m}(3.90 \mathrm{ft})$ from the range and $1.52 \mathrm{~m}(5.00 \mathrm{ft})$ above the floor of the structure, or $0.92 \mathrm{~m}$ ( $2.87 \mathrm{ft}$ ) below the ceiling. Another gauge was installed in the upper cabinets facing the range. Each had a maximum heat flux range of $57 \mathrm{~kW} / \mathrm{m}^{2}\left(5 \mathrm{Btu} / \mathrm{ft}^{2} \cdot \mathrm{s}\right)$.

Gas concentrations were sampled from a port located about the centerline of the room, $1.19 \mathrm{~m}(3.90 \mathrm{ft})$ from the range and $1.52 \mathrm{~m}(5.00 \mathrm{ft})$ above the floor of the structure. The sampling lines were connected to calibrated vacuum pumps which moved the gas samples through a conditioning manifold, which consisted of two in-line filtered cold traps to remove soot particles and moisture. The sampling line had a nominal internal diameter of $9.5 \mathrm{~mm}$. The cold traps were approximately $190 \mathrm{~mm}$ long with an internal diameter of $60 \mathrm{~mm}$ for an approximate volume of $500 \mathrm{~cm}^{3}$ for each trap. The sampling system volume was minimized to avoid damping important peak values in the gas concentration measurements. The volume of each cold trap was reduced by approximately $70 \%$ with the addition of glass wool and glass beads [19]. The dry gas samples were drawn through a series of gas analyzers. Oxygen was measured using a paramagnetic analyzer, while carbon monoxide and carbon dioxide were measured using non-dispersive infrared analyzers. 


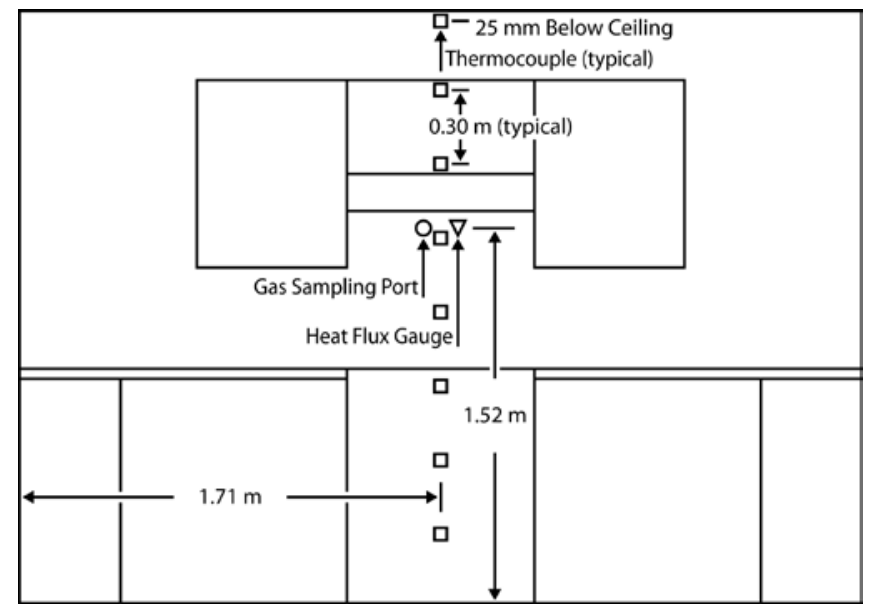

Figure 4-5. Elevation view schematic with instrumentation, oriented toward the range

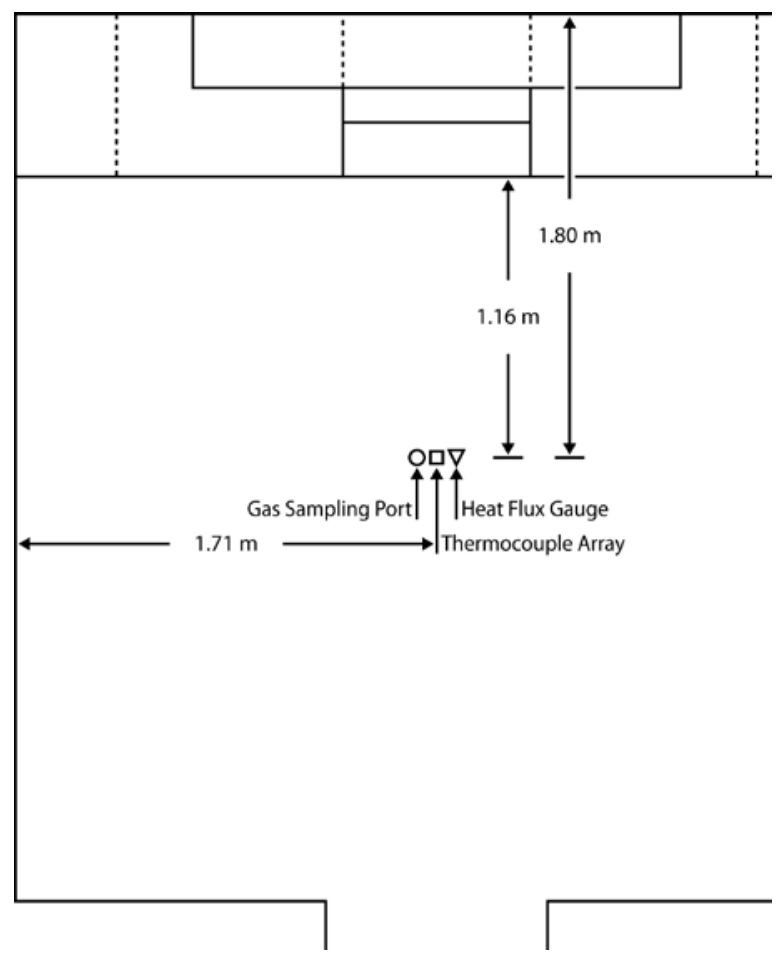

Figure 4-6. Plan view schematic with instrumentation

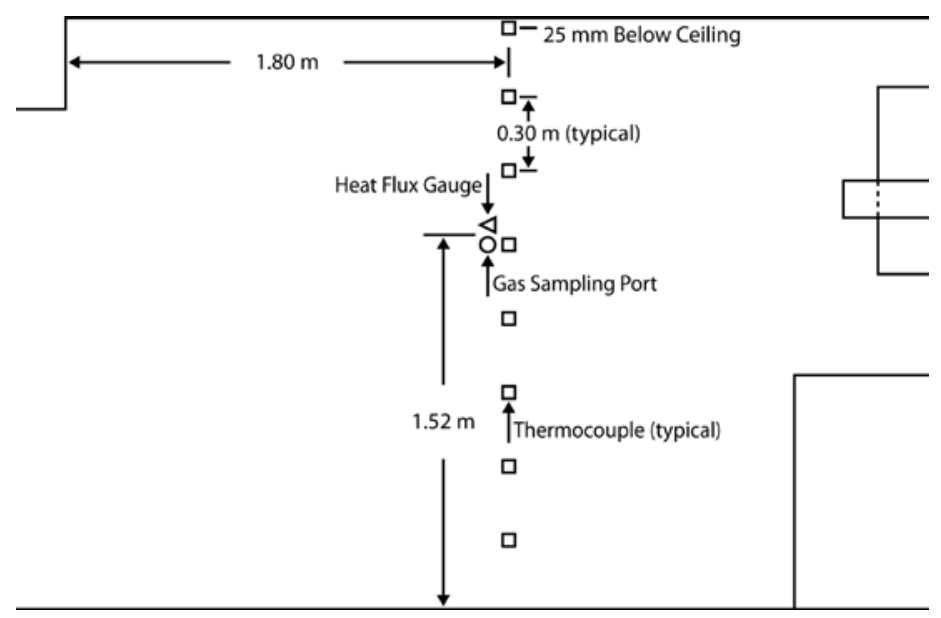

Figure 4-7. Elevation view schematic with instrumentation, oriented parallel to the countertop 


\subsection{Measurement Uncertainty}

There are different components of uncertainty in the mass, length, temperature, heat flux, gas concentrations, mass and flow rate described in this report. Unless otherwise stated, uncertainty is reported as the expanded uncertainty with an expansion factor of 2 . The expanded uncertainties are composed of two components involving statistical methods typically measurement variance and estimates of systematic factors such as instrument specifications (or estimates of instrument uncertainty) [12].

Length measurements such as the room dimensions and instrumentation array locations, were made with a tape measure with a resolution of $\pm 0.5 \mathrm{~mm}(0.02 \mathrm{in})$. Conditions affecting the measurement, such as levelness or tautness of the device, yield an estimated uncertainty of $\pm 0.5 \%$ for measurements in the 0 to $3.0 \mathrm{~m}(9.8 \mathrm{ft}$ ) range. For longer distances (in excess of 3.0 $\mathrm{m}$ or $9.8 \mathrm{ft}$ ), the expanded uncertainty was estimated as $\pm 1 \%$.

The standard uncertainty in the measured thermocouple temperature was $\pm 2.2^{\circ} \mathrm{C}$ at $277^{\circ} \mathrm{C}$, increasing to $\pm 9.5^{\circ} \mathrm{C}$ at $871{ }^{\circ} \mathrm{C}$ as specified by the manufacturer [11]. Temperature variance in the zone near the thermocouple is typically much greater than that of the wire uncertainty [20, 21]. And radiation effects in a compartment can significantly impact the measured reading much more than that of the wire uncertainty $[20,21]$. Small diameter thermocouples $(0.5 \mathrm{~mm}$ diameter) were used to limit the impact of radiative heating and cooling in the compartment. The expanded uncertainty for temperature in these experiments was typically $\pm 15 \%$, which was dominated by measurement variance.

The total heat flux gauges had a manufacturer reported expanded calibration uncertainty of $\pm 3 \%$ [13]. A comprehensive international study on total heat flux gauge calibration and response demonstrated that the expanded uncertainty of heat flux gauges is typically $\pm 8 \%$ [14] .

Gas measurement instrumentation and sampling system used in this series of experiments have an expanded uncertainty of about $\pm 1 \%$ when compared with calibration span gases.

Measurement variance determined through repeat measurements in a typical room fire dominate the expanded uncertainty which is typically $\pm 10 \%[19,22]$.

In the following sections, the measurements are presented in graphic and tabular form with a measurement uncertainty as described above.

\section{Experimental Results}

This section presents the results of the kitchen fire experiments. First, the suppression system technologies are characterized in terms of suppressant delivery. Then, Section 4.4.2 describes the results of the fire suppression measurements. Sections 4.4.3 and 4.4.4 discuss the performance of the systems are considered in terms of room tenability including heat flux, temperature, fuel containment and fuel spatter. Measurements on the effect of the hood fan on 
the wet chemical agent performance is examined in Section 4.4.5. Section 4.4.6 discusses the measurements of the effectiveness of smoke alarms in providing warning to occupants about the impending oil fires.

\subsection{Suppression System Effectiveness}

The performance of the suppression systems was tested on the oil fires. Data collected during the experiments are presented in Appendix 1 for each test. The results include the experimental timelines based on observations (e.g., time to auto-ignition and suppression system activation times), temperature measurements, gas concentrations, and heat flux measurements.

The results of the suppression experiments are summarized in Table 5-1. Auto-ignition took a significant amount of time to occur and depended on the burner power, the mass of the pan, the mass of oil, and other factors. In a few experiments, a torch was used to hasten heat-up. On the electric stovetop, auto-ignition in Pan B (the stainless steel Dutch oven with 4.5 L of oil) and Pan A (the cast iron skillet with $1.6 \mathrm{~L}$ of oil) required about $62 \mathrm{~min}( \pm 13 \mathrm{~min})$ and $46 \mathrm{~min}( \pm 12$ min), respectively. On the gas stovetop, auto-ignition in Pan A and Pan B required about 89 min ( $\pm 12 \mathrm{~min}$ ) and $37 \mathrm{~min}$ ( $\pm 5 \mathrm{~min})$, respectively.

The time of suppressant deployment for both automatic and manually controlled systems are listed in the table as well as the outcome of suppressant delivery. The suppression systems were allowed to fully discharge. Successful extinguishment was confirmed if flaming combustion ceased and the oil cooled to below the auto-ignition temperature. In several tests, the suppression system extinguished the fire for a short period, but not long enough to allow the oil to cool below the auto-ignition temperatures, resulting in reignition. In other tests, the suppression system failed to disrupt the combustion of oil and the fire was not suppressed. Of the 40 suppression experiments, suppression was accomplished $40 \%$ of the time (17 tests) and unsuccessful in $30 \%$ of the cases (12 tests). In $23 \%$ of the tests (9 tests), the fire was successfully extinguished, but reignition occurred. In 2 tests (5\%), the suppression devices did not activate (KSE05 and KSE08) and the fire was manually extinguished. There were an additional two free burns" during which suppression was not attempted (KSG 15 and KSG 20). During the free burns, the oil fire was allowed to spread to the surrounding furnishings.

On average, suppressant activation initially occurred $84 \mathrm{~s}$ and $158 \mathrm{~s}$ after ignition for cases in which the fire was extinguished and not extinguished, respectively. Thus, extinguishment was associated with earlies suppressant activation. Manual suppression of the oil fires using the wet and dry chemicals were successful on every attempt with 6 tests in total (2 dry chemical and 4 wet chemical). The automatically delivered wet chemical was used to suppress the fire on every attempt with 7 tests in total (3 electric and 4 gas). There was only one test of Water Mist System 3, which was successful. The other two water mist systems tested did not successfully suppress the fires. 
Table 5-1. Time of suppression system deployment after ignition and its outcome

\begin{tabular}{|c|c|c|c|c|c|c|c|}
\hline Type & Test & $\begin{array}{c}\text { Time } \\
(\mathrm{s})^{*}\end{array}$ & Outcome & Type & Test & $\begin{array}{c}\text { Time } \\
\text { (s) }\end{array}$ & Outcome \\
\hline \multirow{2}{*}{$\begin{array}{l}\text { Water } \\
\text { Mist } 1\end{array}$} & KSE 16 & 129 & Not Extinguished & \multirow{7}{*}{$\begin{array}{c}\text { Auto } \\
\text { Wet } \\
\text { Chem } 1\end{array}$} & KSE 02 & 61 & Extinguished \\
\hline & KSG 13 & 294 & Not Extinguished & & KSE 03 & 102 & Extinguished \\
\hline Water & KSE 18 & 86 & Not Extinguished & & KSE 04 & 47 & Extinguished \\
\hline Mist 2 & KSE 19 & 78 & Not Extinguished & & KSG 02 & 118 & Extinguished \\
\hline $\begin{array}{l}\text { Water } \\
\text { Mist } 3\end{array}$ & KSE 20 & 92 & Extinguished & & KSG 03 & 74 & Extinguished \\
\hline \multirow{2}{*}{$\begin{array}{l}\text { Manual } \\
\text { Dry Chem }\end{array}$} & KSE 15 & 69 & Extinguished & & KSG 04 & 181 & Extinguished \\
\hline & KSG 12 & 73 & Extinguished & & KSG 19 & 92 & Extinguished \\
\hline \multirow{4}{*}{$\begin{array}{l}\text { Manual } \\
\text { Wet Chem }\end{array}$} & KSE 12 & 63 & Extinguished & \multirow{6}{*}{$\begin{array}{c}\text { Auto } \\
\text { Wet } \\
\text { Chem } 2\end{array}$} & KSE 06 & 206 & Re-Ignition \\
\hline & KSE 13 & 63 & Extinguished & & KSE 07 & 192 & Re-Ignition \\
\hline & KSG 09 & 65 & Extinguished & & KSE 09 & 131 & Re-Ignition \\
\hline & KSG 10 & 61 & Extinguished & & KSG 05 & 149 & Re-Ignition \\
\hline \multirow{2}{*}{ Sprinkler } & KSE 17 & 176 & Extinguished & & KSG 06 & 84 & Extinguished \\
\hline & KSG 14 & 307 & Not Extinguished & & KSG 07 & 178 & Re-Ignition \\
\hline \multirow{6}{*}{$\begin{array}{l}\text { Auto Dry } \\
\text { Chem }\end{array}$} & KSE 01 & 171 & Not Extinguished & \multirow{2}{*}{$\begin{array}{c}\text { Auto } \\
\text { Wet } \\
\text { Chem } 3 \\
\end{array}$} & KSG 08 & 140 & Re-Ignition \\
\hline & KSE 14 & 198 & Not Extinguished & & KSG 18 & 160 & Re-Ignition \\
\hline & KSG 01 & 111 & Re-Ignition & \multirow{4}{*}{$\begin{array}{c}\text { Auto } \\
\text { Wet } \\
\text { Chem } 4\end{array}$} & KSE 10 & 46 & Not Extinguished \\
\hline & KSG 11 & 229 & Not Extinguished & & KSE 11 & 144 & Not Extinguished \\
\hline & KSG 16 & 116 & Not Extinguished & & KSE 21 & 5 & Extinguished \\
\hline & KSG 17 & 57 & Re-Ignition & & KSE 22 & 102 & Not Extinguished \\
\hline
\end{tabular}

Although Wet Chem 1 was most effective, Wet Chem 2 and 3 also extinguished all the fires but most of the time, these fires re-ignited. Wet Chem 4 was less successful despite its relatively large average delivery rate - possibly due to the large spatial variance of the suppressant application (see Table 2-2).

The discussion below considers tenability in terms of benchmark values for thermal injury and incapacitation due to inhalation of combustion products. A qualitative discussion of additional hazards including oil spatter, fire containment, and visibility is also presented.

\subsection{Tenability}

Burn injuries can be caused by convection of combustion products (such as hot gases and smoke) and by radiative heat transfer. The hazard related to heat transfer from a fire environment to an object or human body can be simplified as an exposure temperature for a prescribed duration. 
UL 1626 specifies estimated practical limits for tenability based on temperature. Two limits are specified: a limit at which tenability is instantly compromised and a limit at which tenability is compromised after 2 min of exposure. The estimated instantaneous and 2 min* tenability limits due to temperature are $54{ }^{\circ} \mathrm{C}\left(130^{\circ} \mathrm{F}\right)$ and $93^{\circ} \mathrm{C}\left(200^{\circ} \mathrm{F}\right)$, respectively [16]. The SFPE Handbook of Fire Protection Engineering estimates the tenability limit due to heat flux as $2.5 \mathrm{~kW} / \mathrm{m}^{2}$ for which the time to burn unprotected skin is less than $20 \mathrm{~s}$ [23]. These limits are not absolute, since clothing, humidity, skin composition, and other factors can mitigate or exacerbate the impact of the thermal energy for a given heat level and exposure time. These values are helpful benchmarks and are considered here.

Based on individual exposures, incapacitation can occur due to low oxygen (10\% to $13 \%$ ) or a high level of carbon dioxide (7 \% to $8 \%$ ) or carbon monoxide (0.6 \% to $0.8 \%$ ) after approximately a 5 min exposure [16]. Lower concentrations of oxygen and higher concentrations of carbon dioxide and carbon monoxide, or synergistic effects involving all multiple combustion products can lead to incapacitation in a shorter time. Following the SFPE Handbook, the following values are taken as the limits of tenability: oxygen $<10 \%$, carbon dioxide $>8 \%$, or carbon monoxide $>1 \%$. Measurements were made of the temperature, heat flux, and gas

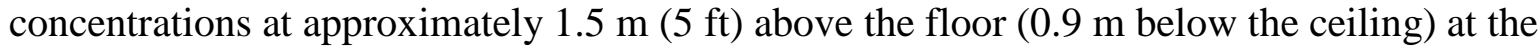
center of the room. This elevation can be considered face height of a typical, standing person. Table 5-2 lists the tests when the tenability limits based on heat flux or temperature were exceeded. In the table, "Time" is the time elapsed between ignition and when the tenability limit was first exceeded.

Tenability limits for low oxygen, elevated levels of carbon monoxide, or elevated levels of carbon dioxide were not reached in any of the tests. All these conditions, however, are dependent upon the amount of ventilation in the kitchen, as well as the volume of the room. Under realistic conditions, these factors could vary significantly from these experiments. Of the 38 suppression experiments in the table, the instantaneous temperature tenability limit of $54{ }^{\circ} \mathrm{C}$ $\left(130^{\circ} \mathrm{F}\right.$ ) was exceeded 5 times (or $13 \%$ ), whereas the 2 min temperature tenability limit of $93^{\circ} \mathrm{C}\left(200^{\circ} \mathrm{F}\right)$ was exceeded only twice (or $5 \%$ ) - both times only after the suppression system had activated. The heat flux tenability limit was exceeded 16 times (or $42 \%$ ). Temperature and heat flux tenability limits were exceeded for the free burn tests in the table, which provide a reference for the other gas stovetop tests. Of the 17 tests in which suppression was successful, tenability limits were exceeded in 3 of those cases. Temperature based tenability limits were exceeded only by the water-based suppression systems. For the two free burn experiments, the limits of tenability were exceeded $350 \mathrm{~s}$ and $160 \mathrm{~s}$ after ignition.

\footnotetext{
* the two min tenability limit requires that the temperature be above $93^{\circ} \mathrm{C}$ for a two min period.
} 
Table 5-2. Tenability

\begin{tabular}{|c|c|c|c|c|c|c|c|c|c|c|c|}
\hline Type & Test & Instant $^{\mathrm{a}}$ & $2 \min ^{b}$ & $\begin{array}{l}\text { Heat } \\
\text { Flux }\end{array}$ & $\begin{array}{c}\text { Timed }^{d} \\
(s)\end{array}$ & Type & Test & Instant & $2 \mathrm{~min}$ & $\begin{array}{l}\text { Heat } \\
\text { Flux }\end{array}$ & $\begin{array}{c}\text { Time } \\
(s)\end{array}$ \\
\hline \multirow{2}{*}{ Sprinkler } & KSE17 & $\mathrm{No}^{\mathrm{e}}$ & No & Yes $^{e}$ & 169 & \multirow{6}{*}{$\begin{array}{l}\text { Auto Wet } \\
\text { Chem } 2\end{array}$} & KSE06 & No & No & Yes & 209 \\
\hline & KSG14 & Yes & Yes & Yes & 307 & & KSE07 & No & No & Yes & 194 \\
\hline \multirow{2}{*}{$\begin{array}{l}\text { Water } \\
\text { Mist } 1\end{array}$} & KSE16 & Yes & Yes & Yes & 145 & & KSE09 & No & No & No & \\
\hline & KSG13 & Yes & No & Yes & 315 & & KSG05 & No & No & No & \\
\hline \multirow{2}{*}{$\begin{array}{l}\text { Water } \\
\text { Mist } 2\end{array}$} & KSE18 & Yes & No & Yes & 73 & & KSG06 & No & No & No & \\
\hline & KSE19 & No & No & Yes & 162 & & KSG07 & No & No & Yes & 176 \\
\hline $\begin{array}{l}\text { Water } \\
\text { Mist } 3\end{array}$ & KSE20 & Yes & No & Yes & 70 & \multirow{2}{*}{$\begin{array}{l}\text { Auto Wet } \\
\text { Chem } 3\end{array}$} & KSG08 & No & No & No & \\
\hline \multirow{7}{*}{$\begin{array}{l}\text { Auto Wet } \\
\text { Chem } 1\end{array}$} & KSE02 & No & No & No & & & KSG18 & No & No & No & \\
\hline & KSE03 & No & No & No & & \multirow{4}{*}{$\begin{array}{l}\text { Auto Wet } \\
\text { Chem } 4\end{array}$} & KSE10 & No & No & No & \\
\hline & KSE04 & No & No & No & & & KSE11 & No & No & No & \\
\hline & KSG02 & No & No & No & & & KSE21 & No & No & No & \\
\hline & KSG03 & No & No & No & & & KSE22 & No & No & No & \\
\hline & KSG04 & No & No & No & & \multirow{2}{*}{$\begin{array}{l}\text { Manual } \\
\text { Dry Chem }\end{array}$} & KSE15 & No & No & No & \\
\hline & KSG19 & No & No & Yes & 95 & & KSG12 & No & No & No & \\
\hline \multirow{6}{*}{$\begin{array}{l}\text { Auto Dry } \\
\text { Chem }\end{array}$} & KSE01 & No & No & Yes & 162 & \multirow{4}{*}{$\begin{array}{l}\text { Manual } \\
\text { Wet } \\
\text { Chem }\end{array}$} & KSE12 & No & No & No & \\
\hline & KSE14 & No & No & Yes & 201 & & KSE13 & No & No & No & \\
\hline & KSG01 & No & No & No & & & KSG09 & No & No & No & \\
\hline & KSG11 & No & No & Yes & 235 & & KSG10 & No & No & No & \\
\hline & KSG16 & No & No & Yes & 165 & \multirow{2}{*}{ Free Burn } & KSG15 & Yes & Yes & Yes & 350 \\
\hline & KSG17 & No & No & Yes & 59 & & KSG20 & Yes & Yes & Yes $^{f}$ & 160 \\
\hline \multicolumn{12}{|c|}{$\begin{array}{l}\text { a. 'Instant' represents the instantaneous tenability limit for temperature exposure to } 54^{\circ} \mathrm{C} \\
\text { b. ' } 2 \text { min' indicates the } 2 \text { min tenability limit for temperature exposure to } 93^{\circ} \mathrm{C}\end{array}$} \\
\hline
\end{tabular}

The tenability limits for heat flux were sometimes exceeded after activation of the suppression system, which agitated the oil fire causing a large, but momentary increase in the heat release rate and a corresponding increase in the heat flux. An example of a flare-up due to a test using automatic dry chemical suppressant delivery is shown in Figure 5-1. Enhanced temperature in the middle of the room due to suppressant delivery was also experimentally observed. Other fire enhancement effects included the observation that small oil droplets were ejected from the cooking pan in the form of spatter. On other occasions, burning oil splashed out of the container onto the range leading to a dramatic increase in the fire size. Delivery of the suppressant was also observed to lead to gas-phase effects, displacing hot gasses away from the range towards the center of the kitchen, where a person could be exposed. 

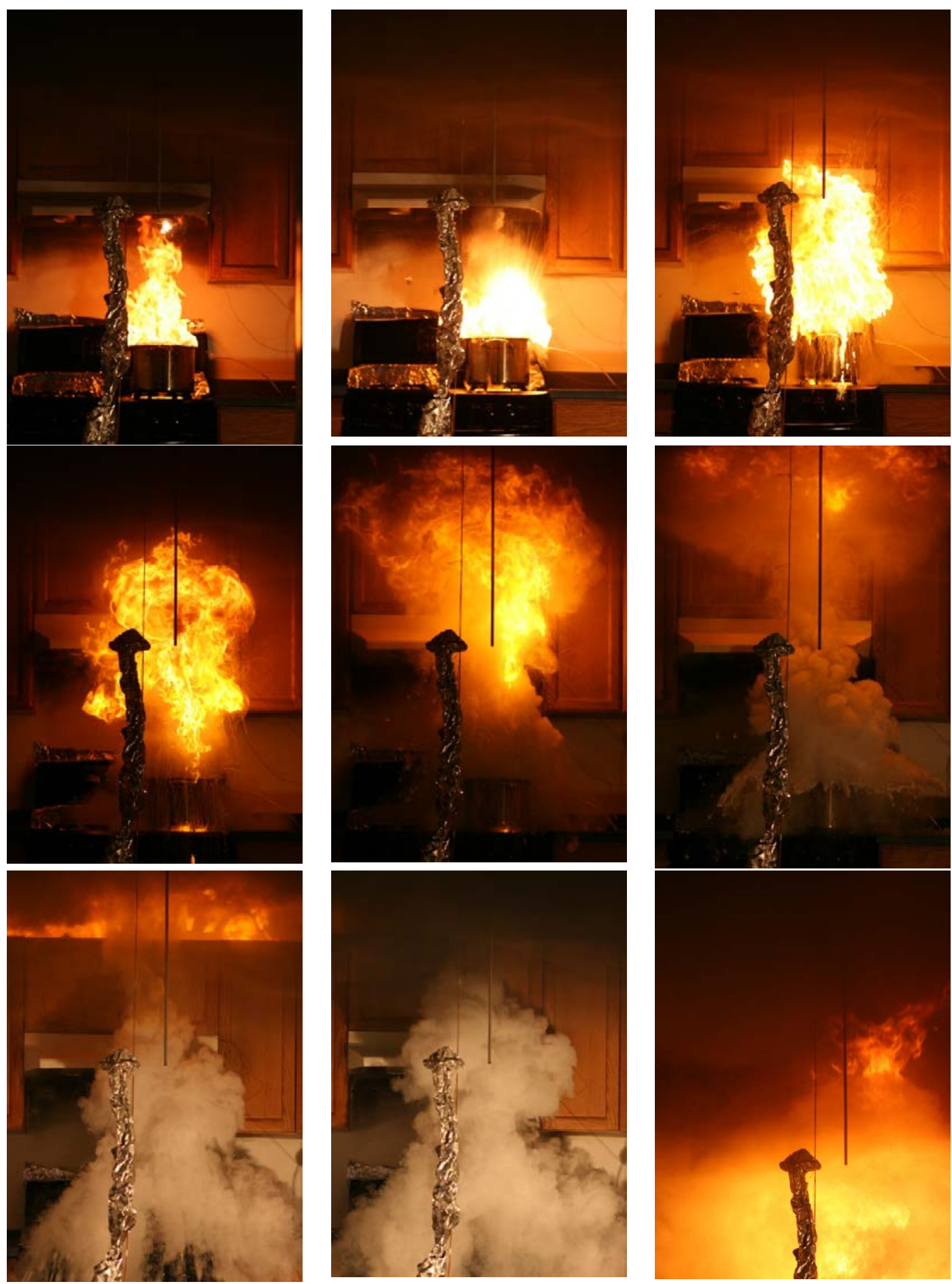

Figure 5-1. Photo of the burning oil just prior to activation of an auto dry chemical system (upper left), followed by 8 photos of the scenario taken within 3 sec of the initiation of suppressant (dry chemical) delivery. 


\subsection{Spatter, Loss of Containment, and Visibility}

In addition to heat flux and temperature, several other phenomena observed during the experiments could present a tenability hazard. They are qualitatively described here. In a free burn scenario, the burning oil eventually boiled, causing the oil to cascade over the top of the pan, which enhanced the fire size, causing direct flame impingement on other items present in the kitchen that might otherwise not be exposed to flame. The suppressions systems always activated before boilover was observed. Loss of containment of the fuel could occur in other ways. Loss of containment occurred due to suppressant delivery, apparently due to the momentum of the suppressant displacing the oil in the container. Instances of observed loss of containment are documented in Table 5-3. Loss of containment could accelerate fire spread or impact tenability. In many cases, loss of tenability occurred within $20 \mathrm{~s}$ after initiation of suppressant delivery. This was generally not the case for the most successful suppression types, such as manual suppression or the automatically delivered wet chemical.

Loss of containment occurred for the automatic dry chemical and water based systems. The dry chemical systems caused loss of containment as oil splashed out of the pan immediately after suppressant activation. The momentum of the dry suppressant into the oil caused some oil to splash out of the container. The sprinkler system produced containment losses due to the violent vaporization of water droplets on the oil surface. The hood mounted water mist systems (water mist $2 \& 3$ ) provided a high velocity jet of nitrogen which was used to produce fine water droplets. This caused visible agitation of the oil as the flames were pushed down and away from the nozzle, ultimately leading to containment failure in these cases. Since a shallow skillet (Pan A which was $5 \mathrm{~cm}$ deep) was used during all hood-mounted water mist system tests, it is unclear whether a deeper container would have led to different results. The ceiling mounted water mist suppression system (water mist 1) led to a containment failure, but the mechanism was not clear in these experiments.

For most tests, a high degree of visibility was maintained within the kitchen at $1.5 \mathrm{~m}$ (5 ft) throughout the experiment, but the hood mounted water mist systems reduced visibility within the kitchen to zero within seconds of activation. This could inhibit the ability of occupants to evacuate the kitchen area and increase the risk occupants will approach the fire or encounter hot surfaces or burning oil. However, the significance of this risk was not studied. 
Table 5-3. Fuel containment results

\begin{tabular}{|c|c|c|c|c|c|c|c|}
\hline Type & Test & Suppression Status & Contained $^{\mathrm{a}}$ & Type & Test & Suppression Status & Contained \\
\hline \multirow{6}{*}{$\begin{array}{l}\text { Auto } \\
\text { Dry } \\
\text { Chem }\end{array}$} & KSE01 & Not Extinguished & No & \multirow{3}{*}{$\begin{array}{l}\text { Auto Wet } \\
\text { Chem } 3\end{array}$} & KSE05 & No Activation & $\mathrm{N} / \mathrm{A}$ \\
\hline & KSE14 & Not Extinguished & No & & KSG08 & Re-Ignition & Yes \\
\hline & KSG01 & Re-Ignition & Yes & & KSG18 & Not Extinguished & Yes \\
\hline & KSG11 & Not Extinguished & No & \multirow{4}{*}{$\begin{array}{l}\text { Auto Wet } \\
\text { Chem } 4\end{array}$} & KSE10 & Not Extinguished & Yes \\
\hline & KSG16 & Not Extinguished & No & & KSE11 & Not Extinguished & Yes \\
\hline & KSG17 & Re-Ignition & No & & KSE21 & Extinguished & Yes \\
\hline \multirow{7}{*}{$\begin{array}{l}\text { Auto } \\
\text { Wet } \\
\text { Chem } \\
1\end{array}$} & KSE02 & Extinguished & Yes & & KSE22 & Not Extinguished & Yes \\
\hline & KSE03 & Extinguished & Yes & \multirow{2}{*}{$\begin{array}{l}\text { Manual } \\
\text { Dry Chem }\end{array}$} & KSE15 & Extinguished & Yes \\
\hline & KSE04 & Extinguished & Yes & & KSG12 & Extinguished & Yes \\
\hline & KSG02 & Extinguished & Yes & \multirow{4}{*}{$\begin{array}{l}\text { Manual } \\
\text { Wet Chem }\end{array}$} & KSE12 & Extinguished & Yes \\
\hline & KSG03 & Extinguished & Yes & & KSE13 & Extinguished & Yes \\
\hline & KSG04 & Extinguished & Yes & & KSG09 & Extinguished & Yes \\
\hline & KSG19 & Extinguished & Yes & & KSG10 & Extinguished & Yes \\
\hline \multirow{7}{*}{$\begin{array}{l}\text { Auto } \\
\text { Wet } \\
\text { Chem } \\
2\end{array}$} & KSE06 & Re-Ignition & Yes & \multirow{2}{*}{ Sprinkler } & KSE17 & Extinguished & No \\
\hline & KSE07 & Re-Ignition & Yes & & KSG14 & Not Extinguished & No \\
\hline & KSE08 & No Activation & N/A & \multirow{2}{*}{$\begin{array}{l}\text { Water } \\
\text { Mist } 1\end{array}$} & KSE16 & Not Extinguished & No \\
\hline & KSE09 & Re-Ignition & Yes & & KSG13 & Not Extinguished & Yes \\
\hline & KSG05 & Re-Ignition & Yes & \multirow{2}{*}{$\begin{array}{l}\text { Water } \\
\text { Mist } 2\end{array}$} & KSE18 & Not Extinguished & No \\
\hline & KSG06 & Extinguished & Yes & & KSE19 & Not Extinguished & Yes \\
\hline & KSG07 & Re-Ignition & Yes & $\begin{array}{l}\text { Water } \\
\text { Mist } 3\end{array}$ & KSE20 & Extinguished & No \\
\hline
\end{tabular}

The different types of extinguishers tested here fared better or worse in terms of tenability and containment of the burning fuel. The handheld extinguishers, for example, were quite effective and created no apparent tenability hazards to their potential users beyond what the oil fire presented prior to their usage. The results were mixed for the automatically discharged Wet chemical 1, which had one test in which tenability was a significant issue and 6 tests in which it wasn't.

Deployment of the wet and dry chemical handheld extinguishers can create a hazard, however, due to several factors. First, the manufacturer instructions may not be necessarily satisfied by a user in a realistic scenario due to lack of training or when in a panic. The wet chemical extinguishers may be manually deployed from a limited distance and thus require that the user be somewhat intimate with the fire, presenting a potential hazard if burning fuel is agitated. The dry 
chemical systems were capable of discharging from a significant distance. If discharged near an oil fire, however, splashing could occur, presenting a hazard to the user.

\subsection{Effect of Hood Fan}

The hood/vent system installed above each range was equipped with a fan, which was not used except in the series of tests for the auto wet chemical systems 1 and 2 . For these tests, the effect of the fan on fire suppressant effectiveness was investigated. The fan extracted air from the hood at a maximum flow speed of $90 \mathrm{~L} / \mathrm{s}$. It was anticipated that the fan would influence hood temperatures, and possibly suppression system activation time. The results are given in Table 5-4.

The discussion below considers tenability in terms of benchmark values for thermal injury and incapacitation due to inhalation of combustion products. A qualitative discussion is also presented of additional hazards including oil spatter, fire containment, and visibility. The difference in the time between auto-ignition and system activation is denoted as "Activation Time" in the table. No significant correlation was apparent between fan status and activation time.

Table 5-4. Activation times and fan status for tests using automatically delivered wet chemicals

\begin{tabular}{|l|c|c|c|c|c|}
\hline Suppression Type & Test & $\begin{array}{c}\text { Nominal Suppressant } \\
\text { Activation Temperature } \\
\left({ }^{\circ} \mathrm{C}\right)\end{array}$ & $\begin{array}{c}\text { Burner } \\
\text { Position }\end{array}$ & Fan & $\begin{array}{c}\text { Activation Time } \\
(\mathrm{s})\end{array}$ \\
\hline & KSE 02 & 100 & Front Left & Off & 61 \\
& KSE 03 & 100 & Front Left & On & 102 \\
& KSE 04 & 100 & Rear Right & On & 47 \\
& KSG 02 & 182 & Front Left & Off & 118 \\
& KSG 03 & 182 & Front Left & On & 76 \\
& KSG 04 & 182 & Rear Left & On & 181 \\
& KSG 19 & 182 & Front Right & Off & 102 \\
\hline & KSE 06 & 182 & Front Left & Off & 206 \\
& KSE 07 & 182 & Front Left & On & 192 \\
& KSE 08 & 182 & Rear Right & On & 155 \\
Auto Wet Chem 2 2 KSE 09 & KSG 05 & 182 & Rear Right & On & 131 \\
& KSG 06 & 182 & Front Left & Off & 151 \\
& KSG 07 & 182 & Front Left & On & 84 \\
& 182 & Rear Right & On & 178 \\
\hline
\end{tabular}




\subsection{Smoke Alarm Activation}

The time of smoke alarm activation relative to the time of auto-ignition is shown in Table 5-5. On average, the smoke alarms inside and just outside the kitchen activated an average of 24 min and 20 min before auto-ignition, respectively. There were three cases when the smoke alarm activated after auto-ignition, indicated by a negative value in the table. This only occurred for electric stoves when the range fan was operating (see entries highlighted in the table). The range fan (90 L/s) extracted smoke from the room over the period before auto-ignition occurred, pulling fresh air from outside the room through the doorway, into the room, and diluting oil vapor to such a level that the smoke alarms didn't activate.

Table 5-5. Time difference between activation of smoke alarms (inside and outside of kitchen) and auto-ignition

\begin{tabular}{|c|c|c|c|c|c|}
\hline Test & $\begin{array}{c}\text { Inside } \\
\text { (s) }\end{array}$ & $\begin{array}{c}\text { Outside } \\
\text { (s) }\end{array}$ & Test & $\begin{array}{c}\text { Inside } \\
\text { (s) }\end{array}$ & $\begin{array}{c}\text { Outside } \\
\text { (s) }\end{array}$ \\
\hline KSE 01 & 197 & 1047 & KSG 01 & 1151 & 78 \\
\hline KSE 02 & 1540 & 1320 & KSG 02 & $*$ & $*$ \\
\hline KSE 03 & $995 * *$ & 360 & KSG 03 & 2010 & 1995 \\
\hline KSE 04 & -26 & -44 & KSG 04 & 1126 & 1116 \\
\hline KSE 05 & 1100 & 986 & KSG 05 & 470 & 332 \\
\hline KSE 06 & 1860 & 1677 & KSG 06 & 501 & 478 \\
\hline KSE 07 & 958 & 826 & KSG 07 & 460 & 676 \\
\hline KSE 08 & -32 & -24 & KSG 08 & 2616 & 1536 \\
\hline KSE 09 & -75 & -90 & KSG 09 & 3585 & 2585 \\
\hline KSE 10 & 2061 & 2684 & KSG 10 & 1889 & 1889 \\
\hline KSE 11 & 2002 & 1848 & KSG 11 & 2556 & 2266 \\
\hline KSE 12 & 1503 & 1375 & KSG 12 & 2400 & 1408 \\
\hline KSE 13 & 1475 & 1378 & KSG 13 & 2055 & 1374 \\
\hline KSE 14 & 1532 & 1336 & KSG 14 & 2195 & 1590 \\
\hline KSE 15 & 1417 & 1127 & KSG 15 & 2628 & 772 \\
\hline KSE 16 & 1034 & 879 & KSG 16 & 1652 & 1540 \\
\hline KSE 17 & 2037 & 1838 & KSG 17 & 340 & 240 \\
\hline KSE 18 & 975 & 962 & KSG 18 & 483 & 453 \\
\hline KSE 19 & 1322 & 1308 & KSG 19 & 1020 & 952 \\
\hline KSE 20 & 1295 & 1295 & KSG 20 & 1443 & 293 \\
\hline KSE 21 & 2624 & 2395 & & & \\
\hline KSE 22 & 3100 & 2760 & & & \\
\hline
\end{tabular}


Recently, Johnsson [4] experimentally found completely different results for photoelectric alarms, which consistently activated about 2 min before stovetop ignition of peanut and canola oils under a hood fan operating at $104 \mathrm{~L} / \mathrm{s}$ in a small room. Differences in room ventilation conditions may explain the difference in results from this study. Further research is needed to clarify these conflicting results.

\section{Discussion of Results}

The experiments described in this report focused on residential cooking and particularly on general purpose ranges and cooktops. The experiments were conducted using full-scale scenarios and commercially-available suppression system technologies addressing realistic fire scenarios. Several types of fresh (previously unused) cooking oil were assessed, and corn oil was selected as a reasonable representation of the hazards associated with cooking oil fires. The pans tested complied with UL300A and included a deep pot and shallow skillets. Both natural gas and electric ranges were tested. Successful performance was deemed to necessitate both fire suppression and prevention of re-ignition. In these terms, some suppression system technologies performed better than others in the full-scale kitchen fire suppression experiments reported here.

Complete extinguishment of cooking oil fires would not only prevent property damage, but would also protect occupants from potentially fatal hazards. During the process of suppression, however, fire conditions could be exacerbated, introducing additional risks to occupants that did not exist prior to suppressant application. Many of the tested systems did not completely extinguish the fire.

The time to ignition was found to vary significantly based on the type of burner, properties of the pan, type of oil, and volume of oil. The peak heat release rate was found to vary based on these same properties - which affected the thermal exposure of nearby furnishings (or tenability) in the room. The volume and type of oil, as well as the pan geometry, affected the ability of a suppression system to effectively lower the temperature of the oil below its auto-ignition point. The capability of a system to depower the stovetop was of critical importance.

Three of the suppression systems successfully extinguished the oil fire in all experiments, 3 systems were successful in some experiments, and 4 systems were not successful in any experiments. One system was tested only once, so the results are inconclusive. Considering all systems, three of the systems consistently provided notable benefits over a no-suppression scenario.

\subsection{Manual Extinguishers}

Both types of manual extinguishers were successful used to extinguish the oil fires. The use of a manual extinguisher, however, precludes immediate egress and puts the user at some risk, depending on the fire scenario and the performance of the user. In this regard, it should be noted 
that kitchen fires lead to a large excessive number of injuries - probably due to people attempting to control the fires. In addition, a large fraction of range and cooktop fires involve unattended cooking. Consequently, a manual extinguisher cannot be considered a substitute for an effective automatic suppression system, fire alarm warning system, or an ignition prevention device.

Successful application of the manual extinguishers suggests that an automatic system should be able to extinguish these fires - if properly engineered.

\subsection{Automatic Systems}

The automatic systems tested in this study included room protection in the form of ceiling mounted water sprinklers and water mists, and localized systems that were hood mounted, including wet chemical, dry chemical, and water mist systems. All the automatic systems exacerbated the fire somewhat when activated; this translated to an increase in heat flux, and in some cases, an increase above the tenability limit.

\subsubsection{Automatic Wet Chemical Systems}

Automatic wet chemical 1 was successful in all 7 experiments tested, making it the most reliable automatic system to successfully extinguish oil fires. Although wet chemical 1 was consistently able to suppress the fire, it did pose a tenability issue in 1 of the 7 tests. Automatic wet chemical 2 demonstrated some success in suppressing the fire, achieving temporary extinguishment in all tests and permanent extinguishment in one test. Automatic wet chemical 3 was unsuccessful in permanently extinguishing the oil fire in any tests, but it did successfully cause temporary extinguishment in one test. Automatic wet chemical 4 was less successful, as it did not provide extinguishment in 3 of 4 tests. This system did however successfully extinguish the oil fire during one test in which the volume of oil was smaller, using the cast iron skillet.

\subsubsection{Automatic Dry Chemical System}

The automatic dry chemical system was not successful in extinguishing the oil fires in any of the experiments, and it introduced tenability hazards which were not present prior to system activation.

\subsubsection{Water Mist Systems (Room and Hood Protection)}

Water mist system 1 (room protection) and water mist system 2 (hood protection) were not successful in extinguishing the oil fire in any experiments and each of these systems introduced tenability hazards which were not present prior to system activation. Water mist 3, a hood mounted water mist system, was successful in the one experiments in which it was tested, which was on the smaller volume of oil. It was a high pressure system, and was associated with both fuel containment and tenability problems. 


\subsubsection{Sprinkler Room Protection}

The residential sprinkler was successful in extinguishing the fire in the first test and unsuccessful in the second test. Unlike some of the other systems, the stovetop power source was not shut as the suppressant (water) was deployed. Neither room protection system tested (water sprinkler and mist) could provide suppression without producing some hazard to occupants. This is partly due to the slower activation times of the room protection systems, which resulted in a larger fire prior to activation. The sprinkler system was able to delay the tenability limit in one test. In the second test, tenability became an issue after sprinkler activation. In general, room protection systems provide suppressant to a wide area, controlling or slowing fire spread to nearby items even when they are not successful in extinguishing the fire. Because of this, sprinklers provide benefit beyond simply cooktop protection, but the delay in application and the lack of a way to depower the cooktop present issues that challenge the performance of these systems.

\section{Summary and Conclusions}

Experiments were conducted investigating a common class of kitchen fires, involving oil burning in a pan that was heated on a cooktop. The performance of real-scale fire suppression systems was tested. Various emerging and commercially-available retrofit fire suppression systems for residential application were tested. The fire scenarios tested are outlined in the UL 300A draft standard. Experiments were conducted in a full-scale residential kitchen with dimensions $3.6 \mathrm{~m} \mathrm{x}$ $3.4 \mathrm{~m} \times 2.4 \mathrm{~m}$ high with an open doorway. Several types of cooking pans and oils were tested for both gas and electric cooktops. The suppression systems tested included automatic and manual suppression technologies using either local or total flooding type suppressant application. Manual devices that were tested included both wet and dry chemical type extinguishers. Automatic systems included total flooding whole-room and range hood installed systems. The total flooding systems provided whole-room protection; the systems tested included a water mist and a residential sprinkler system. The hood installed systems were positioned in the kitchen cabinets above the exhaust hood or in the hood itself, delivering agent onto the cooktop; these included wet and dry chemical systems, and water mist. A series of measurements provided data characterizing the hazard associated with cooking oil fires. The hazard associated with cooktop fires was characterized in terms of the rate of fire growth, and tenability proximate to the cooktop in terms of heat flux, temperature, gas concentration, and the splatter of hot burning oil.

Experimental characterization of the kitchen cooktop fires considered in this study showed that they were quite hazardous. The experiments showed that that the performance of the automatic suppression technologies tested in this study faced challenges in terms of the fire intensity, propensity of the fuel to re-ignite, and tenability. Control experiments conducted without the application of a suppressant demonstrated that the cooktop fires exhibited ultra-fast $\mathrm{t}^{2}$ fire growth behavior. Smoke alarms inside, or just outside, a kitchen may provide early warning of fire, but not for all cases. The results showed that the performance of the commercially available automatic suppression technologies that were tested was problematic due to fire intensity, reignition, and tenability issues. While it is surely possible to mitigate the hazards associated with 
cooking oil and range fires with large fire suppression systems, the results of these experiments suggest that delivering sufficient agent for a long enough duration to a hot oil burning within a pan located somewhere on the cooktop is quite challenging.

The results of the suppression and tenability experiments are summarized in Table 7-1. They show significant variation in the overall effectiveness of the various technologies and the collateral effects such as tenability and lack of fuel containment among the suppression systems tested. The automatically deployed systems demonstrated a mixed set of outcomes, some performing better than others in suppressing the fire, preventing reignition, and minimizing tenability issues near the cooktop. One type of automatic wet chemical system was particularly effective. This is not entirely unexpected as this type of wet chemical system is common in commercial applications. This wet chemical system did present some tenability issues. The hood-installed dry chemical system tested failed to extinguish the oil fire in all experiments, and introduced tenability hazards not present prior to system activation. The water mist automatic systems provided generally inadequate performance; they either could not reliably suppress the fire, or they consistently generated tenability hazards. Whole room systems fared no better. The water sprinkler and water mist systems were not particularly effective for the rapidly growing cooking oil fires.

Table 7-1 shows that the only suppressant types that were fully successfully were the manually applied wet and dry chemicals. For every other suppressant type either failed to suppress the fire, reignition occurred, the suppressant system did not properly activate, or there were issues in terms of tenability or fuel containment. Manual extinguishers consistently suppressed the oil fires while maintaining tenable conditions in the mock-up kitchen. In this sense, control of the direction, rate, and amount of suppressant delivery was advantageous.

The effectiveness of ionization smoke alarms to provide early warning of fire were also tested as part of this study. The results showed that the smoke alarms inside, or just outside, the kitchen fire scenarios considered here generally activated several minutes before auto-ignition occurred, but not for all cases. Further research is needed to determine if kitchen or nearby alarms may be a viable approach, adding to kitchen fire safety. Other approaches for kitchen fire safety should also be considered. This may include consideration of ignition prevention technologies and reliable, early, and nuisance-free warning of pre-ignition conditions possibly through the development of specialized sensors or sensor combinations. The best means to control the fire may be "smart" cooktops that prevent ignition from occurring such as mandated by the recent UL 858 standard for electric cooktops [3]. Future research should consider the best ways to evaluate kitchen fire prevention technologies. In addition, the results of this study suggest that further work is needed to examine the limits of the effectiveness of sprinkler fire protection systems for stovetop fire protection. 
Table 7-1. Summary of Suppression and Tenability Measurements. ${ }^{\text {a }}$

\begin{tabular}{|c|c|c|c|c|c|c|c|}
\hline Type & Test & Suppressed & $\begin{array}{l}\text { Tenable and } \\
\text { Contained }^{\mathrm{b}}\end{array}$ & Type & Test & Suppressed & $\begin{array}{l}\text { Tenable and } \\
\text { Contained }^{b}\end{array}$ \\
\hline \multirow{6}{*}{$\begin{array}{l}\text { Auto } \\
\text { Dry } \\
\text { Chem }\end{array}$} & KSE01 & No & No & \multirow{3}{*}{$\begin{array}{l}\text { Auto Wet } \\
\text { Chem } 3\end{array}$} & KSE05 & $\begin{array}{c}\text { No } \\
\text { Activation }\end{array}$ & N/A \\
\hline & KSE14 & No & No & & KSG08 & Re-Ignition & Yes \\
\hline & KSG01 & Re-Ignition & Yes & & KSG18 & No & Yes \\
\hline & KSG11 & No & No & \multirow{4}{*}{$\begin{array}{l}\text { Auto Wet } \\
\text { Chem } 4\end{array}$} & KSE10 & No & Yes \\
\hline & KSG16 & No & No & & KSE11 & No & Yes \\
\hline & KSG17 & Re-Ignition & No & & KSE21 & Yes & Yes \\
\hline \multirow{7}{*}{$\begin{array}{l}\text { Auto } \\
\text { Wet } \\
\text { Chem } \\
1\end{array}$} & KSE02 & Yes & Yes & & KSE22 & No & Yes \\
\hline & KSE03 & Yes & Yes & \multirow{2}{*}{$\begin{array}{l}\text { Manual } \\
\text { Dry Chem }\end{array}$} & KSE15 & Yes & Yes \\
\hline & KSE04 & Yes & Yes & & KSG12 & Yes & Yes \\
\hline & KSG02 & Yes & Yes & \multirow{4}{*}{$\begin{array}{l}\text { Manual } \\
\text { Wet Chem }\end{array}$} & KSE12 & Yes & Yes \\
\hline & KSG03 & Yes & Yes & & KSE13 & Yes & Yes \\
\hline & KSG04 & Yes & Yes & & KSG09 & Yes & Yes \\
\hline & KSG19 & Yes & No & & KSG10 & Yes & Yes \\
\hline \multirow{7}{*}{$\begin{array}{l}\text { Auto } \\
\text { Wet } \\
\text { Chem } \\
2\end{array}$} & KSE06 & Re-Ignition & No & \multirow{2}{*}{ Sprinkler } & KSE17 & Yes & No \\
\hline & KSE07 & Re-Ignition & No & & KSG14 & No & No \\
\hline & KSE08 & $\begin{array}{c}\text { No } \\
\text { Activation }\end{array}$ & N/A & \multirow{2}{*}{$\begin{array}{l}\text { Water } \\
\text { Mist } 1\end{array}$} & KSE16 & No & No \\
\hline & KSE09 & Re-Ignition & Yes & & KSG13 & No & No \\
\hline & KSG05 & Re-Ignition & Yes & \multirow{2}{*}{$\begin{array}{l}\text { Water } \\
\text { Mist } 2\end{array}$} & KSE18 & No & No \\
\hline & KSG06 & Yes & Yes & & KSE19 & No & No \\
\hline & KSG07 & Re-Ignition & No & $\begin{array}{l}\text { Water } \\
\text { Mist } 3\end{array}$ & KSE20 & Yes & No \\
\hline
\end{tabular}




\section{References}

1. Ahrens, Marty, Home Fires Involving Cooking Equipment. National Fire Protection Association, Quincy, MA., November 2016.

2. Madrzykowski, D., Hamins, A., Mehta, S., "Residential Kitchen Fire Suppression Research Needs: Workshop Proceedings,” National Institute of Standards and Technology, Gaithersburg, MD, February 2007.

3. UL858, Standard for Safety, Household Electric Ranges, Underwriter's Laboratory, Northbrook, IL, 16 ${ }^{\text {th }}$ edition, November 2014.

4. Johnsson, Erik L. and Zarzecki, Mariusz, "Using Photoelectric Smoke Detection to Warn of Pre-Ignition Conditions of Unattended Cooking Fires,” National Institute of Standards and Technology, NIST Technical Report TN 1960, Gaithersburg, MD., July 2017.

5. UL300, "Standard for Fire Testing of Fire Extinguishing Systems for Protection of Commercial Cooking Equipment,” Underwriter's Laboratory, Northbrook, IL, $3^{\text {rd }}$ edition, May 2005.

6. UL 1626, “Standard for Residential Sprinklers for Fire-Protection Service,” Underwriters Laboratories, Northbrook, IL, 2008 Edition.

7. UL300A, Outline of Investigation for Extinguishing System Units for Residential Range Top Cooking Surfaces, Underwriter’s Laboratory, Issue Number 2, June 1991.

8. NFPA 10, “Standard on Portable Fire Extinguishers,” 2013 edition.

9. Gravalos, I., Gialamas, T., Koutsofitis, Z, Kateris, D., Tsiropoulos, Z., Xyraddakis, P., Georgiades, A., Energetic Study on Animal Fats and Vegetable Oils Using Combustion Bomb Calorimeter, J Agricultural Machinery Science 4, 69-74 (2008) and Sciencelab.com, Inc., Material Safety Data Sheets (MSDS) for corn and peanut oils. http://www.Sciencelab.com

10. Bryant, R.A., Ohlemiller, T.J., Johnsson, E.L., Hamins, A.H., Grove, B.S., Guthrie, W.F., Maranghides, A., and Mulholland, G.W., The NIST 3 MW Quantitative Heat Release Rate Facility: Description and Procedures, National Institute of Standards and Technology, Gaithersburg, MD, NISTIR 7052, September 2004.

11. Omega Engineering Inc., The Temperature Handbook, Vol. MM, pages Z-39-40, Stamford, CT., 2004.

12. Taylor, B.N. and Kuyatt, C.E., "Guidelines for Evaluating and Expressing the Uncertainty of NIST Measurement Results,” NIST TN 1297, National Institute of Standards and Technology, Gaithersburg, MD, January 1994.

13. Medtherm Corporation Bulletin 118, “64 Series Heat Flux Transducers,” Medtherm Corporation, Huntsville, AL., August 2003. 
14. Pitts, William, M., Annageri V. Murthy, John L. de Ris, Jean-Rémy Filtz, , Kjell Nygard, Debbie Smith, and Ingrid Wetterlund. "Round robin study of total flux gauge calibration at fire laboratories,” Fire Safety Journal 41, 2006, pp 459-475.

15. Dinaberg, J.B., and Gottuck, D.T., "Development of Standardized Cooking Fires for Evaluation of Prevention Technologies: Data Analysis," Final Report, July 2014 Fire Protection Research Foundation.

16. Purser, David A. and McAllister, J.L., “Assessment of Hazards to Occupants from Smoke, Toxic Gases, and Heat," SFPE Handbook of Fire Protection Engineering, $5^{\text {th }} \mathrm{ed}$., M.J. Hurley (Editor in Chief), NFPA Quincy, MA, 2016.

17. Hamins, A., Kashiwagi, T., and Buch, R., "Characteristics of Pool Fire Burning," in Fire Resistance of Industrial Fluids, ASTM STP 1284 (Eds: G. Totten and J. Reichel), American Society for Testing and Materials (ASTM) Publication Number 04-012840-12, W. Conshocken, PA, pp. 15-41 (1995).

18. Tewarson, A., Table 3 in the Appendix of Quintiere, J.G., Fundamentals of Fire Phenomena, John Wiley \& Sons, 2006.

19. Bundy, M., Hamins, A., Johnsson, E.L., Kim, S.C., Ko, G.H., and Lenhart, D. B., "Measurements of Heat and Combustion Products in Reduced-Scale Ventilated-Limited Compartment Fires”, National Institute of Standards and Technology, Gaithersburg, MD., NIST TN 1483, July 2007.

20. Blevins, L.G., "Behavior of Bare and Aspirated Thermocouples in Compartment Fires", National Heat Transfer Conference, 33 ${ }^{\text {rd }}$ Proceedings. HTD99-280. August 15-17, 1999, Albuquerque, NM, 1999.

21. Pitts, W.M., E. Braun, R.D. Peacock, H.E. Mitler, E. L. Johnsson, P.A. Reneke, and L.G.Blevins, "Temperature Uncertainties for Bare-Bead and Aspirated Thermocouple Measurements in Fire Environments," Thermal Measurements: The Foundation of Fire Standards. American Society for Testing and Materials (ASTM). Proceedings. ASTM STP 1427. December 3, 2001, Dallas, TX.

22. Stroup, D.W., DeLauter, L.A., Lee, J.H., Roadarmel, G.L., “Large Fire Research Facility (Building 205) Exhaust Hood Heat Release Rate Measurement System,” NISTIR 6509, National Institute of Standards and Technology, Gaithersburg, MD, July 2000.

23. SFPE Handbook of Fire Protection Engineering, $5^{\text {th }}$ ed., JM. Hurley (editor in chief), NFPA Quincy, MA, 2016. 


\section{Appendix 1: Experimental Results}

This appendix provides details on the individual results of the full-scale kitchen fire suppression experiments. The following table lists the tests in this series and the pages on which their results can be found.

Table A1-1. Summary of suppression test name, fuel quantity, suppression system, and page number where results are presented.

\begin{tabular}{|l|ll|l|}
\hline $\begin{array}{l}\text { Test } \\
\text { Name }\end{array}$ & Fuel & System & Page \\
\hline KSE 1 & $4.5 \mathrm{~L}$ & Auto. Dry Chem & 54 \\
\hline KSE 2 & $4.5 \mathrm{~L}$ & Auto Wet Chem 1 & 55 \\
\hline KSE 3 & 4.5 L & Auto Wet Chem 1 & 56 \\
\hline KSE 4 & $4.5 \mathrm{~L}$ & Auto Wet Chem 1 & 57 \\
\hline KSE 5 & $4.5 \mathrm{~L}$ & Auto Wet Chem 3 & 58 \\
\hline KSE 6 & $4.5 \mathrm{~L}$ & Auto Wet Chem 2 & 59 \\
\hline KSE 7 & $4.5 \mathrm{~L}$ & Auto Wet Chem 2 & 60 \\
\hline KSE 8 & $4.5 \mathrm{~L}$ & Auto Wet Chem 2 & 61 \\
\hline KSE 9 & $4.5 \mathrm{~L}$ & Auto Wet Chem 2 & 62 \\
\hline KSE 10 & $4.5 \mathrm{~L}$ & Auto Wet Chem 4 & 63 \\
\hline KSE 11 & $4.5 \mathrm{~L}$ & Auto Wet Chem 4 & 64 \\
\hline KSE 12 & $4.5 \mathrm{~L}$ & Manual Wet Chem & 65 \\
\hline KSE 13 & $4.5 \mathrm{~L}$ & Manual Wet Chem & 66 \\
\hline KSE 14 & $4.5 \mathrm{~L}$ & Auto Dry Chem & 67 \\
\hline KSE 15 & $4.5 \mathrm{~L}$ & Manual Dry Chem & 68 \\
\hline KSE 16 & $4.5 \mathrm{~L}$ & Water Mist 1 & 69 \\
\hline KSE 17 & $4.5 \mathrm{~L}$ & Residential & 70 \\
& & Sprinkler & \\
\hline KSE 18 & 1.62 L & Water Mist 2 & 71 \\
\hline 1 KSE 19 & $1.62 \mathrm{~L}$ & Water Mist 2 & 72 \\
\hline KSE 20 & $1.62 \mathrm{~L}$ & Water Mist 3 & 73 \\
\hline KSE 21 & $1.62 \mathrm{~L}$ & Auto Wet Chem 4 & 74 \\
\hline KSE 22 & $4.5 \mathrm{~L}$ & Auto Wet Chem 4 & 75 \\
\hline
\end{tabular}

\begin{tabular}{|c|c|c|c|}
\hline $\begin{array}{l}\text { Test } \\
\text { Name }\end{array}$ & Fuel & System & Page \\
\hline KSG 1 & $4.5 \mathrm{~L}$ & Auto. Dry Chem & 76 \\
\hline KSG 2 & $4.5 \mathrm{~L}$ & Auto Wet Chem 1 & 77 \\
\hline KSG 3 & $4.5 \mathrm{~L}$ & Auto Wet Chem 1 & 78 \\
\hline KSG 4 & $4.5 \mathrm{~L}$ & Auto Wet Chem 1 & 79 \\
\hline KSG 5 & $4.5 \mathrm{~L}$ & Auto Wet Chem 2 & 80 \\
\hline KSG 6 & $4.5 \mathrm{~L}$ & Auto Wet Chem 2 & 81 \\
\hline KSG 7 & $4.5 \mathrm{~L}$ & Auto Wet Chem 2 & 82 \\
\hline KSG 8 & $4.5 \mathrm{~L}$ & Auto Wet Chem 3 & 83 \\
\hline KSG 9 & $4.5 \mathrm{~L}$ & Manual Wet Chem & 84 \\
\hline KSG 10 & $4.5 \mathrm{~L}$ & Manual Wet Chem & 85 \\
\hline KSG 11 & $4.5 \mathrm{~L}$ & Auto Dry Chem & 86 \\
\hline KSG 12 & $4.5 \mathrm{~L}$ & Manual Dry Chem & 87 \\
\hline KSG 13 & $4.5 \mathrm{~L}$ & Water Mist 1 & 88 \\
\hline KSG 14 & $4.5 \mathrm{~L}$ & $\begin{array}{l}\text { Residential } \\
\text { Sprinkler }\end{array}$ & 89 \\
\hline KSG 15 & $4.5 \mathrm{~L}$ & Free Burn & 90 \\
\hline KSG 16 & $1.62 \mathrm{~L}$ & Auto Dry Chem & 91 \\
\hline KSG 17 & $0.5 \mathrm{~L}$ & Auto Dry Chem & 92 \\
\hline KSG 18 & $1.62 \mathrm{~L}$ & Auto Wet Chem 3 & 93 \\
\hline KSG 19 & $1.62 \mathrm{~L}$ & Auto Wet Chem 1 & 94 \\
\hline KSG 20 & $1.62 \mathrm{~L}$ & Free Burn & 95 \\
\hline
\end{tabular}

The uncertainty of data presented in this appendix is presented in Section 4 of this report. The expanded uncertainty in the measured temperature, heat flux, and time is approximately $\pm 15 \%, \pm 8 \%$, and $\pm 5 \mathrm{~s}$, respectively. 

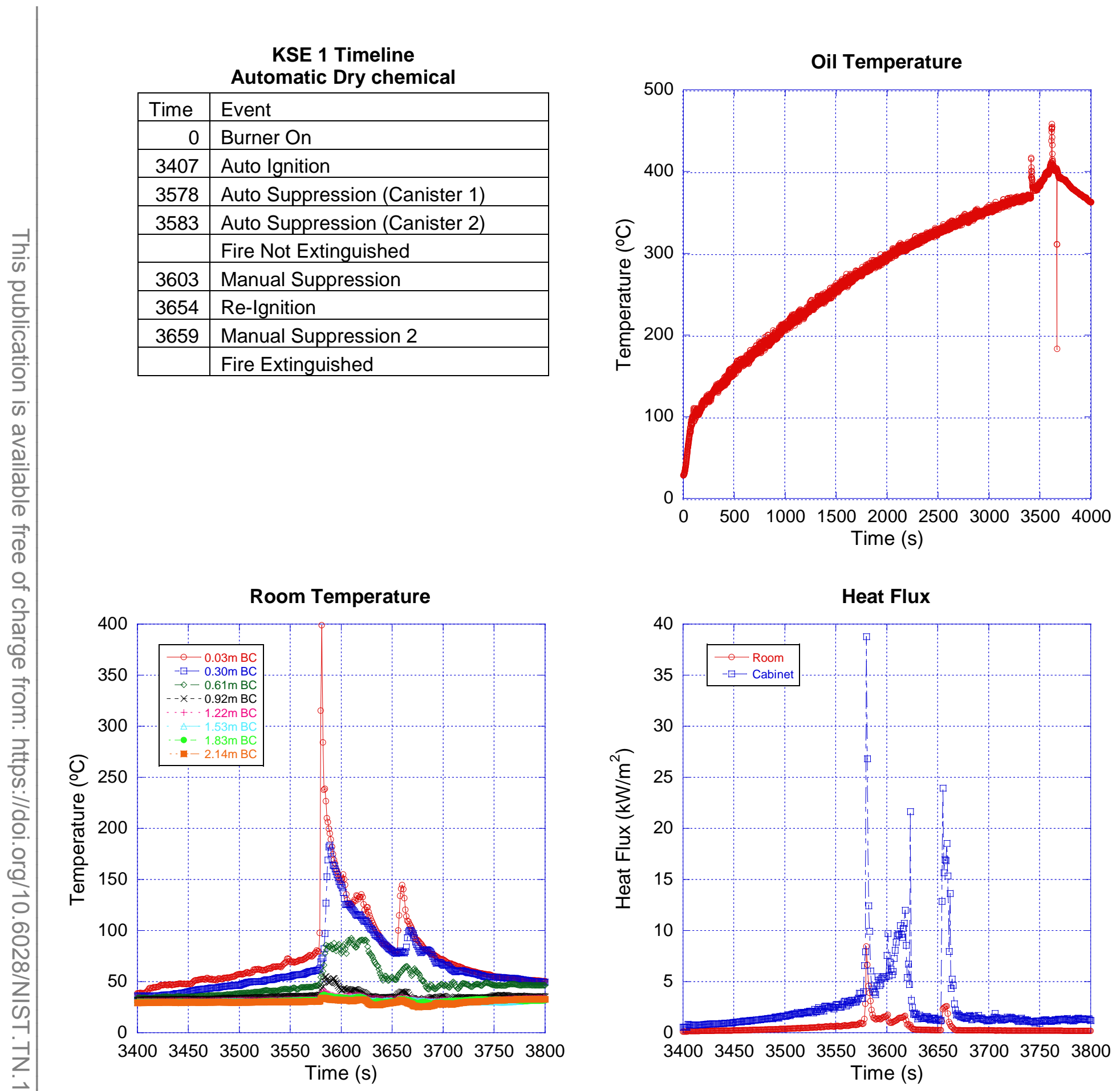

Figure A1-1. Experiment KSE 1 timeline and data 
KSE 2 Timeline

Automatic Wet Chemical 1

\begin{tabular}{|r|l|}
\hline Time & Event \\
\hline 0 & Burner On \\
\hline 3845 & Auto Ignition \\
\hline 3906 & Auto Suppression \\
\hline & Fire Extinguished \\
\hline
\end{tabular}

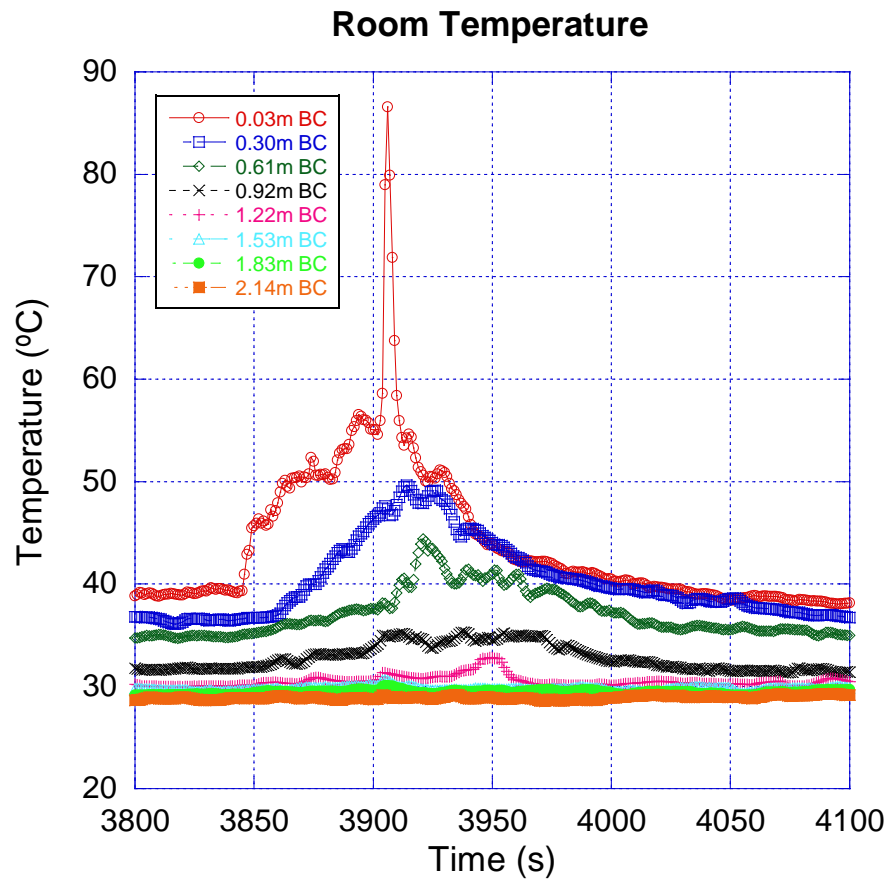

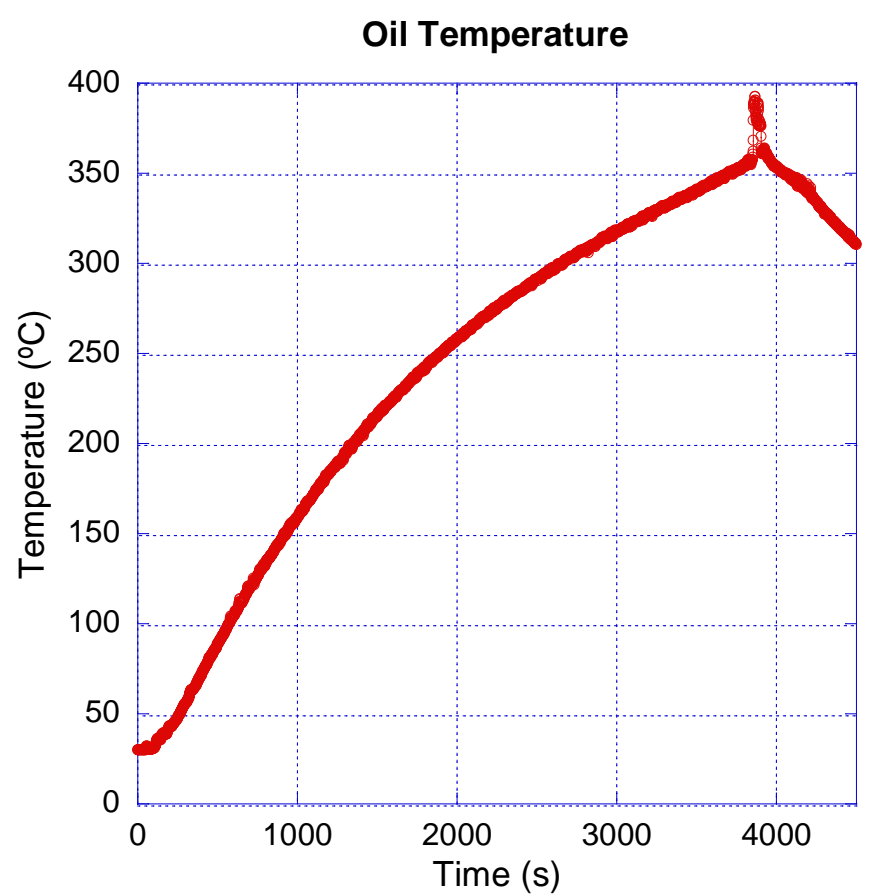

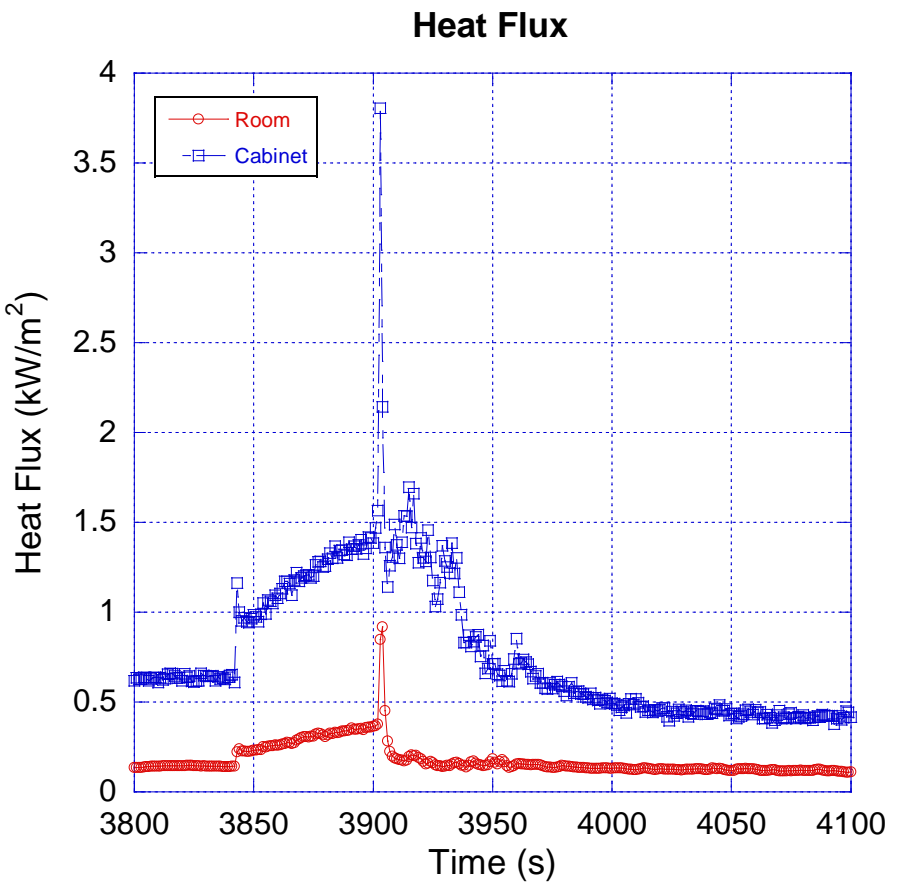

Figure A1-2. Experiment KSE 2 timeline and data 
KSE 3 Timeline

Automatic Wet Chemical 1

\begin{tabular}{|r|l|}
\hline Time & Event \\
\hline 0 & Burner On \\
\hline 2405 & Auto Ignition \\
\hline 2507 & Auto Suppression \\
\hline & Fire Extinguished \\
\hline
\end{tabular}

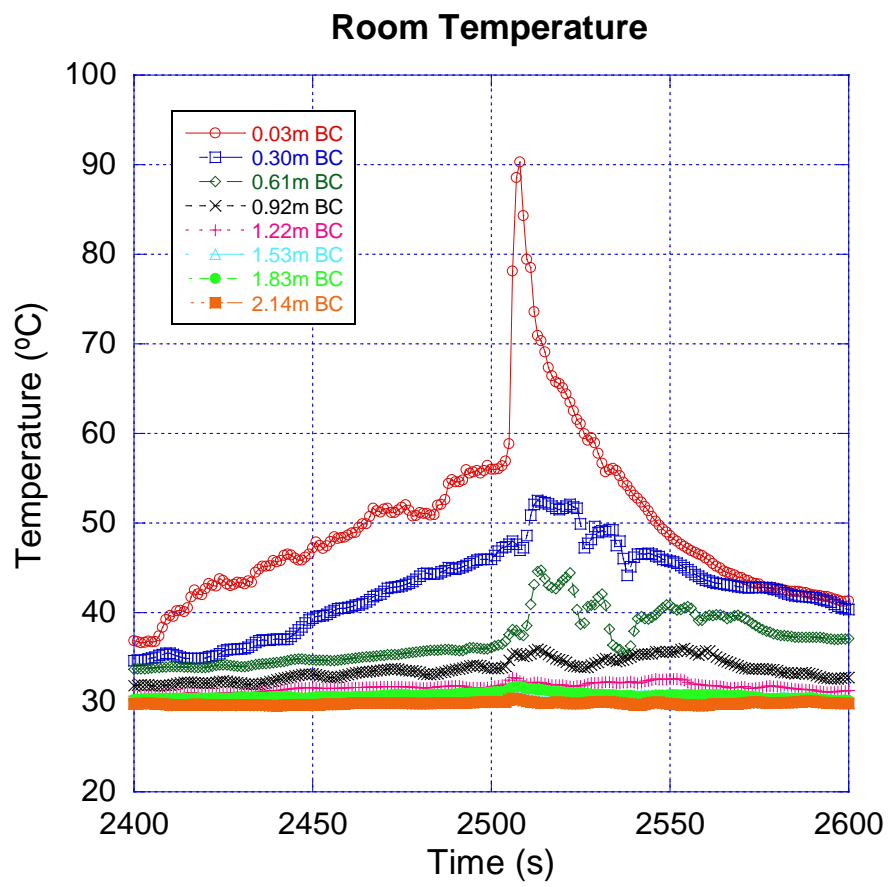

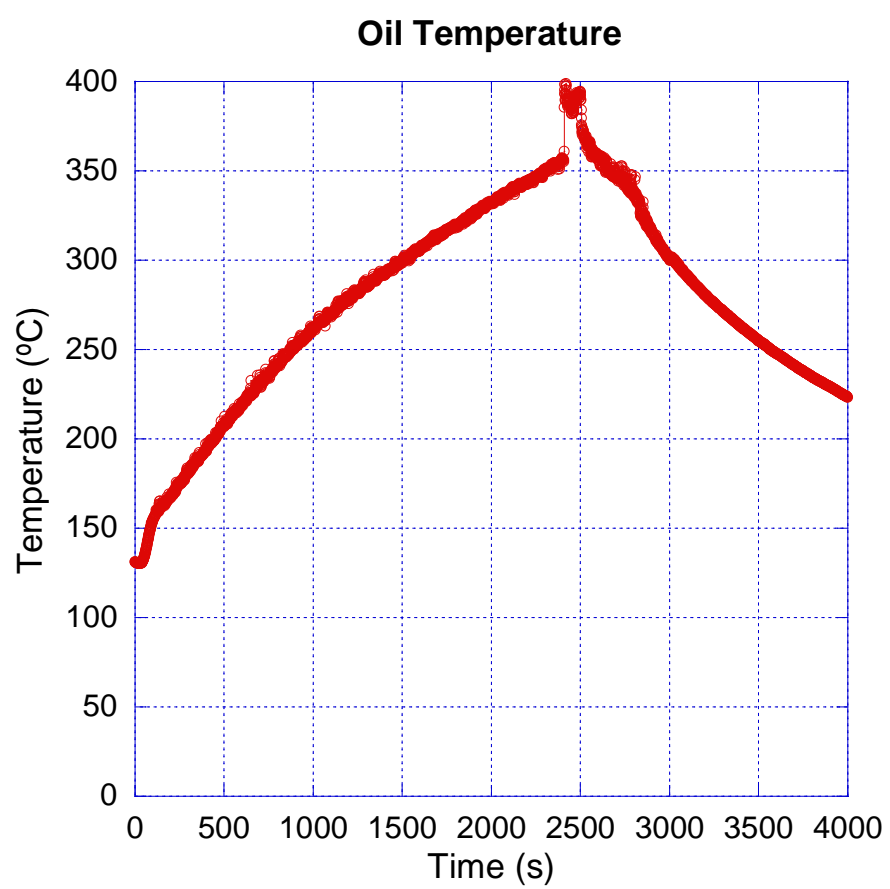

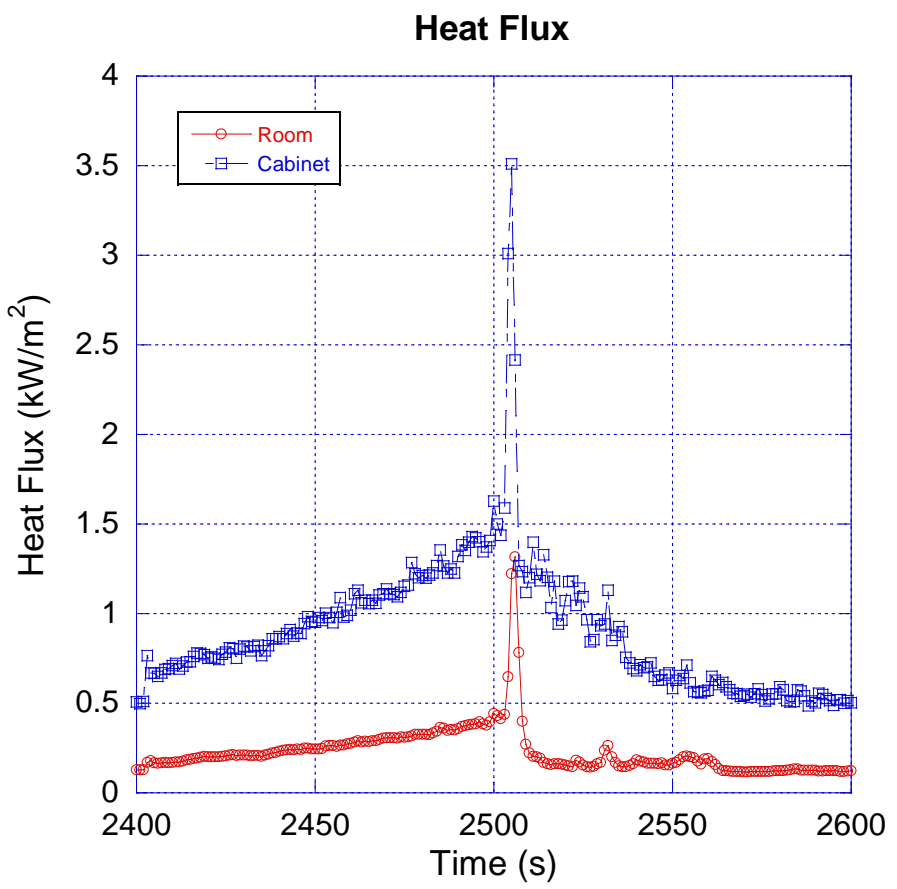

Figure A1-3. Experiment KSE 3 timeline and data 
KSE 4 Timeline

Automatic Wet Chemical 1

\begin{tabular}{|r|l|}
\hline Time & Event \\
\hline 0 & Burner On \\
\hline 3753 & Auto Ignition \\
\hline 3800 & Auto Suppression \\
\hline & Fire Extinguished \\
\hline
\end{tabular}

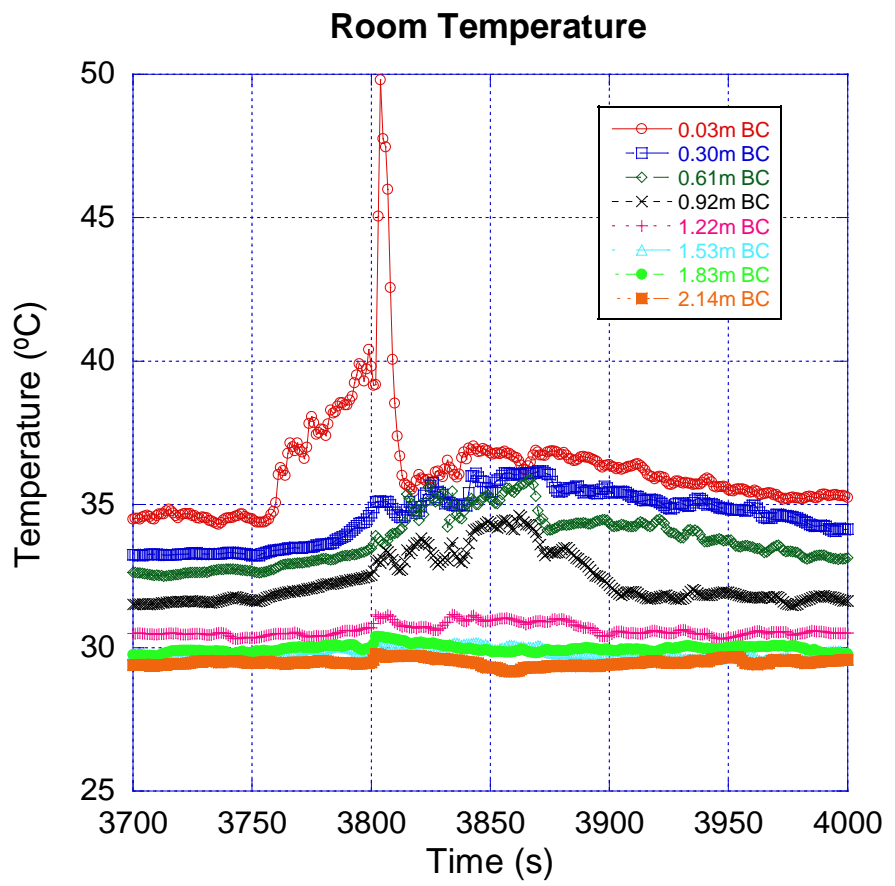

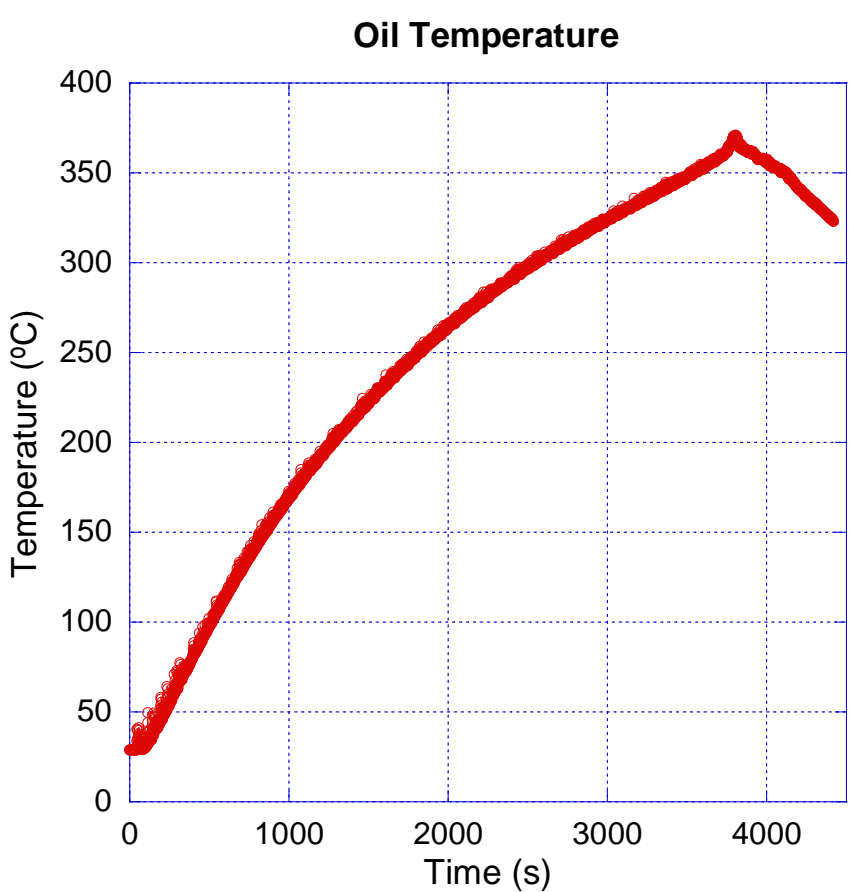

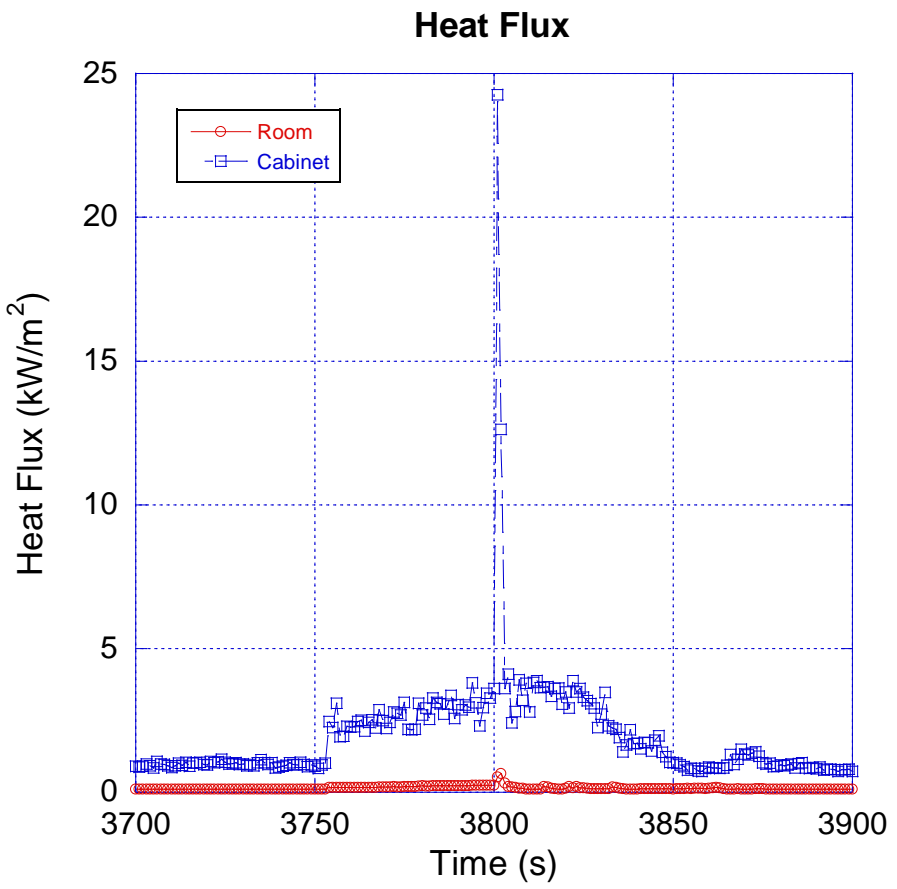

Figure A1-4. Experiment KSE 4 timeline and data 
KSE 5 Timeline

Automatic Wet Chemical 3

\begin{tabular}{|r|l|}
\hline \multicolumn{1}{|c|}{ Time } & Event \\
\hline 0 & Burner On \\
\hline 3524 & Auto Ignition \\
\hline 3707 & Manual Suppression \\
\hline 3775 & Auto Suppression \\
\hline 3811 & Re-Ignition \\
\hline 3816 & Manual Suppression 2 \\
\hline & Fire Extinguished \\
\hline
\end{tabular}

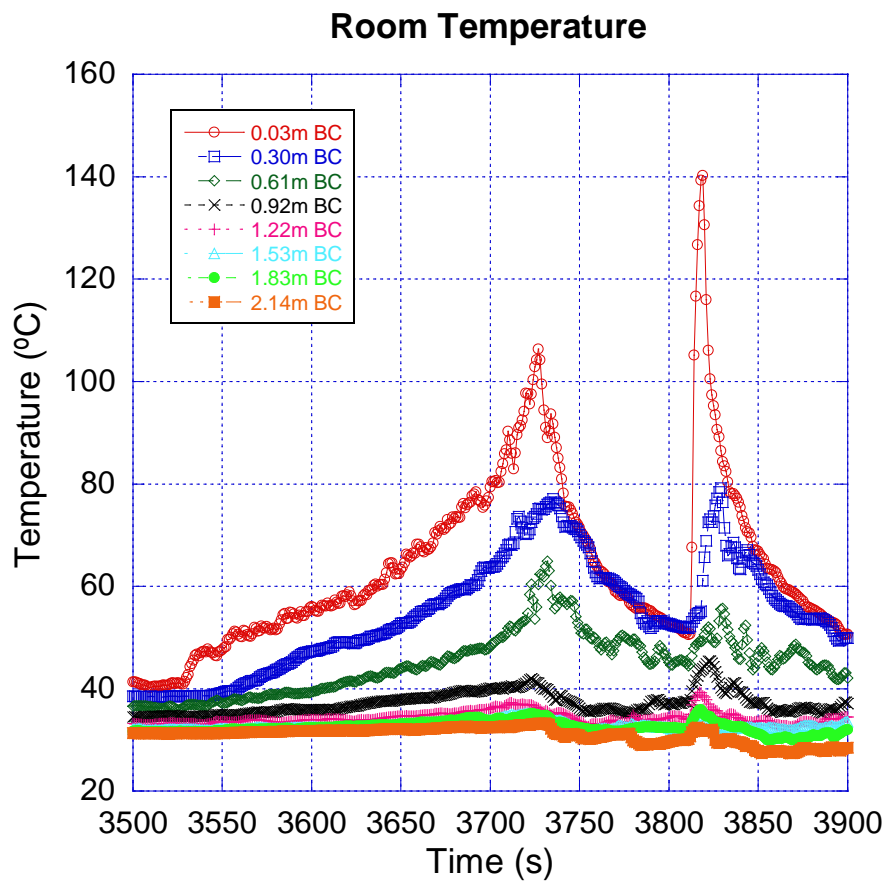

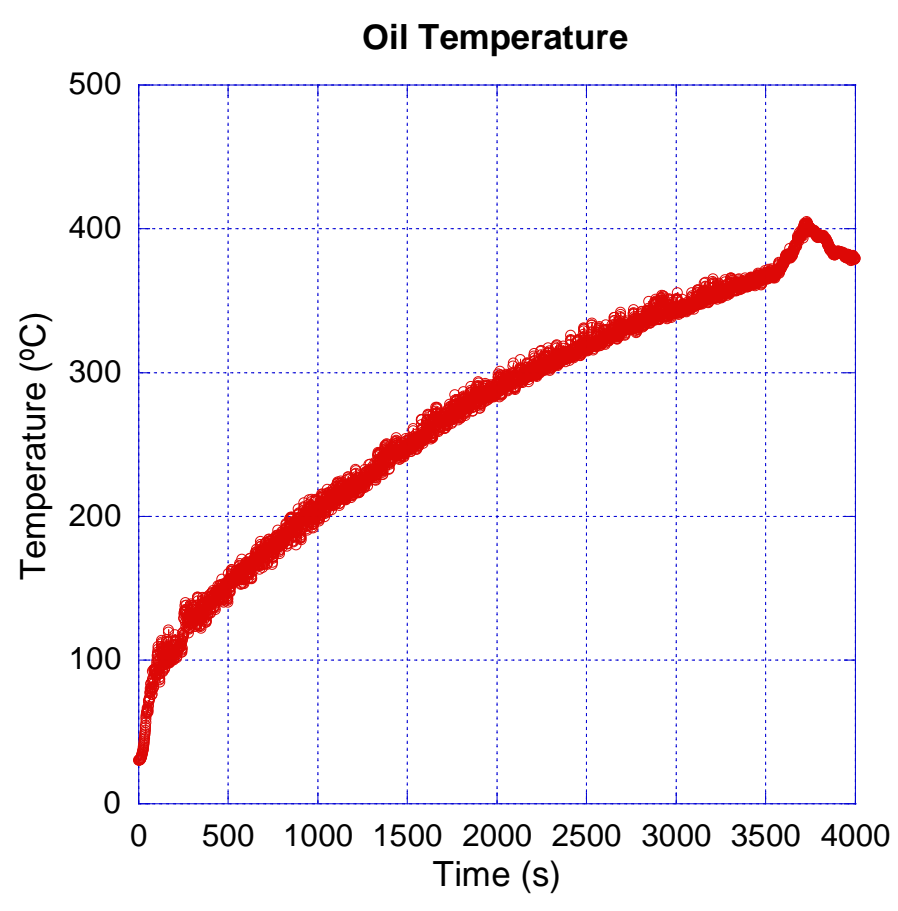

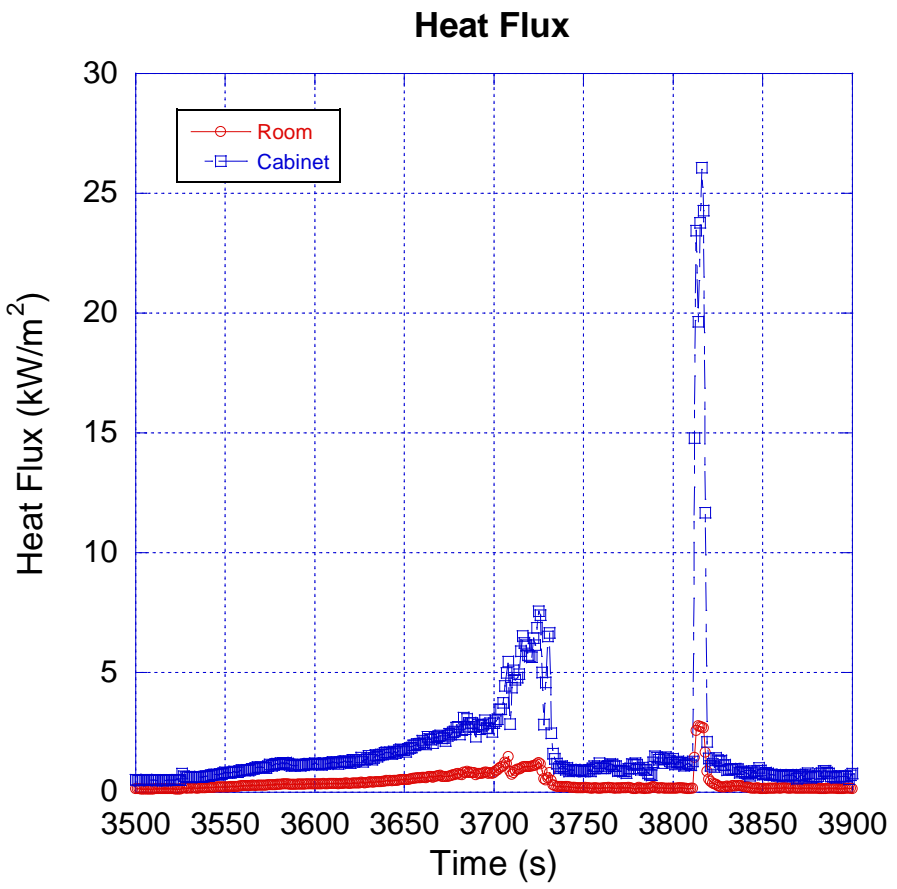

Figure A1-5. Experiment KSE 5 timeline and data 
KSE 6 Timeline

Automatic Wet Chemical 2

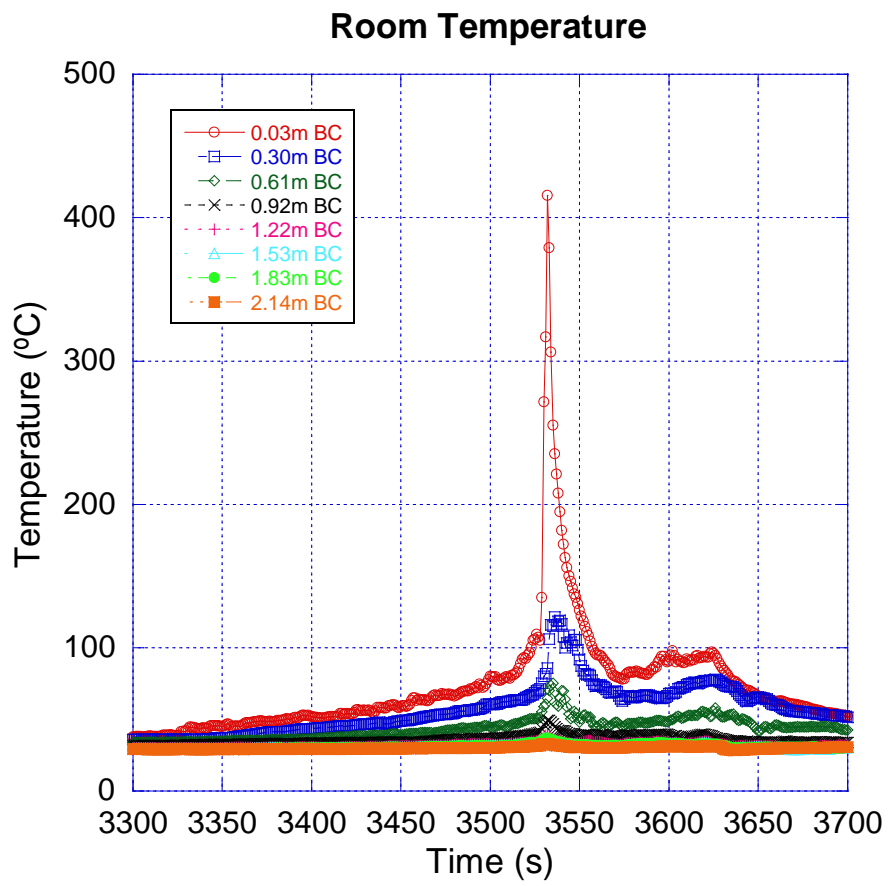

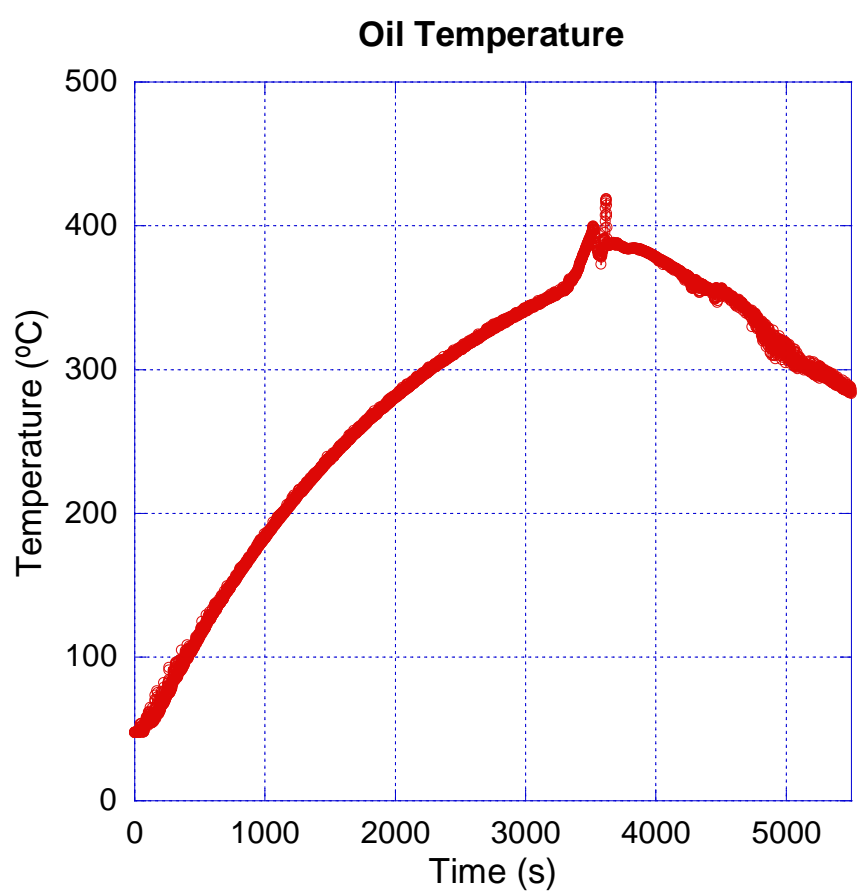

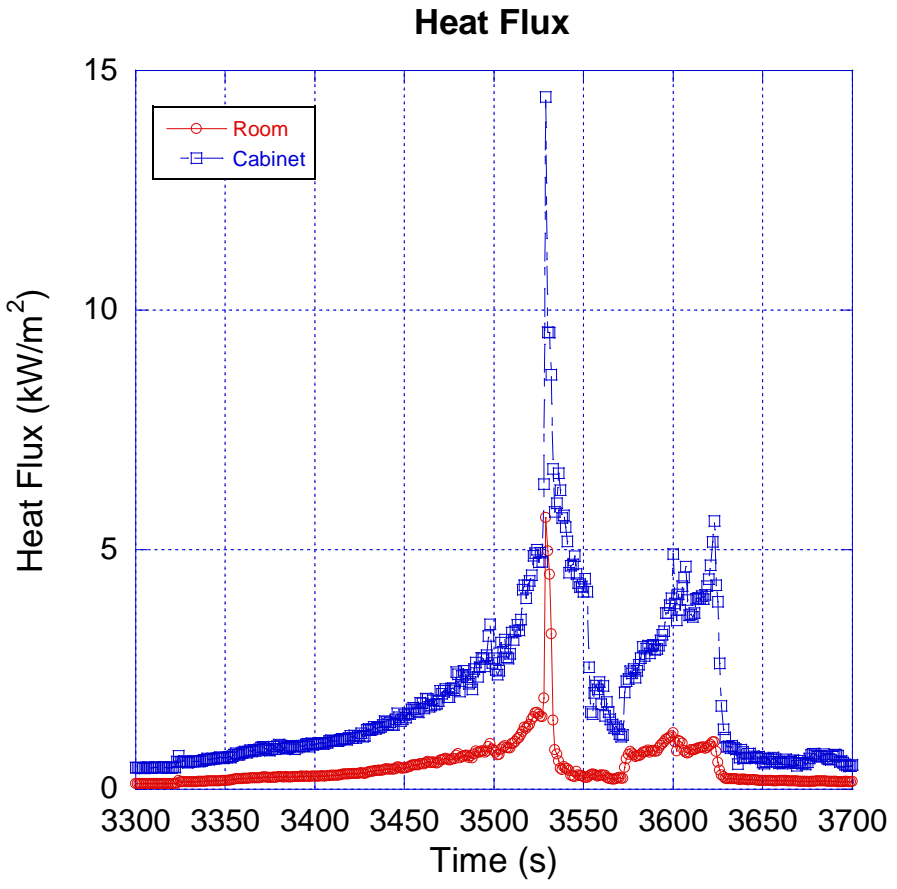

Figure A1-6. Experiment KSE 6 timeline and data 
KSE 7 Timeline

Automatic Wet Chemical 2

\begin{tabular}{|r|l|}
\hline \multicolumn{1}{|c|}{ Time } & Event \\
\hline 0 & Burner On \\
\hline 3557 & Auto Ignition \\
\hline 3749 & Auto Suppression \\
\hline 3793 & Re-Ignition \\
\hline 3808 & Manual Suppression \\
\hline & Fire Extinguished \\
\hline
\end{tabular}

Room Temperature

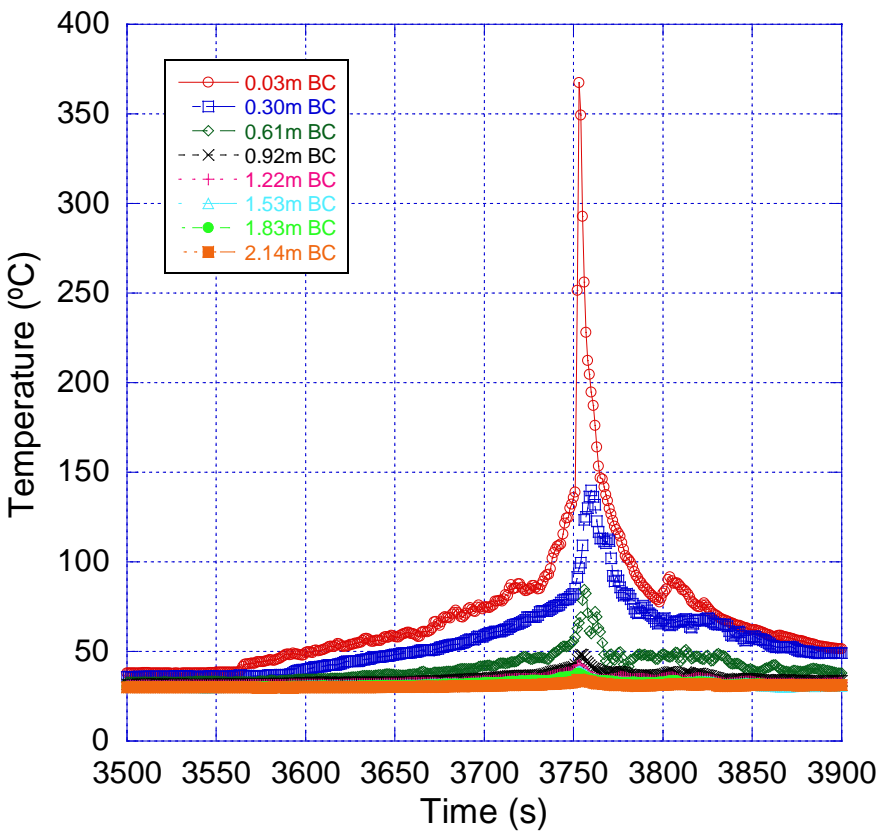

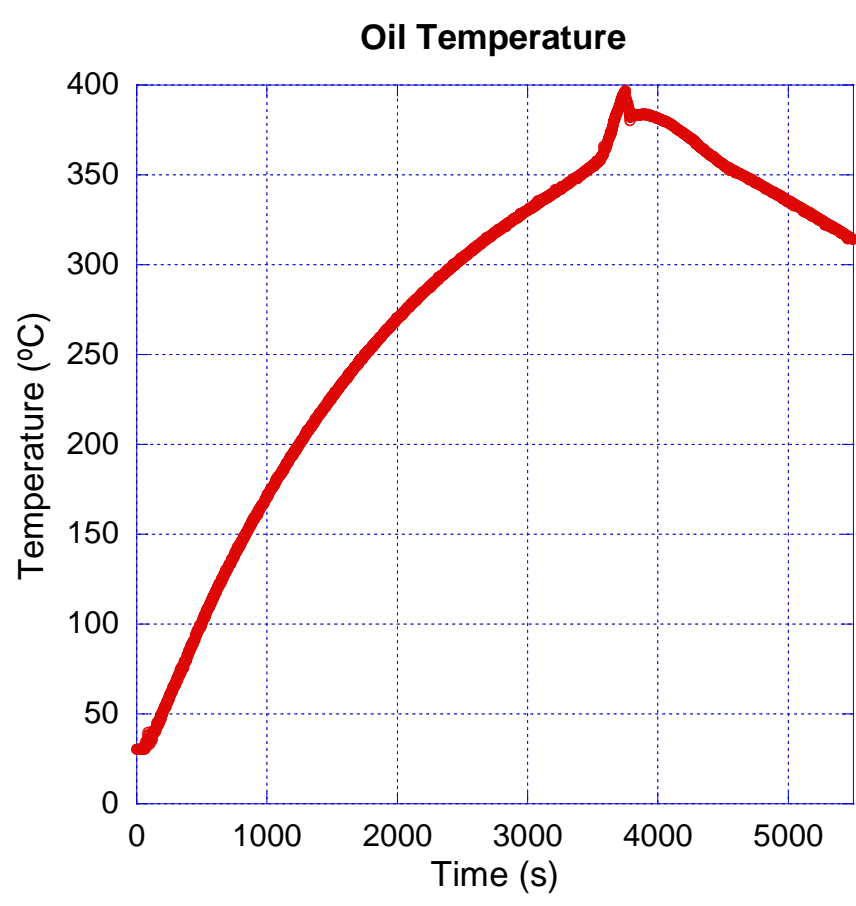

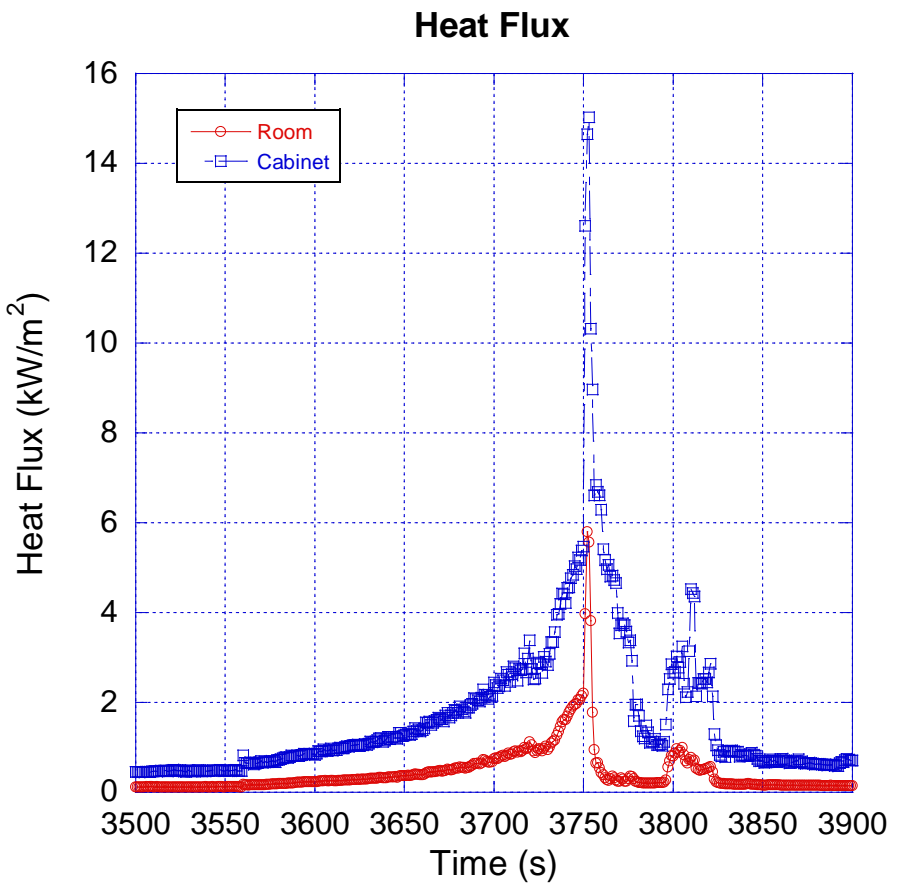

Figure A1-7. Experiment KSE 7 timeline and data 
KSE 8 Timeline

Automatic Wet Chemical 2

\begin{tabular}{|r|l|}
\hline \multicolumn{1}{|l|}{ Time } & Event \\
\hline 0 & Burner On \\
\hline 3358 & Auto Ignition \\
\hline 3513 & Auto Suppression (No Discharge) \\
\hline & Fire Not Extinguished \\
\hline 3546 & Manual Suppression \\
\hline & Fire Extinguished \\
\hline
\end{tabular}

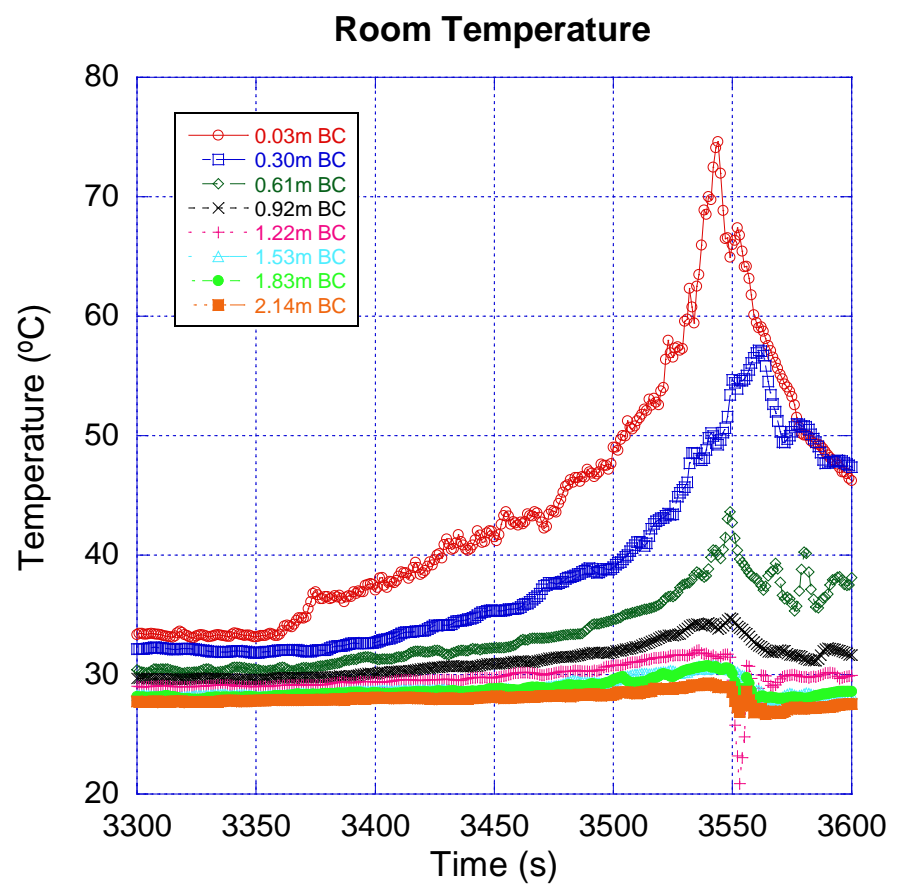

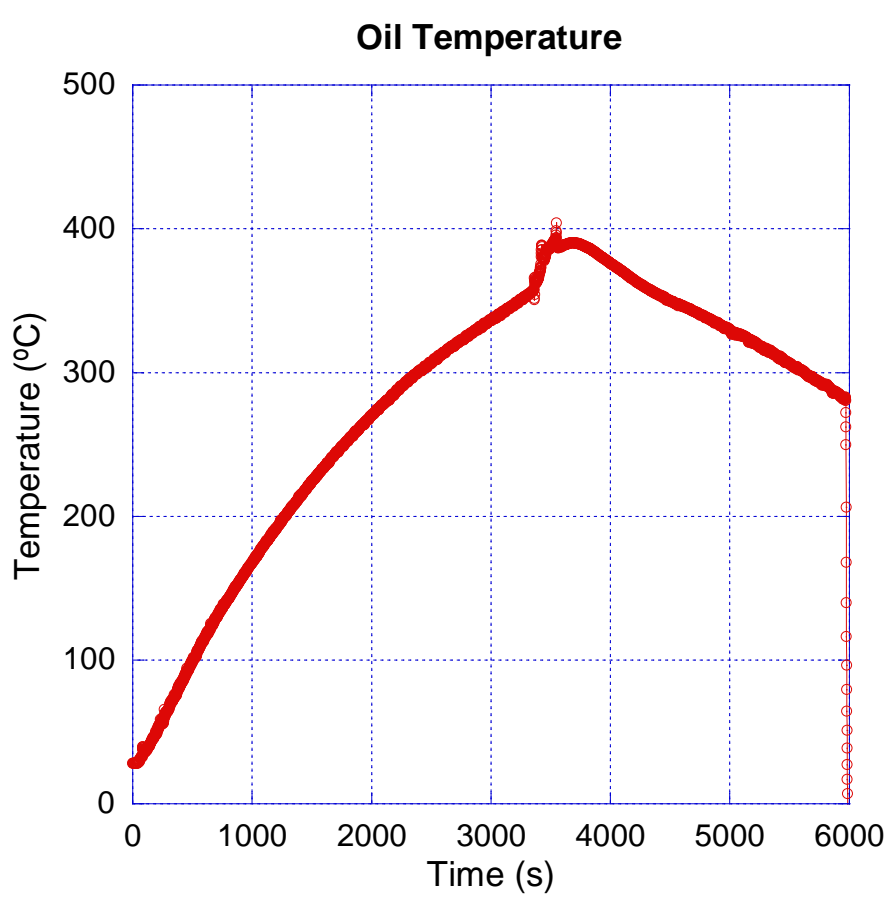

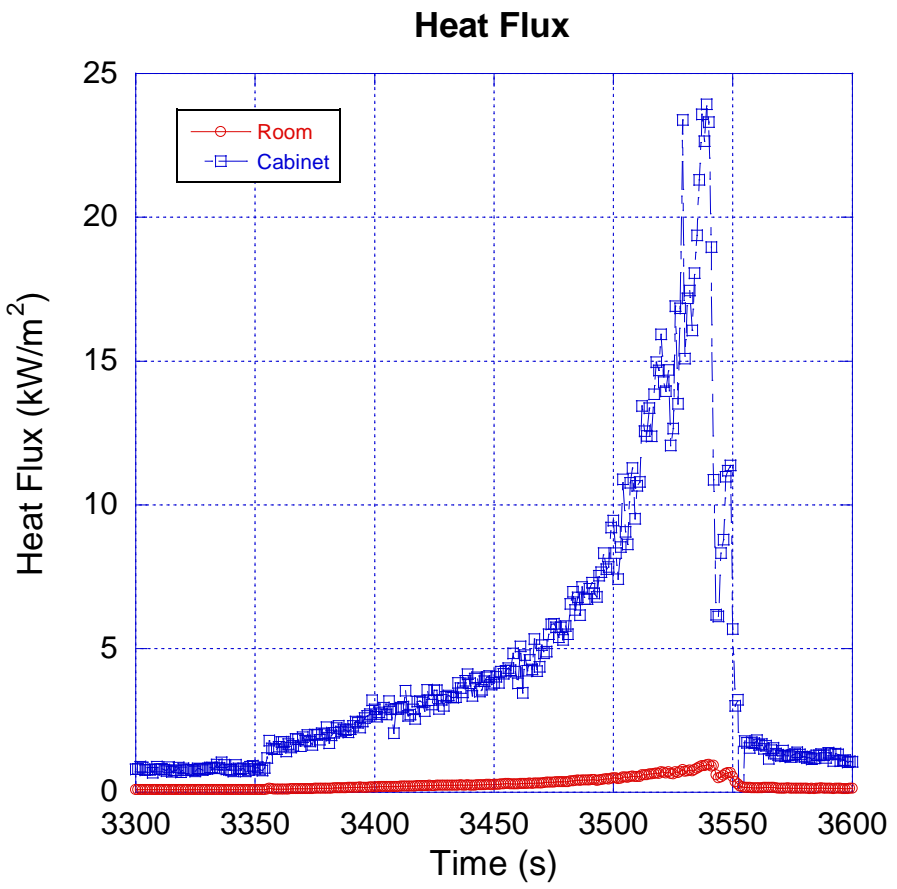

Figure A1-8. Experiment KSE 8 timeline and data 
KSE 9 Timeline

Automatic Wet Chemical 2

\begin{tabular}{|r|l|}
\hline \multicolumn{1}{|l|}{ Time } & Event \\
\hline 0 & Burner On \\
\hline 3632 & Auto Ignition \\
\hline 3763 & Auto Suppression \\
\hline 3844 & Re-Ignition \\
\hline 3862 & Manual Suppression \\
\hline & Fire Extinguished \\
\hline
\end{tabular}

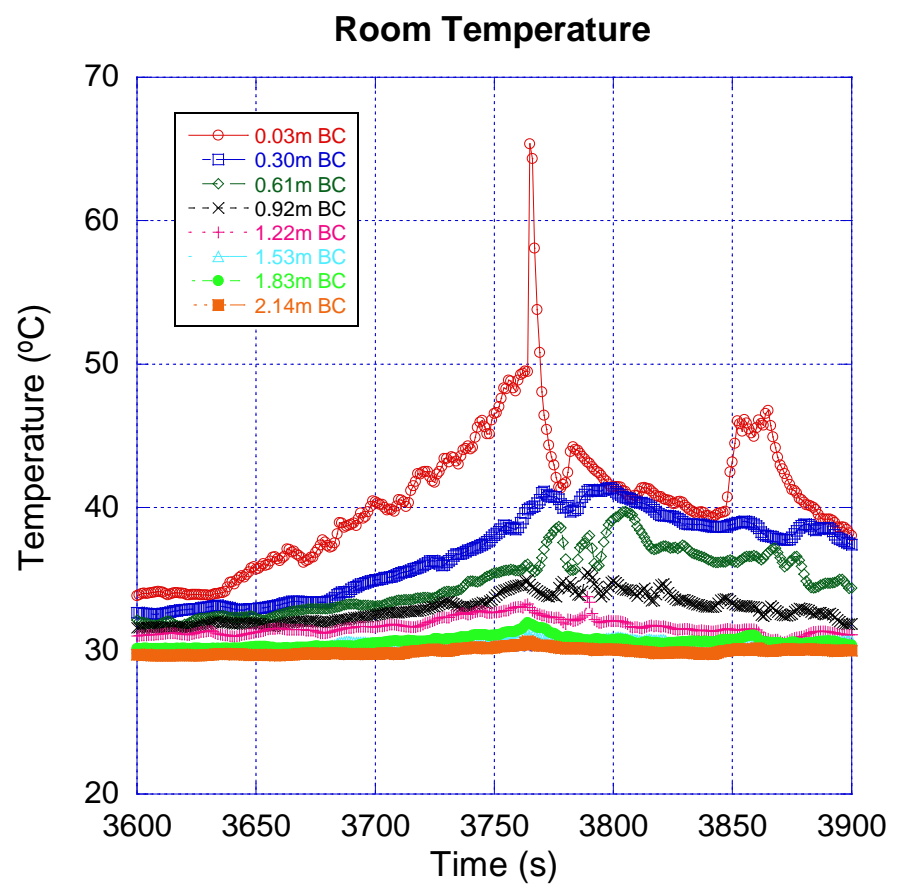

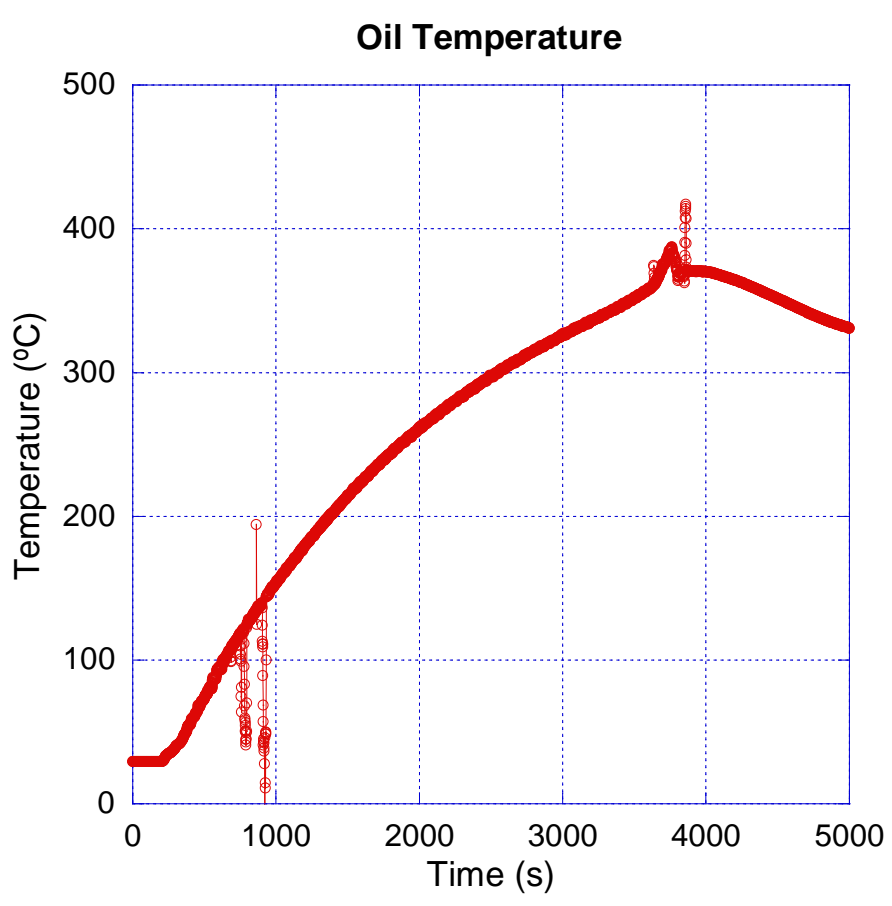

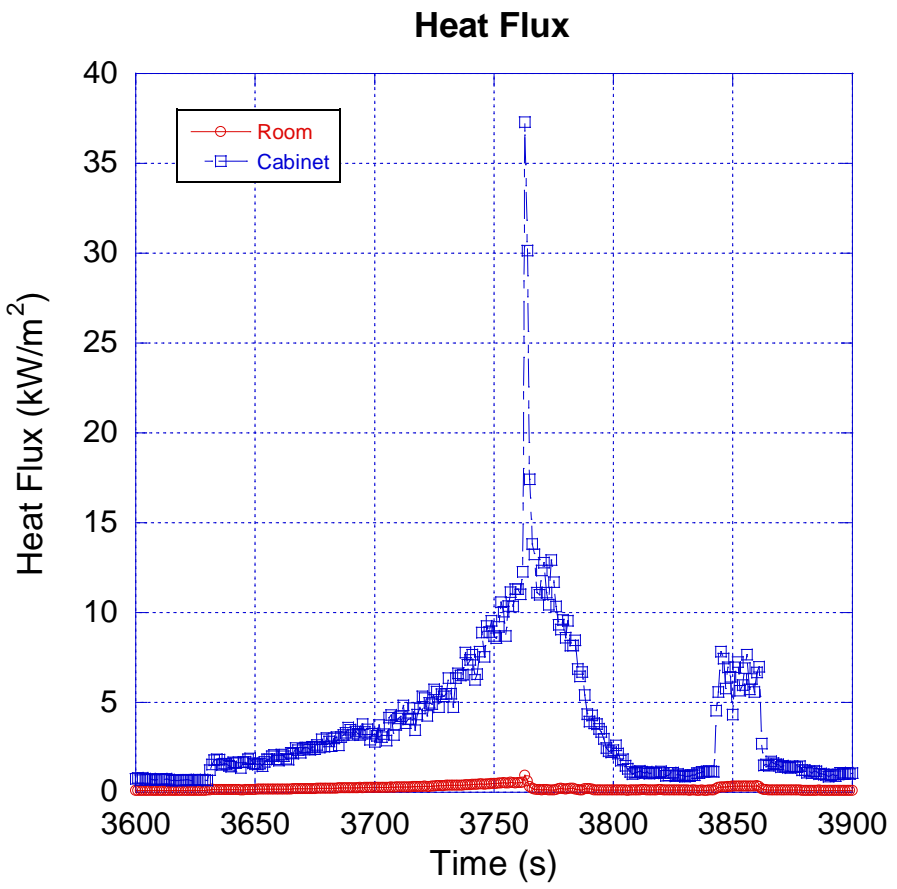

Figure A1-9. Experiment KSE 9 timeline and data 

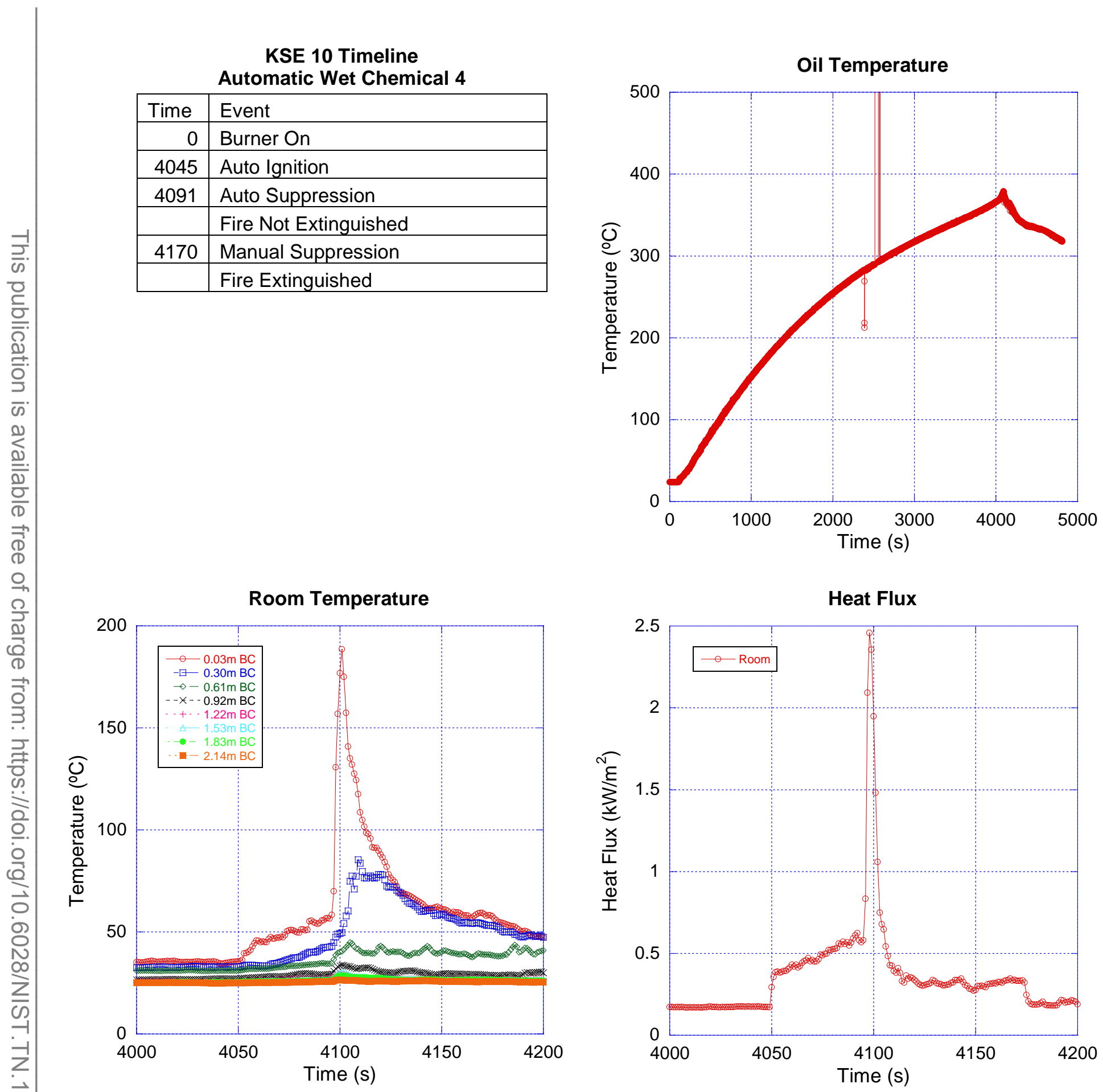

Figure A1-10. Experiment KSE 10 timeline and data 

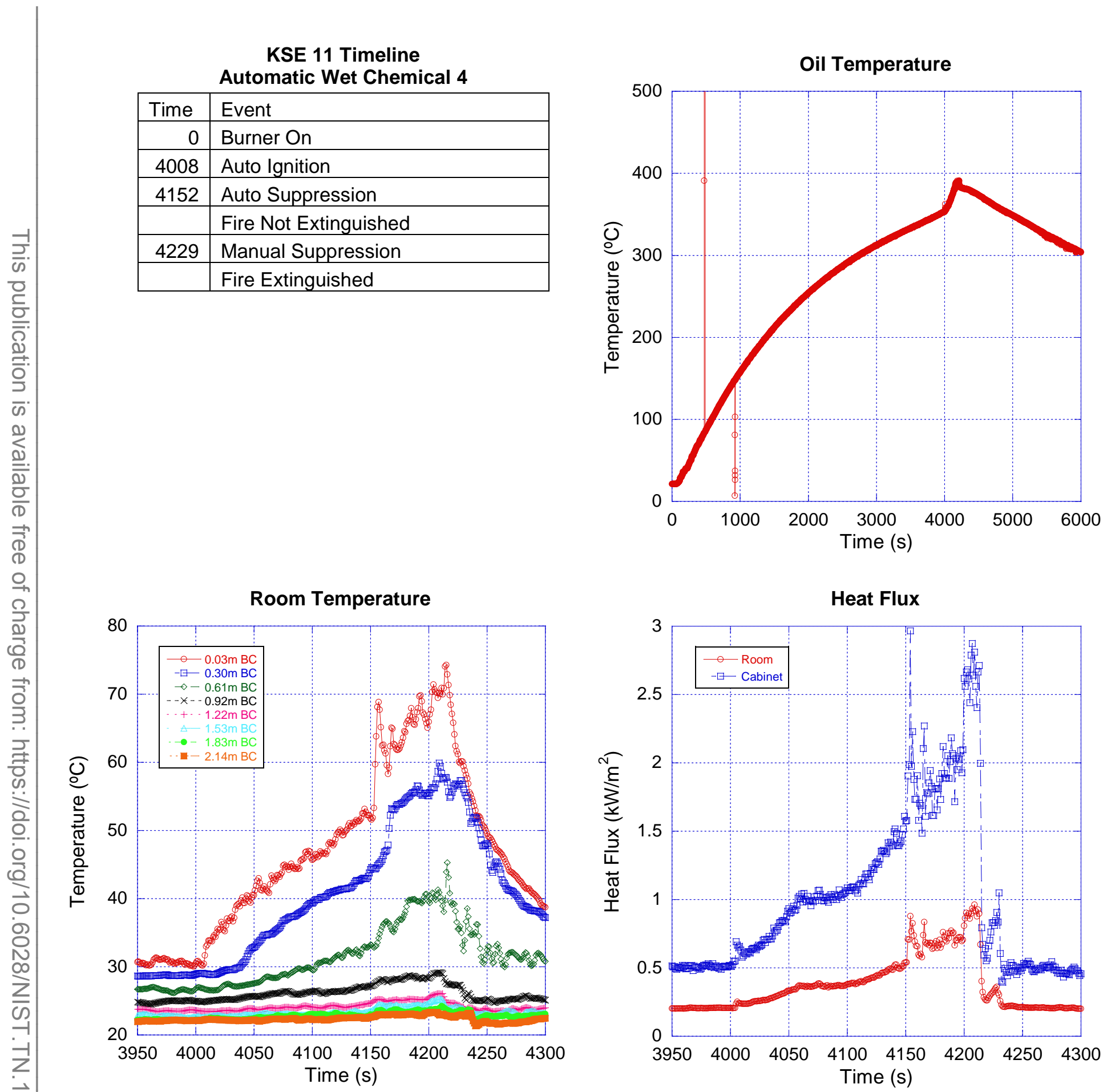

Figure A1-11. Experiment KSE 11 timeline and data 
KSE 12 Timeline Manual Wet Chemical

\begin{tabular}{|r|l|}
\hline \multicolumn{1}{|c|}{ Time } & Event \\
\hline 0 & Burner On \\
\hline 4158 & Auto Ignition \\
\hline 4221 & Manual Suppression \\
\hline & Fire Extinguished \\
\hline
\end{tabular}

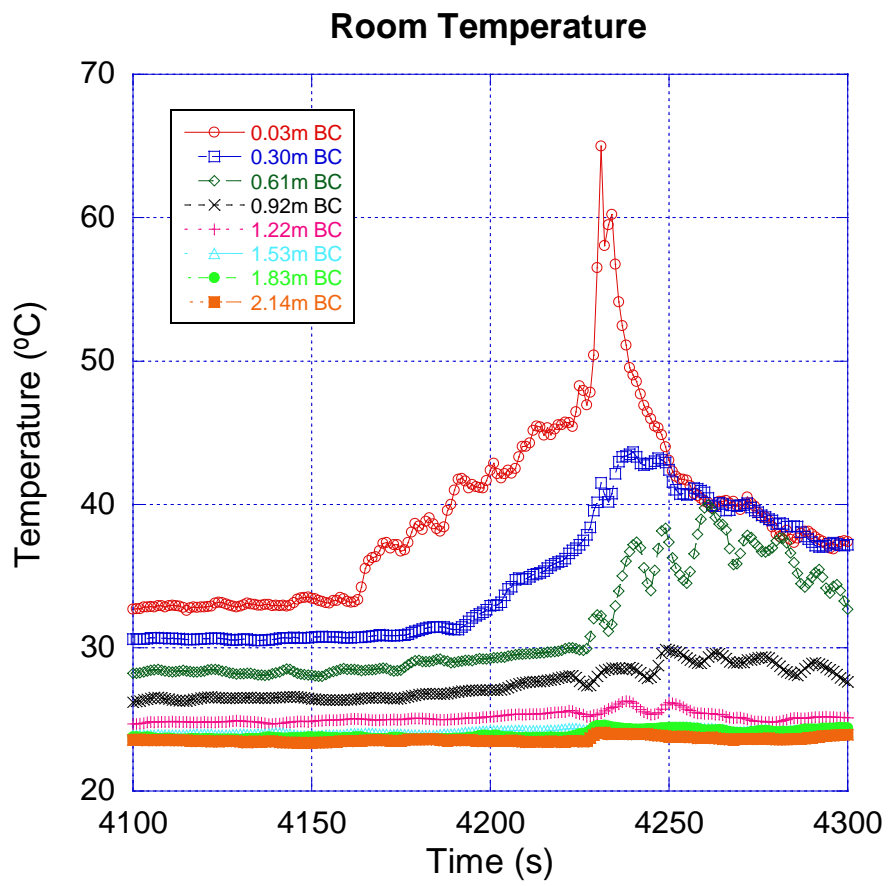

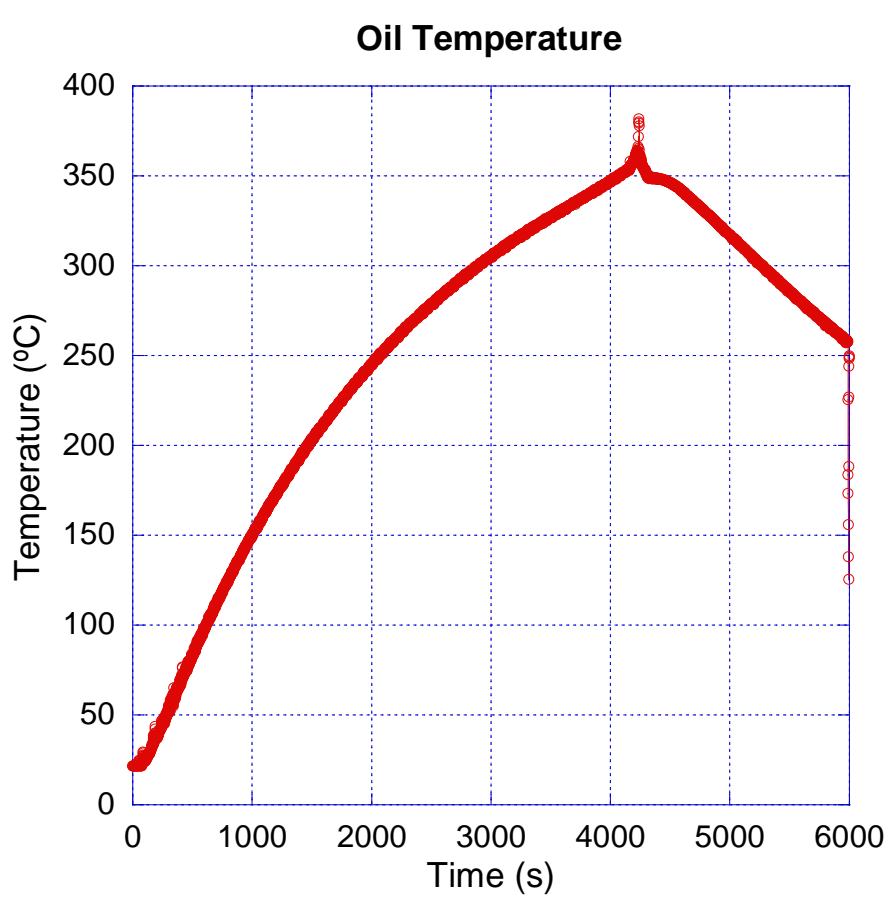

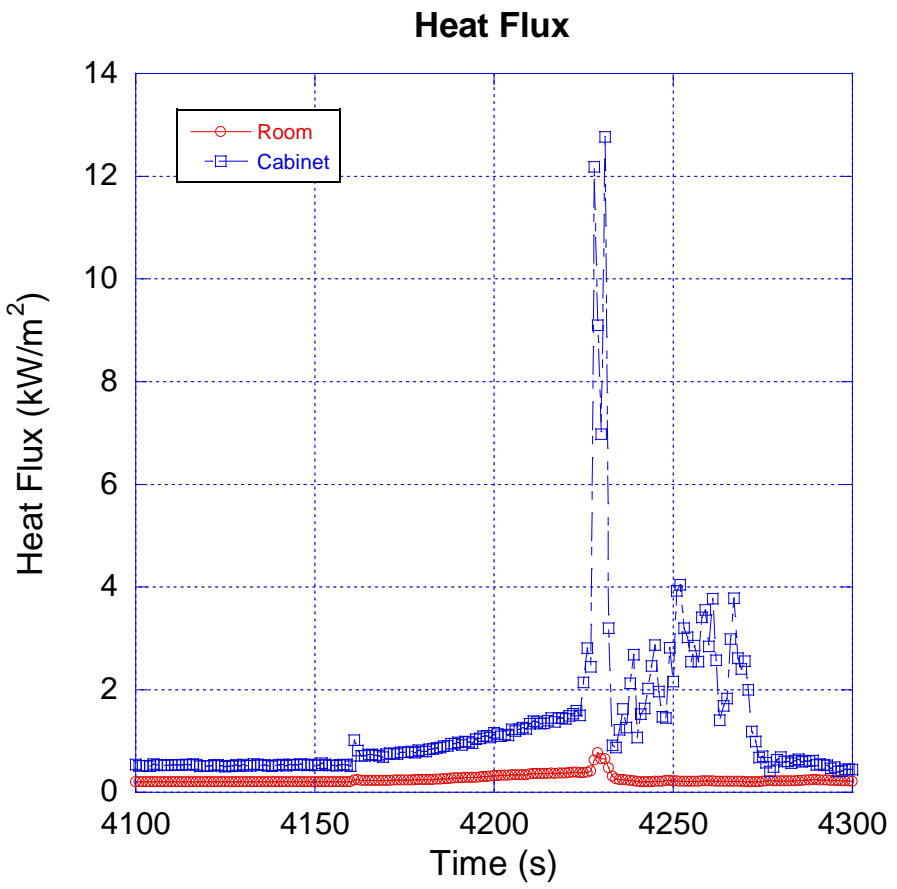

Figure A1-12. Experiment KSE 12 timeline and data 
KSE 13 Timeline Manual Wet Chemical

\begin{tabular}{|r|l|}
\hline Test & Event \\
\hline 0 & Burner On \\
\hline 4010 & Auto Ignition \\
\hline 4073 & Manual Suppression \\
\hline & Fire Extinguished \\
\hline
\end{tabular}

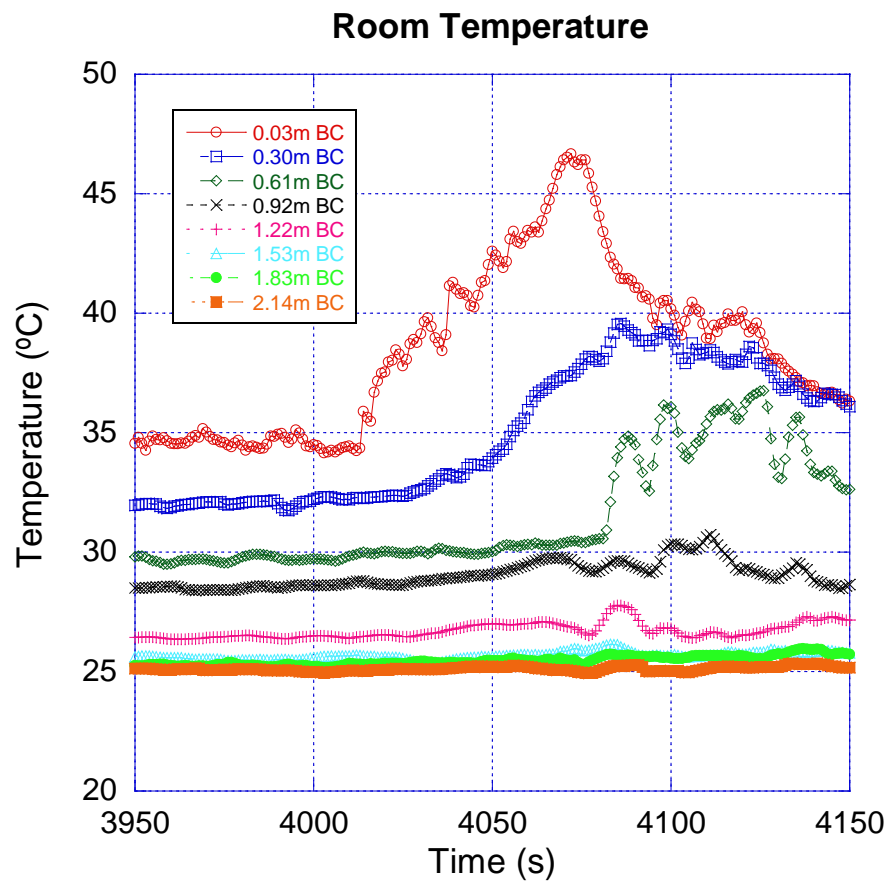

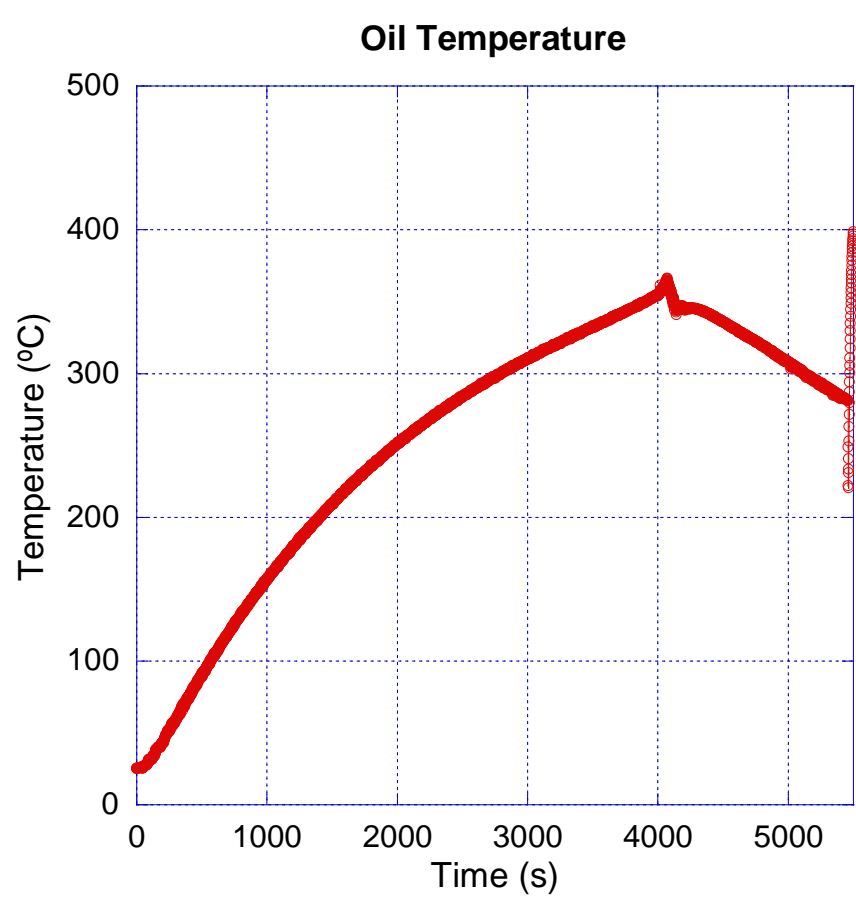

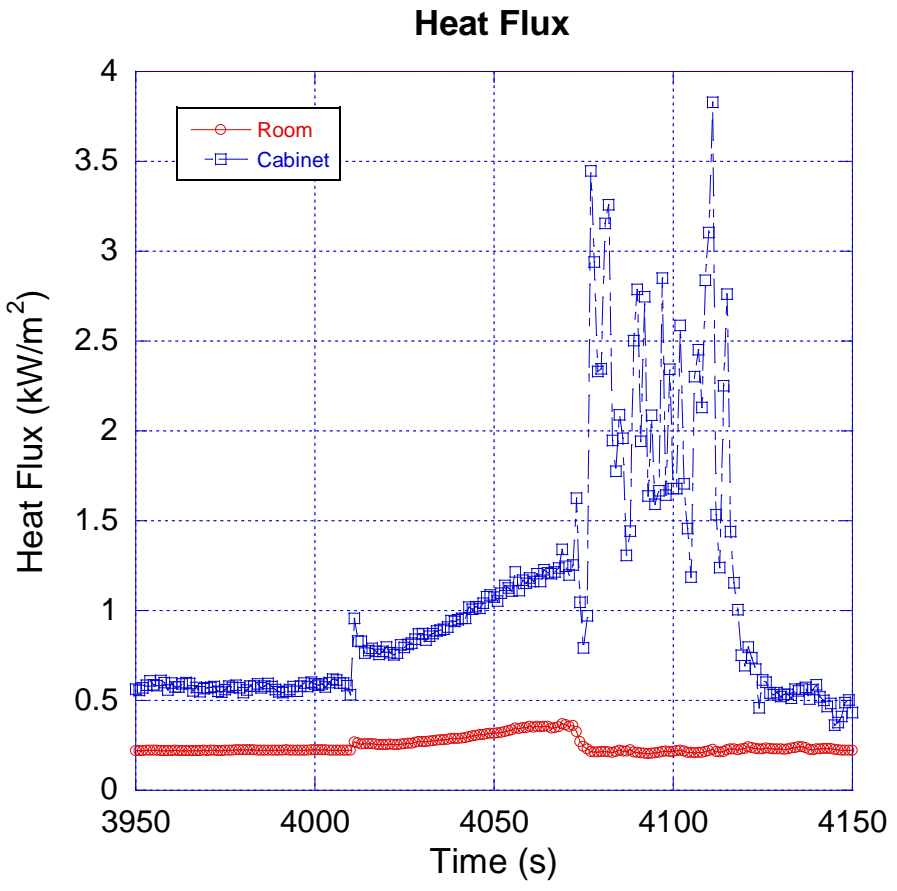

Figure A1-13. Experiment KSE 13 timeline and data 

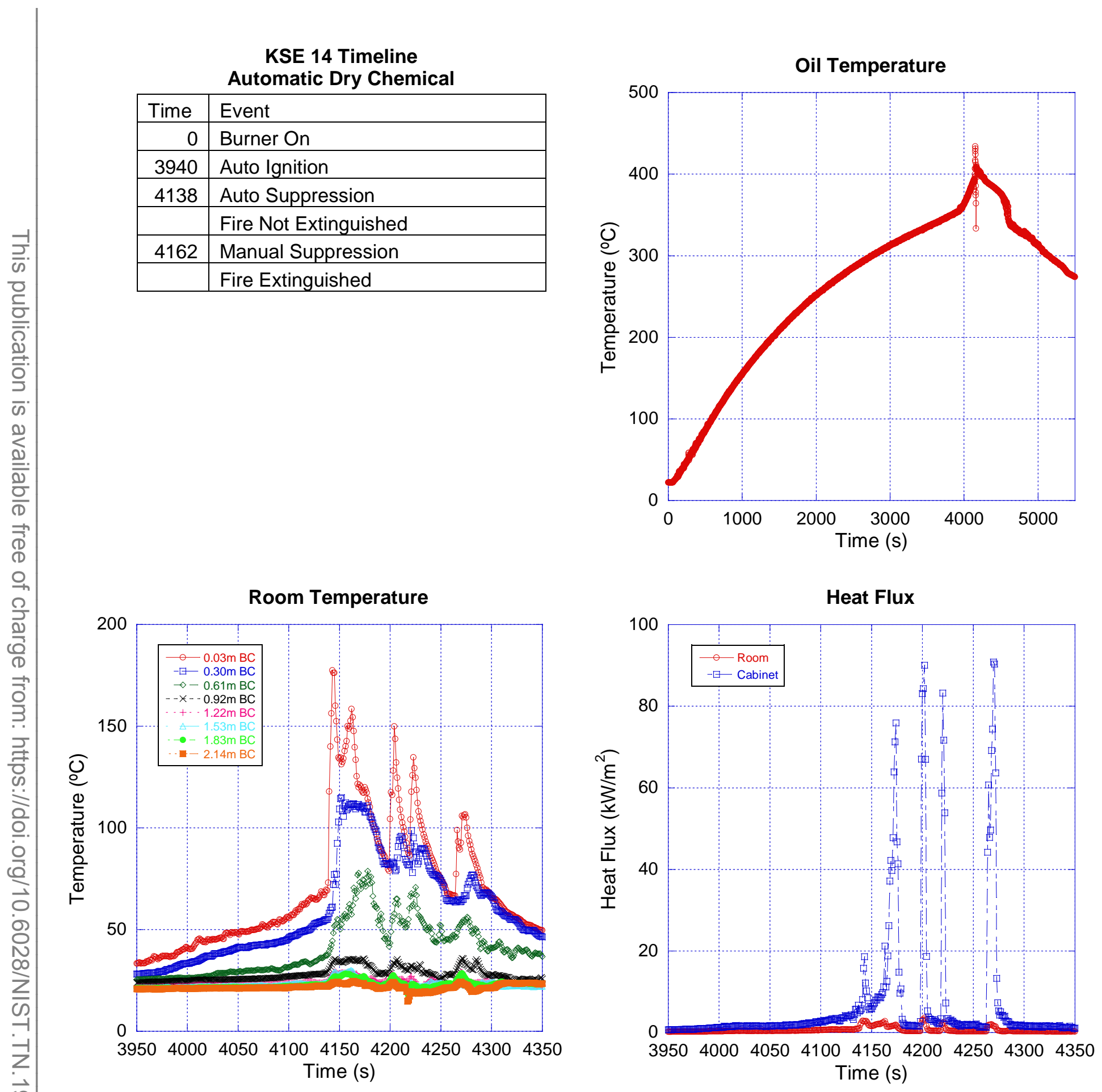

Figure A1-14. Experiment KSE 14 timeline and data 
KSE 15 Timeline Manual Dry Chemical

\begin{tabular}{|r|l|}
\hline \multicolumn{1}{|l|}{ Time } & Event \\
\hline 0 & Burner On \\
\hline 3647 & Auto Ignition \\
\hline 3716 & Manual Suppression \\
\hline & Fire Extinguished \\
\hline
\end{tabular}

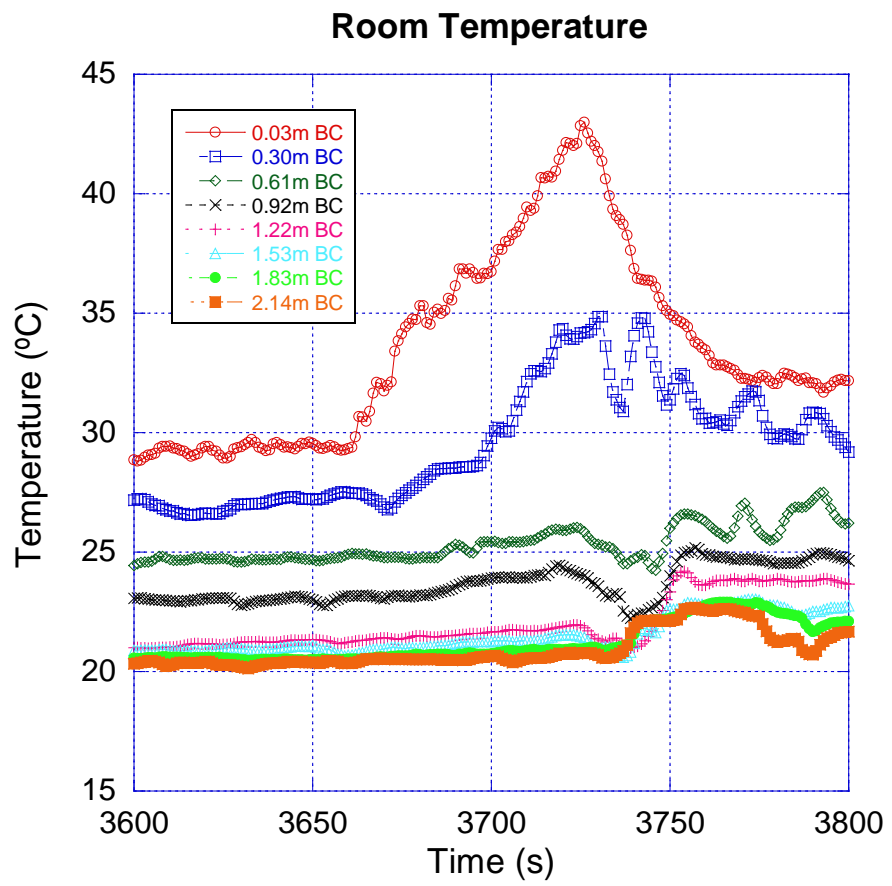

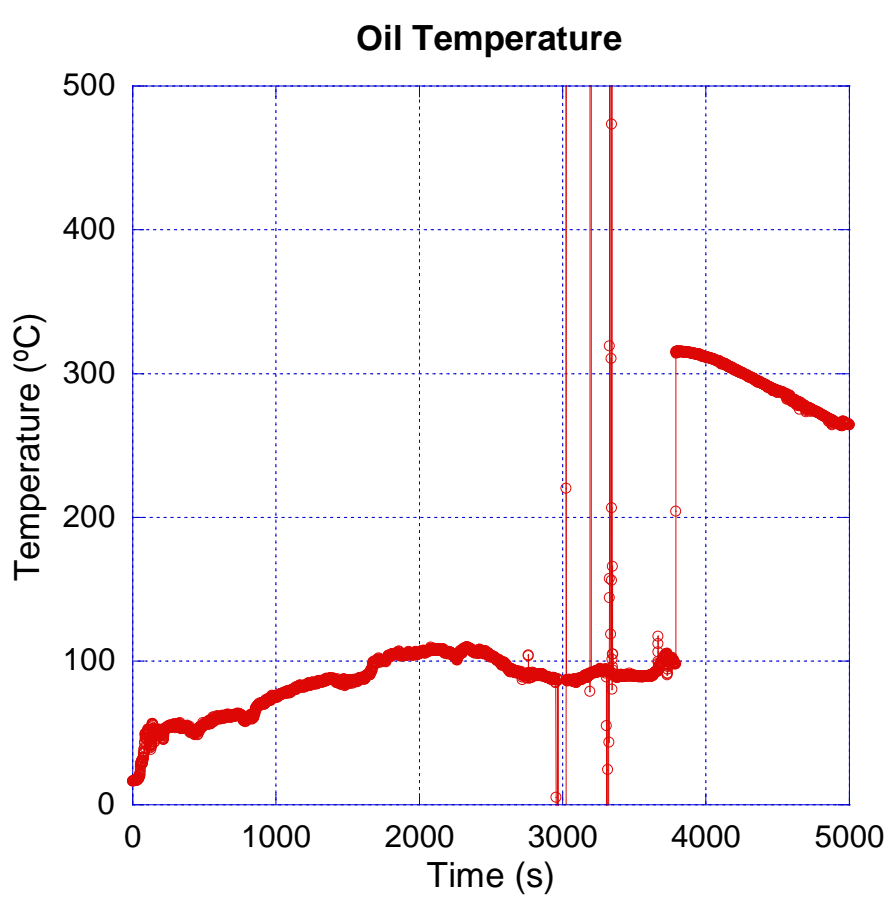

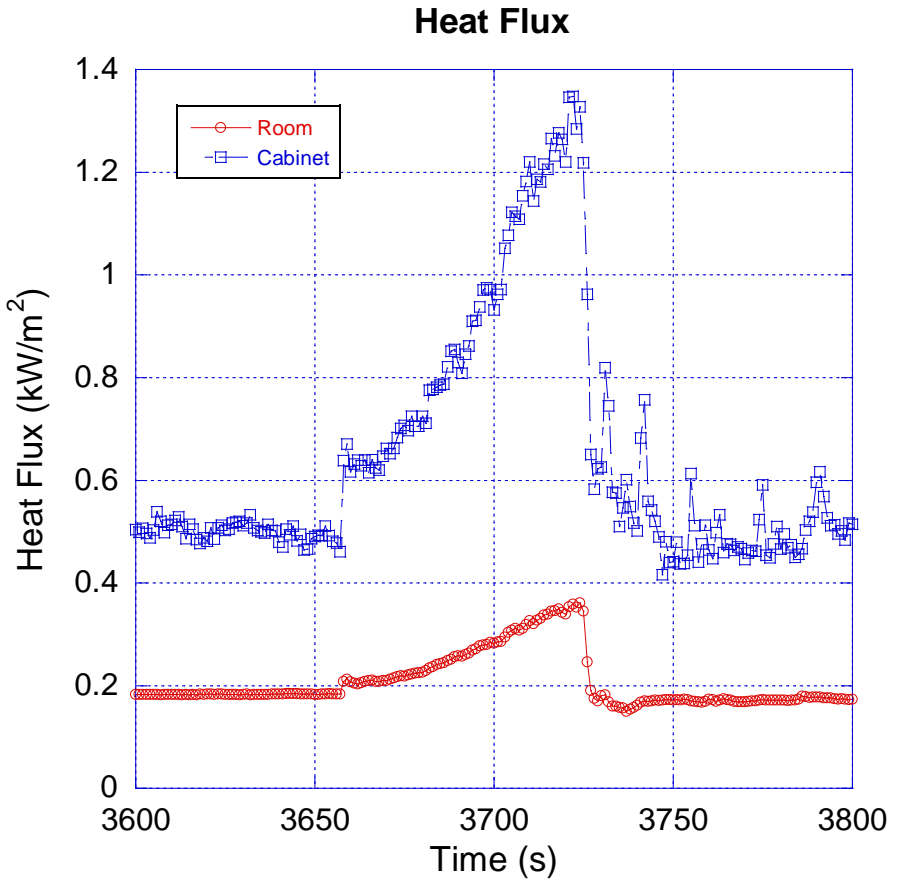

Figure A1-15. Experiment KSE 15 timeline and data 
KSE 16 Timeline

Water Mist 1

\begin{tabular}{|r|l|}
\hline \multicolumn{1}{|l|}{ Time } & Event \\
\hline 0 & Burner On \\
\hline 4694 & Auto Ignition \\
\hline 4823 & Auto Suppression Activation \\
\hline & Fire Not Extinguished \\
\hline 4991 & Manual Suppression \\
\hline & Fire Extinguished \\
\hline
\end{tabular}

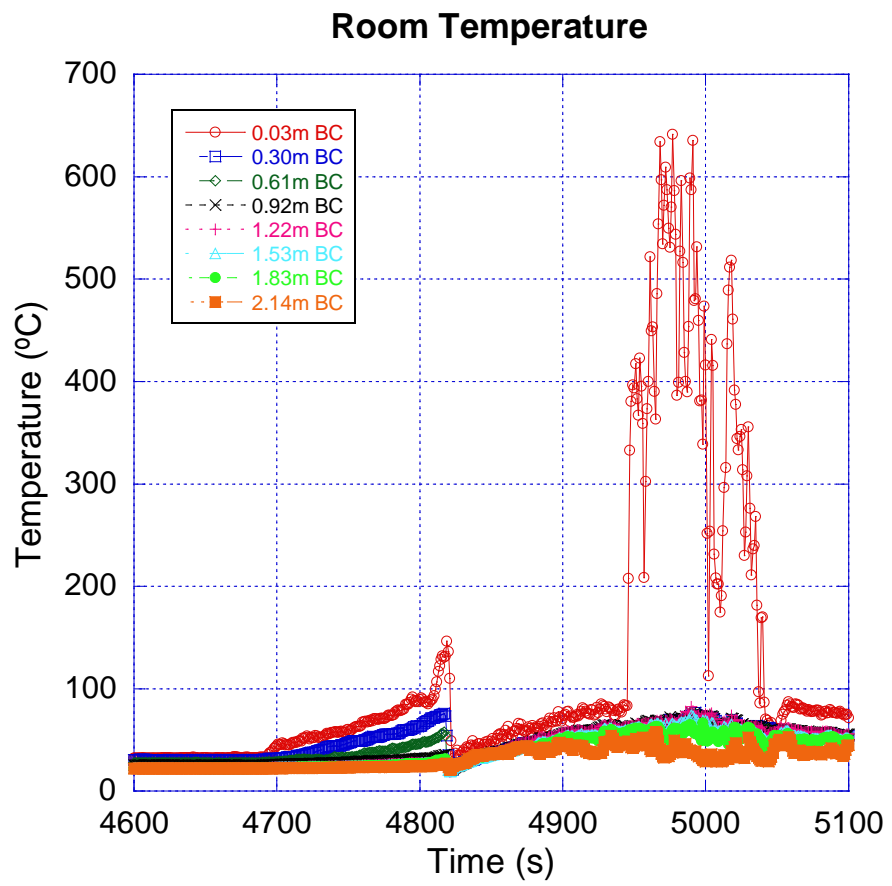

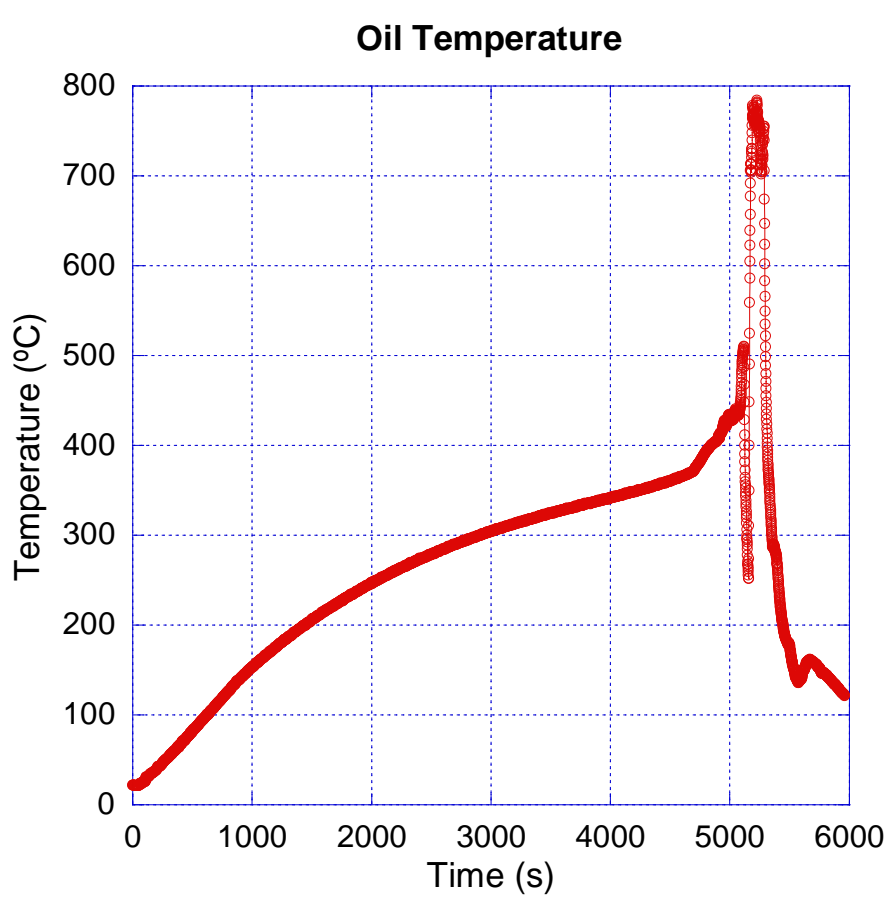

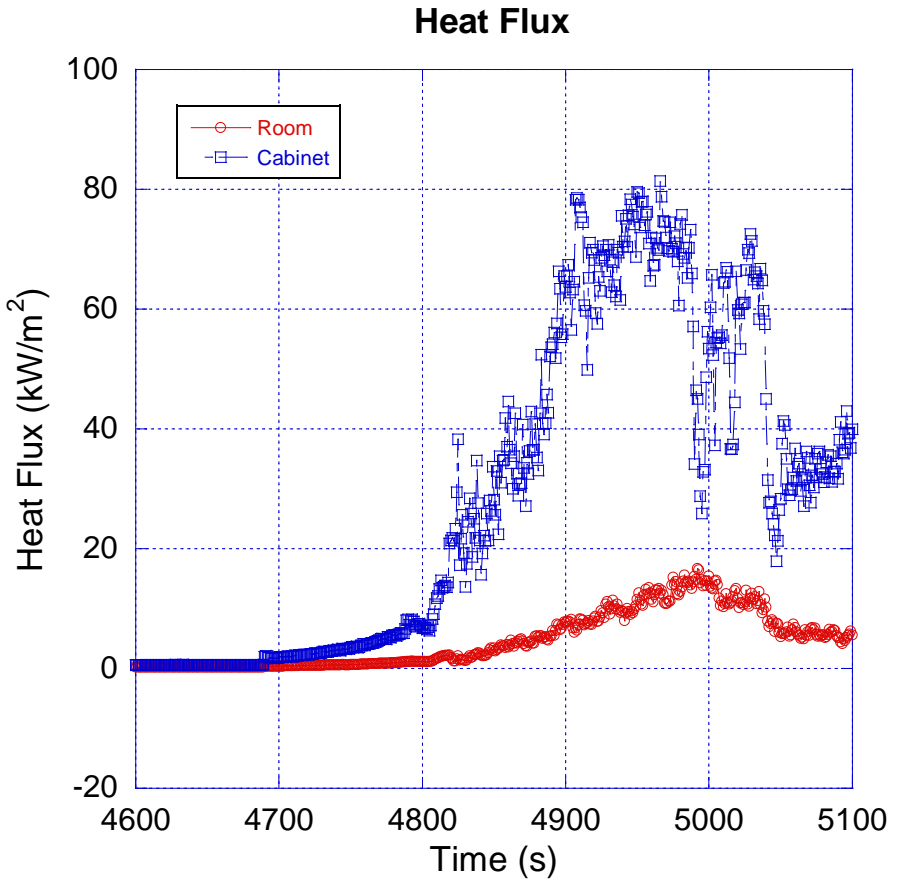

Figure A1-16. Experiment KSE 16 timeline and data 
KSE 17 Timeline Residential Sprinkler

\begin{tabular}{|r|l|}
\hline \multicolumn{1}{|c|}{ Time } & Event \\
\hline 0 & Burner On \\
\hline 4318 & Auto Ignition \\
\hline 4494 & Auto Suppression Activation \\
\hline 4765 & Fire Extinguished \\
\hline
\end{tabular}

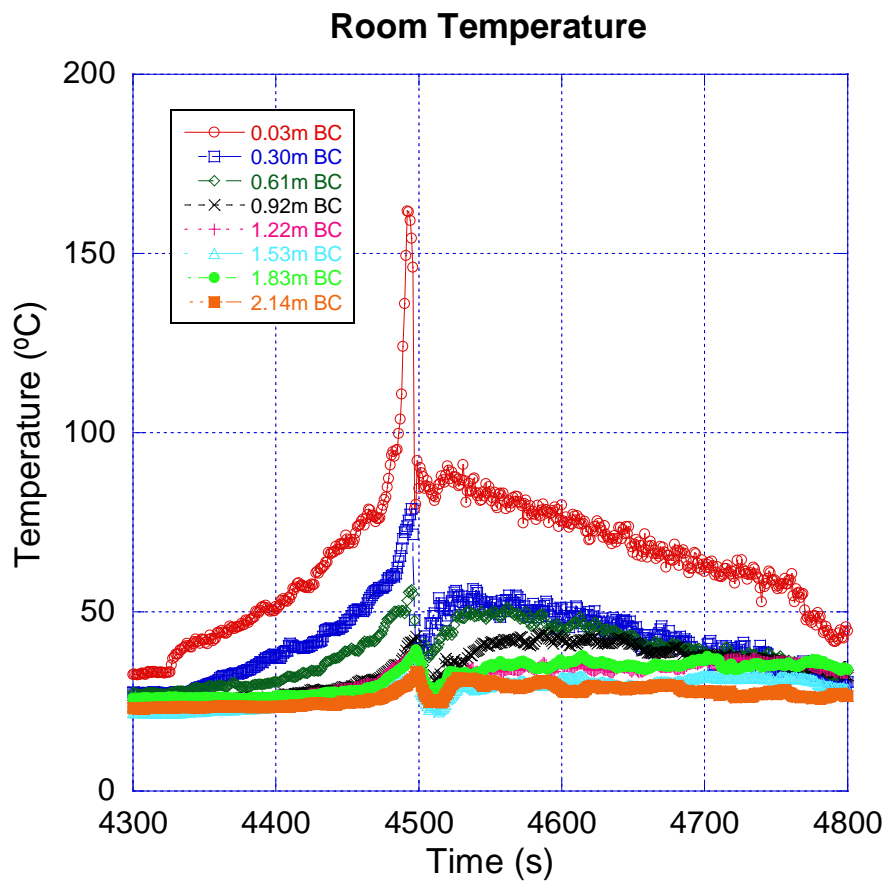

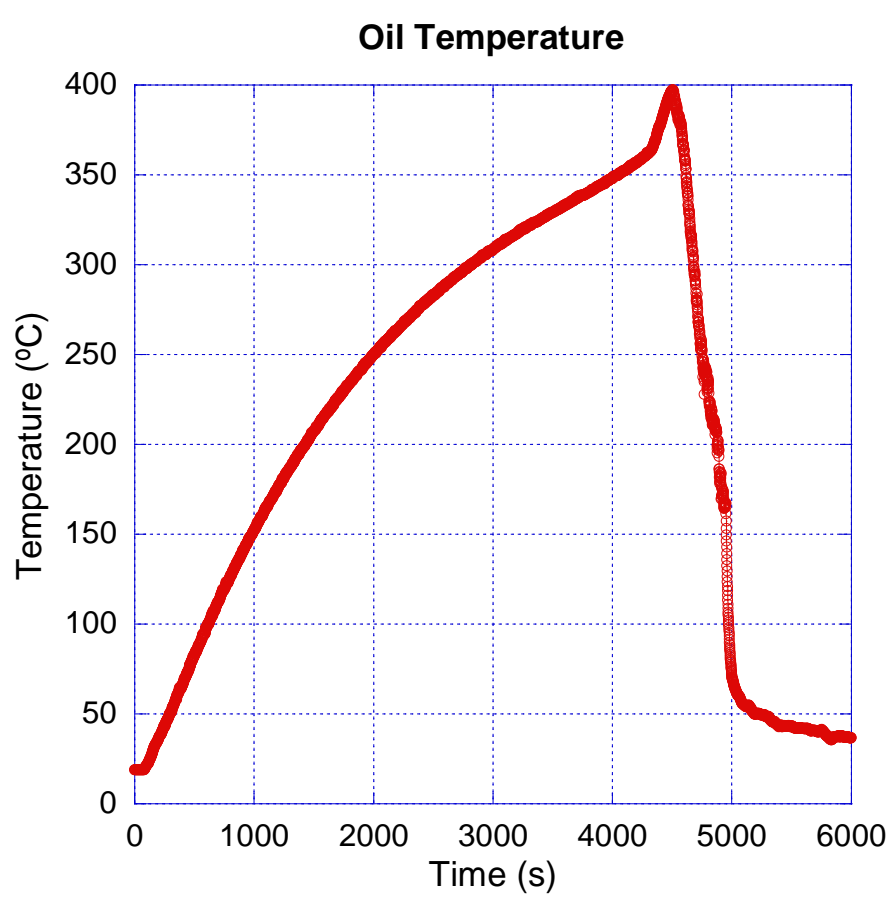

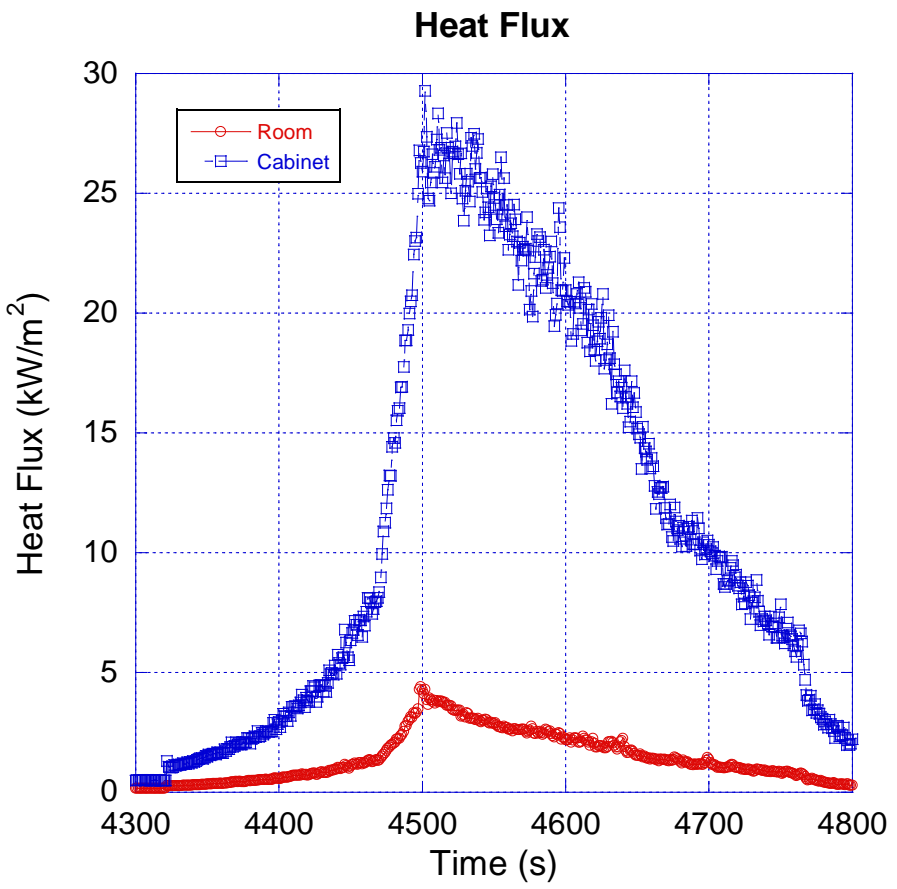

Figure A1-17. Experiment KSE 17 timeline and data 

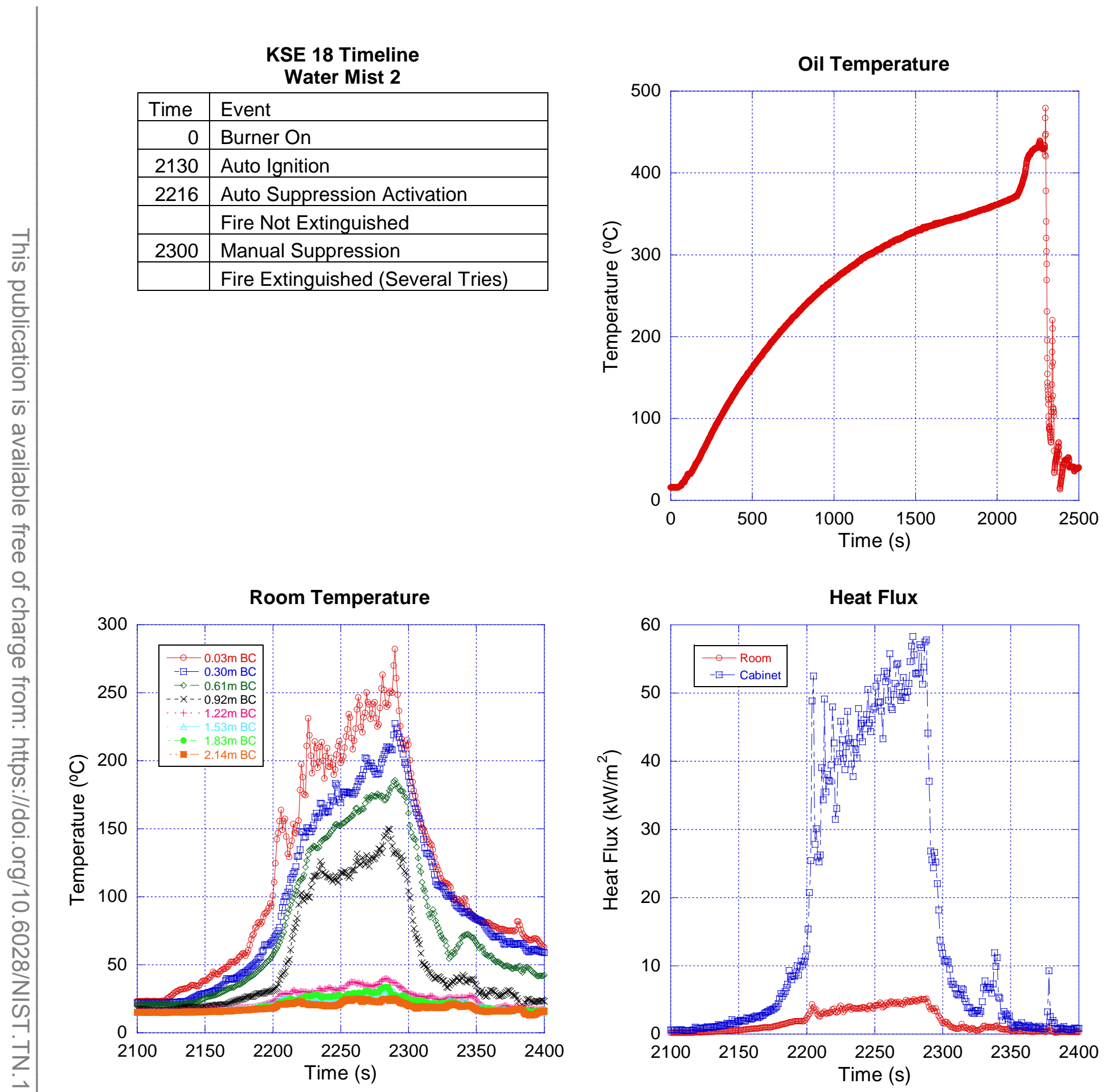

Figure A1-18. Experiment KSE 18 timeline and data 

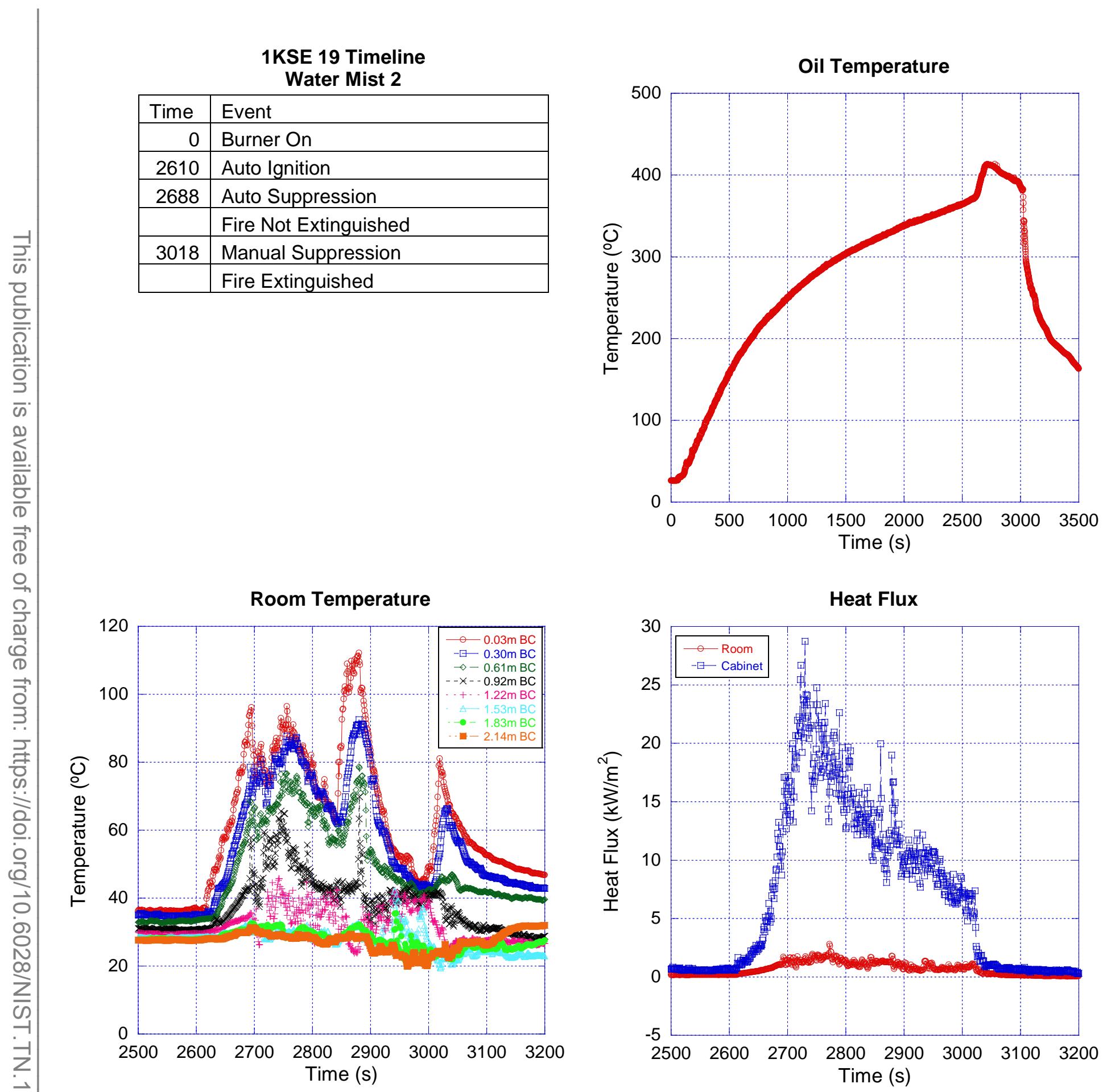

Figure A1-19. Experiment KSE 19 timeline and data 
KSE 20 Timeline

Water Mist 3

\begin{tabular}{|r|l|}
\hline \multicolumn{1}{|c|}{ Time } & Event \\
\hline 0 & Burner On \\
\hline 2445 & Auto Ignition \\
\hline 2537 & Auto Suppression \\
\hline & Fire Extinguished \\
\hline
\end{tabular}

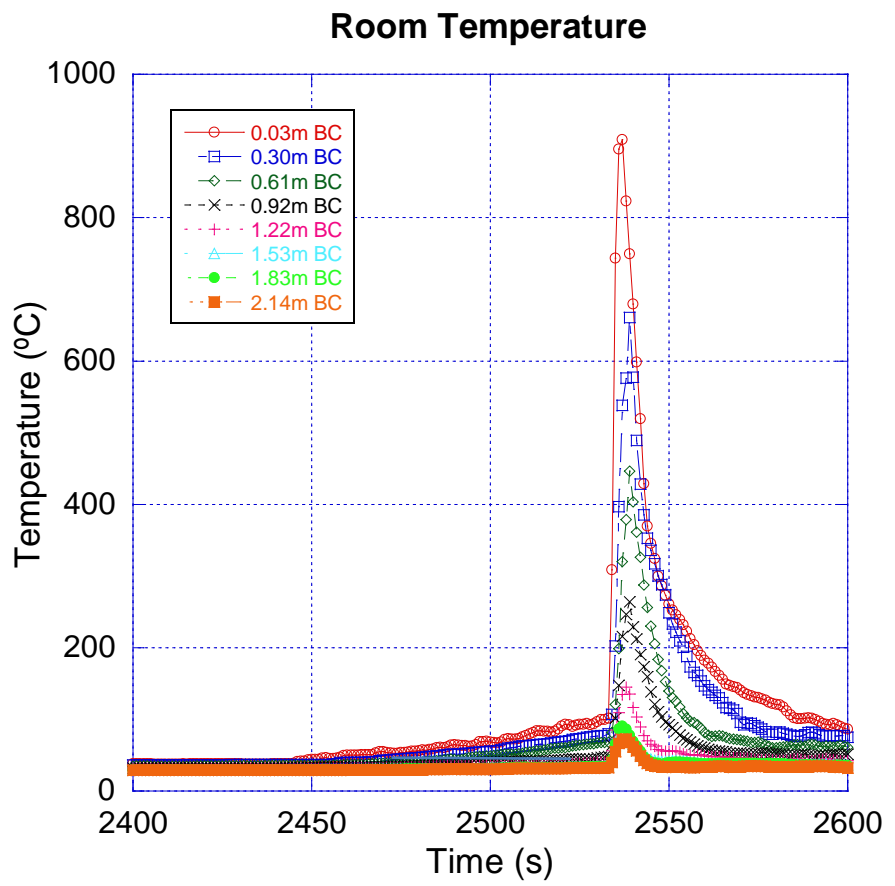

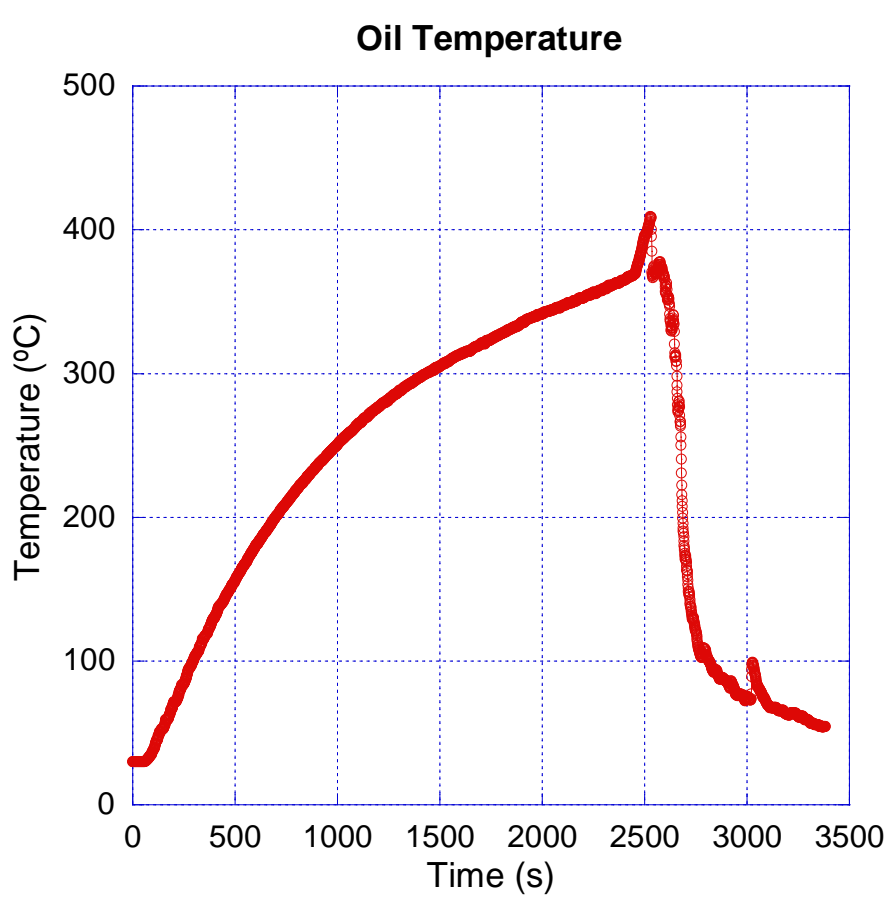

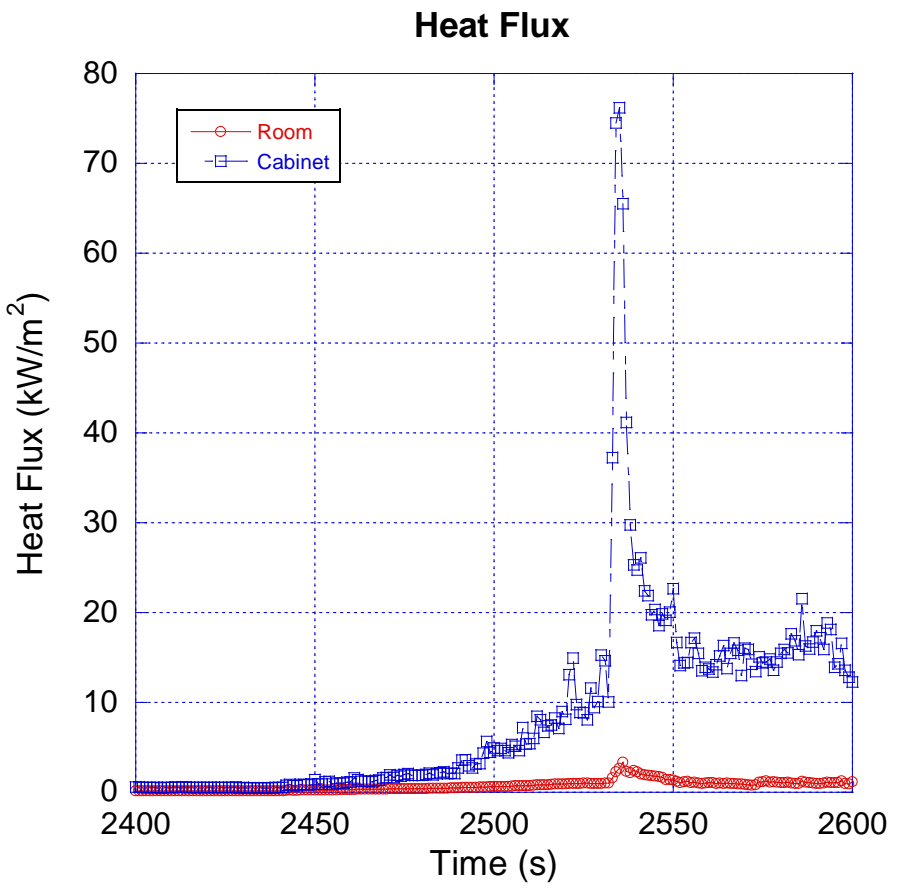

Figure A1-20. Experiment KSE 20 timeline and data 
KSE 21 Timeline

Automatic Wet Chemical 4

\begin{tabular}{|r|l|}
\hline Time & Event \\
\hline 0 & Burner On \\
\hline 3805 & Auto Ignition \\
\hline 3810 & Auto Suppression \\
\hline & Fire Extinguished \\
\hline
\end{tabular}

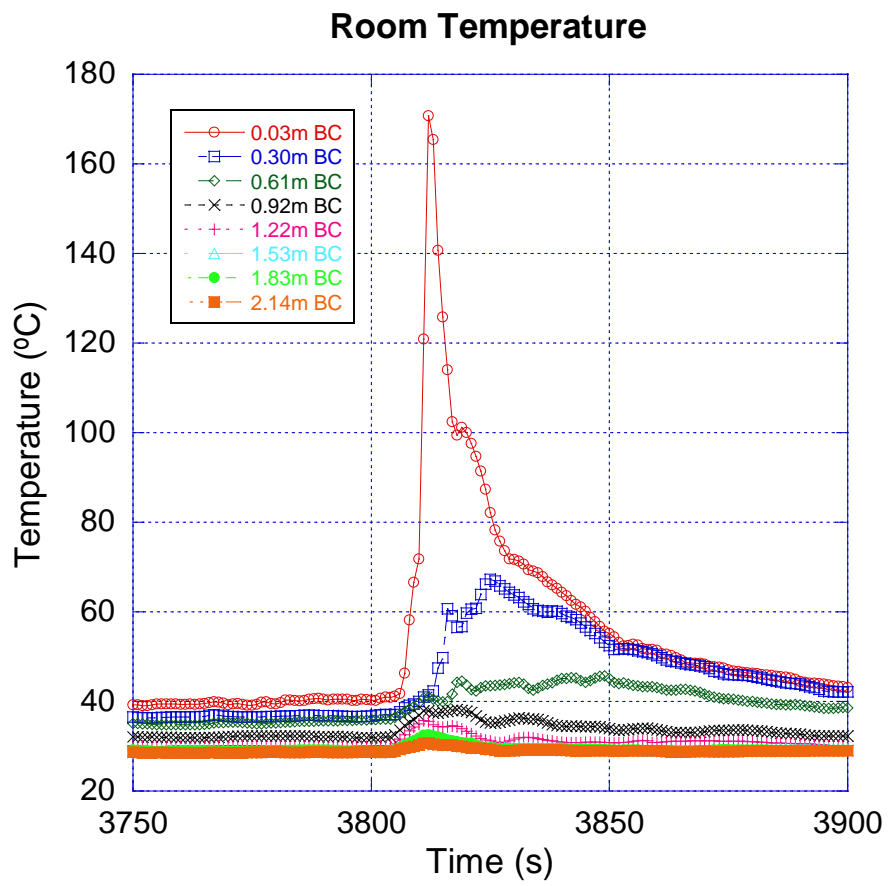

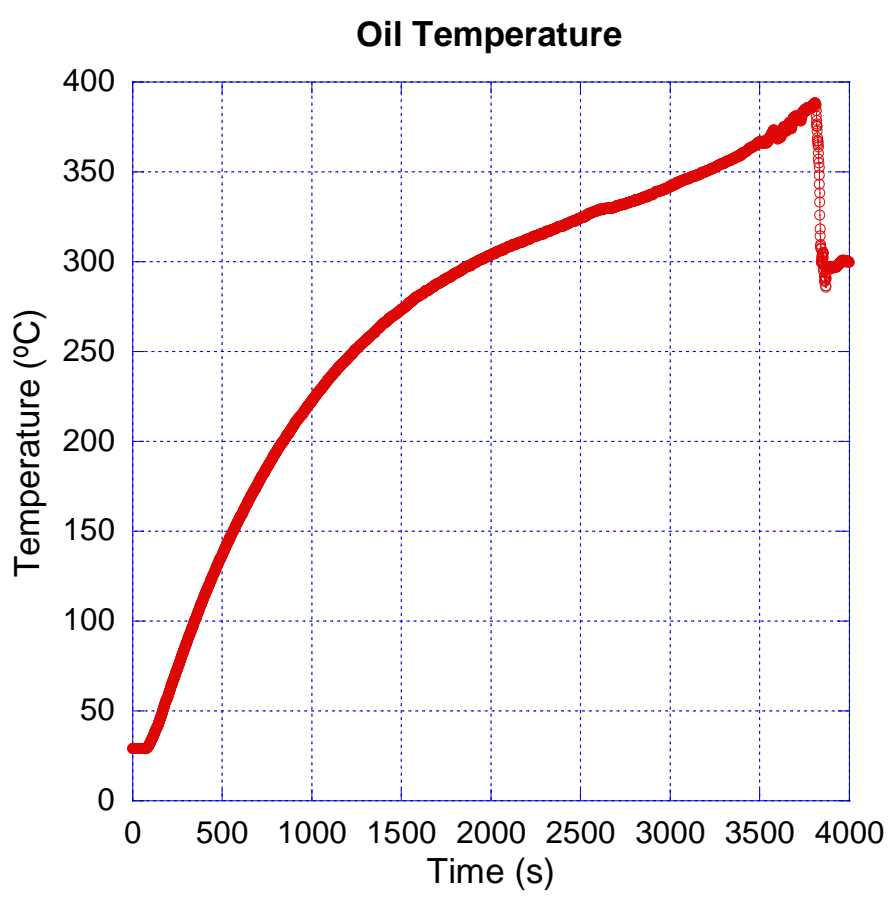

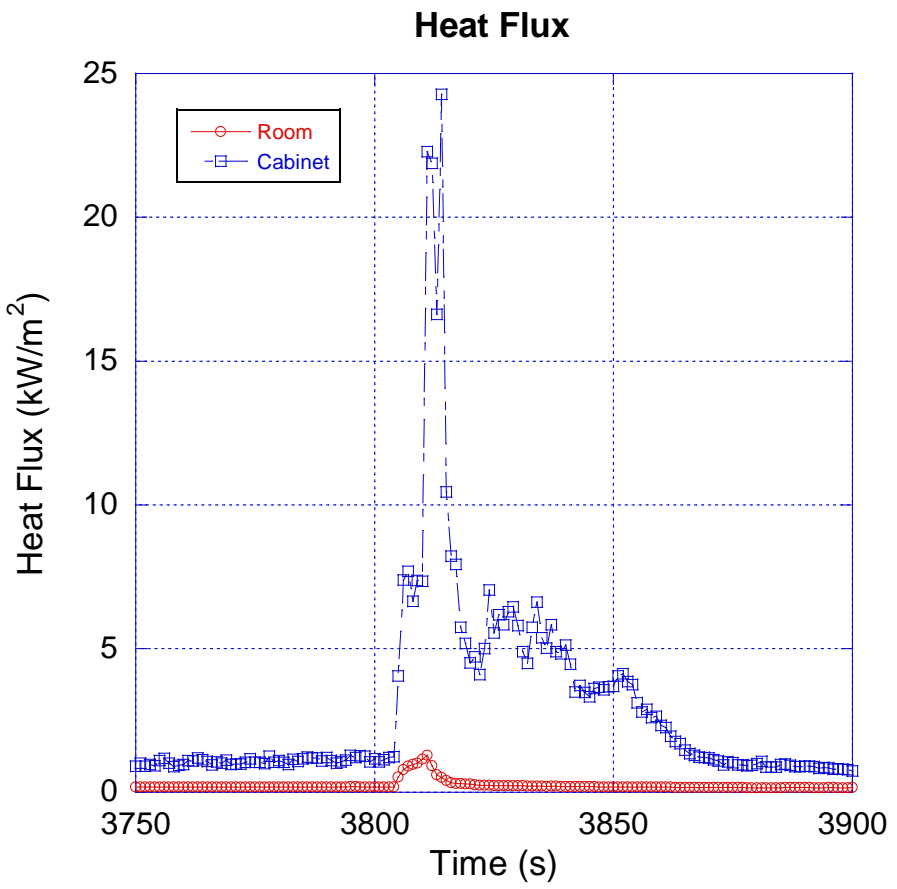

Figure A1-21. Experiment KSE 21 timeline and data 
KSE 22 Timeline

Automatic Wet Chemical 4

\begin{tabular}{|r|l|}
\hline Time & Event \\
\hline 0 & Burner On \\
\hline 5456 & Auto Ignition \\
\hline 5558 & Auto Suppression \\
\hline & Fire Not Extinguished \\
\hline 5675 & Manual Suppression \\
\hline 6021 & Re-Ignition \\
\hline 6078 & Manual Suppression 2 \\
\hline & Fire Extinguished \\
\hline
\end{tabular}

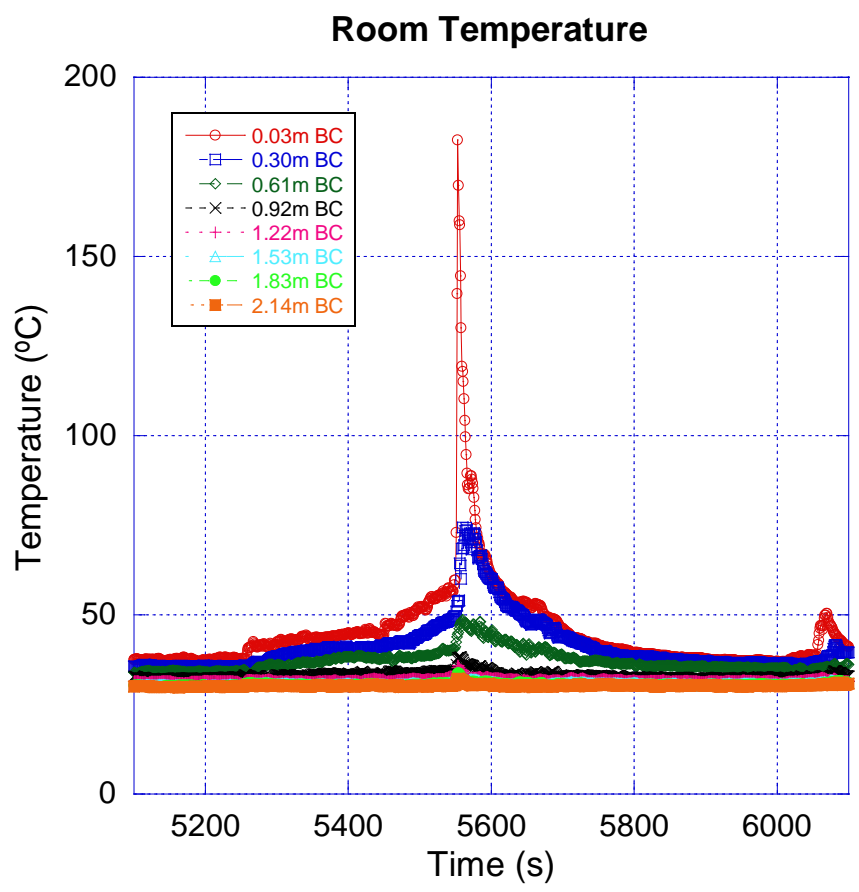

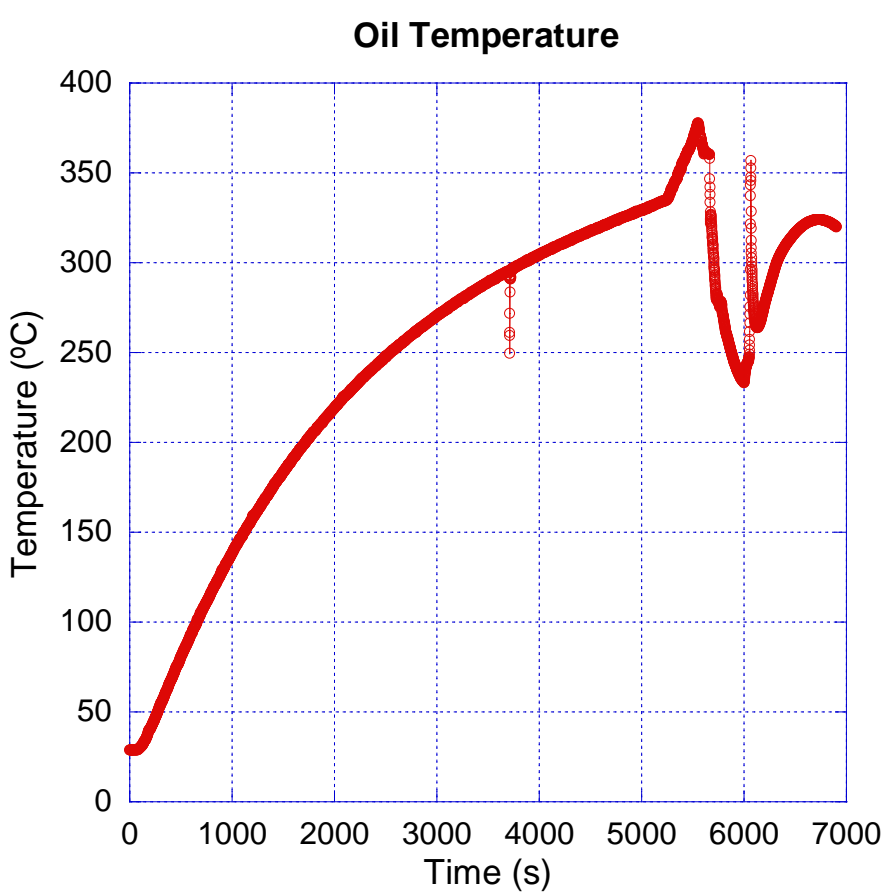

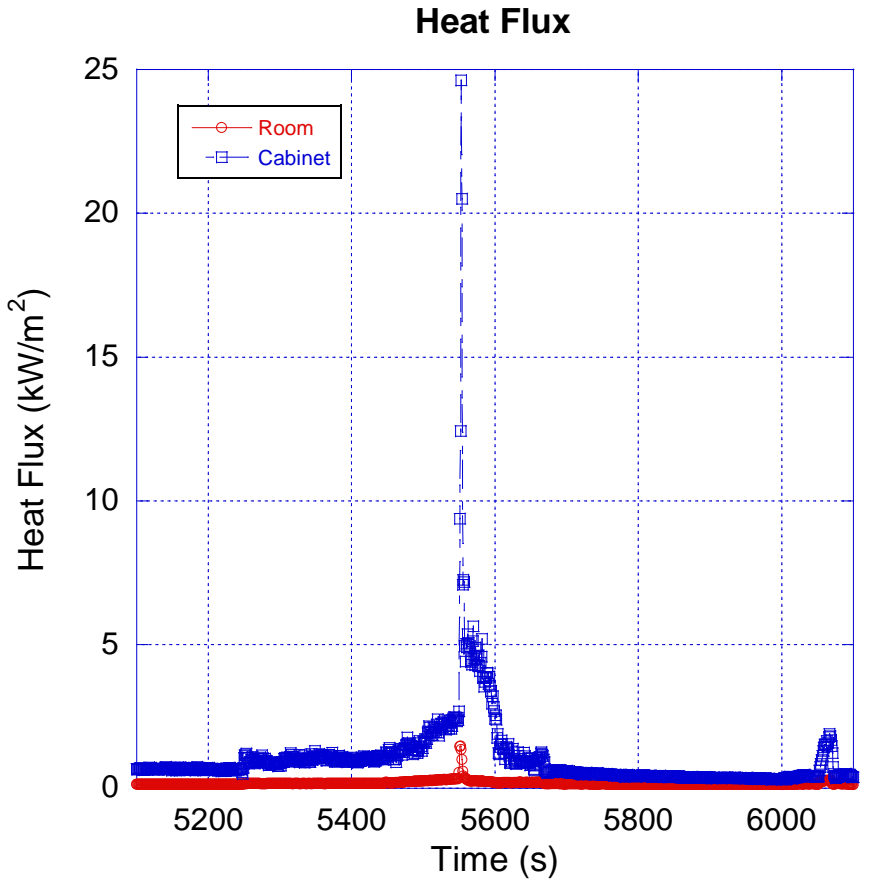

Figure A1-22. Experiment KSE 22 timeline and data 

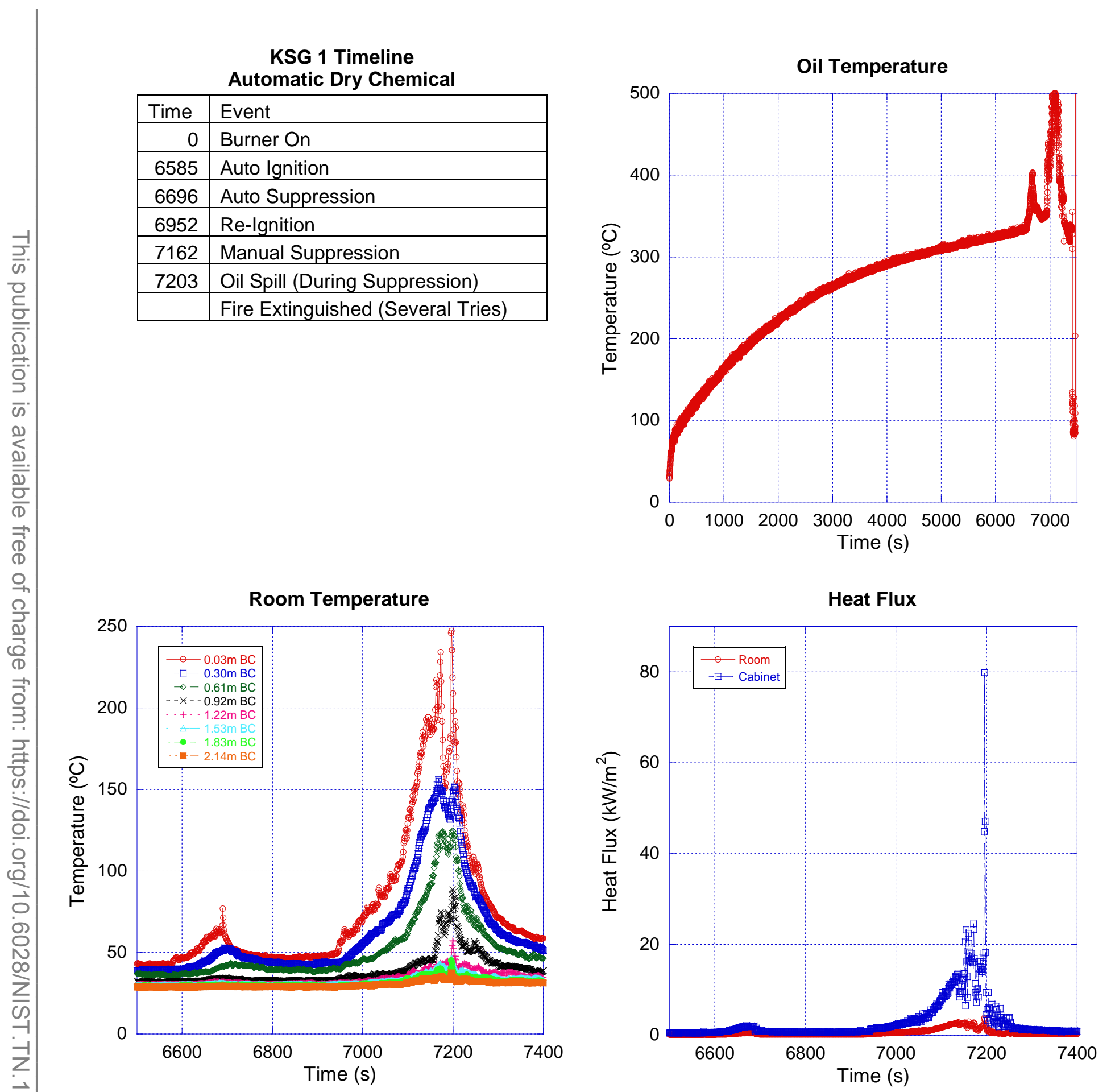

Figure A1-23. Experiment KSG 1 timeline and data 
KSG 2 Timeline

Automatic Wet Chemical 1

\begin{tabular}{|r|l|}
\hline Time & Event \\
\hline 0 & Burner On \\
\hline 5725 & Manual Ignition \\
\hline 5843 & Auto Suppression \\
\hline & Fire Extinguished \\
\hline
\end{tabular}

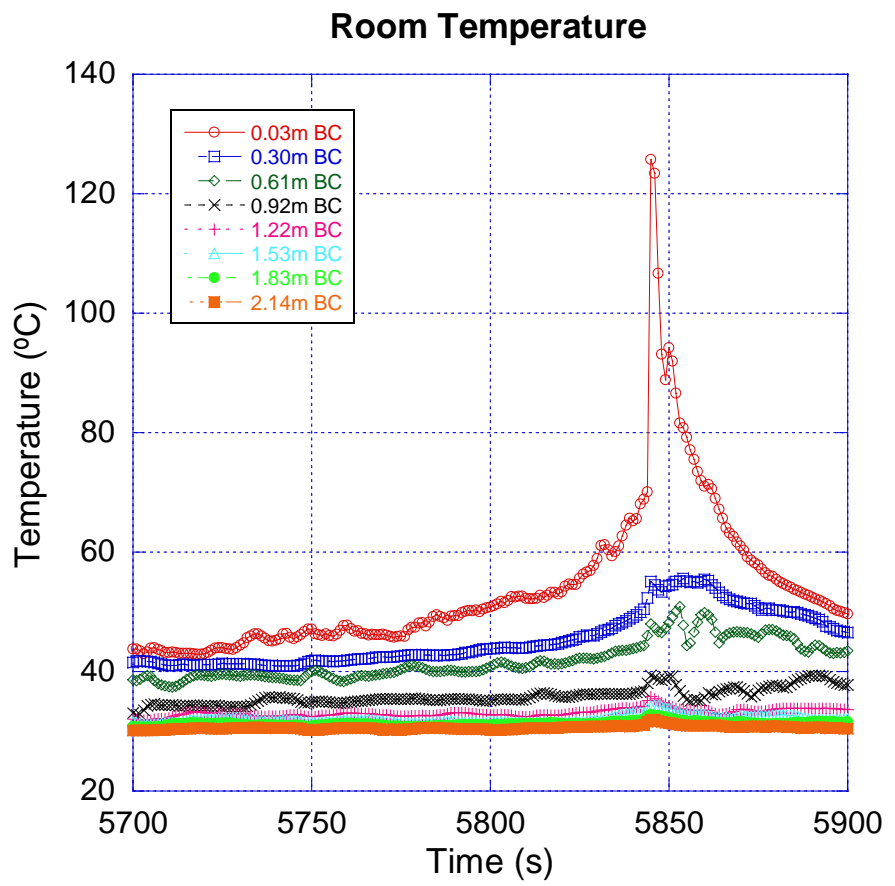

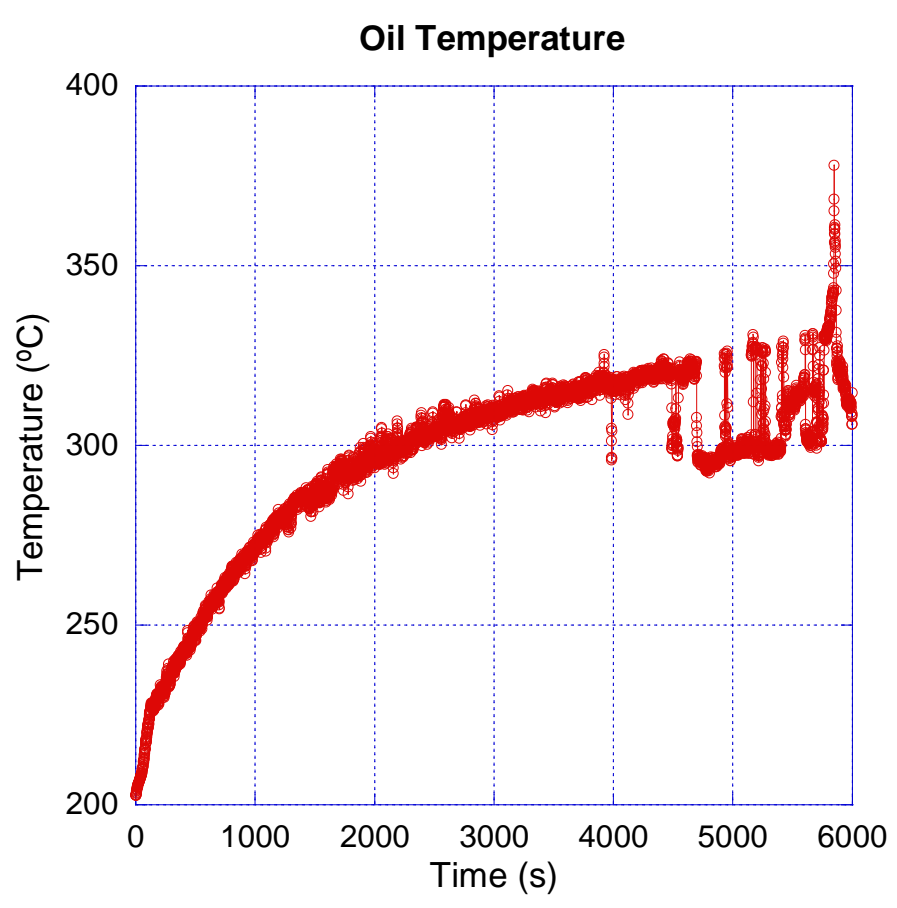

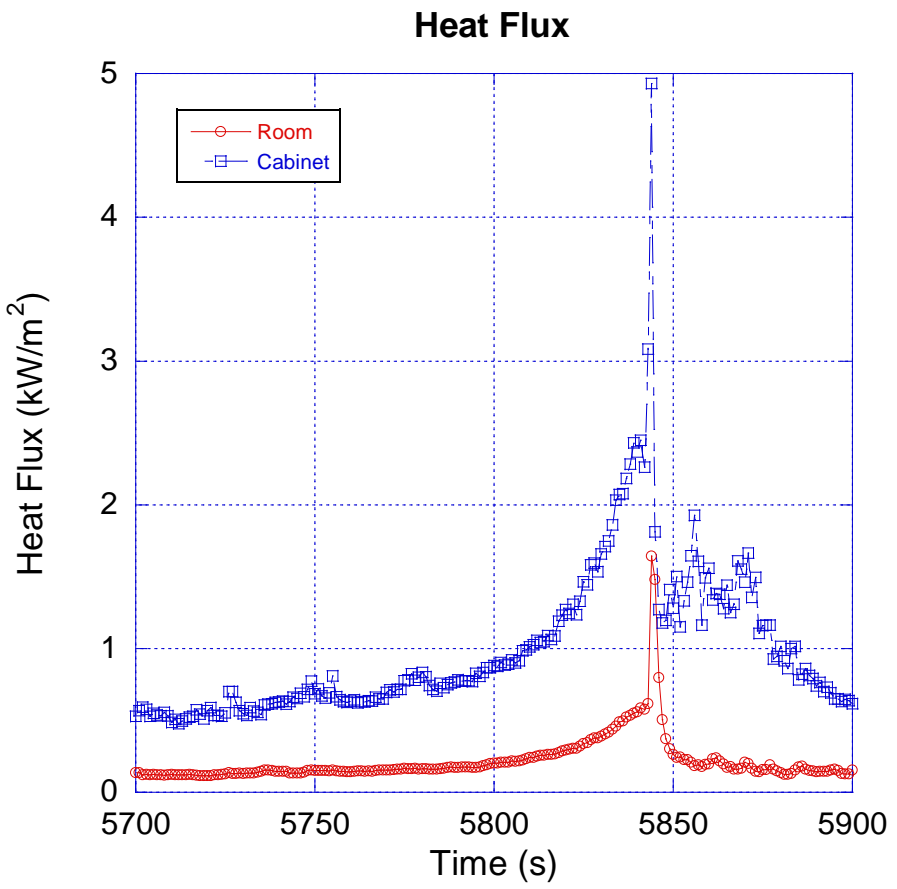

Figure A1-24. Experiment KSG 2 timeline and data 
KSG 3 Timeline

Automatic Wet Chemical 1

\begin{tabular}{|r|l|}
\hline Time & Event \\
\hline 0 & Burner On \\
\hline 4380 & Auto Ignition \\
\hline 4456 & Auto Suppression \\
\hline & Fire Extinguished \\
\hline
\end{tabular}

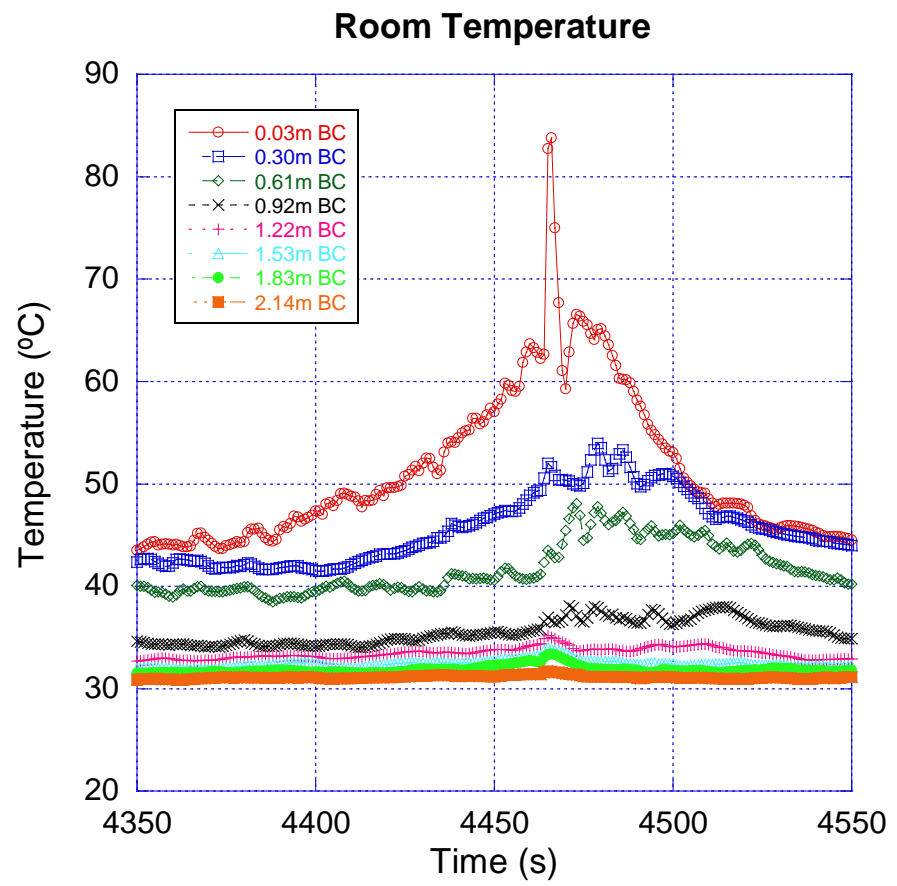

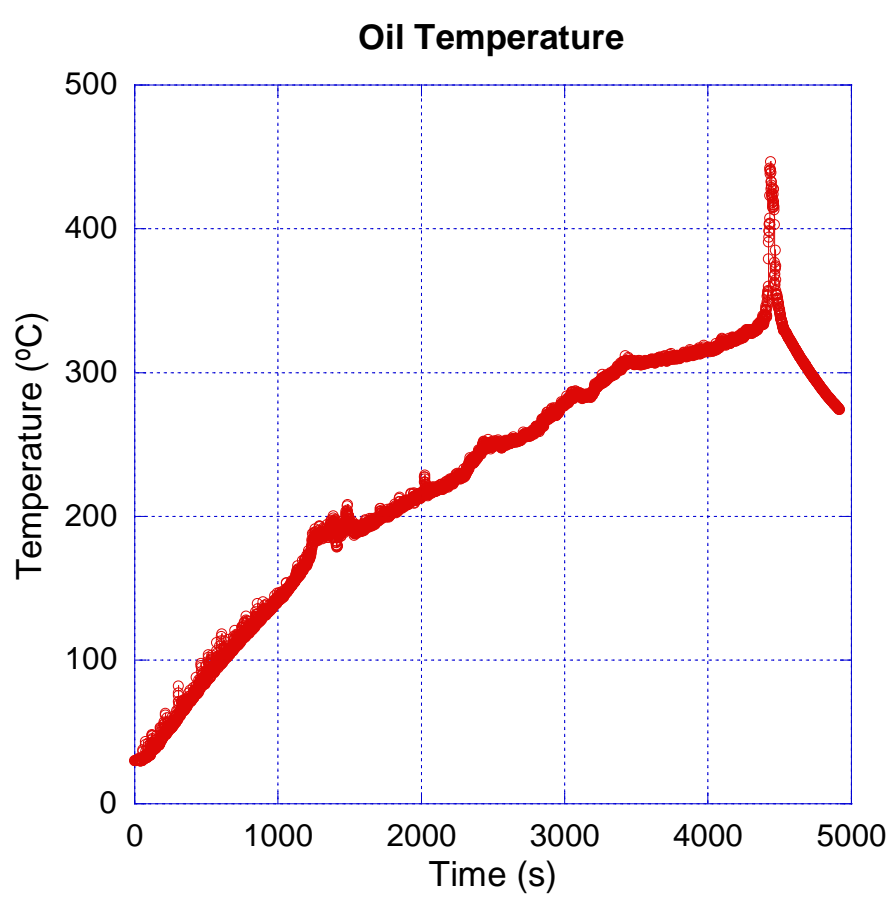

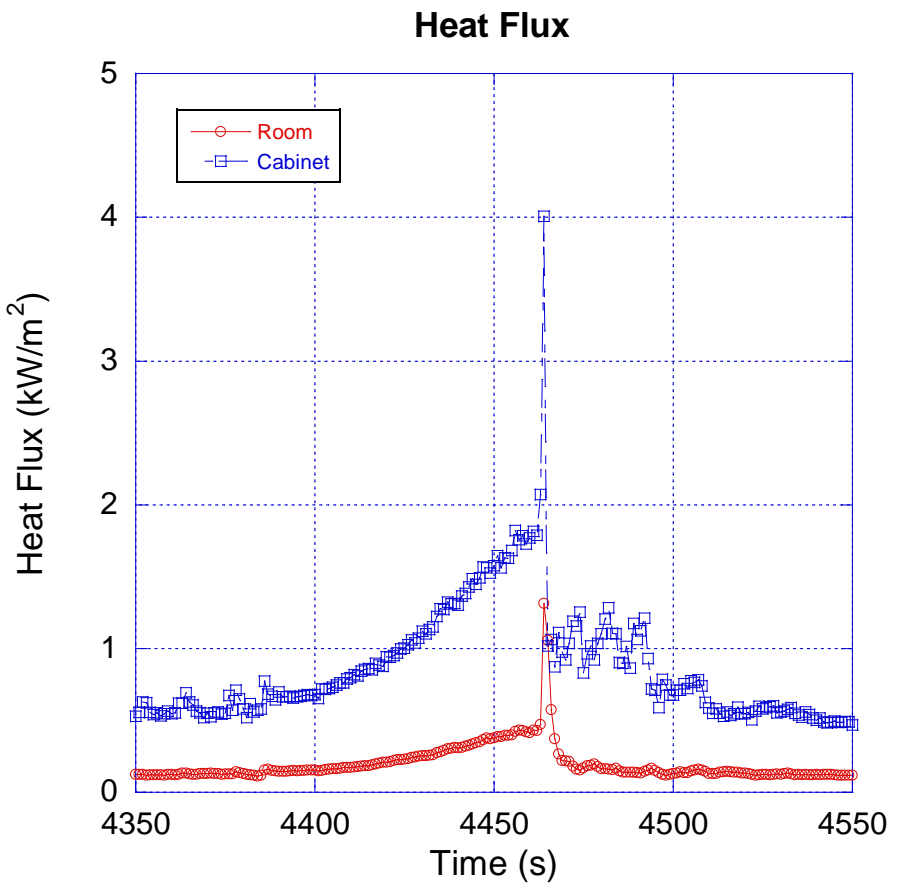

Figure A1-25. Experiment KSG 3 timeline and data 
KSG 4 Timeline

Automatic Wet Chemical 1

\begin{tabular}{|r|l|}
\hline Time & Event \\
\hline 0 & Burner On \\
\hline 6617 & Auto Ignition \\
\hline 6798 & Auto Suppression \\
\hline & Fire Extinguished \\
\hline
\end{tabular}

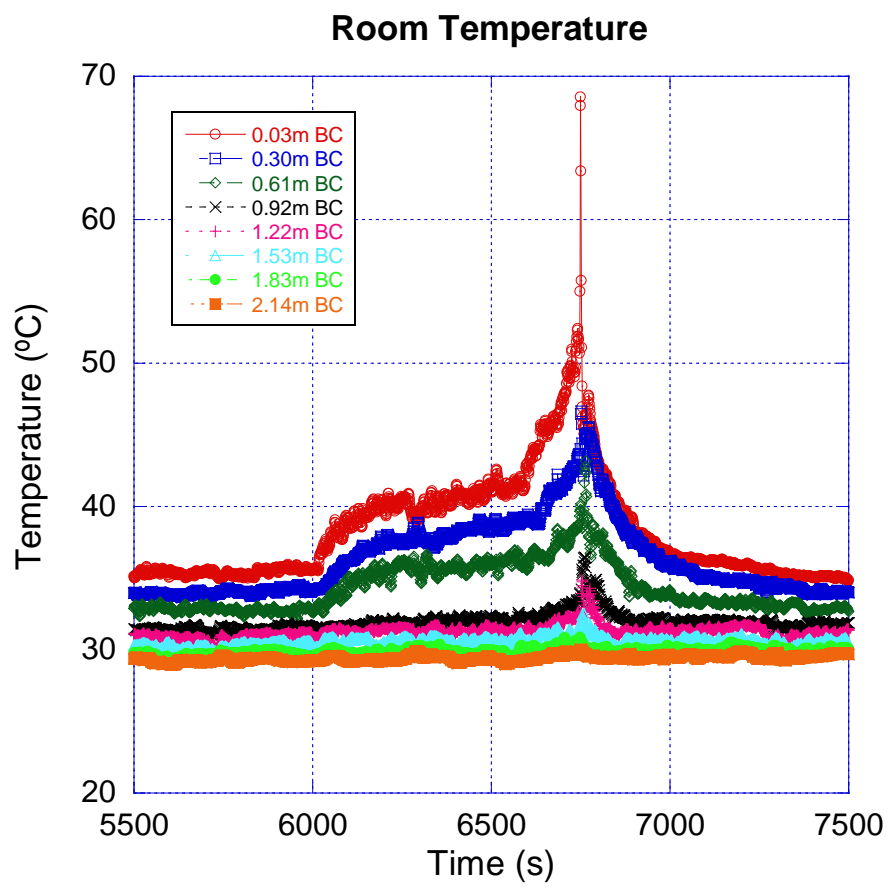

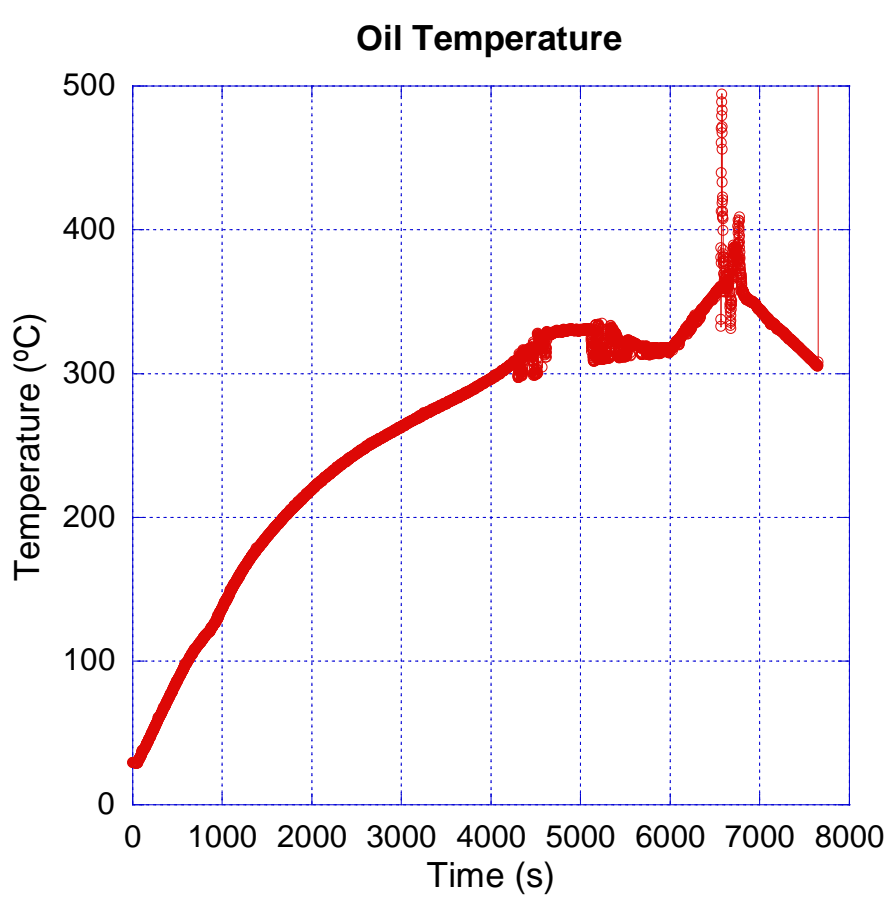

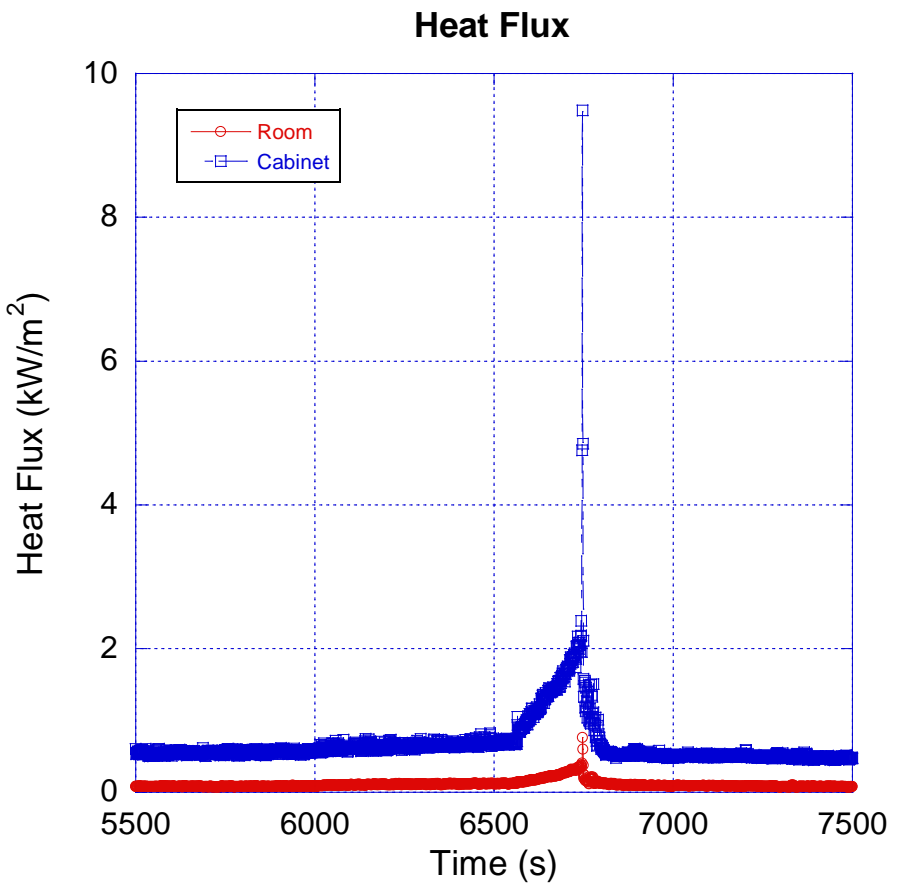

Figure A1-26. Experiment KSG 4 timeline and data 
KSG 5 Timeline

Automatic Wet Chemical 2

\begin{tabular}{|r|l|}
\hline \multicolumn{1}{|c|}{ Time } & Event \\
\hline 0 & Burner On \\
\hline 5329 & Auto Ignition \\
\hline 5480 & Auto Suppression \\
\hline 5576 & Re-Ignition \\
\hline 5594 & Manual Suppression \\
\hline & Fire Extinguished \\
\hline
\end{tabular}

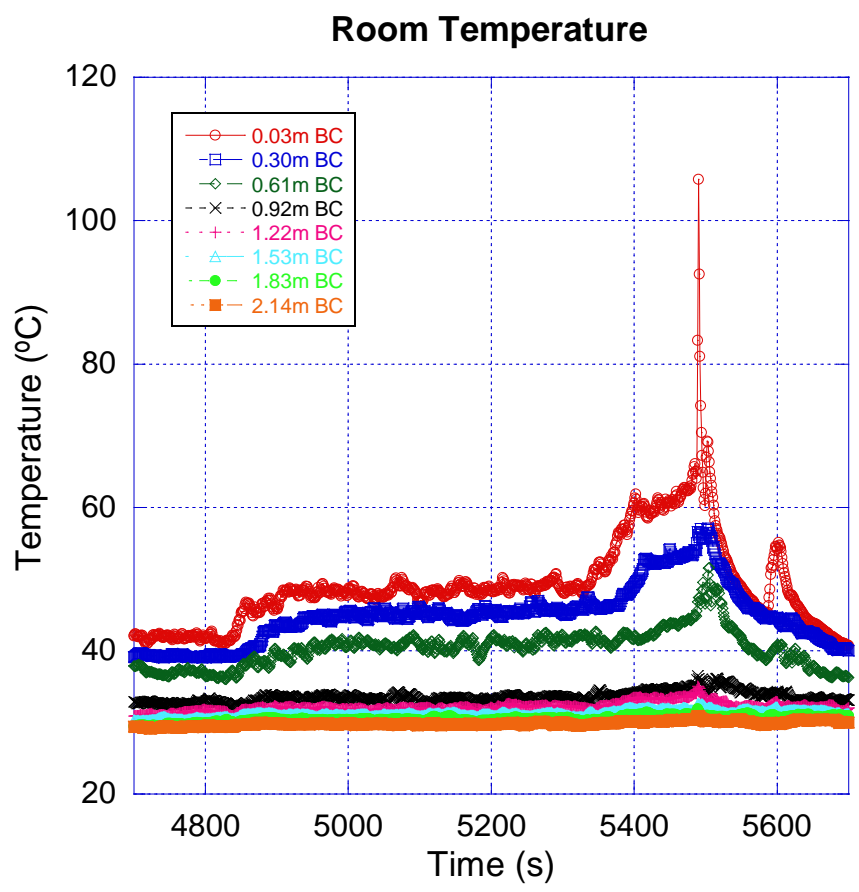

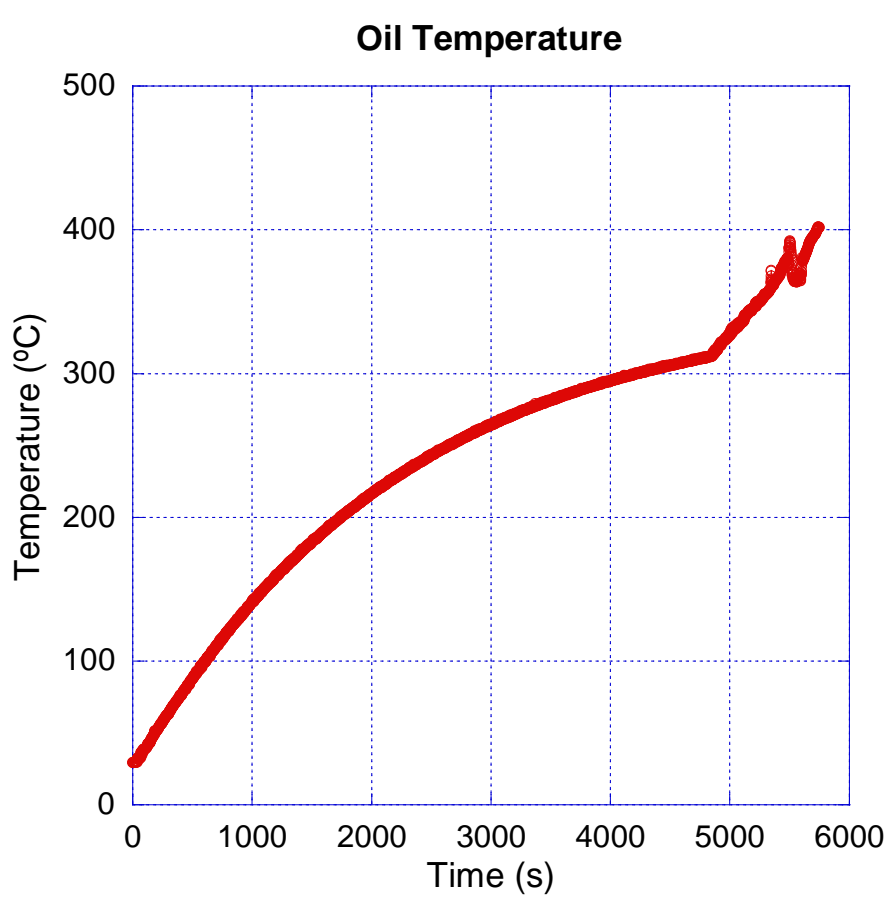

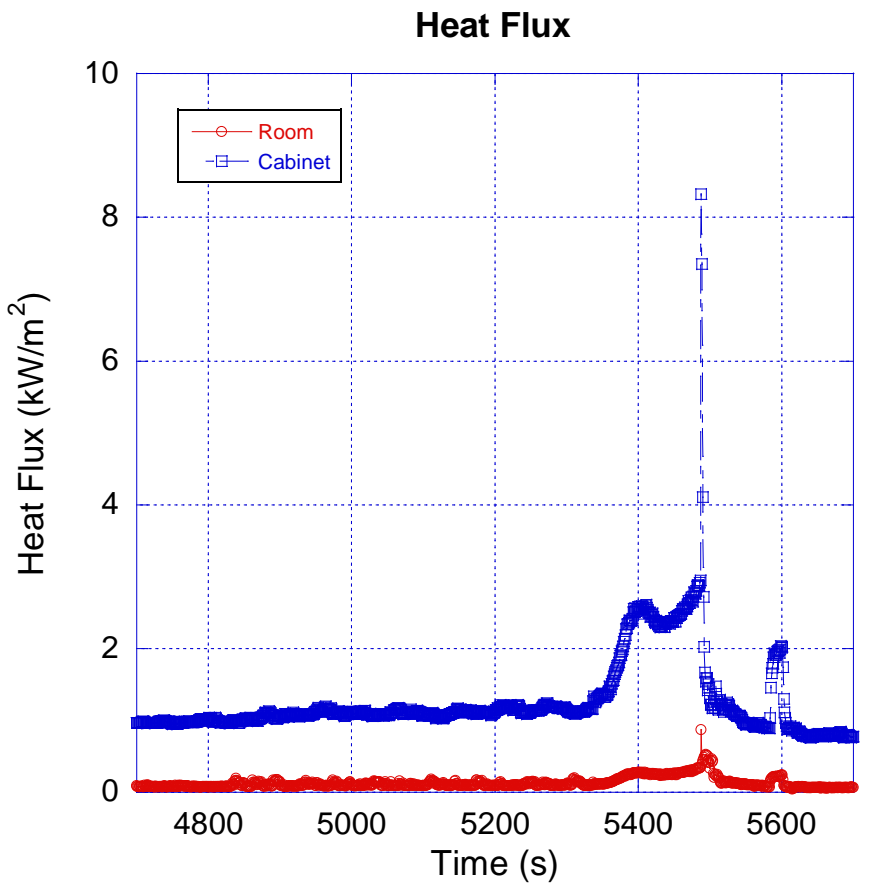

Figure A1-27. Experiment KSG 5 timeline and data 
KSG 6 Timeline

Automatic Wet Chemical 2

\begin{tabular}{|r|l|}
\hline \multicolumn{1}{|c|}{ Time } & Event \\
\hline 0 & Burner On \\
\hline 5347 & Auto Ignition \\
\hline 5431 & Auto Suppression \\
\hline & Fire Extinguished \\
\hline
\end{tabular}

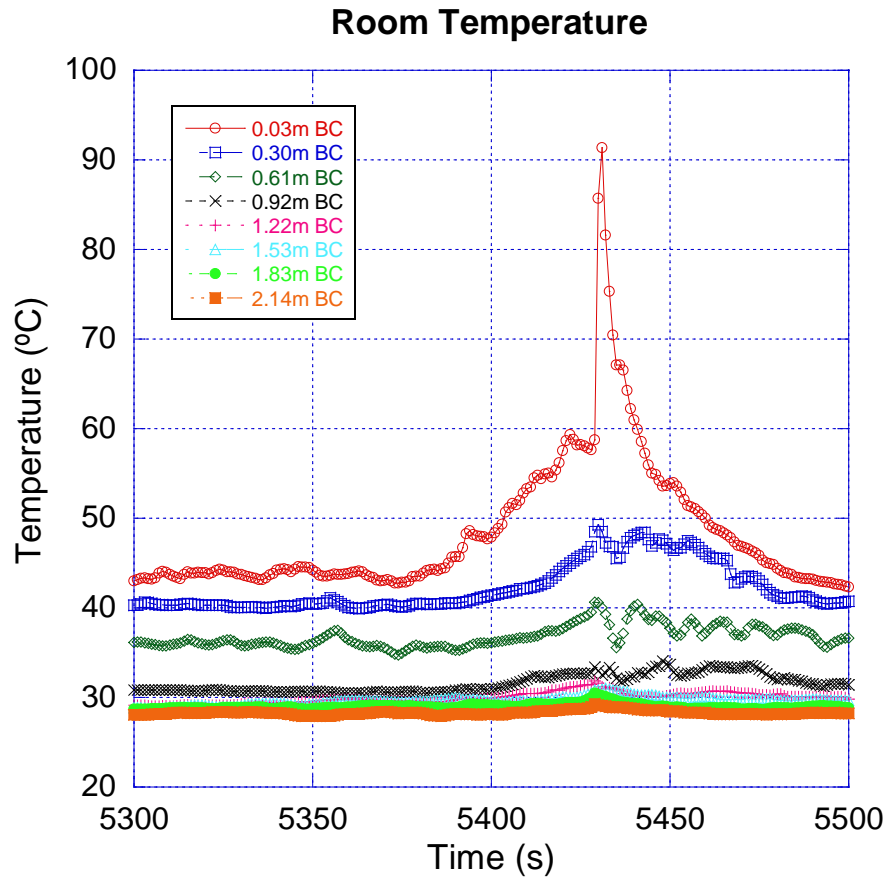

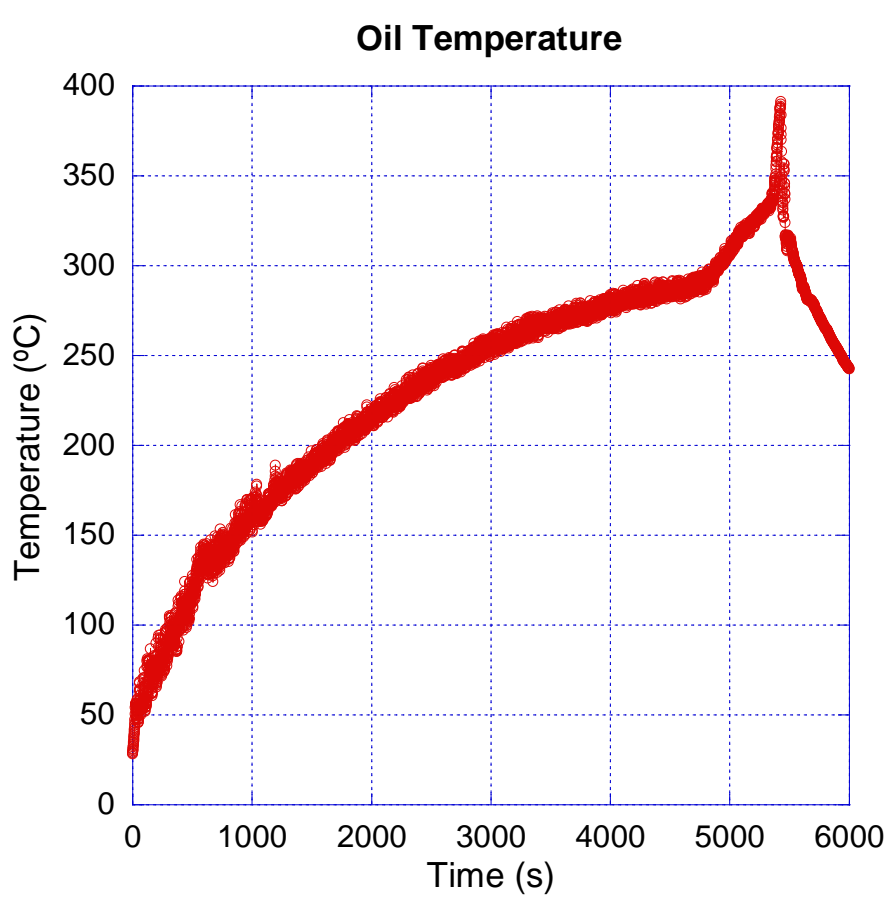

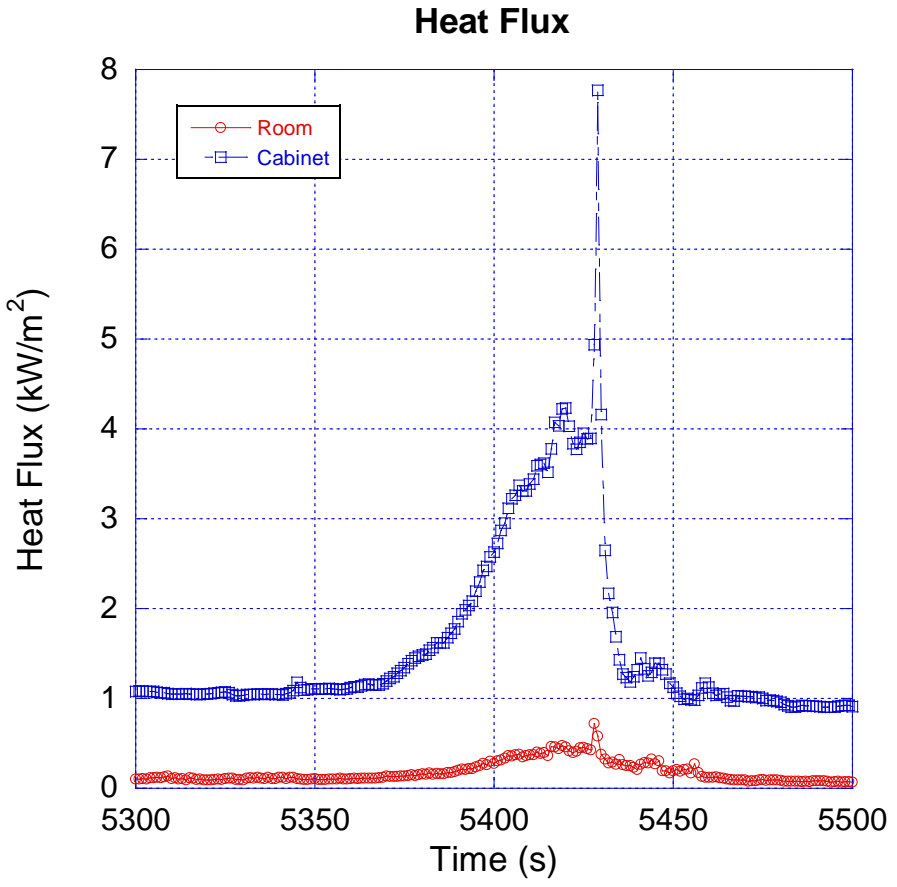

Figure A1-28. Experiment KSG 6 timeline and data 

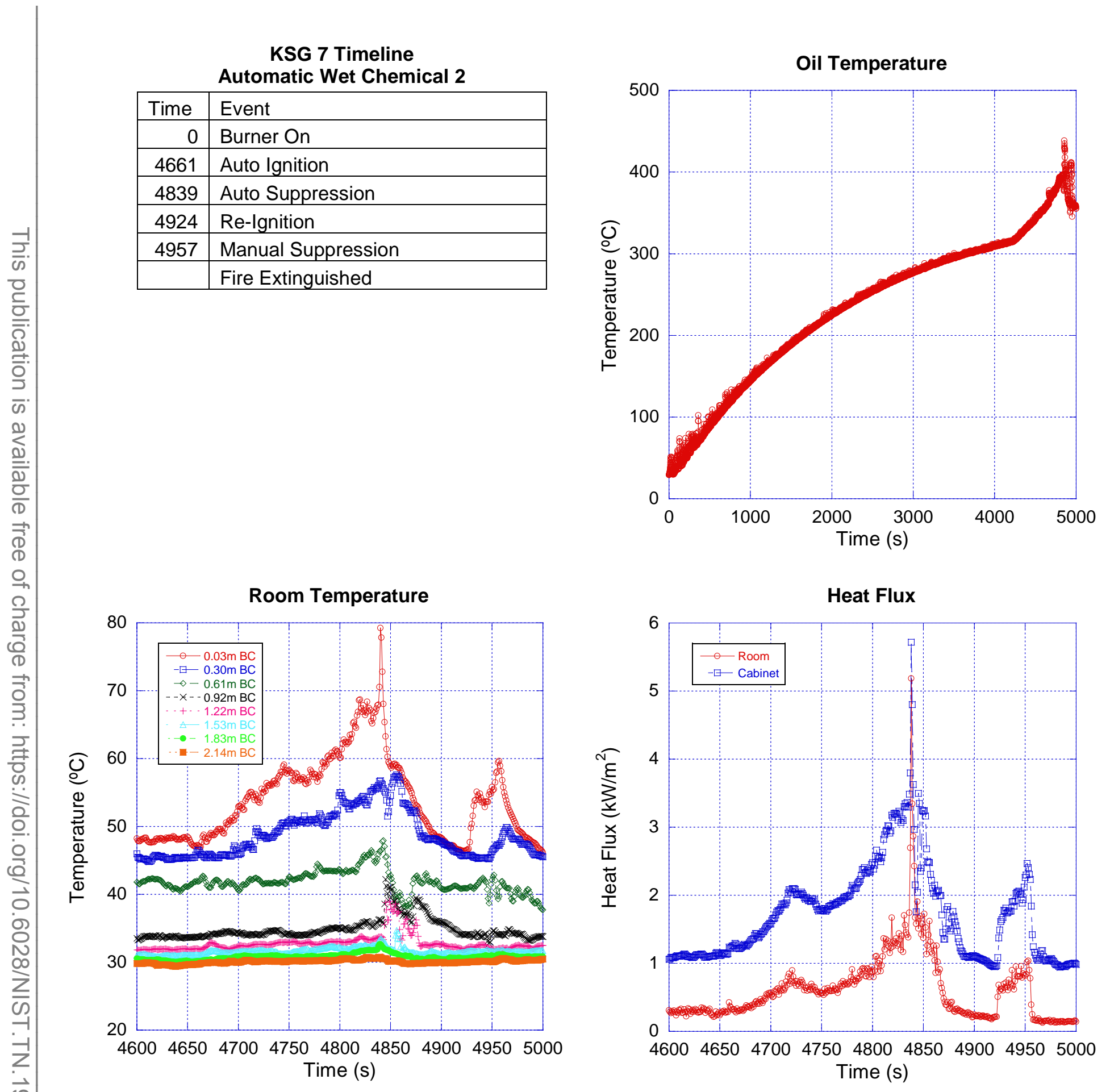

Figure A1-29. Experiment KSG 7 timeline and data 

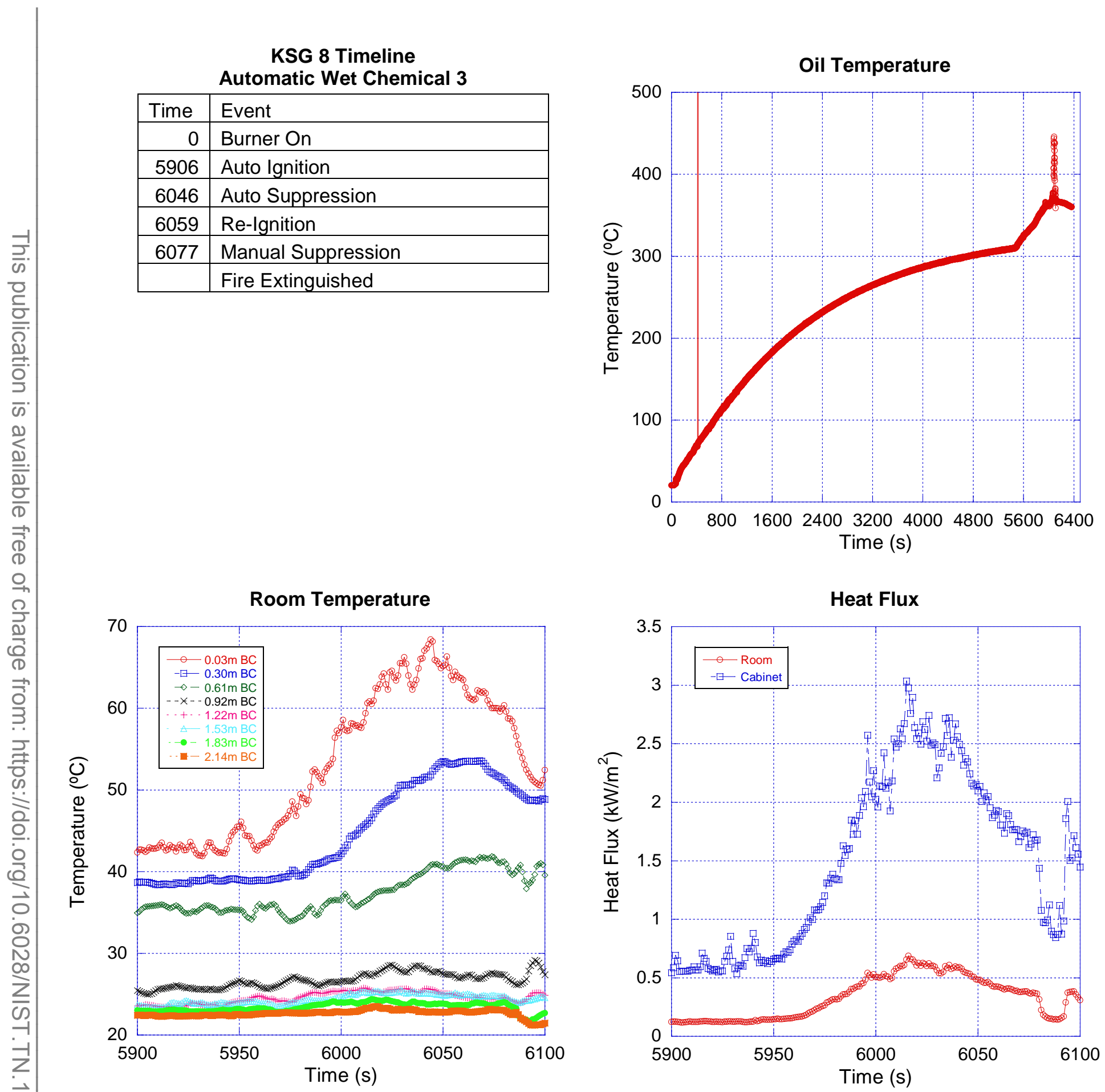

Figure A1-30. Experiment KSG 8 timeline and data 
KSG 9 Timeline Manual Wet Chemical

\begin{tabular}{|r|l|}
\hline \multicolumn{1}{|c|}{ Time } & Event \\
\hline 0 & Burner On \\
\hline 5038 & Auto Ignition \\
\hline 5103 & Auto Suppression \\
\hline & Fire Extinguished \\
\hline
\end{tabular}

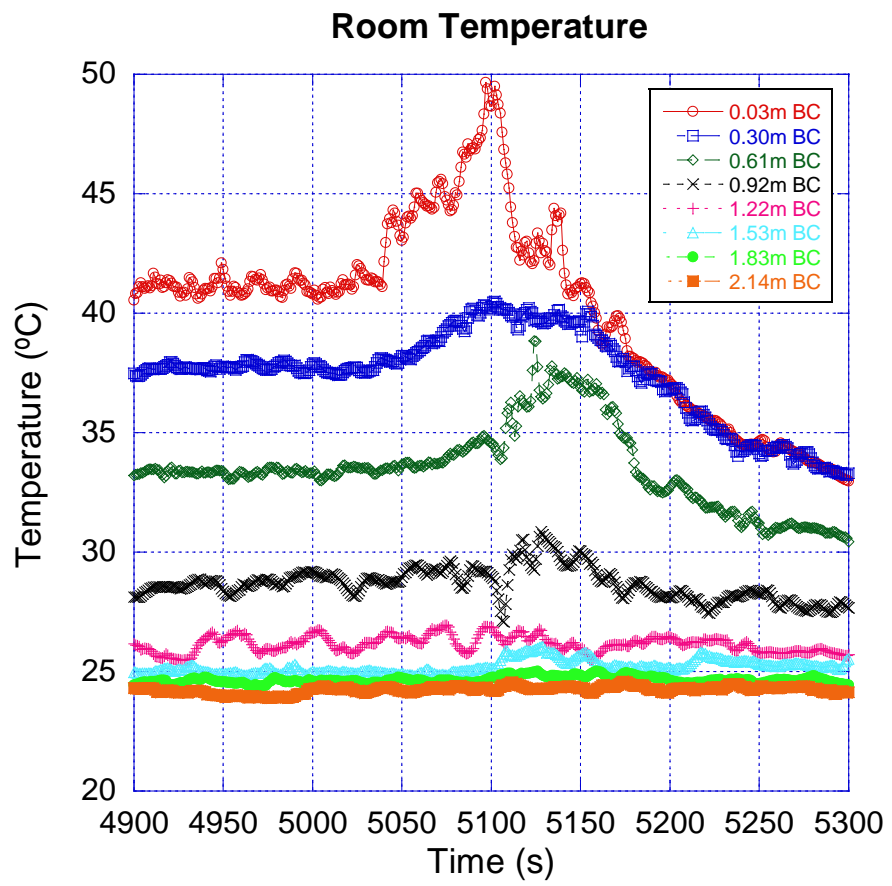

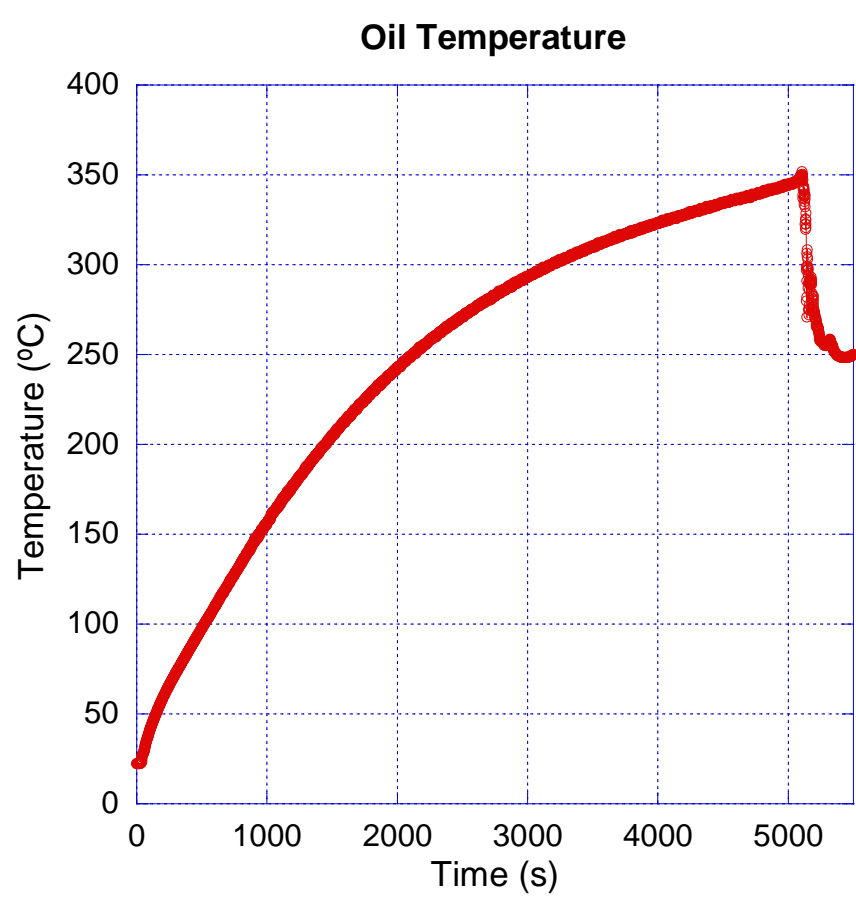

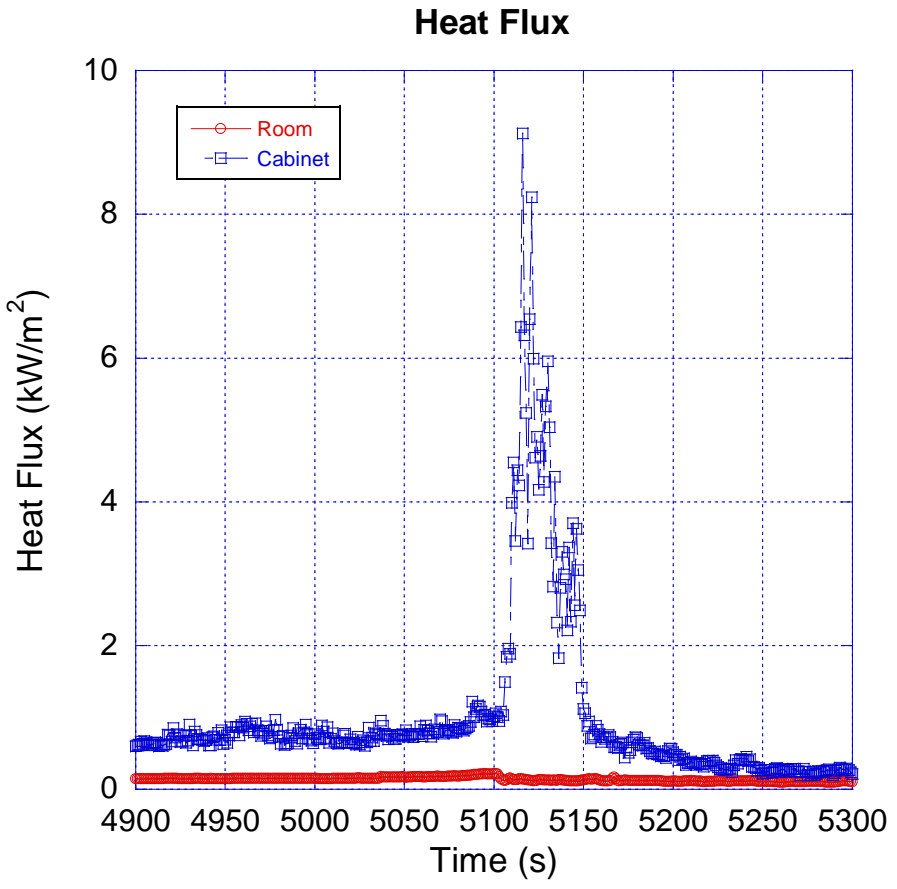

Figure A1-31. Experiment KSG 9 timeline and data 
KSG 10 Timeline Manual Wet Chemical

\begin{tabular}{|r|l|}
\hline Time & Event \\
\hline 0 & Burner On \\
\hline 5145 & Auto Ignition \\
\hline 5206 & Auto Suppression \\
\hline & Fire Extinguished \\
\hline
\end{tabular}

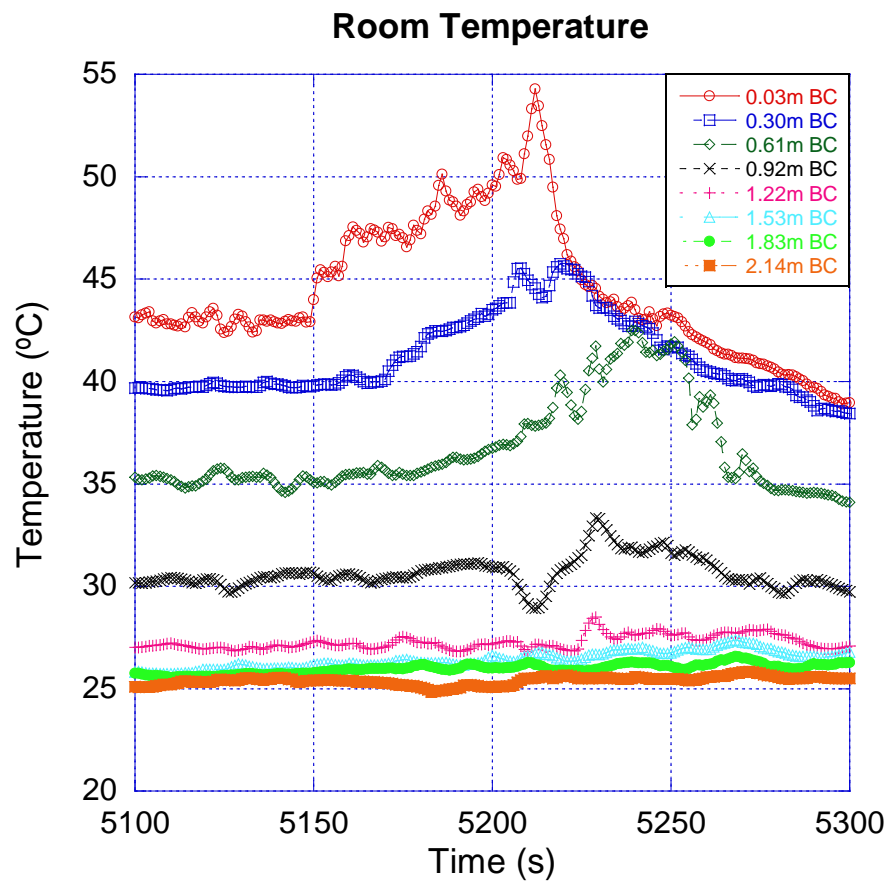

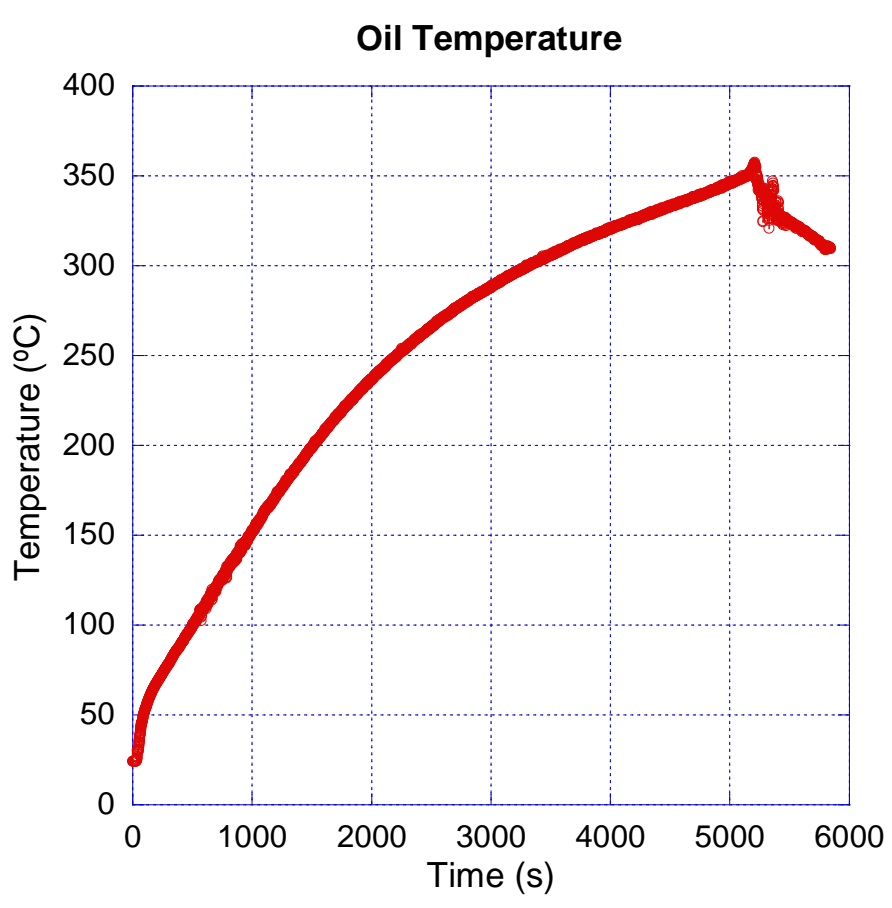

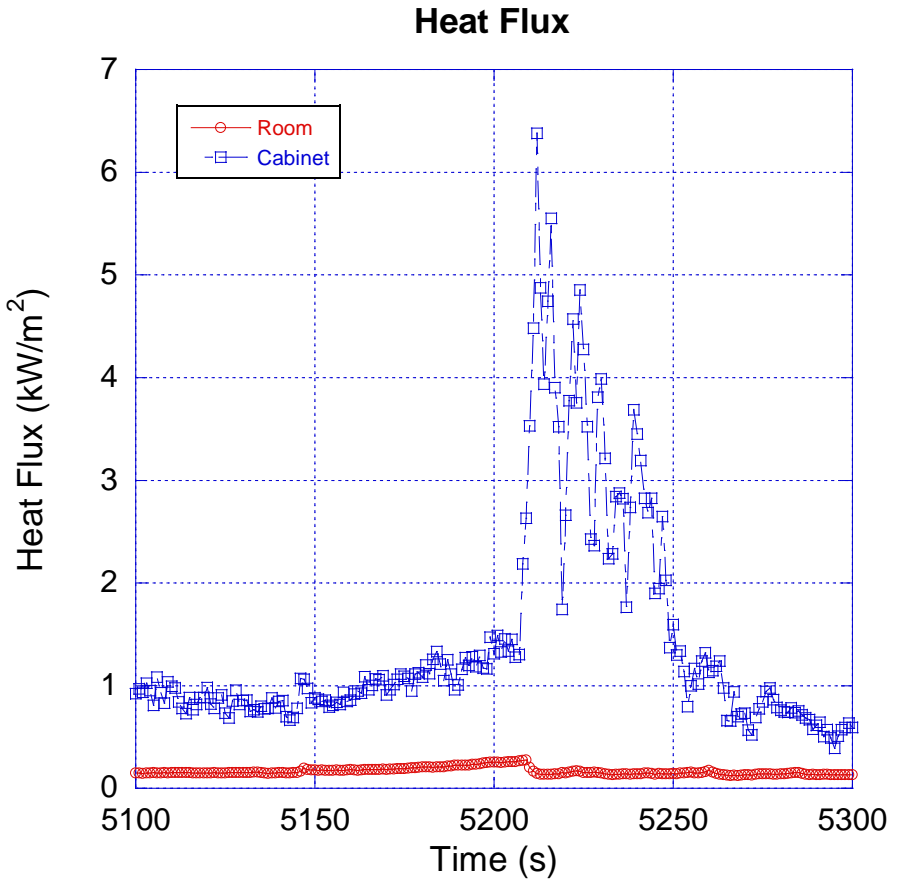

Figure A1-32. Experiment KSG 10 timeline and data 
KSG 11 Timeline

Automatic Dry Chemical

\begin{tabular}{|r|l|}
\hline \multicolumn{1}{|l|}{ Time } & Event \\
\hline 0 & Burner On \\
\hline 5160 & Auto Ignition \\
\hline 5389 & Auto Suppression \\
\hline & Fire Not Extinguished \\
\hline 5402 & Manual Suppression \\
\hline & Fire Extinguished \\
\hline
\end{tabular}

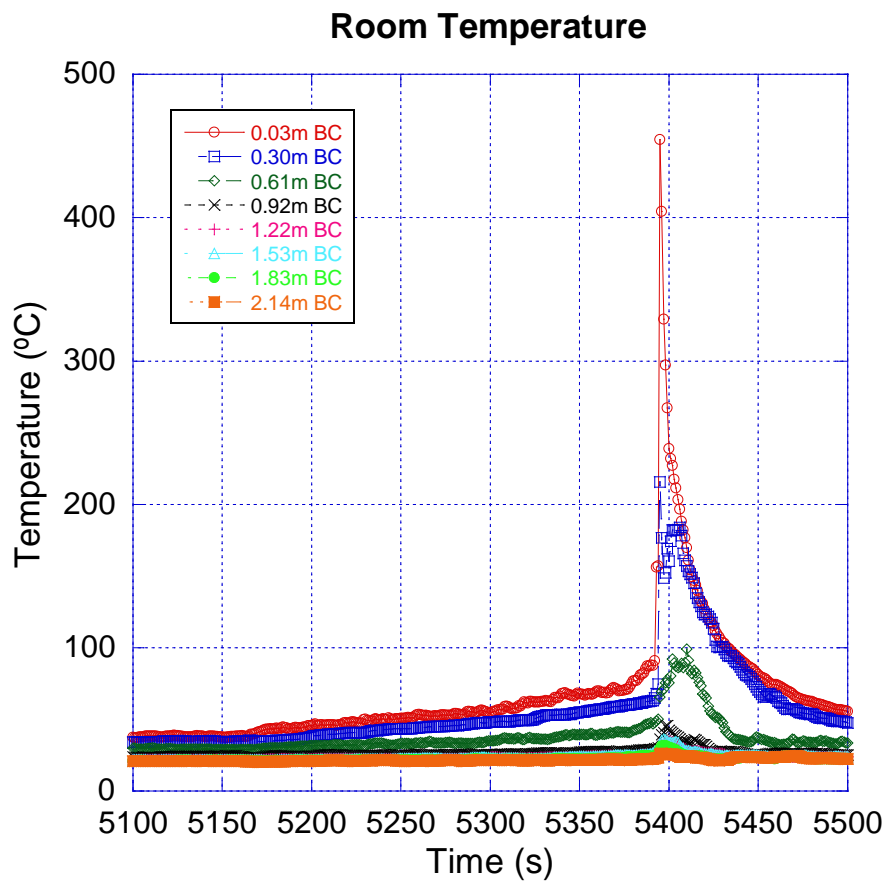

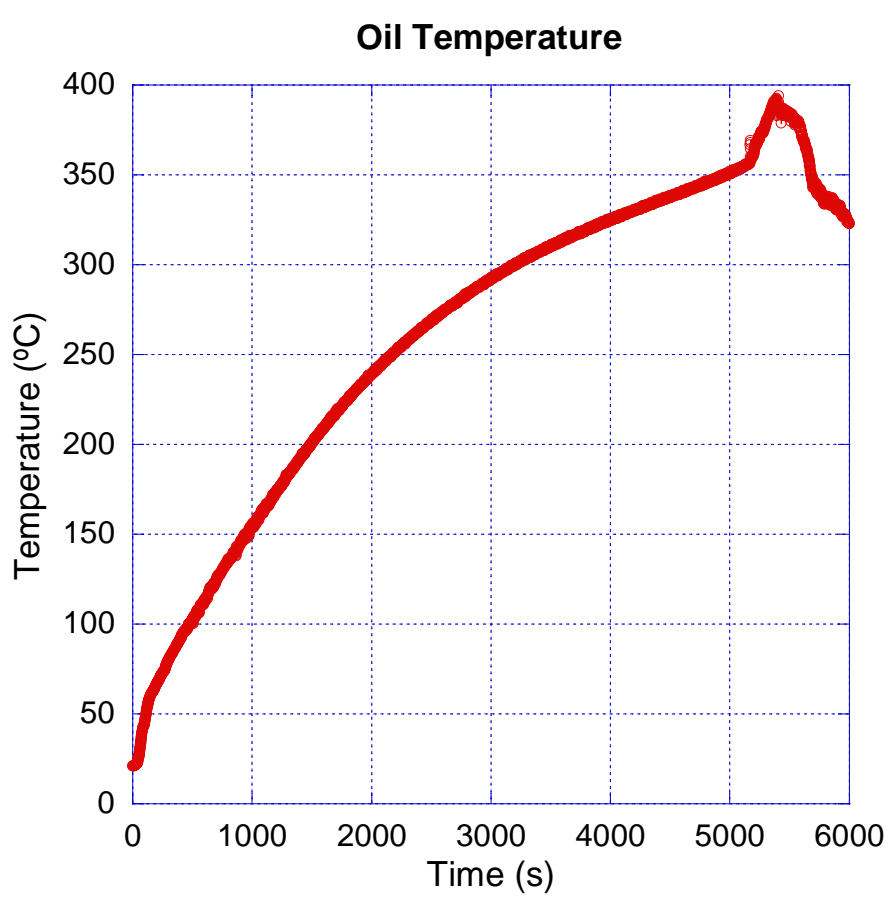

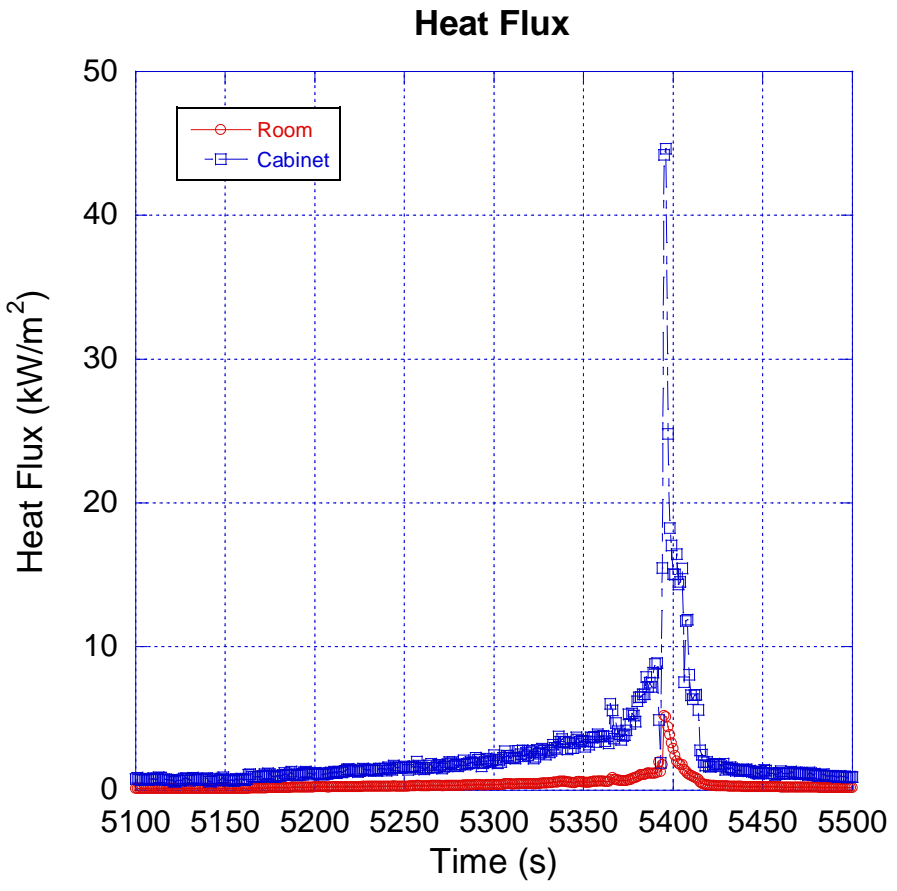

Figure A1-33. Experiment KSG 11 timeline and data 

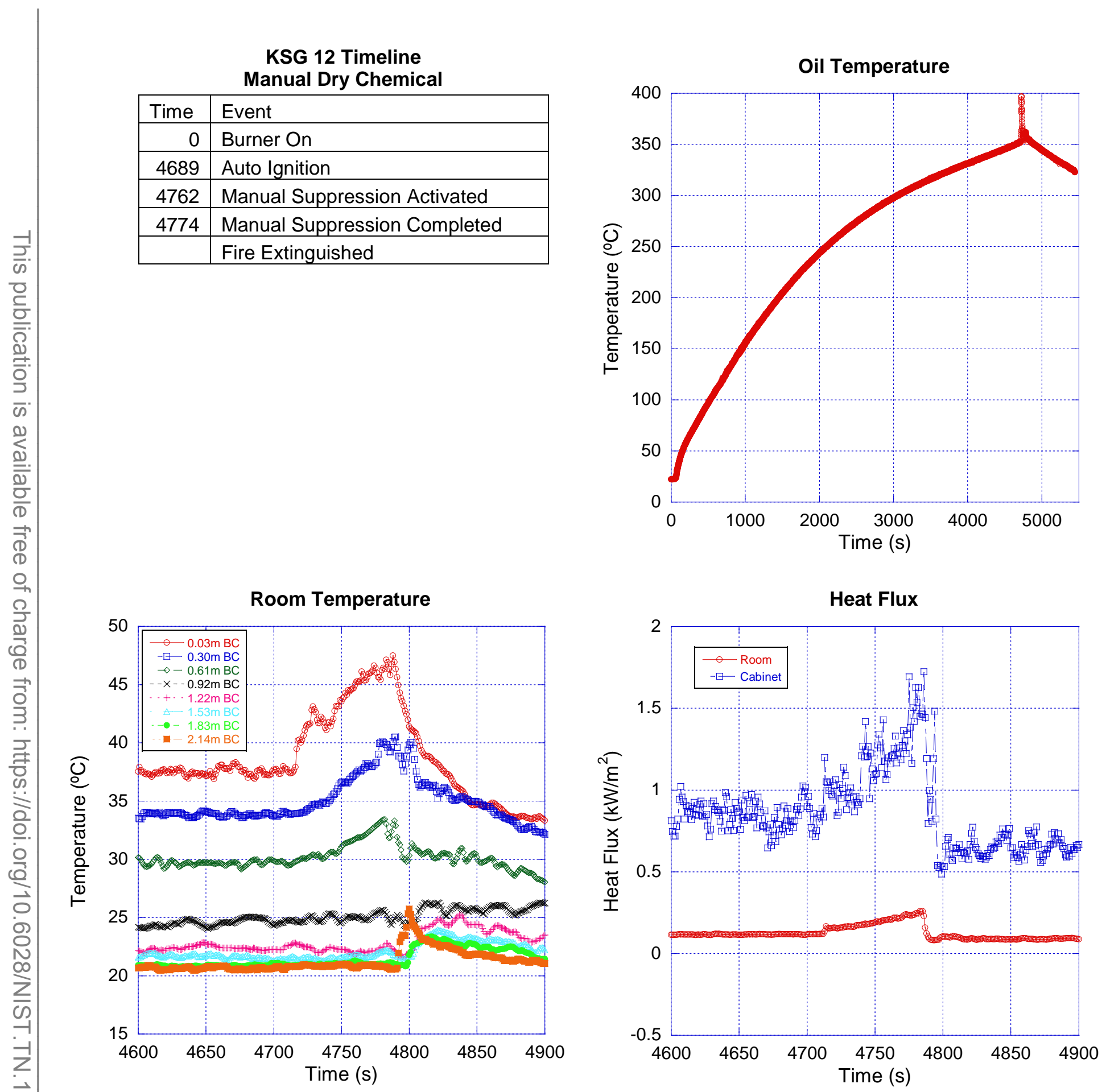

Figure A1-34. Experiment KSG 12 timeline and data 

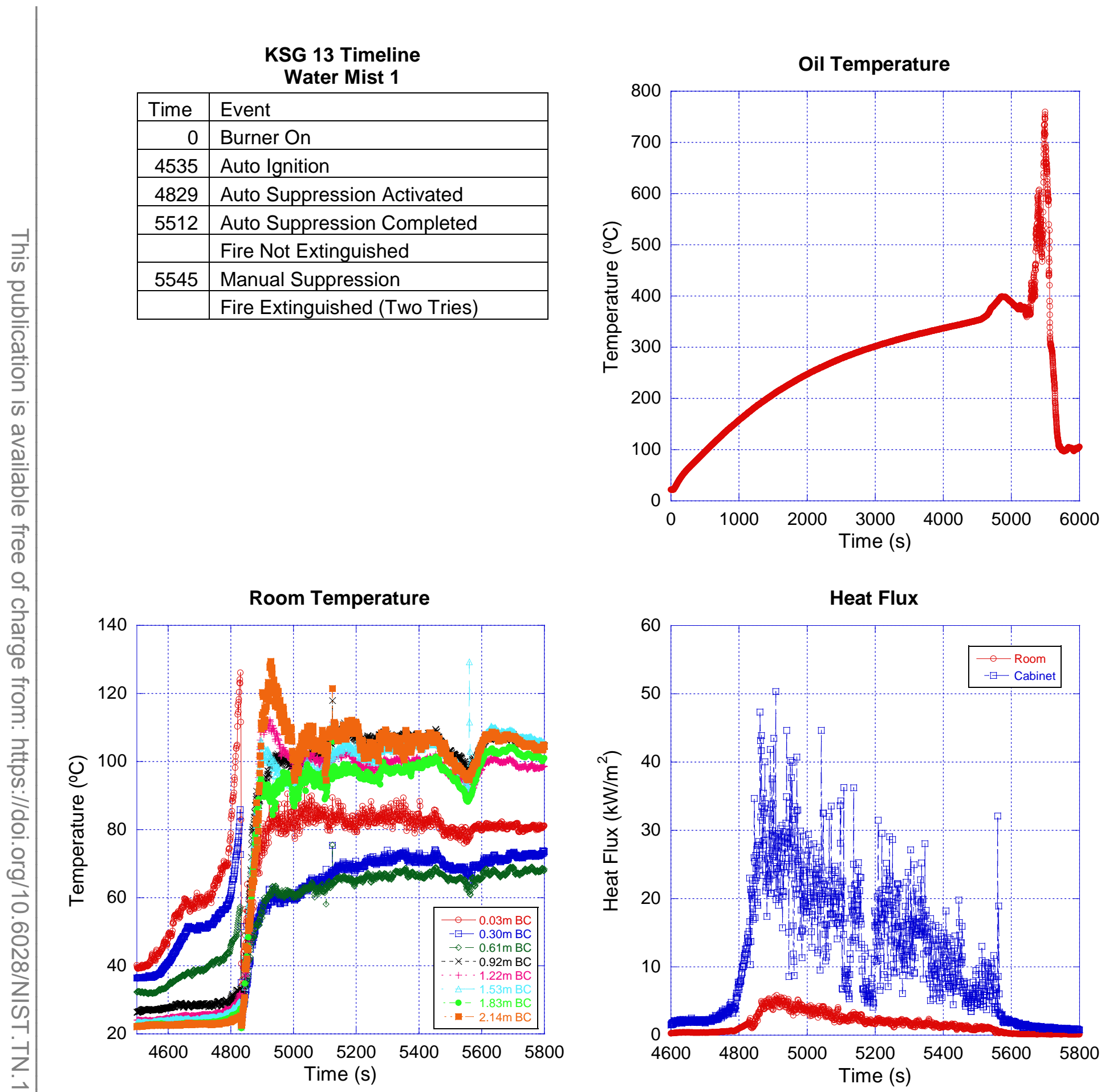

Figure A1-35. Experiment KSG 13 timeline and data 

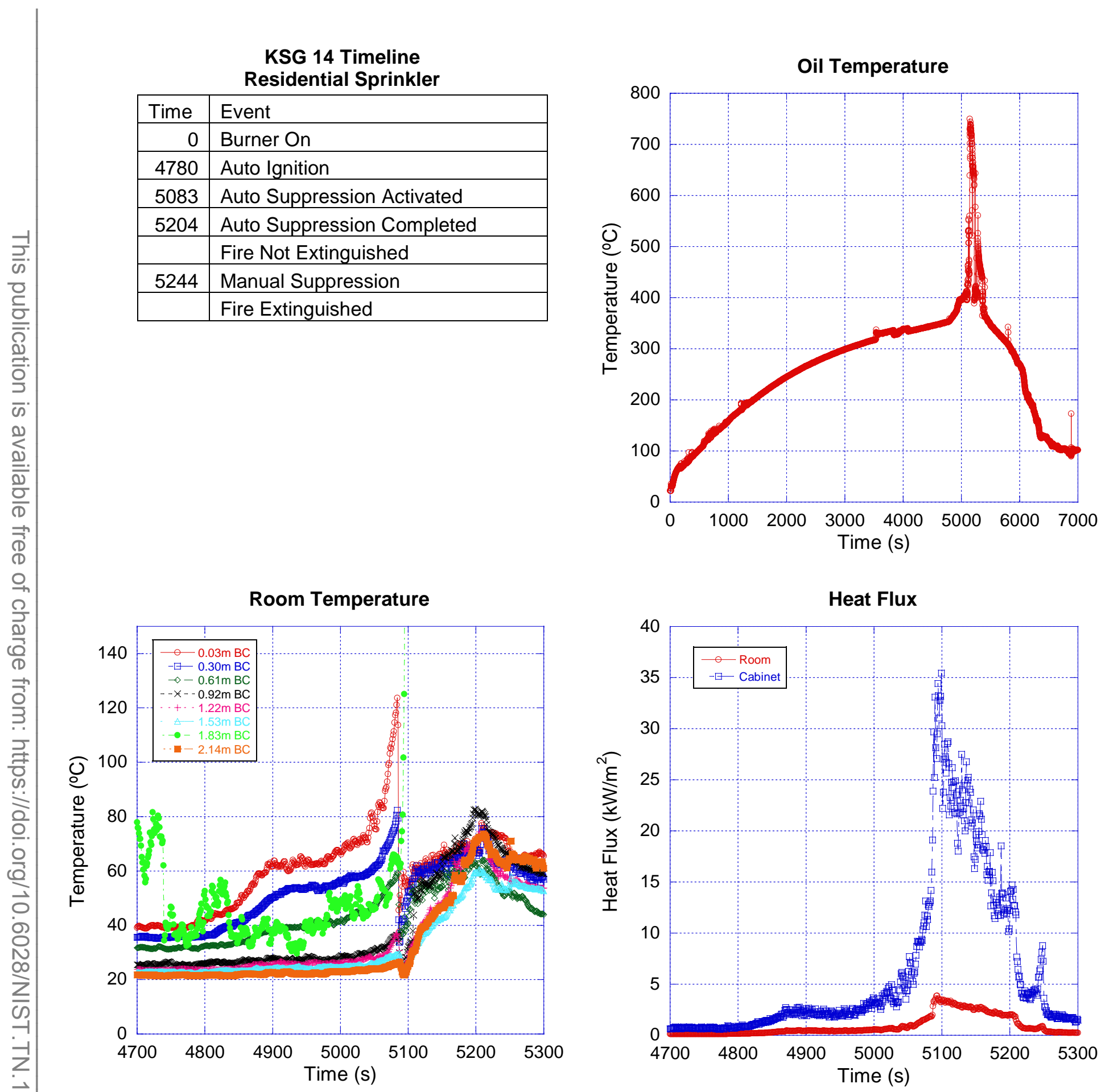

Figure A1-36. Experiment KSG 14 timeline and data 
KSG 15 Timeline

Free Burn

\begin{tabular}{|r|l|}
\hline \multicolumn{1}{|l|}{ Time } & Event \\
\hline 0 & Burner On \\
\hline 5339 & Auto Ignition \\
\hline 5853 & Manual Suppression Start \\
\hline 6056 & Manual Suppression End \\
\hline & Fire Extinguished \\
\hline
\end{tabular}

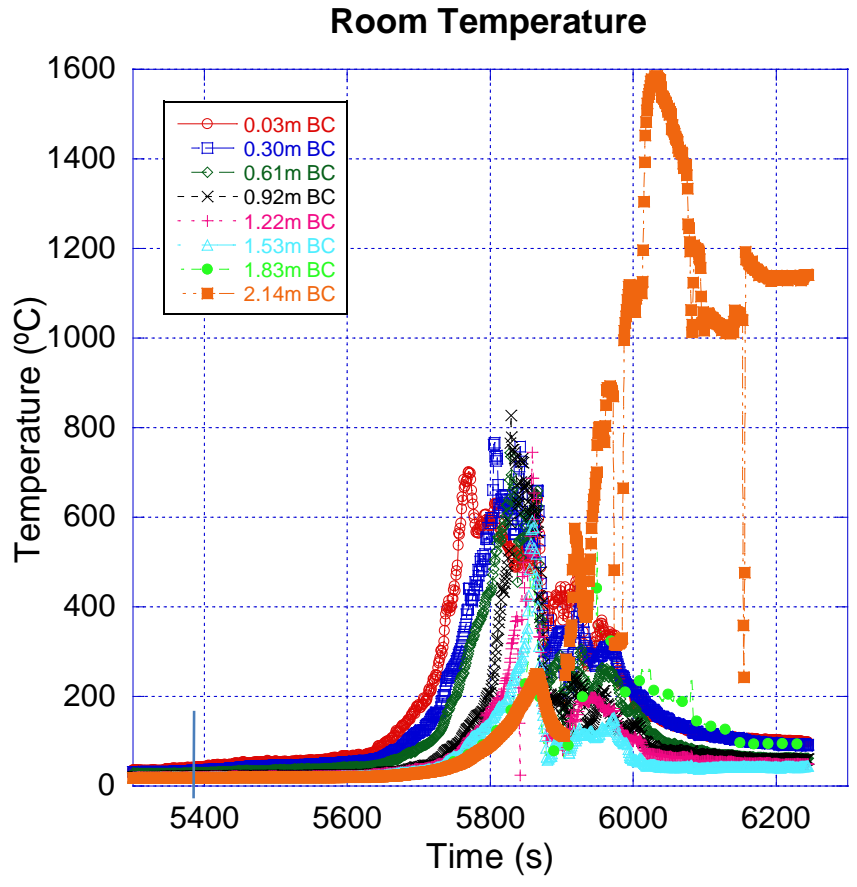

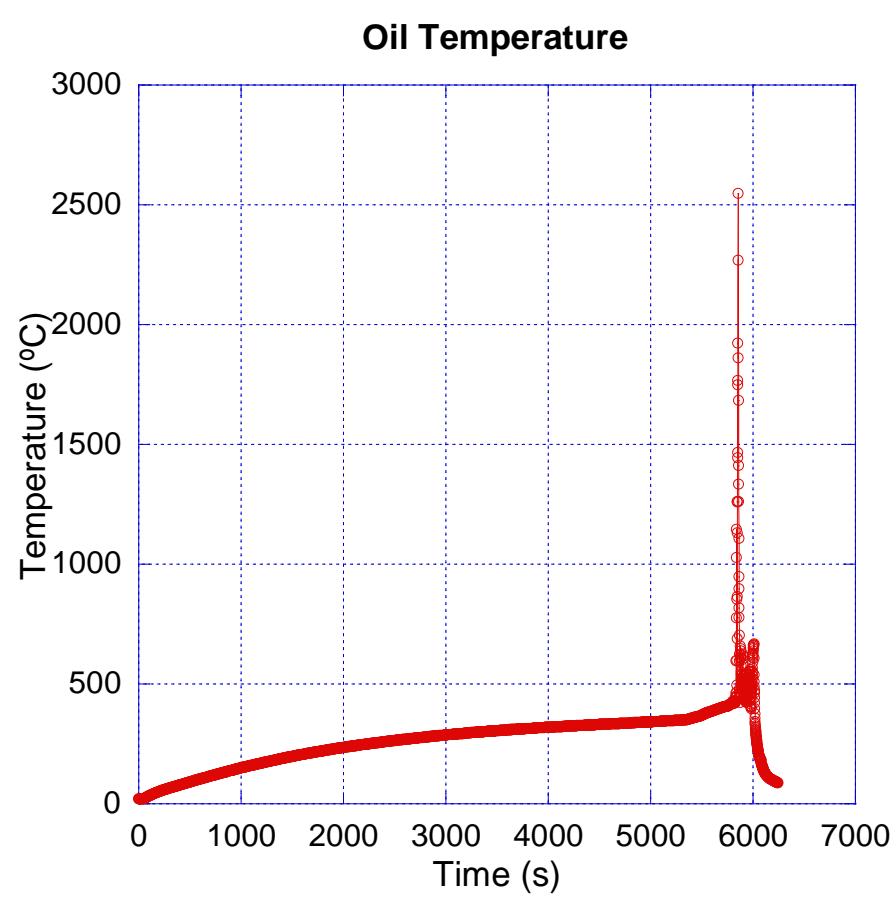

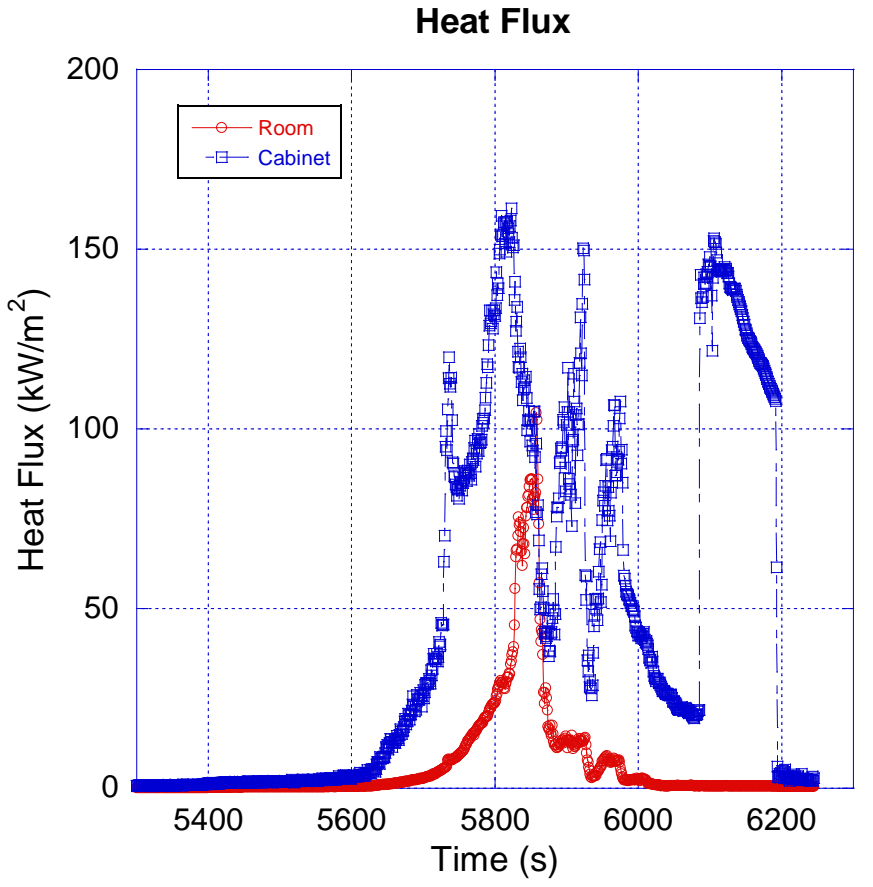

Figure A1-37. Experiment KSG 15 timeline and data 

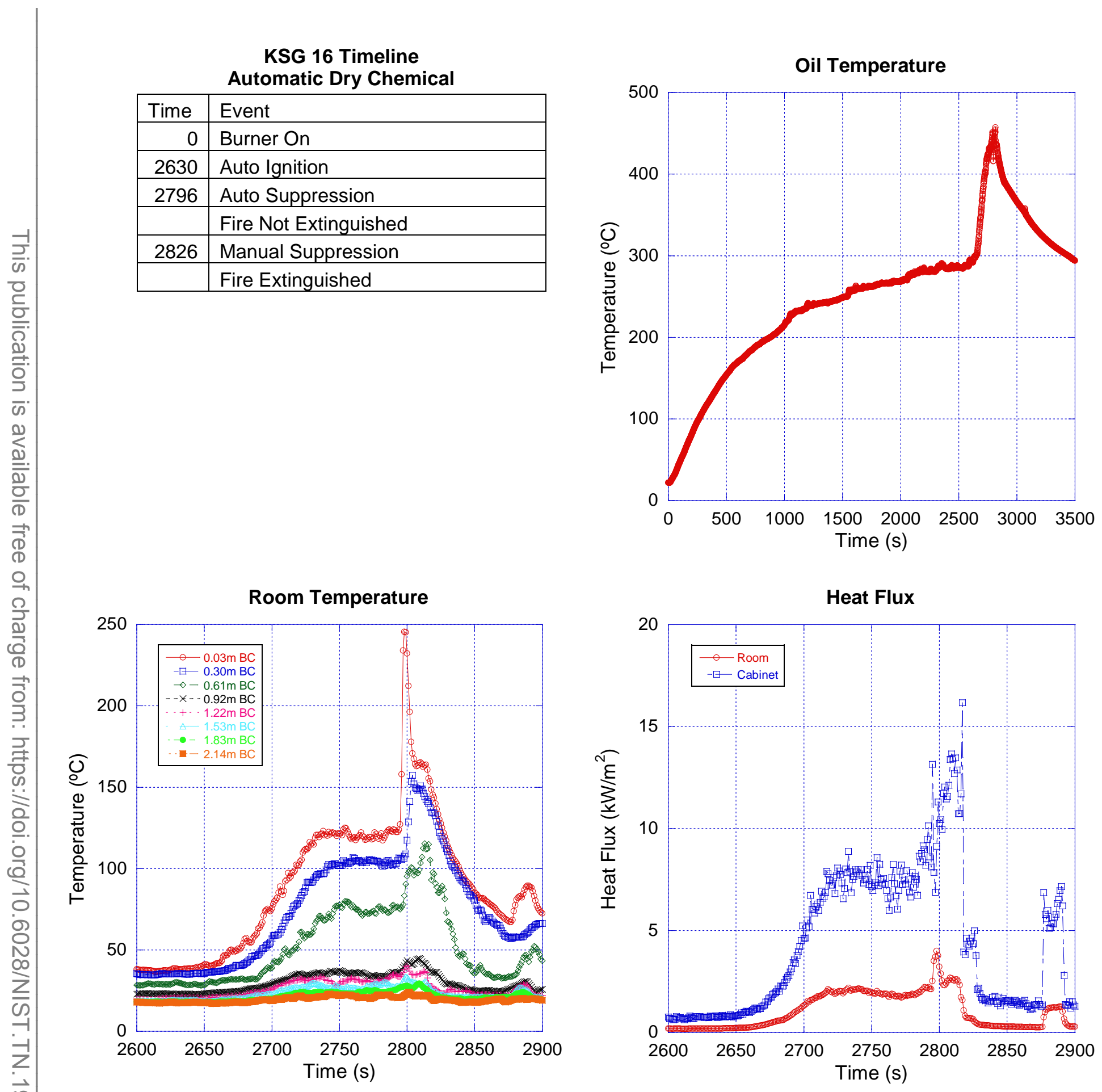

Figure A1-38. Experiment KSG 16 timeline and data 

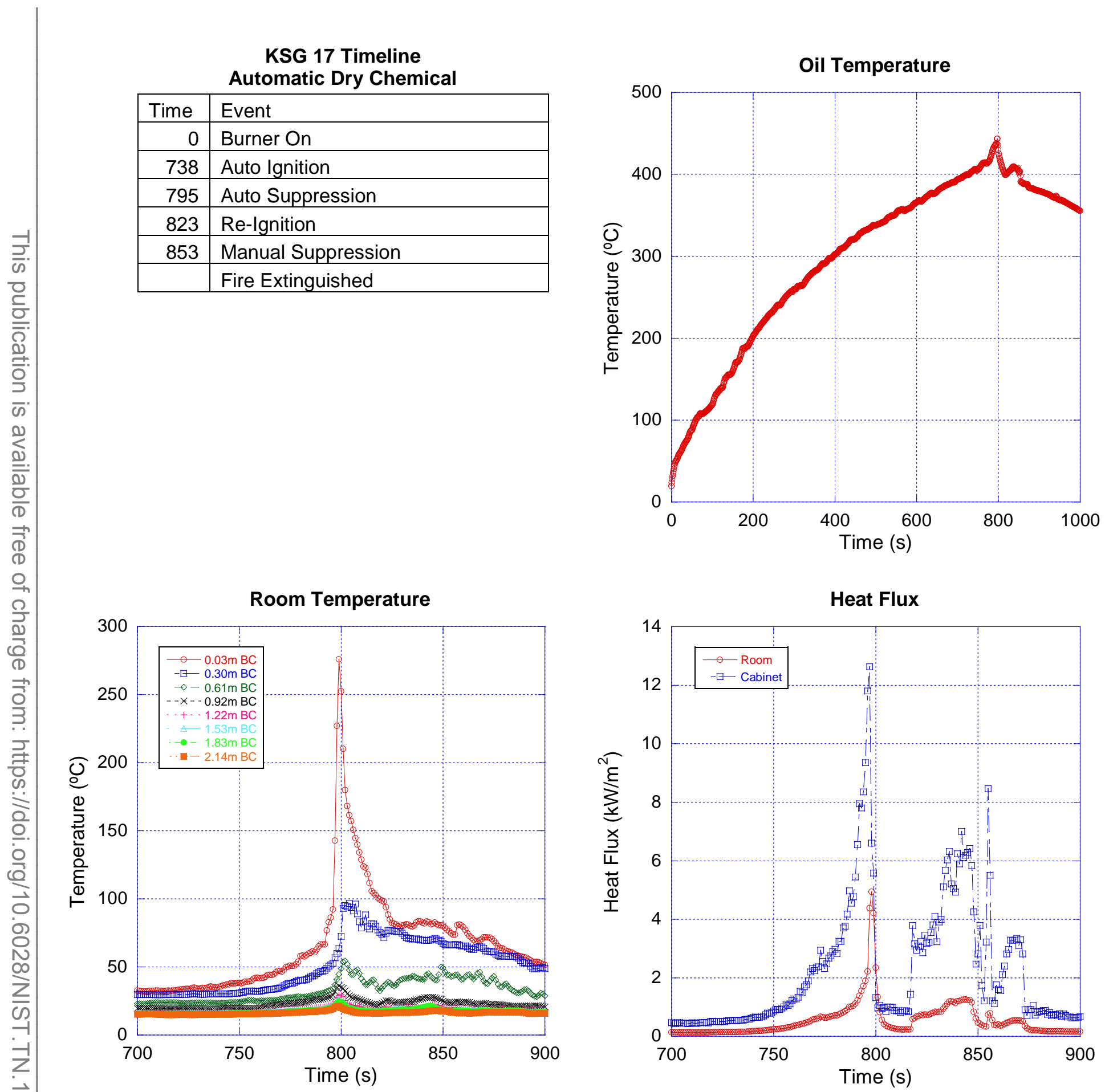

Figure A1-39. Experiment KSG 17 timeline and data 

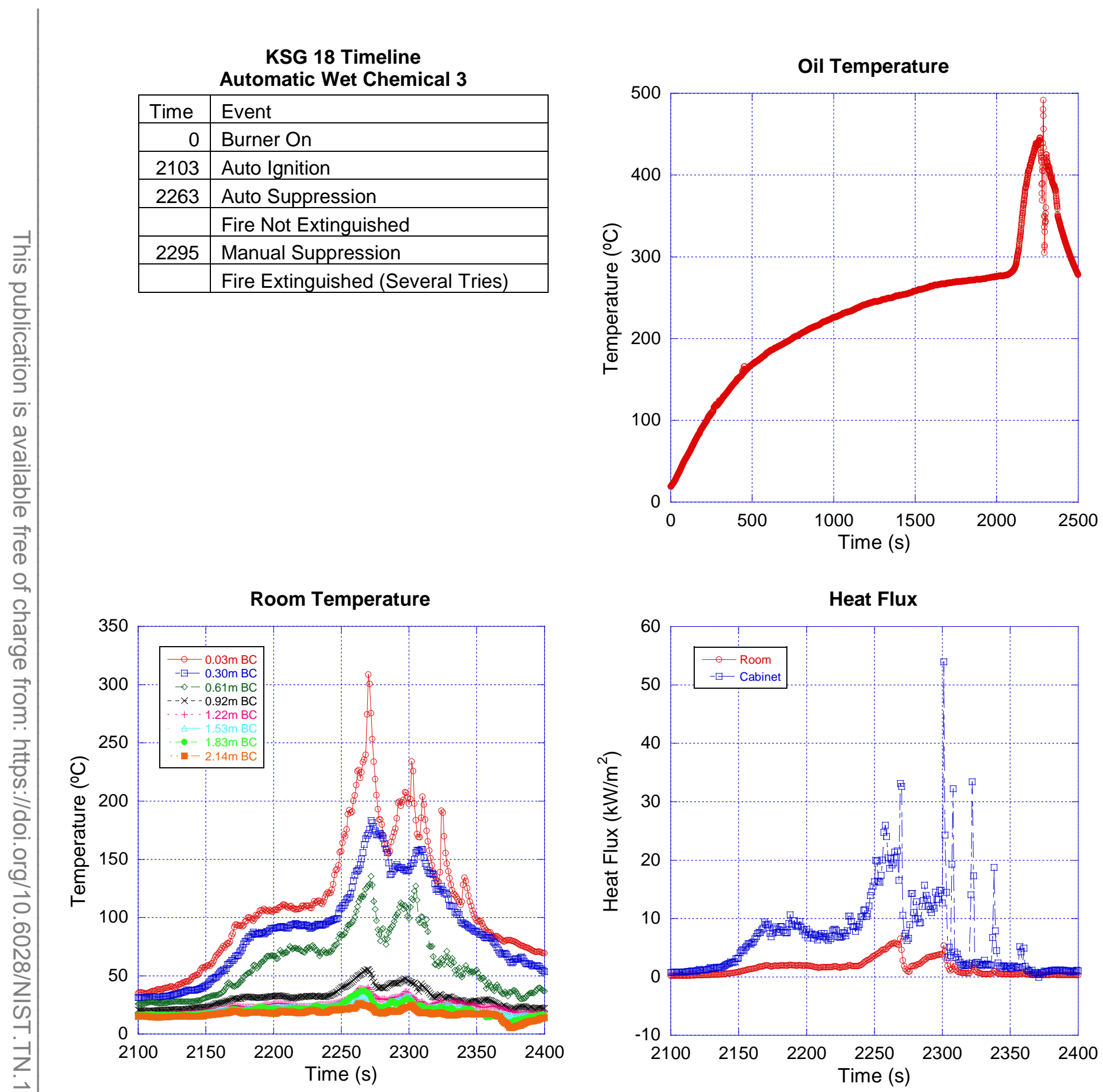

Figure A1-40. Experiment KSG 18 timeline and data 
KSG 19 Timeline

Automatic Wet Chemical 1

\begin{tabular}{|r|l|}
\hline Time & Event \\
\hline 0 & Burner On \\
\hline 1946 & Auto Ignition \\
\hline 2038 & Auto Suppression \\
\hline & Fire Extinguished \\
\hline
\end{tabular}

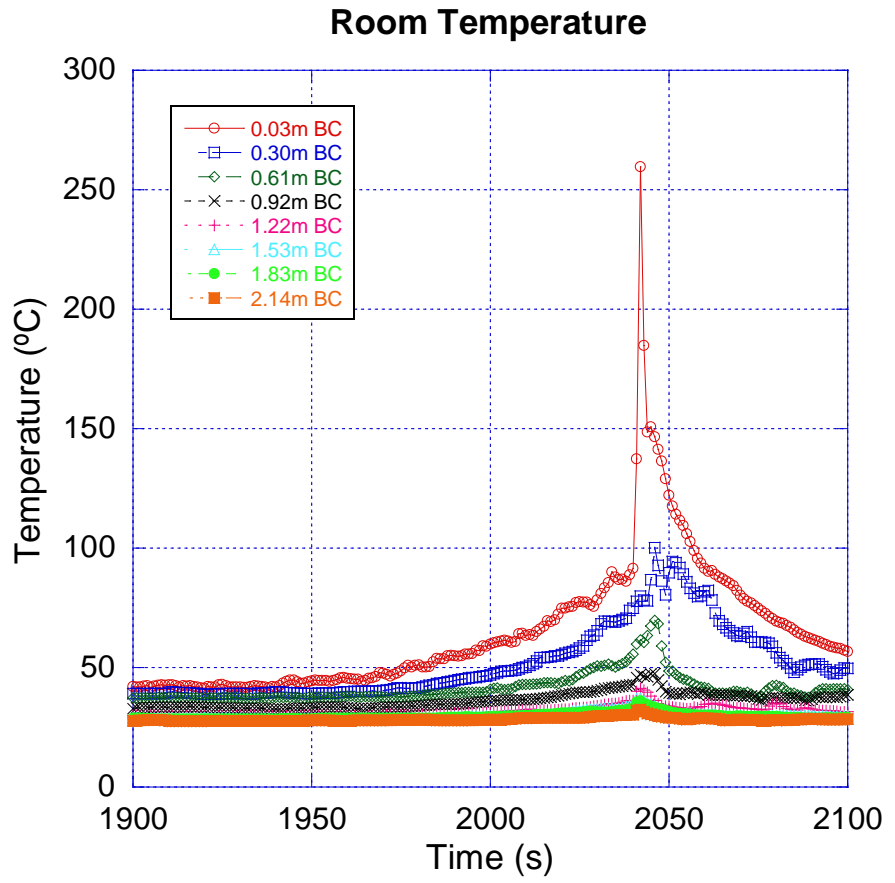

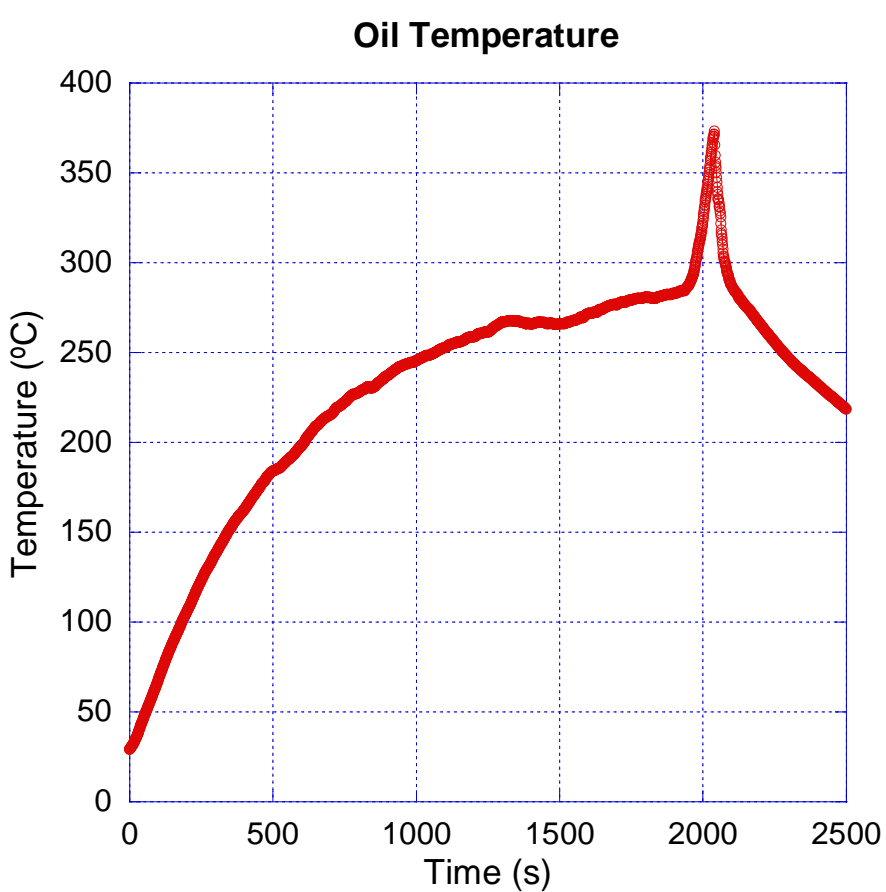

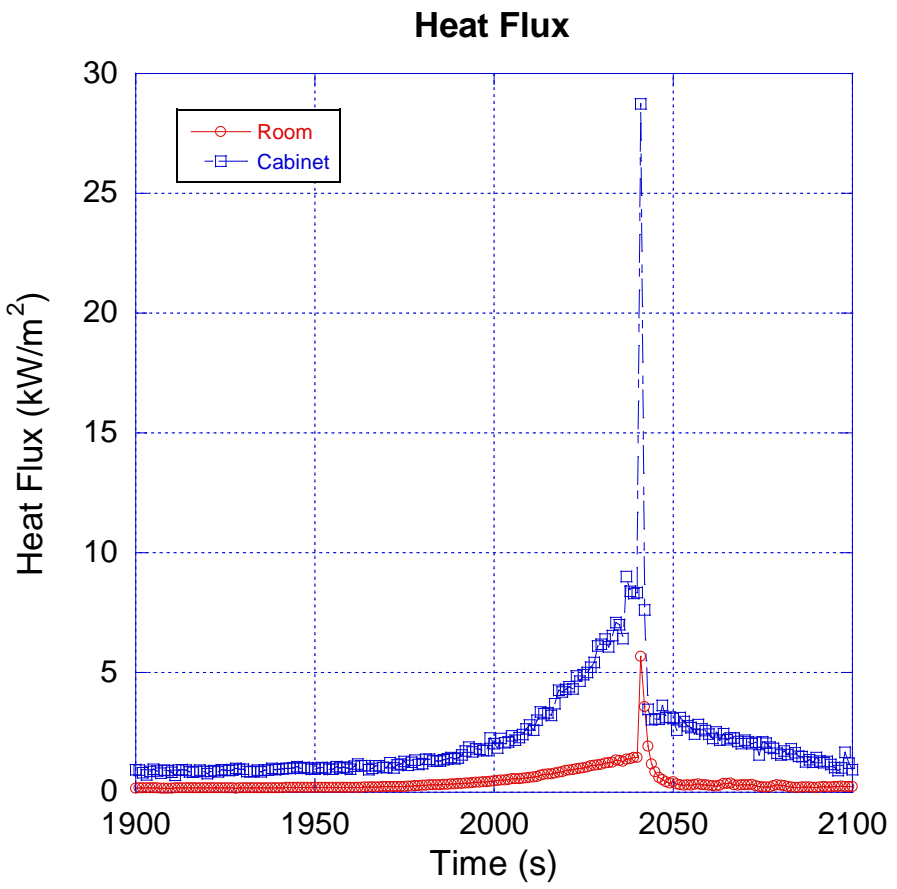

Figure A1-41. Experiment KSG 19 timeline and data 
KSG 20 Timeline

Free Burn

\begin{tabular}{|r|l|}
\hline \multicolumn{1}{|l|}{ Time } & Event \\
\hline 0 & Burner On \\
\hline 2280 & Auto Ignition \\
\hline 2722 & Manual Suppression Start \\
\hline 2758 & Manual Suppression Complete \\
\hline & Fire Extinguished \\
\hline
\end{tabular}

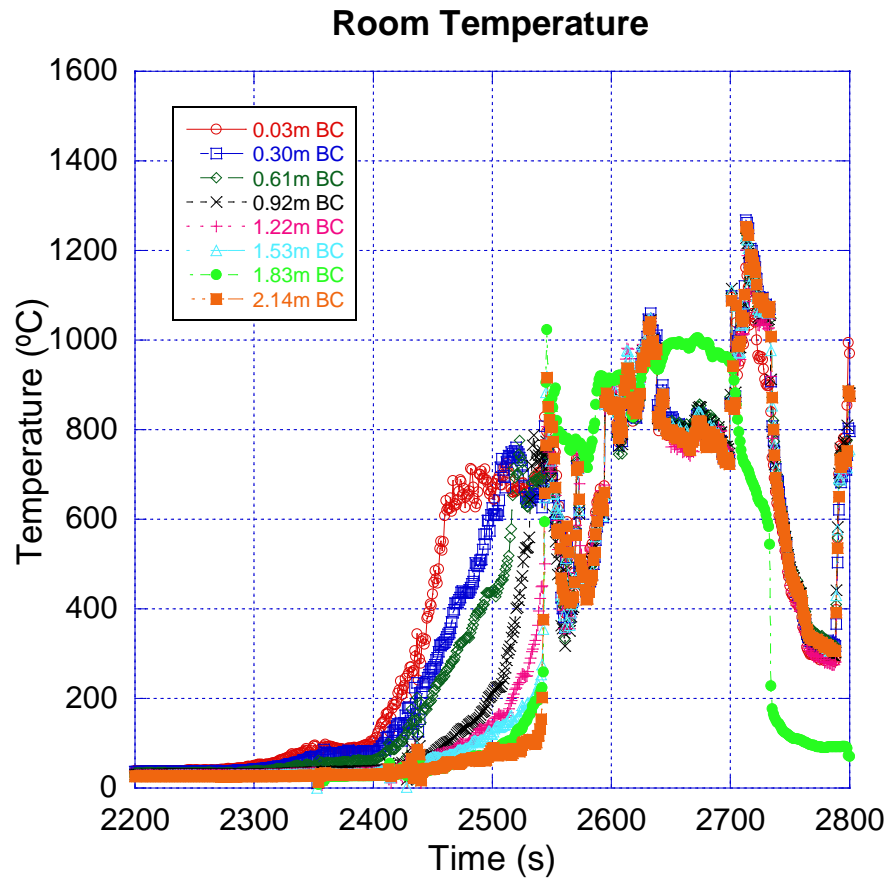

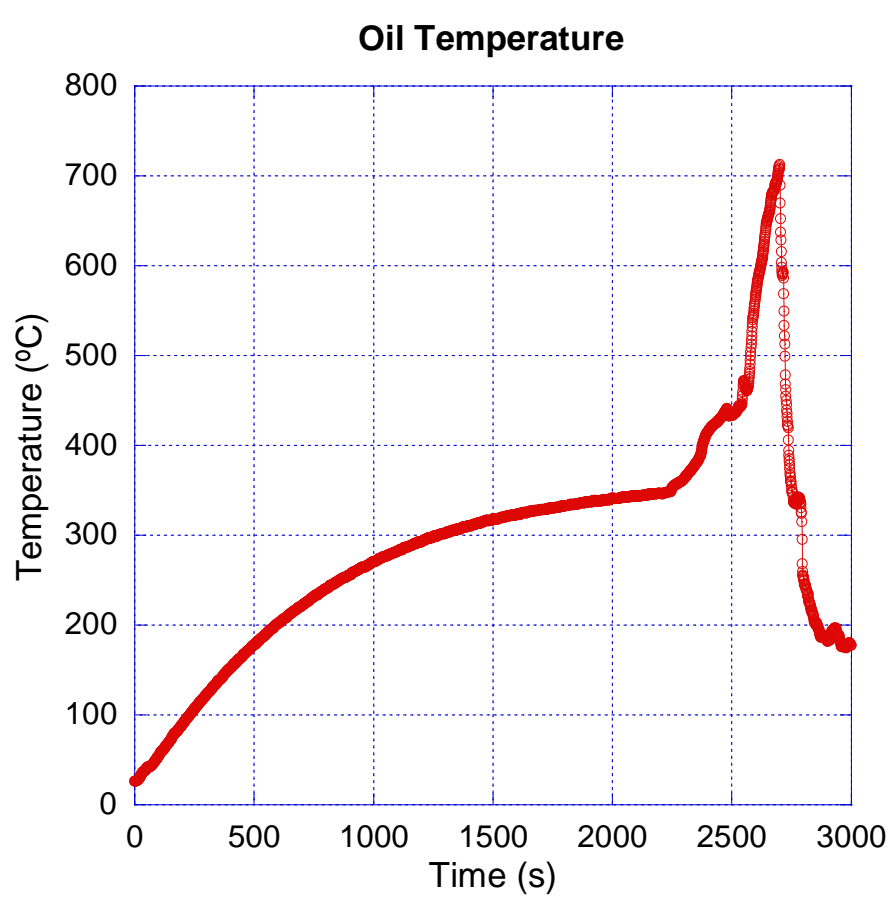

Figure A1-42. Experiment KSG 20 timeline and data 


\section{Appendix 2: Experimental Environmental Conditions}

The table below indicates the ambient temperature and relative humidity during each of the suppression experiments in the full-scale kitchen fire series. The estimated expanded uncertainty is $\pm 1{ }^{\circ} \mathrm{C}$ for temperature and $5 \%$ for relative humidity.

Table A2-1. Environmental conditions during the experiments.

\begin{tabular}{|c|c|c|c|c|c|}
\hline Test & Temperature $\left({ }^{\circ} \mathrm{C}\right)$ & Relative Humidity & Test & Temperature $\left({ }^{\circ} \mathrm{C}\right)$ & Relative Humidity \\
\hline KSE 01 & 31.1 & 52 & KSG 01 & 28.9 & 68 \\
\hline KSE 02 & 29.6 & 63 & KSG 02 & 30.6 & 63 \\
\hline KSE 03 & 30.7 & 56 & KSG 03 & 31.0 & 58 \\
\hline KSE 04 & 28.6 & 57 & KSG 04 & 29.4 & 64 \\
\hline KSE 05 & 31.8 & 53 & KSG 05 & 30.6 & 51 \\
\hline KSE 06 & 29.4 & 64 & KSG 06 & 27.3 & 66 \\
\hline KSE 07 & 30.6 & 51 & KSG 07 & 30.0 & 56 \\
\hline KSE 08 & 27.3 & 66 & KSG 08 & 21.0 & 46 \\
\hline KSE 09 & 30.0 & 56 & KSG 09 & 22.6 & 61 \\
\hline KSE 10 & No Data & No Data & KSG 10 & 23.9 & 60 \\
\hline KSE 11 & 21.0 & 46 & KSG 11 & 18.8 & 55 \\
\hline KSE 12 & 21.9 & 62 & KSG 12 & 18.5 & 55 \\
\hline KSE 13 & 23.9 & 60 & KSG 13 & 20.6 & 67 \\
\hline KSE 14 & 18.8 & 55 & KSG 14 & 20.1 & 53 \\
\hline KSE 15 & 18.5 & 55 & KSG 15 & 16.2 & 27 \\
\hline KSE 16 & 20.6 & 48 & KSG 16 & 14.8 & 21 \\
\hline KSE 17 & 16.4 & 26 & KSG 17 & 13.4 & 19 \\
\hline KSE 18 & 12.5 & 20 & KSG 18 & 19.7 & 13 \\
\hline KSE 19 & 26.1 & 44 & KSG 19 & 26.4 & 56 \\
\hline KSE 20 & 28.0 & 35 & KSG 20 & 25.2 & 56 \\
\hline KSE 21 & 27.7 & 59 & & & \\
\hline KSE 22 & 28.6 & 52 & & & \\
\hline
\end{tabular}

